\section{ADVANCED STEEL CONSTRUCTION}

\section{An International Journal}

Volume 11 Number 4 (Special Issue)

December 2015

CONTENTS

Technical Papers

Development of Connections to Concrete-Filled Rectangular Tubular Columns

Zhihua Chen, Ying Qin and Xiaodun Wang

Test and Design of Stainless Steel Welded I-Columns

Baofeng Zheng, Ganping Shu and Xiaoming Shen

Experimental Study on Fracture Toughness of High-Strength Structural Steel and Its Butt Weld Yuanqing Wang, Xiyue Liu, Yun Lin, Yongjiu Shi and Hui Zhou

Static Equilibrium Form-Finding Analysis of Cable-Strut System Based on Nonlinear Dynamic Finite Element Method Bin Luo, Zhengxing Guo, Xiangnan Chen, Feng Gao and Kai Wang

Research on the Membrane Action of Profiled Steel Sheet-Concrete Composite Floors in Fire Shenggang Fan, Wenjun Sun, HongZhao Wei and Meijing Liu

The Art of Application of High-Strength Steel Structures for Buildings in Seismic Zones Guo-Qiang Li, Yan-Bo Wang and Su-Wen Chen

Form-Finding Analysis of Irregular Tensegrity Structures by Matrix Iteration Jin Yu Lu, Na Li and GanPing Shu

Announcement by IJASC :

Announcement for SDSS 2016

Announcement for ICMS 2016

Announcement for ICSAS 2016

Copyright $\Theta 2015$ by

The Hong Kong Institute of Steel Construction

Website: http://rwwo.hkisc.org

ISSN 1816-112X

Science Citation Index Expanded, Materials Science Citation Index and ISI Alerting

Cover: Scene of London with aesthetic steel buildings

e-copy of IJASC is free to download at "www.ascjournal.com" in internet and mobile apps.

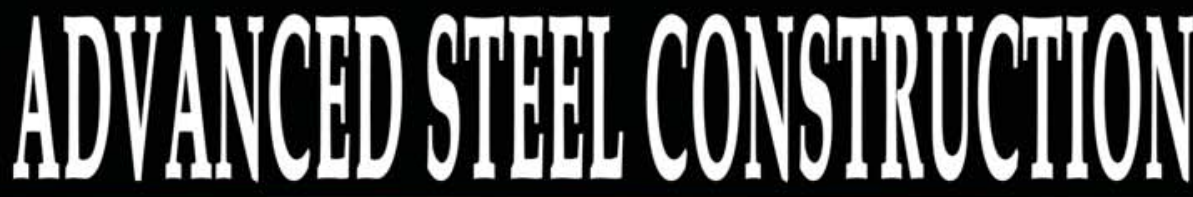

an International ]ounal

ISSN 1816-112X

Volume 11 Number 4 (Special Issue)

December 2015

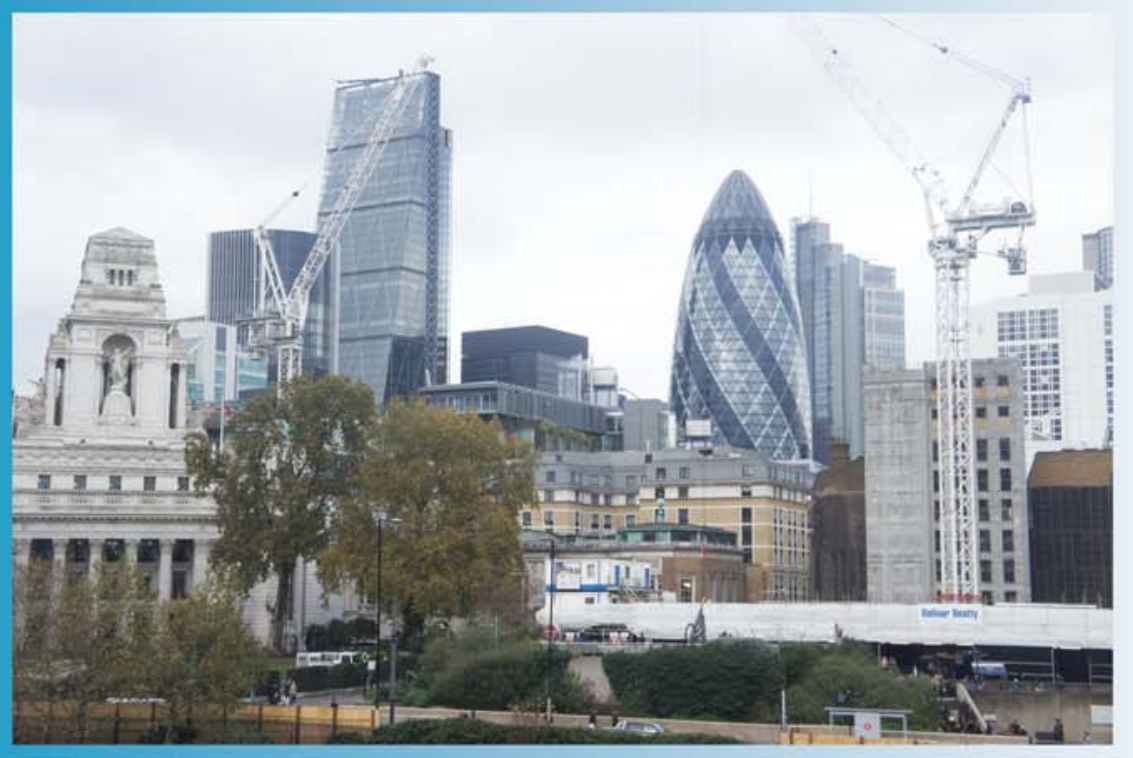

Editors-in-Chief

S.L. Chan, The Hong Kong Polytechnic University, Hong Kong

W.F. Chen, University of Hawaii at Manoa, USA

R. Zandonini, Trento University, Italy 


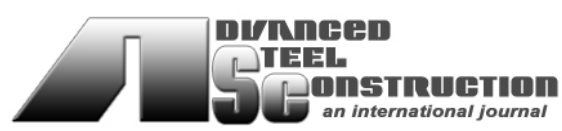

ISSN 1816-112X

Science Citation Index Expanded, Materials Science Citation Index and ISI Alerting

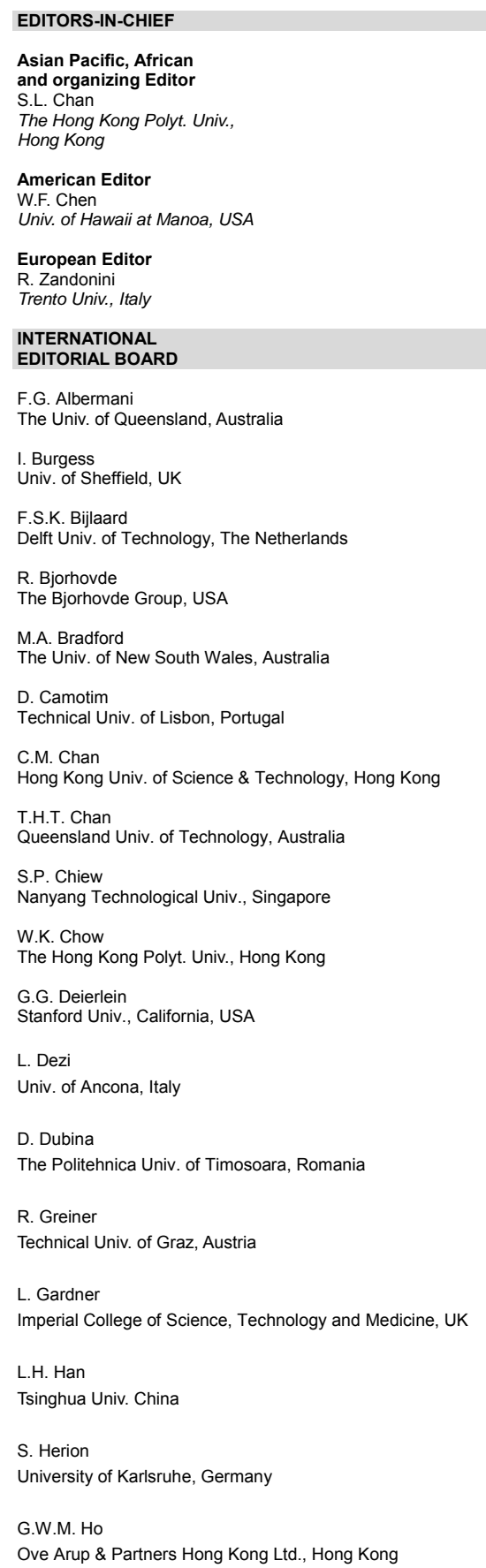

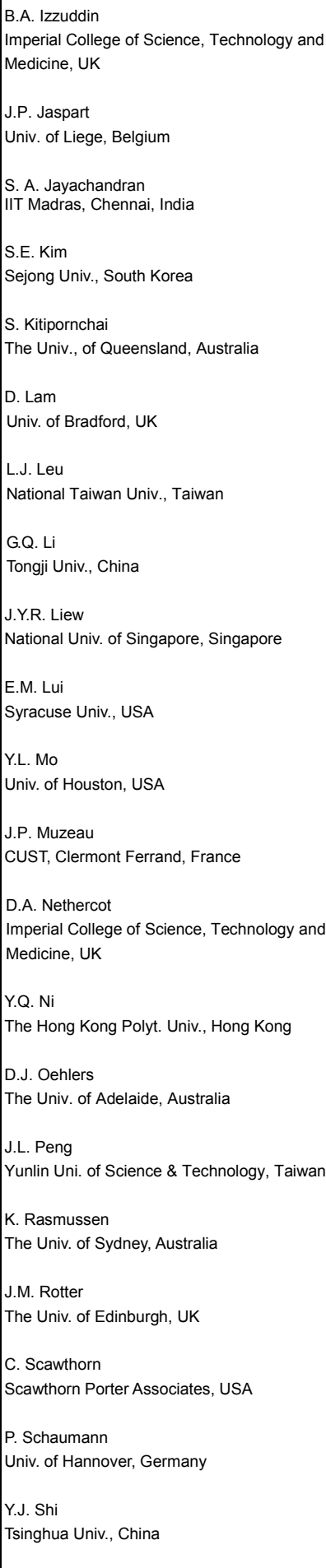

\section{Advanced Steel Construction an international journal}

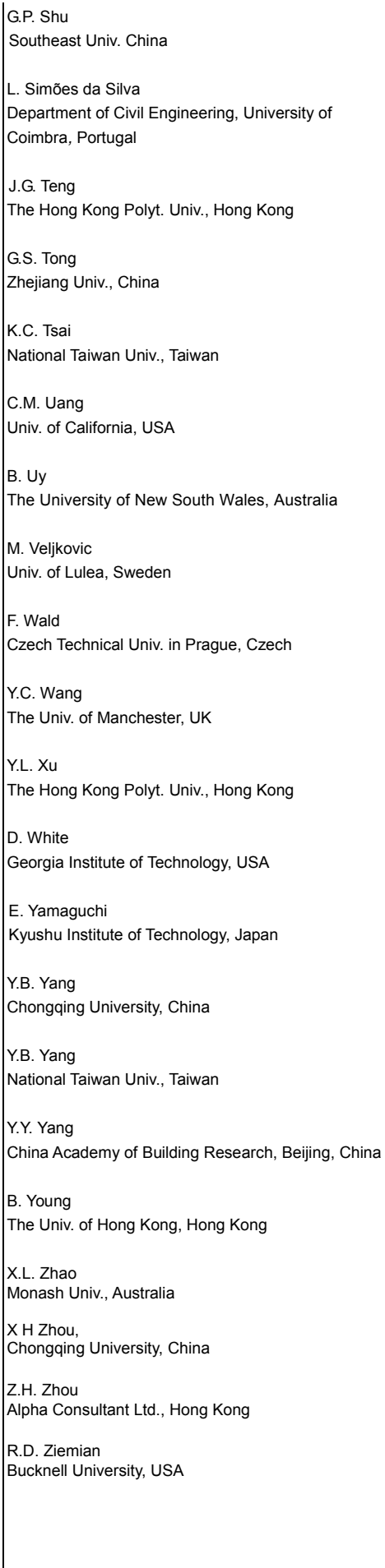

Cover: Scene of London with aesthetic steel buildings

e-copy of IJASC is free to download at "www.ascjournal.com" in internet and mobile apps. 


\section{General Information}

\section{Advanced Steel Construction, an international journal}

\section{Aims and scope}

The International Journal of Advanced Steel Construction provides a platform for the publication and rapid dissemination of original and up-to-date research and technological developments in steel construction, design and analysis. Scope of research papers published in this journal includes but is not limited to theoretical and experimental research on elements, assemblages, systems, material, design philosophy and codification, standards, fabrication, projects of innovative nature and computer techniques. The journal is specifically tailored to channel the exchange of technological know-how between researchers and practitioners. Contributions from all aspects related to the recent developments of advanced steel construction are welcome.

\section{Instructions to authors}

Submission of the manuscript. Authors may submit on-line at www.hkisc.org

Asian Pacific , African and organizing editor : Professor S.L. Chan, Email: ceslchan@polyu.edu.hk

American editor:

European editor :

Professor W.F. Chen, Email: waifah@hawaii.edu

Professor R. Zandonini, Email: riccardo zandonini@ing.unitn.it

All manuscripts submitted to the journal are recommended to accompany with a list of four potential reviewers suggested by the author(s). This list should include the complete name, address, telephone and fax numbers, email address, and at least five keywords that identify the expertise of each reviewer. This scheme will improve the process of review.

Style of manuscript

General. Author(s) should provide full postal and email addresses and fax number for correspondence. The manuscript including abstract, keywords, references, figures and tables should be in English with pages numbered and typed with double line spacing on single side of A4 or letter-sized paper. The front page of the article should contain:

a) a short title (reflecting the content of the paper);

b) all the name(s) and postal and email addresses of author(s) specifying the author to whom correspondence and proofs should be sent;

c) an abstract of $100-200$ words; and

d) 5 to 8 keywords.

The paper must contain an introduction and a conclusion. The length of paper should not exceed 25 journal pages (approximately 15,000 words equivalents).

Tables and figures. Tables and figures including photographs should be typed, numbered consecutively in Arabic numerals and with short titles. They should be referred in the text as Figure 1, Table 2, etc. Originally drawn figures and photographs should be provided in a form suitable for photographic reproduction and reduction in the journal.

Mathematical expressions and units. The Systeme Internationale (SI) should be followed whenever possible. The numbers identifying the displayed mathematical expression should be referred to in the text as Eq. 1, Eq. 2.

References. References to published literature should be referred in the text, in the order of citation with Arabic numerals, by the last name(s) of the author(s) (e.g. Zandonini and Zanon [3]) or if more than three authors (e.g. Zandonini et al. [4]). References should be in English with occasional allowance of 1-2 exceptional references in local languages and reflect the current state-of-technology. Journal titles should be abbreviated in the style of the Word List of Scientific Periodicals. References should be cited in the following style [1, 2, 3].

Journal: [1] Chen, W.F. and Kishi, N., "Semi-rigid Steel Beam-to-column Connections, Data Base and Modelling", Journal of Structural Engineering, ASCE, 1989, Vol. 115, No. 1, pp. 105-119.

Book: [2] Chan, S.L. and Chui, P.P.T., "Non-linear Static and Cyclic Analysis of Semi-rigid Steel Frames", Elsevier Science, 2000.

Proceedings: [3] Zandonini, R. and Zanon, P., "Experimental Analysis of Steel Beams with Semi-rigid Joints", Proceedings of International Conference on Advances in Steel Structures, Hong Kong, 1996, Vol. 1, pp. 356-364.

Proofs. Proof will be sent to the corresponding author to correct any typesetting errors. Alternations to the original manuscript at this stage will not be accepted. Proofs should be returned within 48 hours of receipt on-line.

Copyright. Submission of an article to "Advanced Steel Construction" implies that it presents the original and unpublished work, and not under consideration for publication nor published elsewhere. On acceptance of a manuscript submitted, the copyright thereof is transferred to the publisher by the Transfer of Copyright Agreement and upon the acceptance of publication for the papers, the corresponding author must sign the form for Transfer of Copyright.

Permission. Quoting from this journal is granted provided that the customary acknowledgement is given to the source.

Page charge and Reprints. There will be no page charges if the length of paper is within the limit of 25 journal pages. A total of 30 free offprints will be supplied free of charge to the corresponding author. Purchasing orders for additional offprints can be made on order forms which will be sent to the authors. These instructions can be obtained at the Hong Kong Institute of Steel Construction, Journal website: http://www.hkisc.org

The International Journal of Advanced Steel Construction is published quarterly by learnt society, The Hong Kong Institute of Steel Construction, c/o Department of Civil \& Environmental Engineering, The Hong Kong Polytechnic University, Hung Hom, Kowloon, Hong Kong.

Disclaimer. No responsibility is assumed for any injury and / or damage to persons or property as a matter of products liability, negligence or otherwise, or from any use or operation of any methods, products, instructions or ideas contained in the material herein.

Subscription inquiries and change of address. Address all subscription inquiries and correspondence to Member Records, IJASC. Notify an address change as soon as possible. All communications should include both old and new addresses with zip codes and be accompanied by a mailing label from a recent issue. Allow six weeks for all changes to become effective.

The Hong Kong Institute of Steel Construction

HKISC

c/o Department of Civil and Environmental Engineering,

The Hong Kong Polytechnic University,

Hunghom, Kowloon, Hong Kong, China.

Tel: 852- 27666047 Fax: 852- 23346389

Email: ces/chan@polyu.edu.hk Website: http://www.hkisc.org/

ISSN 1816-112X

Science Citation Index Expanded, Materials Science Citation Index and ISI Alerting

Copyright $\odot 2015$ by:

The Hong Kong Institute of Steel Construction. 


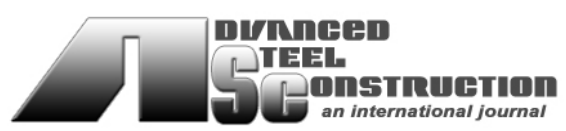

ISSN 1816-112X

Science Citation Index Expanded, Materials Science Citation Index and ISI Alerting

\section{EDITORS-IN-CHIEF}

Asian Pacific, African and organizing Editor

S.L. Chan

The Hong Kong Polyt. Univ., Hong Kong

Email: ces/chan@polyu.edu.hk

\section{American Editor}

W.F. Chen

Univ. of Hawaii at Manoa, USA

Email: waifah@hawaii.edu

\section{European Editor}

R. Zandonini

Trento Univ., Italy

Email: riccardo.zandonini@ing.unitn.it

\section{Advanced Steel \\ Construction an international journal}

\section{VOLUME 11 NUMBER 4 Special Issue \\ For selected papers in "The 7th International Conference on Advances in Steel Structures"} DECEMBER 2015

Technical Papers

Development of Connections to Concrete-Filled Rectangular

Tubular Columns

Zhihua Chen, Ying Qin and Xiaodun Wang

Test and Design of Stainless Steel Welded I-Columns

Baofeng Zheng, Ganping Shu and Xiaoming Shen

Experimental Study on Fracture Toughness of High-Strength

Structural Steel and Its Butt Weld

Yuanqing Wang, Xiyue Liu, Yun Lin, Yongjiu Shi and Hui Zhou

Static Equilibrium Form-Finding Analysis of Cable-Strut System Based on Nonlinear Dynamic Finite Element Method Bin Luo, Zhengxing Guo, Xiangnan Chen, Feng Gao and Kai Wang

Research on the Membrane Action of Profiled Steel

Sheet-Concrete Composite Floors in Fire

Shenggang Fan, Wenjun Sun, HongZhao Wei and Meijing Liu

The Art of Application of High-Strength Steel Structures for Buildings in Seismic Zones

Guo-Qiang Li, Yan-Bo Wang and Su-Wen Chen

Form-Finding Analysis of Irregular Tensegrity Structures by Matrix Iteration

JinYu Lu, Na Li and GanPing Shu

Announcement by IJASC :

Announcement for SDSS 2016

Announcement for ICMS 2016

Announcement for ICSAS 2016 


\title{
DEVELOPMENT OF CONNECTIONS TO CONCRETE-FILLED RECTANGULAR TUBULAR COLUMNS
}

\author{
Zhihua Chen ${ }^{1,2}$, Ying Qin ${ }^{1,2}$ and Xiaodun Wang ${ }^{2, *}$ \\ ${ }^{1}$ Key Laboratory of Coast Civil Structure Safety of China Ministry of Education, \\ Tianjin University, Tianjin, China \\ ${ }^{2}$ Department of Civil Engineering, Tianjin University, Tianjin, China \\ *(Corresponding author: E-mail : maodun2004@126.com)
}

\begin{abstract}
Concrete-filled rectangular tubular column composite frame systems with steel beams have been widely used in moment-resisting frames for engineering practice. This paper reviewed a variety of connection details to concrete-filled rectangular tubular (CFRT) columns that have been developed by different researchers. The research on CFRT connections was divided into three phrases. The first phase dates back to the late sixties of twentieth century, when the steel moment-resisting frames were regarded as one of the most ductile systems. The second phase is defined as the period between middle nineties and the beginning of the twenty-first century, during the early stage of which the Northridge earthquake and Kobe earthquake occurred and the conventional knowledge of traditional connections were subverted, leading to the requirement of paying more attention to the investigation of connection behavior under seismic loading. The third phase passes through the following year up to the present. During this phase, various connection alternatives were proposed and studied. Based on the summary of previous studies, the future developments were presented at the end of the paper.
\end{abstract}

Keywords: Concrete-filled rectangular tubular column; Development, Steel beam, Connection, Three phases, Future work

DOI: 10.18057/IJASC.2015.11.4.1

\section{INTRODUCTION}

Concrete filled rectangular tubular (CFRT) columns are structural members that combine two materials in one member. They have the beneficial merits of steel, such as high tensile strength and ductility, and of concrete, such as the high compressive strength and stiffness. Structures with CFRT columns are widely used in engineering applications such as bridges, high-rise buildings, underwater structures and so on [1,2]. In addition to the advantages mentioned above, the CFRT structures can reduce the time and cost of construction by serving the tube as the framework for casting concrete. It makes the most efficient use of the steel as it is placed at the perimeter of the section, providing the highest contribution to the moment of inertia. The steel tube provides the confinement to the concrete, which puts the concrete under a tri-axial state of stresses and enhances the performance of concrete. Even more, the steel prevents concrete from spalling. At the same time, the concrete infill prolongs local buckling of steel tube by preventing inward buckling, thus increasing the stability and strength of the column as a system [3].

However, the advantages of utilizing concrete-filled tubular columns may still remain unexploited due to the lack of design guideline on appropriate cost-effective and construction-efficient connections between concrete-filled tubular columns and steel H-shaped beams. This dearth of information is even more pronounced with regards to connections to CFRT columns. 
The CFRT column-to-beam connections are broadly classified into two categories [4]. The most convenient way is directly attaching the steel beam to the column tube or through the diaphragm plate. For the other connection category, the beam flange, the web or the entire cross-section are penetrated through the steel tube or the beam end is welded with anchorage which is embedded in the CFRT column. Connections to the face of the steel tube include: welding the beam directly to the tube skin, using web angles or shear tabs to connect the beam to the tube, providing diaphragms and variations on these details. Connections with embedded elements include: through bolting beam end plates, and continuing structural steel shapes into and through the column. Analysis of test data suggests that embedding connection components into the concrete core alleviates high shear demand on the tube wall, which may improve the seismic performance of the connections [5].

\section{FIRST PHASE-PRE-NORTHRIDGE CONNECTION STUDIES}

Since 1960s, engineers began to regard welded steel moment-frame buildings as being among the most ductile systems. They believed that the steel moment-resisting frames were invulnerable to earthquake-induced structural damage and they should be limited to moderate yielding and localized buckling of the steel components and not induce collapse at all [6]. As to the CFRT column systems, they considered that it was more convenient to connect the beam to the steel tube using welding materials without any embedded members. Much attention was paid to the strength and failure modes of fully-welded connections at that time.

Previous research on CFRT column systems include the experiment taken by Furlong [7] which involved assessing the strength of CFRT beam-columns. The results demonstrated the benefits of filling the steel tube with concrete. The concrete infill prevented local bucking of the steel tube and enhanced the strength of the specimen compared to hollow steel tube column-to-beam one.

Ansourian [8] tested connections with exterior stiffeners, as shown in Figure 1 for connection details. Two specimens were welded with tension plates. These specimens failed by fracture of the V-butt weld connecting the tension plate to the tube. Another two specimens were fabricated with the tension flange force transferred as a compression force to the other side of the tube. The remaining specimens were shop welded but assembled using high strength bolts. Most of these specimens experienced panel zone failure after extensive deformation of the tube.

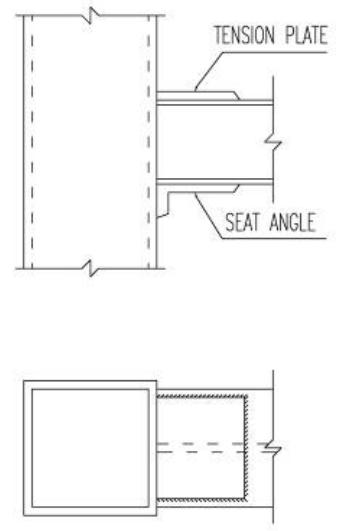

(a) Specimen 1
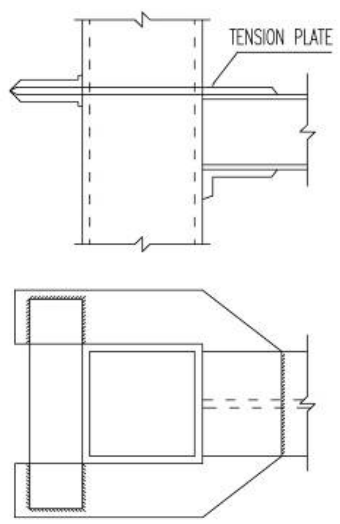

(b) Specimen 3

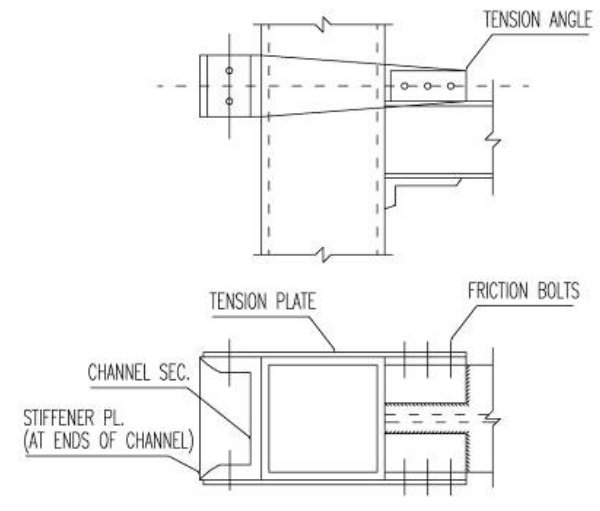

(c) Specimen 7

Figure 1. Connection Details Tested by Ansourian [8] 
Tomii and Sakino [9-10] conducted monotonic and cyclic load tests on CFRT beam-column specimens with various b/t ratio, the axial load level, the shear span ratio, the steel yielding strength and the concrete compressive strength. The test results indicated that the increase in the b/t ratio or the axial load level lead to the decrease in the ductility of the specimen. Analytical equations to evaluate the loading capacity of the connections were also developed.

Matsui [11] developed a method to design the wide flange beam-to-CFRT column connections with exterior and interior stiffeners. Six specimens were tested to verify the strength formula. The connection details are shown in Figure 2. The connections were designed to have yielding developed in the stiffener and panel zone. The test results indicated that the specimens had excellent performance when the stiffeners were designed by these proposed formulas.

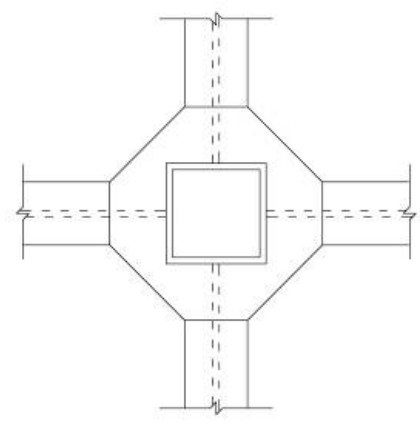

(a) Outside stiffener

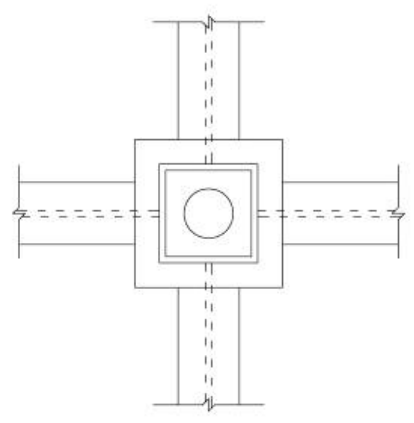

(b) Through stiffener

Figure 2. Connection Details by Matsui

Kanatani, et al [12] developed through-bolted moment connection as an alternative to diaphragm connection, aiming for evaluating out-of-plane deformation of the connections and eliminating difficulties in field welding. As shown in Figure 3, four types of connections were studied. The monotonic load tests showed that the split tee connection was able to perform better than diaphragm connection in terms of strength. The result of cyclic load tests demonstrated that through-bolts and split tee did as good as, or even better than internally and externally welded stiffeners in transferring force from beam to column. When the steel tube width-to-thickness ratio (b/t) is 42, the failure was caused by local buckling of column flange regardless the present of concrete.

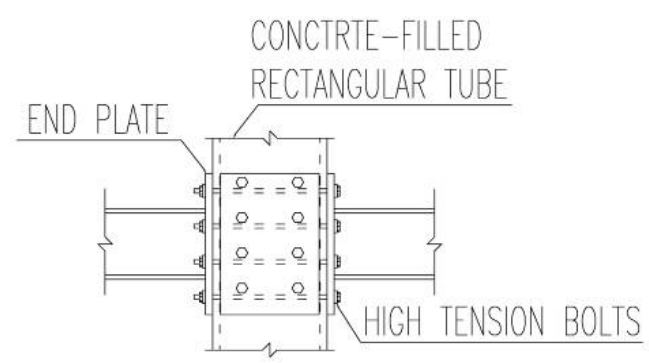

(a) Connection with end plate

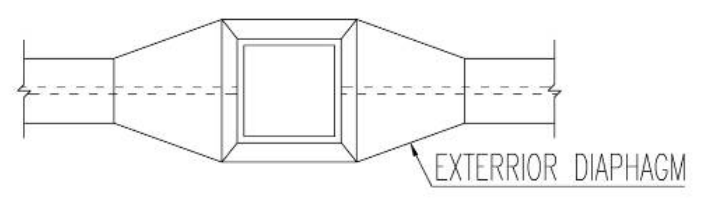

(c) Connection with exterior diaphragm

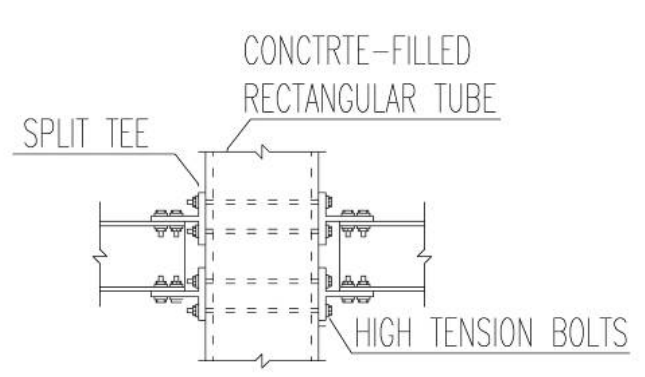

(b) Connection with split tee

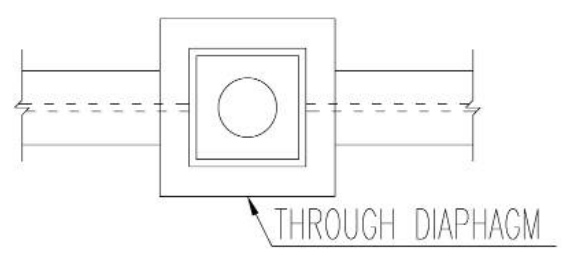

(d) Connection with through diaphragm

Figure 3. Connection Details Studies by Kanatani et al. 
Prion and McLellan [13] tested similar bolted connections; however, end-plates were fully welded to the girder. These endplates were attached to the CFRT using bolts continuous through the tube column. Results suggested that good shear capacity was obtained from the through depth bolts, however, it was noted that the bolts were subjected to shear and bending stress due to the large eccentricities.

Azizinamini [14] suggested a new through-beam connection. A certain height of the column tube, together with a short beam stub passing through the column and welded to the tube, was fabricated in the shop to form a tree column, as shown in Figure 4. This "tree column" was transported to the field and the floor beams were then spliced to it. One cruciform specimen was tested under monotonic loading only. Results suggested that the beam web within the joint experienced a shear type failure, thereby activating a concrete compressive strut. This strut acted as a diagonal stiffener to assist the beam web in resisting joint shear. A finite element analysis was undertaken to analyze the proposed detail, and tentative guidelines for the design of such joints were proposed.

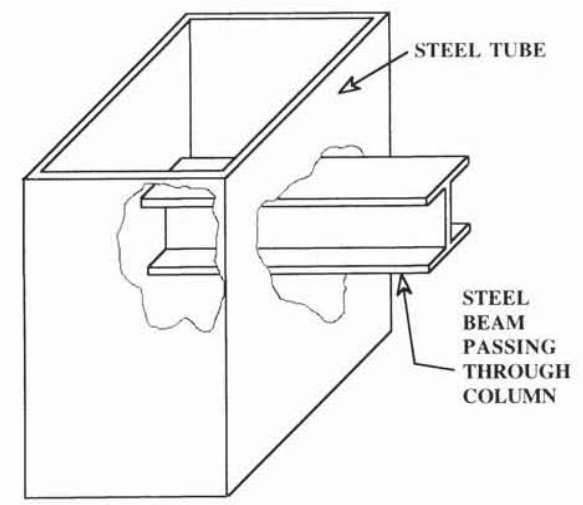

Figure 4. Through Connection Detail

\section{SECOND PHASE-PRIOR STUDIES TO IMPROVE CONNECTION BEHAVIOR}

The second phase began in 1994, when the Northridge earthquake occurred on January 17, 1994, followed by the Kobe earthquake on January 17, 1995. Engineers' conventional knowledge that steel moment-frame buildings would behave in a ductile manner was challenged. Observation of damage sustained by buildings indicated that, in many cases, brittle fractures initiated within the connections at very low levels of plastic demand, and some time, the structure still remained elastic. Many cracks started at the weld zone of the bottom beam flange. It was found that welding the beam directly to the steel tube prohibited the formation of the plastic hinge in the beam and induced severe stresses at the beam-to-column connection. It was urgent to pay more attention to the investigation of seismic behavior of these connections. Since then, researchers have extensively evaluated the inspection of affected connections, the repair of damaged connections, the upgrade of existing connections to improve their future performance, and the design of new connections to provide reliable seismic performance $[15,16]$.

Considering the importance of developing design guideline of composite structures, U.S. - Japan Cooperative Earthquake Research Program on Composite and Hybrid Structures was formed [17]. Research in Japan concentrated on the connections with interior, exterior or through steel plate diaphragms, as shown in Figure 5. Investigation was made on the strength, ductility, and behavior of the connection, as well as the effect of temperature on the connection performance, the ultimate resistance of advanced connection method, the material properties of steel and weld metal, the 
effect of welding heat, the geometry of weld access hole and other weld details, and the elimination of weld access hole [18]. On the U.S. side, Lehigh University and The University of Texas at Austin took the work of researching the connections to rectangular tubular column. And it was decided that the research at Lehigh University would focus on the design and development of the connection and the research at The University of Texas at Austin would focus on the interior joint shear force transfer mechanism, by failing of the joint [19].

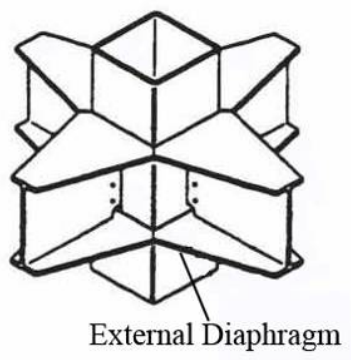

(a) External diaphragm

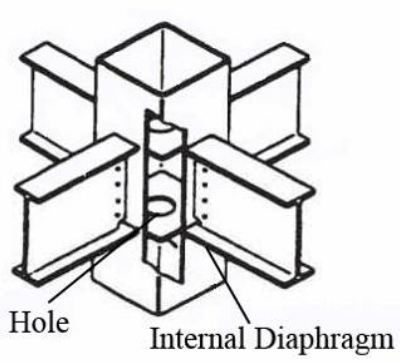

(b) Internal diaphragm

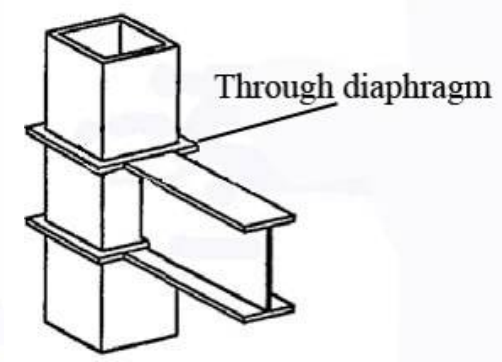

(c) Through diaphragm

Figure 5. Typical CFRT Column-to-beam Moment Connections in Japan

Morino, et al [20] tested planar and three-dimensional subassemblies consisting of CFT column and wide flange beams, as given in Figure 6. Diaphragm plates, with the same thickness as the beam flange, passed through the column and had openings for proper concrete casting. Two types of failure mode were expected in the experiment: shear failure of the panel zone and flexural failure of the column. It was observed that the panel-failing mode was more stable and exhibited more energy dissipation capacity compared with the column-failing mode.

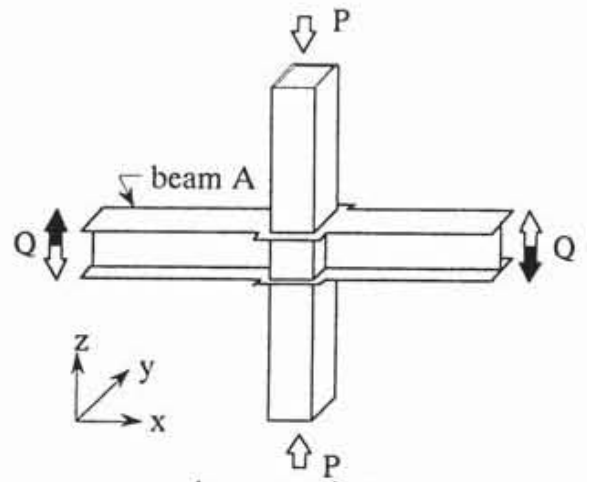

(a) Planar specimen

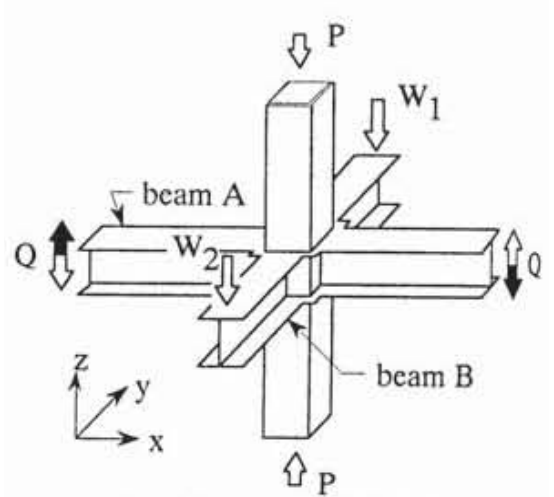

(b) Three-dimensional specimen

Figure 6. Schematic View of Test

Matsui and Kawano [21] suggested the connection using vertical stiffeners instead of diaphragm for external joints, as shown in Figure 7. The later one has the high structural reliability of columns, but the size of the external diaphragm may place limits on the design of exterior frames for the building. The proposed new type of connection was expected to overcome the disadvantage of the exterior diaphragm. It was observed that this connection type had sufficient capacities to gain a stable structural behavior and had superior seismic performances to the usual outer diaphragm connection system. 


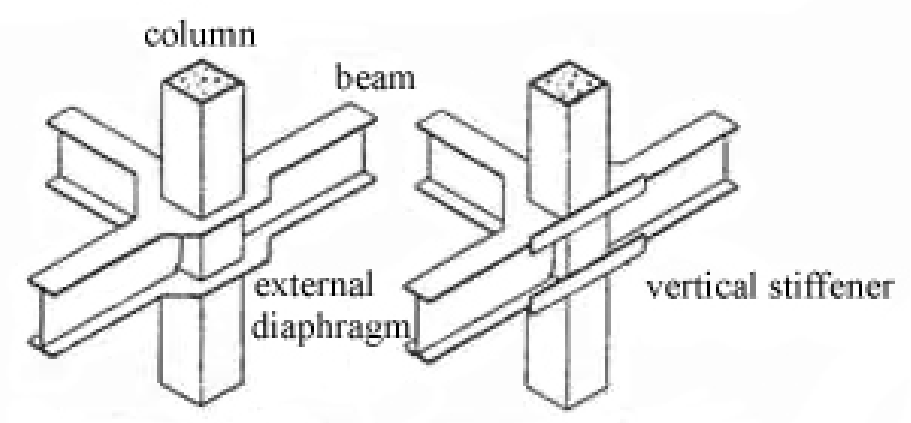

Figure 7. Beam-to-column Connections Studied by Matsui et al.

Viest [19] proposed the connections that utilize anchor bolts, embedded elements, and steel through-beam connection possibilities. The connection detail was shown in Figure 8. According to Viest's study, welding beam directly to the steel tube should be avoided to prevent: (a) separation of the steel tube from the concrete core due to flange tensile forces, (b) large residual stresses in the steel due to restraint of the other connecting elements, and (c) possible compromise of the confinement due to the additional stresses on the steel tube.

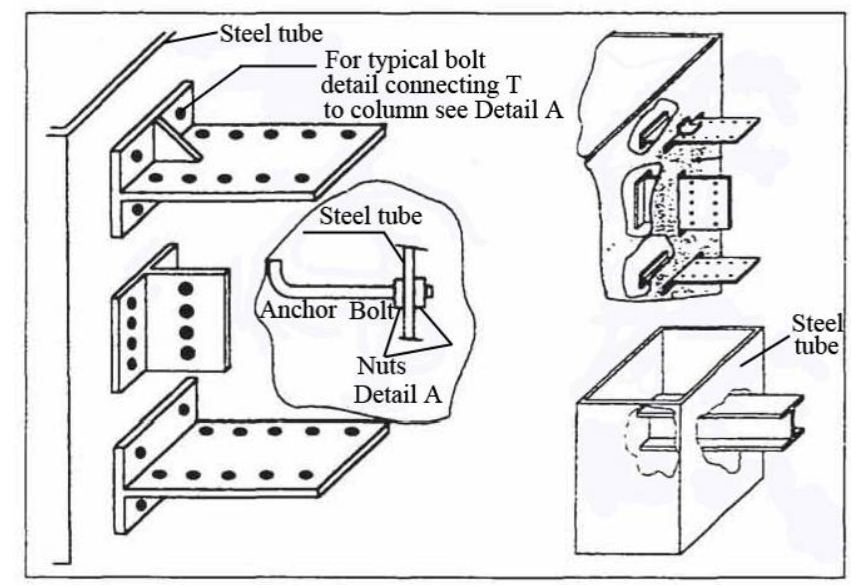

Figure 8. CFT Connection type by Viest

With respect to computational research geared for analyzing complete composite CFT systems, Hajjar et al. [22-23] presented a fiber-based distributed plasticity finite element formulation to perform three-dimensional monotonic analysis of square or rectangular concrete-filled steel tube (CFT) beam-columns. The stiffness-based beam-column element formulation accounted for all significant geometric nonlinearity exhibited by CFT beam-columns and interlayer slip between the steel tube and concrete core, which was extended to cyclic analysis of composite CFT frames. Details of the steel and concrete constitutive models were provided in their paper.

France [24] conducted experiments to learn the behavior of connection between universal beam and concrete filled tubular columns using endplates bolted directly to the column face with ordinary bolts screwed into the threaded holes formed using the flowdrill process. The test results were compared with those from a parallel series of tests in which the tubes were unfilled and substantial increase in the resistance of the column in the compression zone was observed, which forced the rotation axis of the joint moving towards the compression flange of the beam and resulted in the greater moment capacity in the joint. 
Fujimoto, et al [25-26] conducted a series of wide flange beam-to-CFRT column connection tests. A total of eleven one-half scale CFRT column-to-wide flange beam interior and exterior connections were tested under cyclic loading, as illustrated in Figure 9 for the connection configurations. These specimens utilized high strength material, i.e., up to an unconfined compression strength of $110 \mathrm{MPa}$ for concrete and up to a tensile strength of $809 \mathrm{MPa}$ for structural steel, in order to expand the application of the CFRT column system to the field of high performance materials. The test results showed that the elastic stiffness of CFRT connections matches the theoretical value given in the current AIJ design formula regardless of the material strength and the ductility of CFRT connections using high strength materials was sufficient.

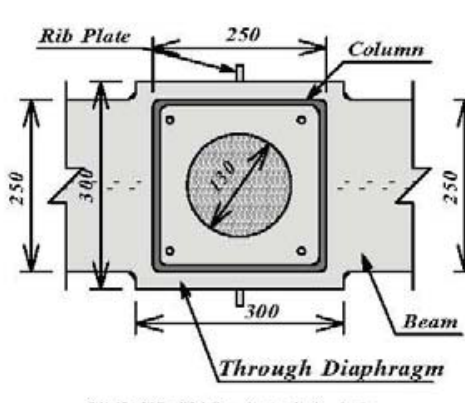

SPECMEN : R1, R2, R3

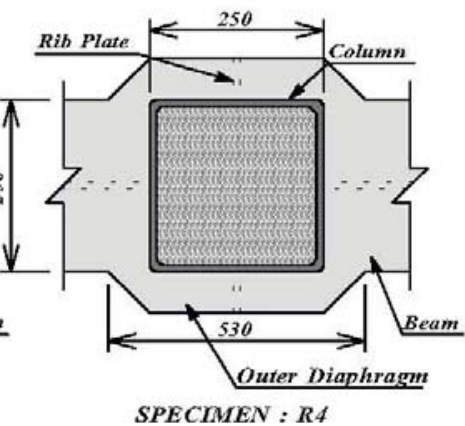

SPECMMEN : R4

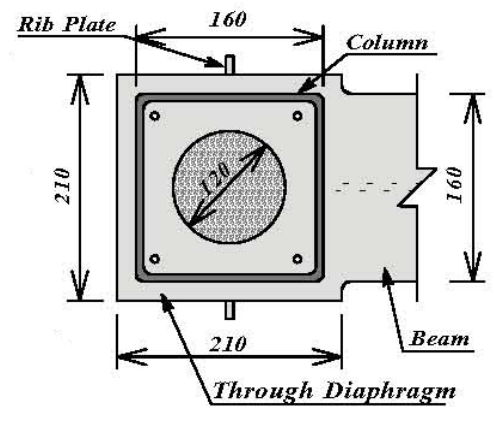

SPECMMEN : R5, R5

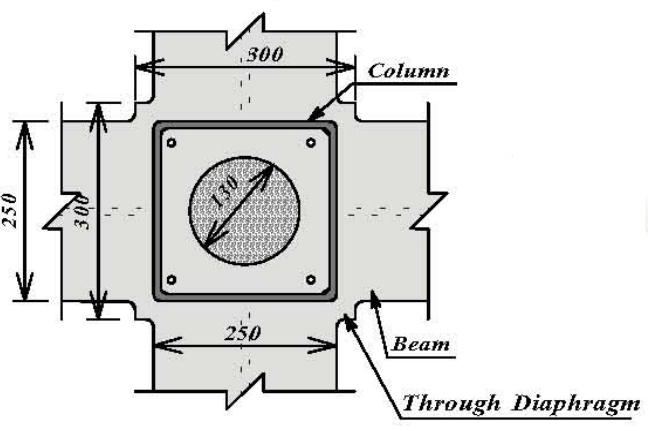

SPECIMEN : R6

Figure 9. Details of Specimens

Ricles, et al [27] carried out the full-scale experiments to learn the inelastic cyclic behavior of connections in square CFT column-WF beam MRF systems, supported by the U.S.-Japan Cooperative Research Program on Composite and Hybrid Structures. The tested connections details, including interior diaphragms, exterior extended structural tees and split tees, were shown in Figure 10. The test results indicated that welded connection with interior or exterior structural tee diaphragms and bolted split-tees have exceptional cyclic strength, stiffness, and ductility. The best performance was obtained in both welded and bolted connections when the details minimized the possibility of strain concentrations developing in the connection area, whereby beam flange fracture was inhibited. 

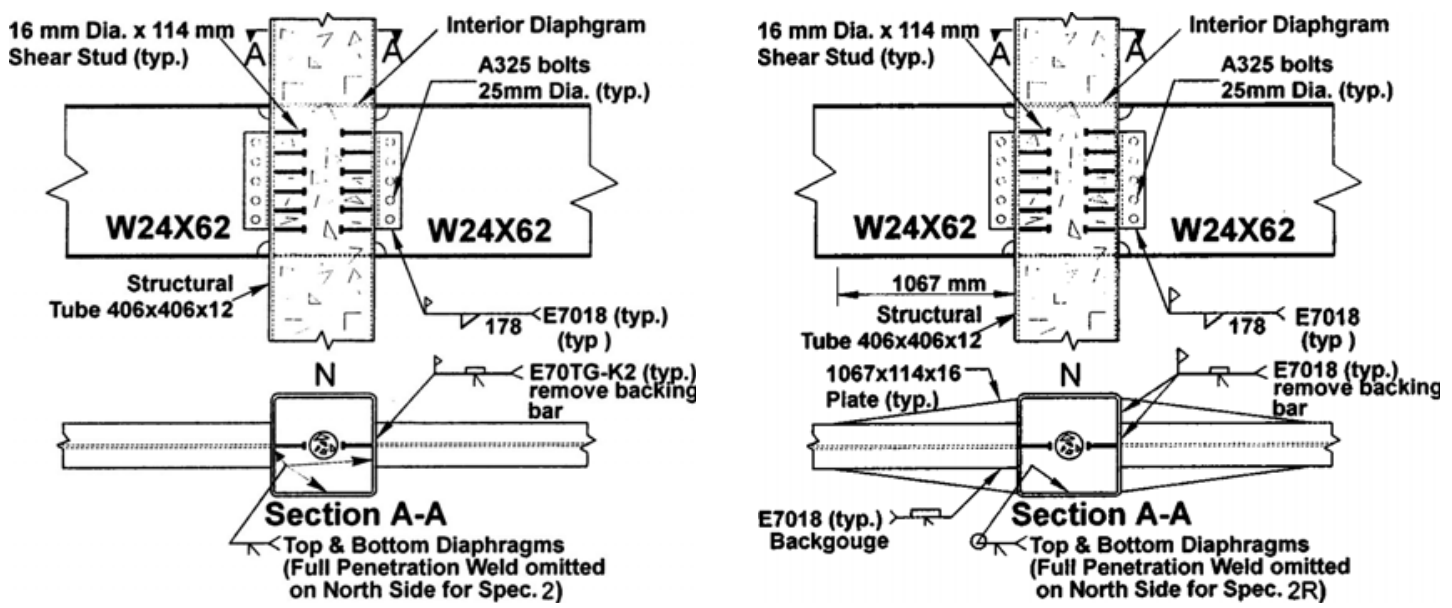

(a) Interior diaphragm connection

(b) Interior diaphragm connection with tapered plate
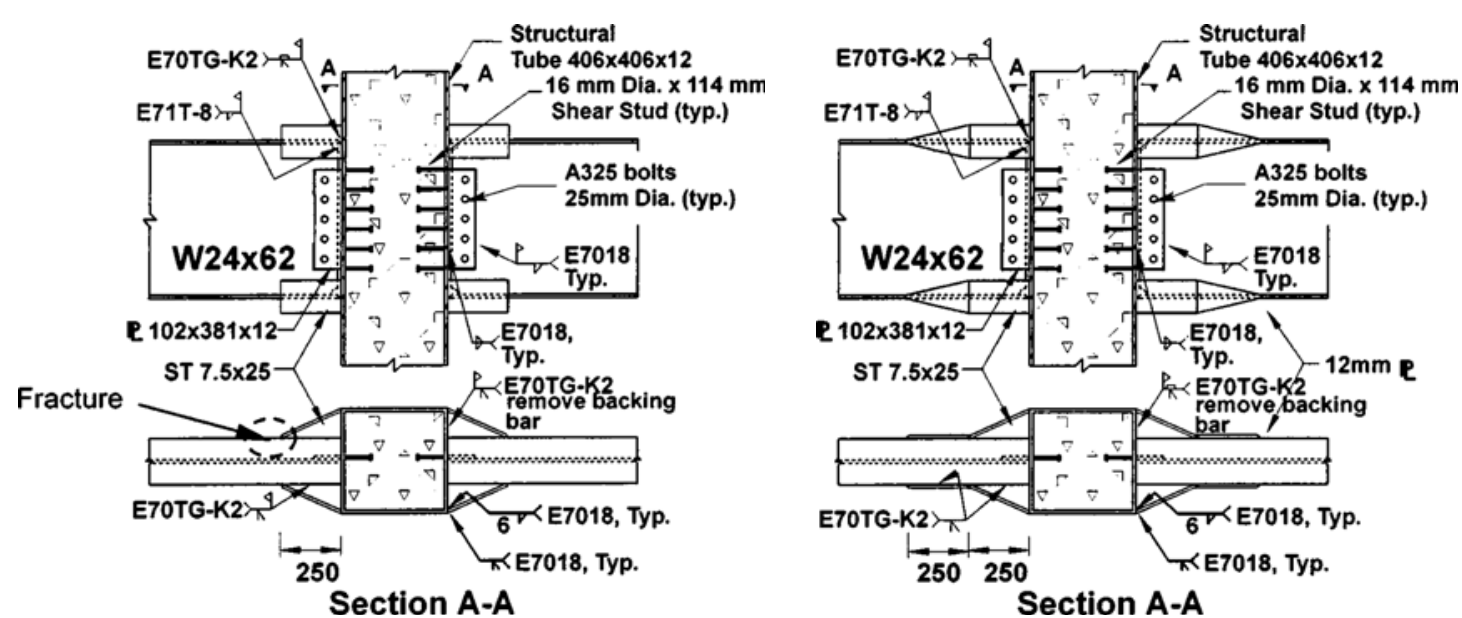

(c) Extended tee connection

(d) Extended tee connection with tapered plates

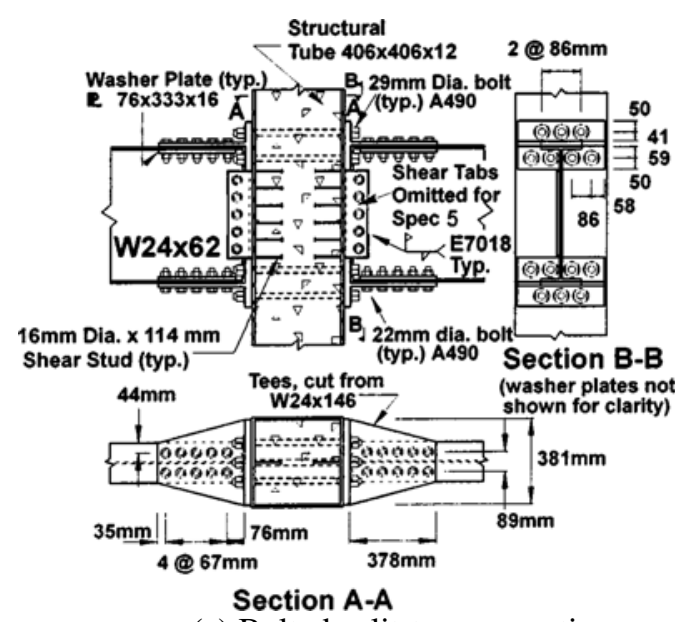

(e) Bolted split-tee connection

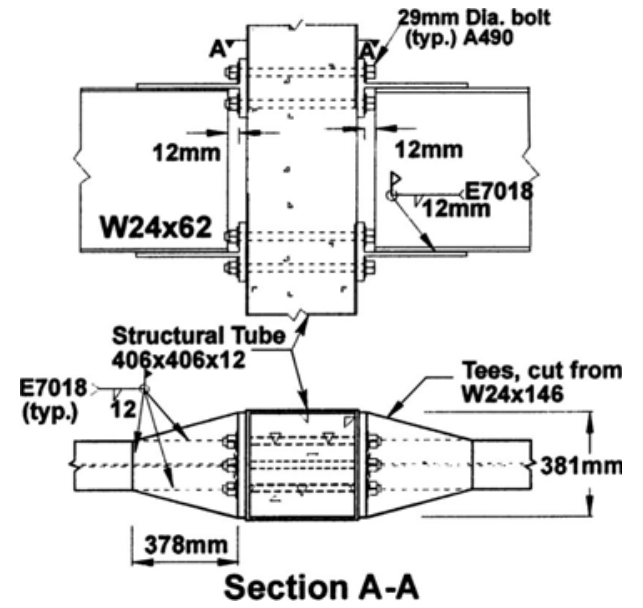

(f) Welded split-tee connection

Figure 10. Connection details by Ricles

Koester, et al. [19] took the investigation with the purpose of identifying the force transfer mechanism and failure modes associated with the split-tee through-bolted moment connection detail investigated by Ricles et al. Fifteen CFT moment connections, idealizing the panel zone of the split-tee through-bolted connection by simulating tee forces against the joint, were designed and tested, as shown in Figure 11. Failure was observed to include a combination of panel zone shear distress and localized bearing failure at the location of the reaction blocks against the steel tube surface. New model and equation were developed for panel zone shear calculation. 


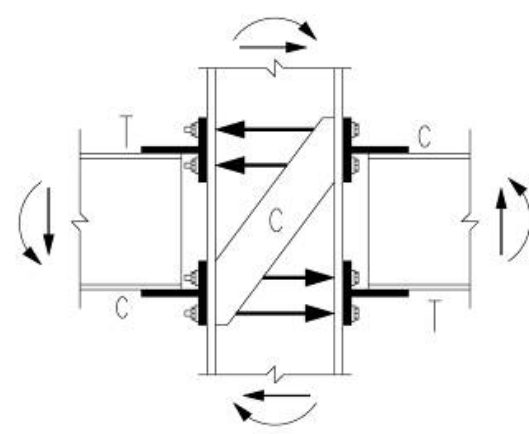

(a) Actual panel zone

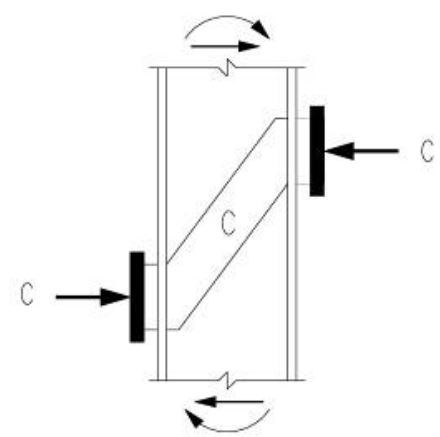

(b) Panel zone modelled in Test Setup

Figure 11. Idealization of Connection Zone by Koester et al.

\section{THIRD PHASE-NEW STUDIES TO DEVELOP CONNECTION ALTERNATIVES}

Research on the CFRT column connection intensified in the third phase in the 2000's when researchers focused on developing various connection configurations. Since then, comprehensive investigations on the behavior and performance of new types of CFRT column connections under monotonic or cyclic loading have been conducted by a number of researchers.

Kang [28] studied the CFT column to H-beam welded connections that were reinforced externally with T-shaped stiffeners at the junction of the column and beam, and with a reinforcing bar or bent plate which penetrated a column. The details were shown in Figure 12. The results of the tests demonstrated that an increased stiffener length was more effective than an increase in the area of penetrated elements for the criteria of both strength and stiffness.

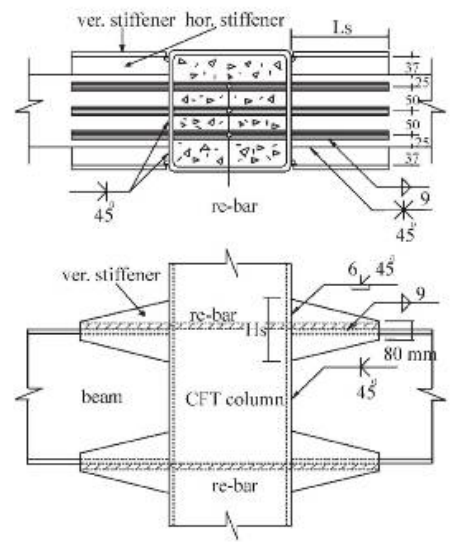

(a) T-stiffener with re-bars
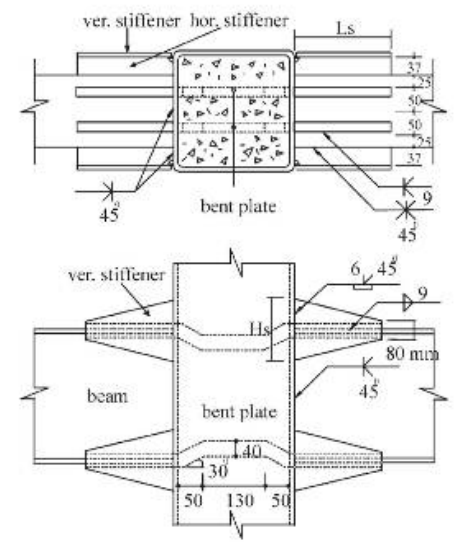

(b) T-stiffener with bent plates

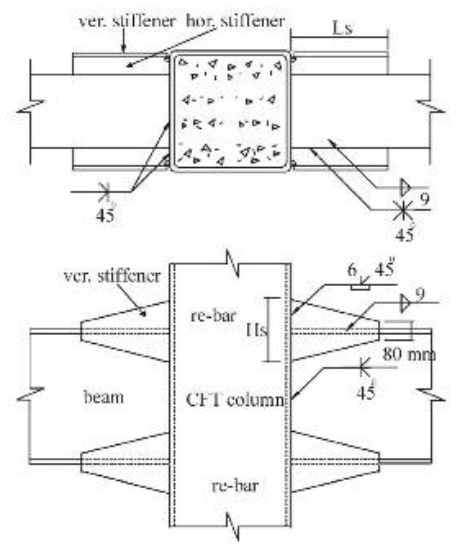

(c) T-stiffener connection

Figure 12. Test Specimen by Kang

Al-Roda [29] carried out tests on four full-scale composite T-cleat connections, as shown in Figure 13. The T-cleats were welded to the column section using fillet weld along the toe of the T-cleat flange. On the other side, each T-cleat was connected to the beam web by either a single or double row of four grade 8.8, M20 bolts. Two steel beams were unsymmetrically loaded. The test results showed the moment carrying potential of T-cleat connections to concrete-filled tubular columns. 
(2)

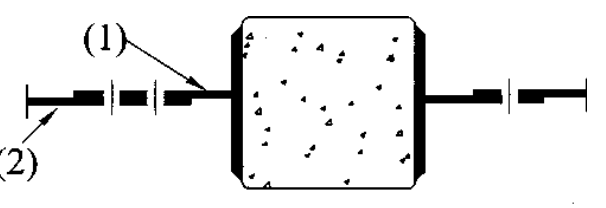

(1) T-Cleat (2) Beam web

Figure 13. Rectangular Section with T-cleat

Shin [30] focused on the experimental and analytical behavior of CFRT column to H-beam welded moment connections with external T-stiffeners. Three types of failure modes, horizontal stiffeners failure, vertical stiffener failure and beam failure, were obtained. The connections reinforced with T-stiffeners having $130 \%$ of strength to beam flanges exhibited stable hysteretic behavior and good ductility. The force transfer mechanism was given in Figure 14.
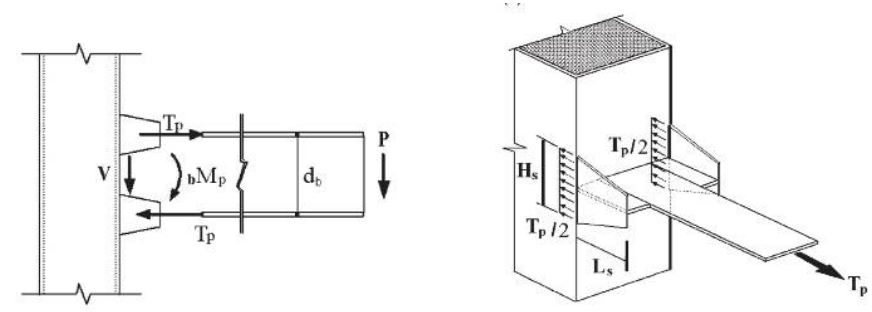

Figure 14. Force Transfer Mechanism of Connection with T-stiffener

Chung, et al. [18] developed the connection proposed by Matsui [18], in order to apply this connection system not only to external joints but also to inner joints, as shown in Figure 15. It was found that this connection had sufficient capacities exceeding the full plastic strength of beam and it had possibility as a new connection method for steel moment-frames.

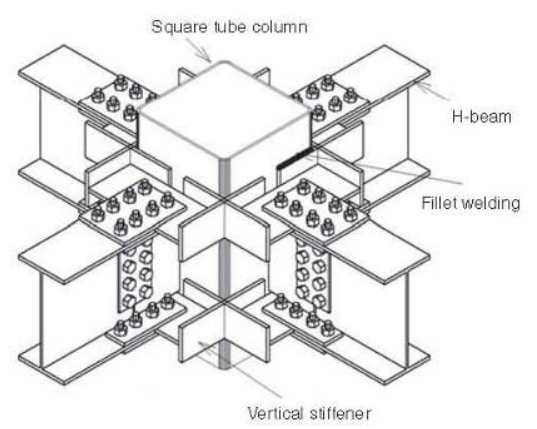

Figure 15 Beam-to-column connection with vertical stiffeners

Fukumoto [31] conducted tests on the panel zone within steel beam to CFRT column moment connections made from high-strength material to investigate their elastoplastic behavior. A nonlinear shear force-deformation model for predicting the elastoplastic behavior of the panel zones was proposed. A method for evaluating load resistance was also proposed, in which a new theoretical compression strut mechanism is utilized, taking into account the confinement of the tube flange.

Wu, et al. [32] proposed a new design of bolted beam-to-column connections for CFRT as shown in Figure 16. A mechanical model was established in order to derive theoretical equations for calculation the stiffness, the yielding shear strength and the ultimate shear strength of the panel zone. And the test results demonstrated that the bolted connections had superior seismic resistance in stiffness, strength, ductility and energy dissipation mechanisms. 


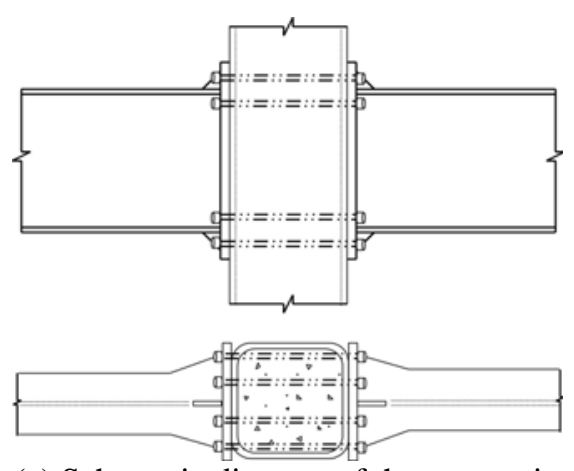

(a) Schematic diagram of the connection

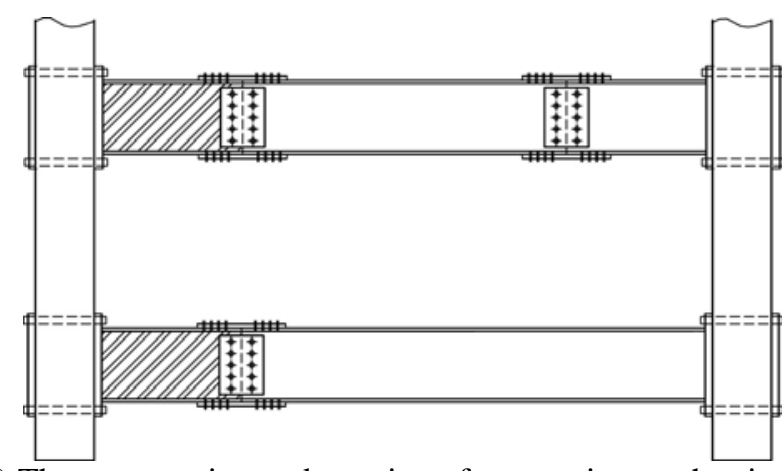

(b) The construction and erection of connection on the site Figure 16. The Proposed Bolted Connection by Wu

Park, et al. [33] described the force transfer mechanism and the cyclic performance of wide flange beams to square concrete-filled tube column joints reinforced with stiffening plates around the column. The force transfer mechanism at the joint was assessed using an analytical yield line method. The test results showed that the derived nominal strength equation provided a reasonable prediction and total rotation of 0.04 rad which was required for special moment resisting frames could be obtained.

Choi [34] focused on a moment-rotation relationship for CFT frames composed of beam-column connections of exterior diaphragm with four rectangular plates. A function formula of the moment-rotation curve for the connection was established, using a three-parameter power model and a least-mean-square technique. The initial rotational stiffness of beam-to-column connection was determined by slope from zero to the analytical results.

Huang [35] studied the nonlinear FEM models of outer diaphragm connection between concrete-filled square tubular columns and steel beams involving geometric large deformation and material nonlinear. Joint behaviors and stress distribution were analyzed under the monotonic load. The results indicated that some of the end moments of beams were transformed to the column tube web and the core concrete at the panel zone by the outer diaphragm connected to the column web. Others were directly transformed to the column tuber flange and the core concrete by the diaphragm near the column corner. Serious stress concentration occurred in diaphragm near the column corner. The specimen was failed because compressed flanges were buckled and the plastic hinges were formed at narrowest section.

Wu [36] proposed bidirectional bolted beam-to-column connections for CFRTs. A mechanical model was established to derive theoretical equations for calculating the stiffness, the yielding shear strength and ultimate shear strength of the panel zone, and it was verified by a series of cyclic loading experiments. The experimental results demonstrated that the bidirectional bolted connections had superior earthquake resistance in stiffness, strength, ductility and energy dissipation mechanism.

Cheng [37] investigated the seismic performance of four steel beams to CFRT column connections with floor slabs, including two interior and two exterior joints. The seismic behavior of new connection details such as the taper flange or larger shear tab in the beam-end was investigated to prevent complete joint penetration welds (CJP) of the girder flanges from the unexpected brittle failure found in the latter after the Northridge earthquake. The slab effect on the shear transfer in the panel zone might be neglected. 
Park, et al. [38] proposed a new detail of partially restrained composite connection (PR-CC) which could be applied to concrete-filled tubular structures incorporating the effect of composite slabs and the performance for construction work. A welded bottom beam flange connection (WP) was proposed to enhance the capacity of the bottom of the connection and to improve ductility and fabrication. In addition, a reduced beam section (RBS) was adopted for the bottom beam flange to examine its effect on ductility. A seat-angle connection with penetrating bolts was also suggested and compared with the welded bottom beam flange connection. The detail was shown in Figs. 17 and 18. Both monotonic and cyclic loading tests were conducted on the five full scale specimens to compare and evaluate their ductility characteristics.
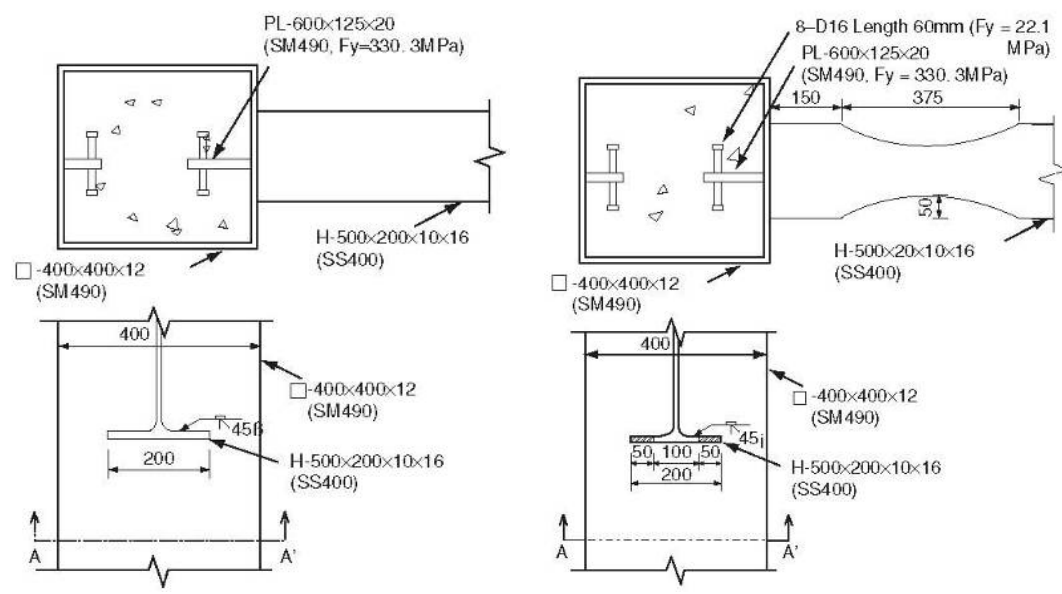

(a) BW

(b) BW type with a reduced beam section

Figure 17. Proposed Bottom Connection Details

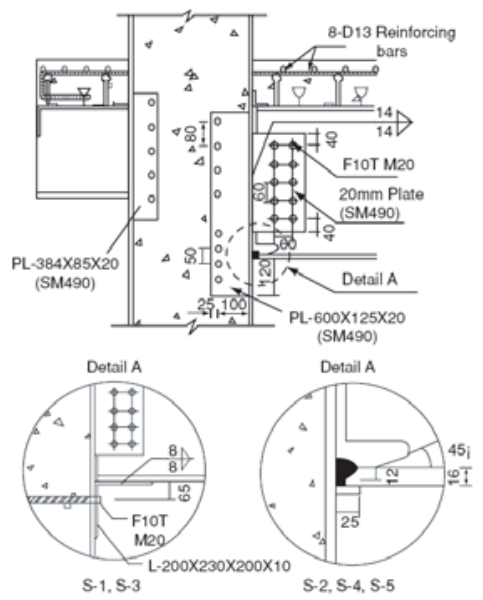

Figure 18. Proposed Connection Details

Shin [39] studied connections reinforced with T-shaped stiffeners attached to the beam flanges. The specimens were divided into three series: TS series specimens reinforced with T-shaped stiffeners only, TSD series specimens with RBS beams in addition to the stiffeners, and TSH series specimens with small holes in the stiffeners. All the specimens developed plastic rotations in excess of 3\% rad, suggesting that the ductility capacity of the specimens exceeds the requirements for special moment frame connections in the AISC seismic provisions. The tapered horizontal stiffener elements, RBS cutouts and the horizontal stiffener holes were effective in reducing the stress concentration at the tip of the horizontal element. However, some of the specimens failed by a premature fracture in the HAZ of vertical element welds, suggesting that strain hardening should be considered for the design of T-stiffeners. 
Choi [40] proposed a new CFRT column-to-beam connection with combined-cross diaphragm (Figure 19), featuring a column flange penetration in the major-axis direction and an interior diaphragm in the minor-axis direction. Simple tension tests were performed in order to evaluate the initial stiffness and strength of the connections. The test results demonstrated that the new connection was not inferior to the traditional one in terms of initial stiffness and ultimate strength. Additionally, stress concentration on the connection could be alleviated by improvement to the detail.

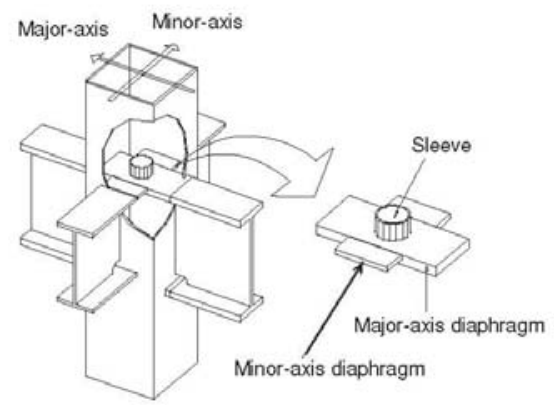

Figure 19. Connections with Combined-cross diaphragm

Nie [41] did research on the flexural capacity of connections composed of concrete-filled square steel tubular columns and steel concrete composite beams with interior diaphragms or anchored studs. Analytical models were proposed to take into account the effects of axial load, concrete slab, middle interior diaphragm, beam and column width condition, and punching shear failure mode. Formulae in different conditions were established based on these models.

Wang [42-43] carried out tests for bolted moment joints connecting CFT column to H-shaped steel beam using high-strength blind bolts, as shown in Figure 19. The cruciform specimens were under monotonic or cyclic loading to investigate the static or seismic performance, stiffness degradation, energy dissipation and failure modes of the blind bolted connection. The test parameters varied were the column section type and the thickness of the end plate. The results showed that the proposed connection displayed not only reasonable strength and stiffness, but also excellent hysteretic behavior in terms of their moment-rotation response, strain distributions and energy dissipation. It was a reliable and effective solution for moment-resisting composite frame structures.

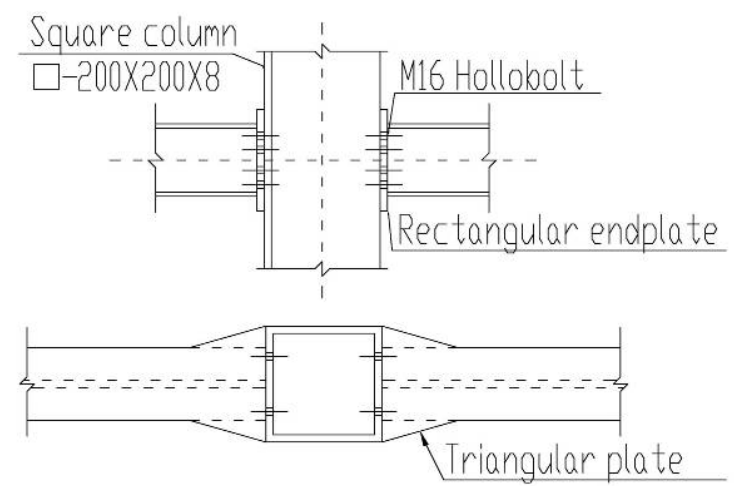

Figure 19. Square CFST Connections

Choi [44] studied the development of the through type concrete filled square steel tube column to beam connection, reinforced with an asymmetric lower diaphragm, which could be used in weak-earthquake regions such as Korea. The proposed connection was shown in Figure 20. Simple tension tests and cyclic loading tests were taken out. The horizontal T-bar and stud bolts in the vertical plates were designed to transmit the tensile stress from the bottom flange of the beam to the 
filled concrete. All the test specimens satisfied the 0.01 radian inelastic rotation capacity requirements for the composite ordinary moment frame (C-OMF) of the AISC seismic provisions.

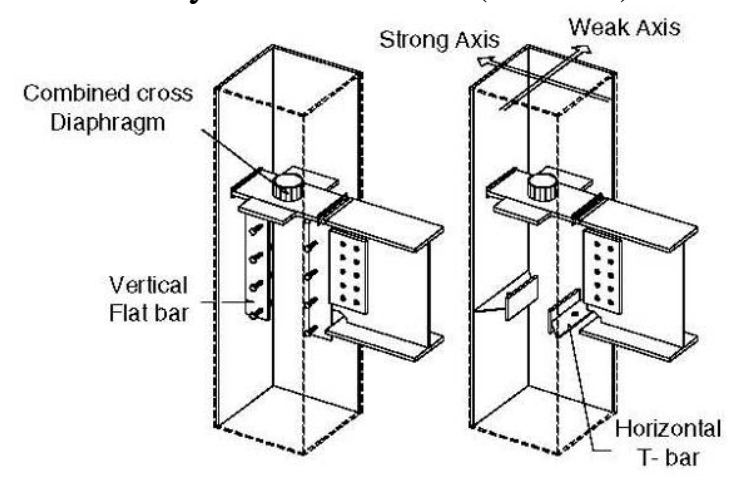

Figure 20. Supposed Connection Detail

Jones [45-46] presented simple hand calculation methods for fin-plate to rectangular column connections under tensile loading or bending and shear loading based upon defining a rigid plate deformation pattern for the column face and then applying the virtual work principle. The simple hand calculation method was compared favorably with a large range of finite element simulations. The proposed method could be used in the component based method for joints involving a fin-plate component in tension or in shear and bending.

Park [47] improved the detail for a CFT square column-to-beam partially restrained composite connection (PR-CC). The bottom beam flange was welded to the column tube to prevent brittle fracture at the bottom of the bema flange, as shown in Figure 21. This type was evaluated to exhibit equal or more ductility than the existing type.

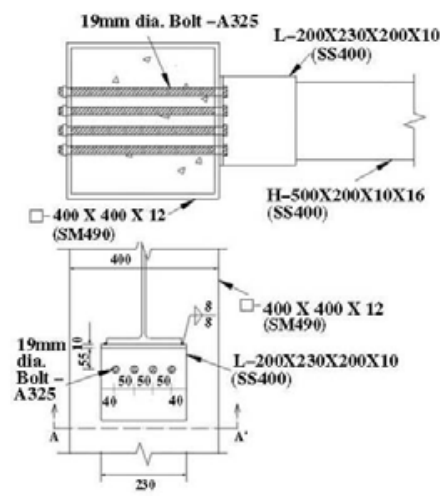

(a) existing type
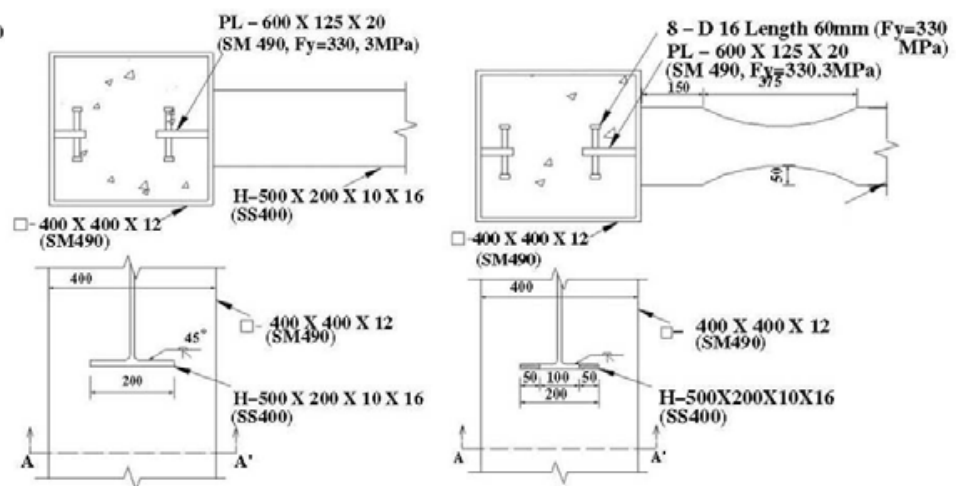

(c) suggested type II

Figure 21. Bottom Connection Details of Specimens

Zhao [48] proposed a computationally efficient macromodeling scheme to simulate the nonlinear behavior of composite structural connections consisting of steel-concrete composite beams and concrete-filled steel tubular (CFST) columns. The model adopted fiber-based stress-strain relations that enabled the consideration of strength and ductility for confined concrete and local buckling of the steel tube. The flexibility of the composite-beam-to-CFST-column connection was modeled as a panel zone. Compared with both overall response and local actions with those obtained from test results, the computational efficiency of such an approach made it a viable methodology for application in the nonlinear analysis of complete composite building systems composed of steel-concrete beams and composite columns. 
Hu [49] studied the performance of composite-moment frames with smart partially restrained (PR) CFT column connections. The innovative PR connections utilized the recentering properties of super-elastic SMA tension bars and the energy dissipation capacity of low-carbon steel tension bars, as figured out in Figure 22. Simplified user joint elements based on the mechanical modeling approach were formulated in an effort to simulate the realistic behavior of bolted connections. The performance of the proposed frame was compared with the conventional welded frame in terms of time history response, residual roof drifts and inter-story drift ratios. It was observed that frames with the PR composite connections showed superior performance.

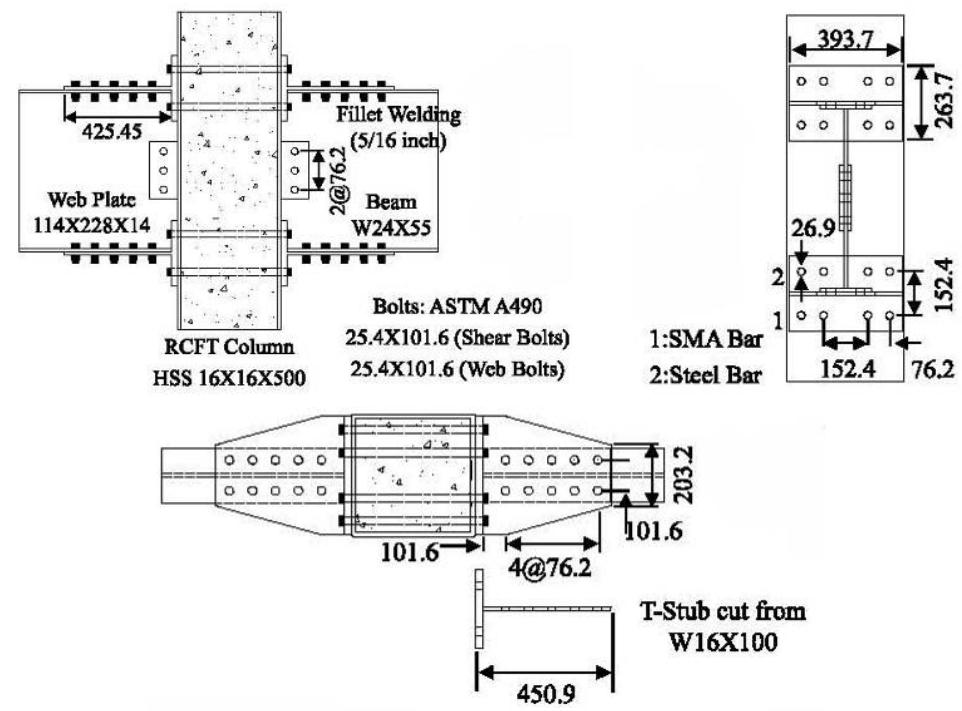

Figure 22. Smart PR-CFT Connection Model (T-Stub Connection Detail)

Mirza [50] investigated the performance of beam-column flush end-plate connections when using blind bolts. The strength on medium rise buildings in regions of medium to high seismicity was studied. It was found that the maximum strength capacity, as well as ultimate displacement ductility, was satisfactory and it was unsafe to estimate the actual strength capacity using code provisions when large hysteretic displacements governed the structural response. Moreover, adequacy of standardizing increased earthquake return periods within structural design connections was investigated.

Tizani [51] presented a blind-bolted connection to concrete-filled square hollow sections using a modified blind-bolt that addressed the issue of flexibility of the blind-bolt connector as well as that of the tube face. An experimental program was conducted to measure the resulting connection stiffness with varied connection endplate type, column thickness and concrete strength. It concluded that the connection was able to develop the required stiffness for it to be used as a rigid connection in braced frames.

\section{SUMMARY AND CONCLUSIONS}

CFRT column composite frame systems with steel beams have been widely used in moment-resisting frame systems for engineering practice. This paper has presented a brief summary of connection details that have been developed from the viewpoints of structural performance, economy and productivity. 
Based on the previous research, it can be seen that considerable amount of work has been done to optimize the connection details. However, it is far from satisfactory. Both theoretical analysis and experimental data need to be expanded on the seismic behavior of these types of connections. The future developments could be as follows:

(1) It is necessary to develop the most suitable model of the load-deformation relationship for predicting the yielding and ultimate flexural and shear strength of connections to CFRT columns.

(2) The configuration and behavior of fully-bolted connection should be investigated. Fully -welded open beam-to-CFRT column connections have been widely studied by many researchers. However, the cost and inspection implications associated with on-site welding, and their critical performance under cyclic loading remains as potential problems for this type of connections. In contrast, bolted connections can provide similar or even more favorable behavior than their fully-welded counterparts under various loading conditions.

(3) The viability of connections between CFRT columns and HSS beams should be explored. HSS beams are beneficial because of their reduction in surface area and decrease in lateral bracing requirements compared with open sections. Furthermore, connections with HSS beams can be a challenge. The complex, unusual configuration of connections can pose geometrical and access difficulty for fabricators and workers, and reinforcement such as horizontal stiffeners may not be feasible to include on closed sections.

\section{ACKNOWLEDGEMENTS}

This work is sponsored by the National Natural Science Foundation of China (Grant No. NSFC61272264), the twelfth five-year national science and technology support program (Grant No. 2011BAJ08B02-04) and key project in the Tianjin Science \& Technology Pillar Program (Grant No. 11ZCGYSF01000). The authors also appreciate the financial support provided by the Chinese Scholarship Council (File No. 201206250067) that enables the Visiting Research Scholar to cooperate with Dr. Benjamin W. Schafer at Johns Hopkins University at Baltimore.

\section{REFERENCE}

[1] Faschan, W., “The Bank of China, Advancing the Art of Composite Construction” , Composite Construction of Steel and Concrete II, ASCE, 1992, pp. 576.

[2] Viest, I., “Composite Construction Recent Past, Present, and Near Future” , Composite Construction of Steel and Concrete II, ASCE, 1992, pp. 1-16.

[3] Viest, I.M., Colaco, J.P., Furlong, R.W., Griffis, L.G., Leon, R.T. and Wyllie, L.A. “Composite Construction Design For Buildings", McGraw-Hill Companies, Inc. and the American Society of Civil Engineers, United States of America, 1997.

[4] Huang, C.H., Chung, L.L., Yeh, Y.K., Yeh, C.H., Lu, L.Y. and Liu, C.Y., "Review of researches on concrete-filled steel tubes”, Report No. NCREE-98-012. National Center for Research on Earthquake Engineering.

[5] Schneider, S.P. and Alostaz, Y.M., "Experimental Behavior of Connections to Concrete-Filled Steel Tubes”, Journal of Constructional Steel Research, 1998, Vol. 45, No. 3, pp. 321-352.

[6] Federal Emergency Management Agency, FEMA-350, 2000.

[7] Furlong, R. W., "Strength of Steel-Encased Concrete Beam Columns", Jamal of the Structural Division, Proceeding of the ASCE, Vol. 93, ST 5, October 1967, pp. 113-124. 
[8] Ansourian, P., “Connections to Concrete-Filled Tube Columns" , International Association of Bridge and Structural Steel Engineers, 1976, Vol. 36, No. 1, pp. 1-22.

[9] Tomii, M. and Sakino, K., "Experimental Studies on the Ultimate Moment of Concrete Filled Square Steel Tubular Beam-Columns", Transactions of the Architectural Institute of Japan, No. 275, 1979, pp. 55-63.

[10] Sakino, K. and Tomii, M., "Hysteretic Behavior of Concrete Filled Square Steel Tubular Beam-Columns Failed in Flexure”, Transactions of the Japan Concrete institute, Vol. 3, 1981, pp. 439-446.

[11] Matsui, C., "Strength and Behavior of Frames with Concrete Filled Square Steel Tubular Columns under Earthquake Loading”, Proceedings of the International Specialty Conference on Concrete Filled Tubular Structures, Harbin, China, August 1985, pp. 104-111.

[12] Kanatani, H., Tabuchi, M., Kamba, T., Hsiaolien, J. and Ishikawa, M., “A Study on Concrete Filled RHS Column to H-Beam Connections Fabricated with HT Bolts in Rigid Frames”, Composite Construction in Steel and Concrete, ASCE, June 1987, pp. 614-635.

[13] Prion, H.G.L. and McLellan, A.B., "Connecting Steel Beams to Concrete-Filled Steel Columns", Proceedings of the ASCE Structures Congress on Composite Compression Members, San Antonio, TX, 1992, pp. 918-921.

[14] Azizinamini, A. and Parakash, B., "A Tentative Design Guidelines for a New Steel Beam Connection Detail to Composite Tube Column”, AISC Engineering Journal, 3rd quarter, 1993, pp. 108-115.

[15] Mehanny, S.S.F. and Deierlein, G.G., "Seismic damage and collapse assessment of composite moment frames”, Journal of Structural Engineering, 2001, Vol. 127, No. 9, pp.1045-1053.

[16] Tort, C., "Reliability-Based Performance-Based Design of Rectangular Concrete-Filled Steel Tube (RCFT) Members and Frames”, PhD dissertation, Dept. of Civil and Environmental Eng., Univ. of Minnesota, 2007.

[17] Goel, S.C., “U.S.-Japan Cooperative Research Program on Composite and Hybrid Structures”, ACI SP-174: Hybrid and Composite Structures, eds. Shahrooz, B.M., and Sabnis, G.M., ACI, 1998, pp. 213-224.

[18] Chung, J., Seo, S., Matsui, C. and Choi, S., "Hysteresis Behavior of Square Tube Columns to H-Beam Connections with Vertical Stiffeners”, Advances in Structural Engineering, 2005, Vol. 8, No. 6, pp. 561-571.

[19] Koester, B., "Panel Zone Behavior of Moment Connections Between Rectangular Concrete-Filled Steel Tubes and Wide Flange Beams”, PhD dissertation, Dept. of Civil and Environmental Eng., Univ. of Texas, Austin, Austin, Tex, 2000.

[20] Morino, S., Kawaguchi, J., Yasuzaki, C. and Kanazawa, S., “Behavior of Concrete Filled Steel Tubular Three Dimensional Subassemblages”, Composite Construction of Steel and Concrete II, ASCE, 1996, pp. 726-741.

[21] Kawano, A. and Matsui, C., "New connections using vertical stiffeners between H-shaped beams and hollow or concrete-filled square tubular columns”, Proceedings of an Engineering Foundation Conference, 1996, pp.172-185.

[22] Hajjar, J.F., Schiller, P.H. and Molodan, A., “A distributed plasticity model for concrete-filled steel tube beam-columns with interlayer slip”, Engineering Structures, 1998, Vol. 20, No. 8, pp. 663-376.

[23] Hajjar, J.F., Molodan, A. and Schiller, P.H., “A distributed plasticity model for cyclic analysis of concrete-filled steel tube beam-columns and composite frames”, Engineering Structures, 1998, Vol. 20, No. 4-6, pp.398-412.

[24] France, J.E., Davison, B.J. and Kirby, P.A., "Moment-capacity and rotational stiffness of endplate connections to concrete-filled tubular columns with flowdrilled connectors”, Journal of Constructional Steel Research, 1999, Vol. 50, No. 1, pp. 35-48. 
[25] Fujimoto, T., Inai, E., Tokinoya, H., Kai, M., M and Mori, K. "Behavior of Beam-to-Column Connection of CFT Column System Under Seismic Force”, Proceeding of 6th ASCCS Interactional Conference on Steel-Concrete Composite Structures, Los Angeles, 2000.

[26] Nishiyama, I., Fujimoto, T., Fukumoto, T. and Yoshioka, K., "Inelastic Force-Deformation Response of Joint Shear Panels in Beam-Column Moment Connections to Concrete-Filled Tubes”, Journal of Structural Engineering, 2004, Vol. 130, No. 2, pp. 244-252.

[27] Ricles, J.M., Peng, S.W. and Lu, L.W. "Seismic Behavior of Composite Concrete Filled Steel Tube Column-Wide Flange Beam Moment Connections”, Journal of Structural Engineering, 2004, Vol. 130, No. 2, pp. 223-232.

[28] Kang, C.H., Shin, K.J., Oh, Y.S. and Moon, T.S., "Hysteresis behavior of CFT column to H-beam connections with external T-stiffeners and penetrated elements", Engineering Structures, 2001, Vol. 23, No. 9, pp. 1194-1201.

[29] Al-Rodan, A.K., "T-Cleat Connections to Concrete-Filled Tubular Internal Columns”, Journal of Structural Engineering, 2004, Vol. 130, No. 5, pp. 725-731.

[30] Shin, K.J., Kim, Y.J., Oh, Y.S. and Moon, T.S., "Behavior of Welded CFT Column to H-beam Connections with External Stiffeners”, Engineering Structures, 2004, Vol. 26, No. 13, pp. 1877-1887.

[31] Fukumoto, T. and Morita, K., "Elastoplastic Behavior of Panel Zone in Steel Beam-to-Concrete Filled Steel Tube Column Moment Connections”, Journal of Structural Engineering, 2005, Vol. 131, No. 12, pp. 1841-1853.

[32] Wu, L.Y., Chung, L.L., Tsai, S.F., Shen, T.J. and Huang, G.L., "Seismic Behavior of Bolted Beam-To-Column Connections for Concrete Filled Steel Tube”, Journal of Constructional Steel Research, 2005, Vol. 61, No. 10, pp. 1387-410.

[33] Park, J.W., Kang, S.M. and Yang, S.C., "Experimental Studies of Wide Flange Beam to Square Concrete-Filled Tube Column Joints with Stiffening Plates around the Column”, Journal of Structural Engineering, 2005, Vol. 131, pp. 1866-1876.

[34] Choi, S.M., Hong, S.D. and Kim, Y.S., "Modeling Analytical Moment-Rotation Curves of Semi-Rigid Connections for CFT Square Columns and Steel Beams", Advances in Structural Engineering, 2006, Vol. 9, No. 5, pp. 697-706.

[35] Huang, B.S., Du, P.Y. and Fan, J.H., "Nonlinear Analysis on Connection with Outer Diaphragms between Square Concrete Filled Steel Tube Columns and Steel Beams”, Journal of Harbin Institute of Technology, 2007, Vol. 39, pp455-458.

[36] Wu, L.Y., Chung, L.L., Tsai, S.F., Lu, C.F. and Huang, G.L., "Seismic behavior of bidirectional bolted connections for CFT columns and H-beams”, Engineering Structures, 2007, Vol. 29, No. 3, pp. 395-407.

[37] Cheng, C.T., Chan, C.F. and Chung, L.L., "Seismic Behavior of Steel Beams and CFT Column Moment-resisting Connections with Floor Slabs”, Journal of Constructional Steel Research, 2007, Vol. 63, No. 11, pp. 1479-1493

[38] Park, S. Choi, S. Park, Y. and Kim, Y., "Ductility Characteristics of Partially Restrained Beam-to-Column Composite Connections in Concrete Filled Square Tubes”, Advances in Structural Engineering, 2008, Vol. 11, No. 5, pp. 565-575.

[39] Shin, K.J., Kim, Y.J. and Oh, Y.S., "Seismic Behaviour of Composite Concrete-filled Tube Column-to-beam Moment Connections”, Journal of Constructional Steel Research, 2008, Vol. 64, No. 1, pp. 118-127.

[40] Choi, S., Lee, S., Hong, S. and Kim, J., "Structural Capacities of Tension Side for CFT Square Column-to-beam Connections with Combined-cross Diaphragm”, Advances in Structural Engineering, 2008, Vol. 11, No. 2, pp. 209-227.

[41] Nie, J.G., Qin, K. and Cai, C.S., "Seismic Behavior of Composite Connections-flexural Capacity Analysis”, Journal of Constructional Steel Research, 2009, Vol. 65, No. 5, pp. 1112-1120. 
[42] Wang, J.F., Han, L.H. and Uy, B., "Behaviour of Flush End Plate Joints to Concrete-filled Steel Tubular Columns”, Journal of Constructional Steel Research, 2009, Vol. 65, No. 4, pp. 925-939.

[43] Wang, J.F., Han, L.H. and Uy, B., "Hysteretic Behaviour of Flush End Plate Joints to Concrete-filled Steel Tubular Columns", Journal of Constructional Steel Research, 2009, Vol. 65, No. 8-9, pp. 1644-1663.

[44] Choi, S.M., Park, S.H., Yun, Y.S. and Kim, J.H., “A Study on the Seismic Performance of Concrete-filled Square Steel Tube Column-to-beam Connections Reinforced with Asymmetric Lower Diaphragms”, Journal of Constructional Steel Research, 2010, Vol. 66, No. 7, pp. 962-970.

[45] Jones, M.H. and Wang, Y.C., “Tying Behaviour of Fin-plate Connection to Concrete-filled Rectangular Steel Tubular Column - Development of a Simplified Calculation Method” , Journal of Constructional Steel Research, 2010, Vol. 66, No. 1, pp. 1-10.

[46] Jones, M.H. and Wang, Y.C., "Shear and Bending Behaviour of Fin Plate Connection to Concrete Filled Rectangular Steel Tubular Column -- Development of a Simplified Calculation Method”, Journal of Constructional Steel Research, 2011, Vol. 67, No. 3, pp. 348-359.

[47] Park, S.H., Choi, S.M., Kim, Y.S., Park, Y.W. and Kim, J.H., "Hysteresis Behavior of Concrete Filled Square Steel Tube Column-to-beam Partially Restrained Composite Connections”, Journal of Constructional Steel Research, 2010, Vol. 66, No. 7, pp. 943-953.

[48] Zhao, H.L., Kunnath, S.K. and Yuan, Y., "Simplified Nonlinear Response Simulation of Composite Steel-concrete Beams and CFST Columns”, Engineering Structures, 2010, Vol. 32, No. 9, pp. 2825-2831.

[49] Hu, J.W., Choi, E. and Leon, R.T., "Design, Analysis and Application of Innovative Composite PR Connections between Steel Beams and CFT Columns", Smart Materials and Structures, 2011, Vol. 20, No. 2, pp. 0964-1726.

[50] Mirza, O. and Uy, B., "Behaviour of Composite Beam-column Flush End-plate Connections Subjected to Low-probability, High-consequence loading”, Engineering Structures, 2011, Vol. 33, No. 2, pp. 647-662.

[51] Tizani, W., Al-Mughairi, A., Owen, J.S. and Pitrakkos, T., "Rotational Stiffness of a Blind-bolted Connection to Concrete-filled Tubes using Modified Hollo-bolt”, Journal of Constructional Steel Research, 2013, Vol. 80, pp. 317-331. 


\title{
TEST AND DESIGN OF STAINLESS STEEL WELDED I-COLUMNS
}

\author{
Baofeng Zheng ${ }^{1}$, Ganping Shu ${ }^{1}$ and Xiaoming Shen ${ }^{2}$ \\ ${ }^{1}$ School of Civil Engineering, Southeast University, No. 2 Sipailou, Nanjing, China, 210096 \\ ${ }^{2}$ ARTS Group Co., Ltd, Suzhou, China, 215020
}

\begin{abstract}
This paper describes a series of tests on austenitic stainless steel welded I-columns. Two stub column tests and seven long column tests were carried out. Geometric dimensions, local and overall imperfections of the columns were measured. Material properties of the columns were obtained from tensile coupon and stub column tests. The material enhancement due to the shear cutting in the fabrication of the columns was also measured. The effects of this material enhancement and the residual stresses caused in welding, on the flexural buckling strengths of columns were evaluated using finite element method. The strengths obtained from long column tests were compared with the strengths predicted by European design code (Eurocode3: Part 1.4) and American design code (SEI/ASCE-8-02). It is concluded that the column curve for welded I-column buckled in minor axis of European design code is more reliable in the strength predictions for welded I-columns buckled in major axis and columns buckled in minor axis.
\end{abstract}

Keywords: Stainless steel, Welded I-column, Test, Design, Column curve

\section{INTRODUCTION}

Stainless steel sections are increasingly used in architectural and structural applications because of their superior corrosion resistance, ease of maintenance and pleasing appearance in recent years.

Stainless steel column behaviors have been investigated both experimentally and theoretically. Most of the previous researches focus on the behavior of the cold formed stainless steel columns. Few researches have been reported on the welded I-columns. Kuwamura[1], Saliba and Gardner[2], and Yuan et al. [3] reported tests on stainless steel stub column tests of welded I-sections. Bredenkamp and Van den Berg [4] carried out two stub column tests and thirteen long column tests on welded I-columns of Grade 3CR12. Burgan et al. [5] reported fifteen long column tests on welded I-columns of Grade S304 and S31803. Up to date, a total of twenty eight long column tests are available on the welded I-sections.

On the design code side, American design code (SEI/ASCE-8-02) [6] was developed for the design of cold formed stainless members. Tangent modulus method is adopted in this code to calculate the flexural buckling strength of stainless steel columns. Validation is required to check whether this method is still suitable for the strength predictions of welded I-columns. European design code (Eurocode3: Part 1.4) [7] uses Perry formula to predict the flexural buckling strengths of welded I-columns. In the Perry formula, the imperfection parameters for the design of low carbon steel columns are directly used for the design of stainless steel columns. As few test data are available, more test data on the welded I-columns are need to validate and to improve the design codes.

This paper presents a comprehensive experimental program on stainless steel welded I-columns, including the measurements of geometric dimension and imperfection, tensile coupon tests, stub columns tests, and long columns tests. Furthermore, the effect of the fabrication, including the shearing edge enhancement and the residual stresses, on the flexural buckling strengths of columns were investigated using finite element method. Finally, the strengths from the long column tests 
were compared with the predictions using the current design codes. Recommendations on the strength predictions for stainless steel welded I-columns are given.

\section{TEST PROGRAM}

The material used in the tests is austenitic stainless steel Grade 304. The surface of the virgin plate is No.1 Grade, i.e. no polishing and with color in silvery white. These plates were cut into strips by shearing machine, and then the strips were welded into I-columns using TIG welding. The columns were put into a reforming machine to reduce the imperfection due to the welding.

The nominal cross section used in the test is $100 \mathrm{~mm} \times 100 \mathrm{~mm} \times 6 \mathrm{~mm} \times 6 \mathrm{~mm}$. The test program consists of six material tensile coupon tests, two stub column tests and seven long column tests. Prior to the column tests, geometric dimensions were measured. Local imperfections and overall imperfections were measured for the stub columns and the long columns, respectively. Table 1 shows the measured geometric dimensions and imperfections.

Table 1. Measured Dimensions and Imperfections

\begin{tabular}{|c|c|c|c|c|c|c|c|}
\hline \multirow{2}{*}{ Test Type } & \multirow{2}{*}{ Specimens } & \multirow{2}{*}{$\begin{array}{l}\text { Length } \\
L(\mathrm{~mm})\end{array}$} & \multirow{2}{*}{$\begin{array}{c}\text { Depth } \\
H(\mathrm{~mm})\end{array}$} & \multirow{2}{*}{$\frac{\text { Width }}{B(\mathrm{~mm})}$} & \multirow{2}{*}{$\begin{array}{c}\text { Thickness } \\
t(\mathrm{~mm})\end{array}$} & \multicolumn{2}{|c|}{ Imperfection(mm) } \\
\hline & & & & & & Major & Minor \\
\hline \multirow{2}{*}{ Stub column } & $\mathrm{H}-\mathrm{S}-\mathrm{a}$ & 400 & \multirow{9}{*}{100} & \multirow{9}{*}{100} & \multirow{9}{*}{5.85} & $1.17^{*}$ & $1.08 *$ \\
\hline & H-S-b & 400 & & & & $1.51^{*}$ & $0.44 *$ \\
\hline \multirow{4}{*}{$\begin{array}{l}\text { Long column } \\
\text { Major axis }\end{array}$} & H-L-1500M & $1580^{\dagger}$ & & & & 0.79 & 1.33 \\
\hline & H-L-2000M & $2080^{\dagger}$ & & & & 2.39 & 1.39 \\
\hline & H-L-2500M & $2580^{\dagger}$ & & & & 2.39 & 2.35 \\
\hline & H-L-3000M & $3080^{\dagger}$ & & & & 1.81 & 2.73 \\
\hline \multirow{3}{*}{$\begin{array}{l}\text { Long column } \\
\text { Minor axis }\end{array}$} & H-L-1500R & $1580^{\dagger}$ & & & & 2.01 & 1.87 \\
\hline & H-L-2000R & $2080^{\dagger}$ & & & & 1.97 & 1.17 \\
\hline & H-L-2500R & $2580^{\dagger}$ & & & & 0.99 & 11.45 \\
\hline
\end{tabular}

Note: * these values are measured local imperfections. 'Major' and 'Minor' mean local imperfection of the flange and that of the web, respectively. $\dagger$ This length is the distance between the two knife-edges.

\subsection{Material Tests}

Material test coupons were cut from the columns by Spark Cutting machine. This machine does not introduce heat or cold work into the coupons during cutting. The cutting positions of the coupons on the cross section and the shape of the coupon are shown in Figure 1. Three coupons were cut from the center of the web, termed HZ-xx. Another three coupons were cut from the edge of the flange, termed HB-xx. The reason for the cutting the coupons from the flange edge is that we want to quantify the shear cutting effect on the material property.

Coupons were tested in a $100 \mathrm{kN}$ capacity MTS displacement controlled testing machine with friction grips. The load rate was $1 \mathrm{~mm} / \mathrm{min}$ controlled by the machine automatically. Pair of stain gauges were pasted on each face of the coupon. Stain were recorded until the stain gauge peeled off from the coupon. Figure 2 shows the material test setup.

Material test results were processed according to Eq. (1) (Gardner and Nethercot [8]). In this equation, $\sigma$ and $\varepsilon$ are engineering stress and strain, respectively, $E_{0}$ is the initial Young's modulus, $\sigma_{0.2}$ is the $0.2 \%$ proof stress (also called yield strength), $n$ is a strain hardening exponent, $\sigma_{1.0}$ is the $1.0 \%$ proof stress, and $n_{0.2,1.0}$ is a strain hardening coefficient representing a curve that passes 
through $\sigma_{0.2}$ and $\sigma_{1.0}$. Table 2 shows the material test results. In this table, $\sigma_{\mathrm{u}}$ is the ultimate stress, $\varepsilon_{\mathrm{t} 0.2}$ and $\varepsilon_{\mathrm{t} 1.0}$ are the total strain corresponding to $\sigma_{0.2}$ and $\sigma_{1.0}$, respectively.

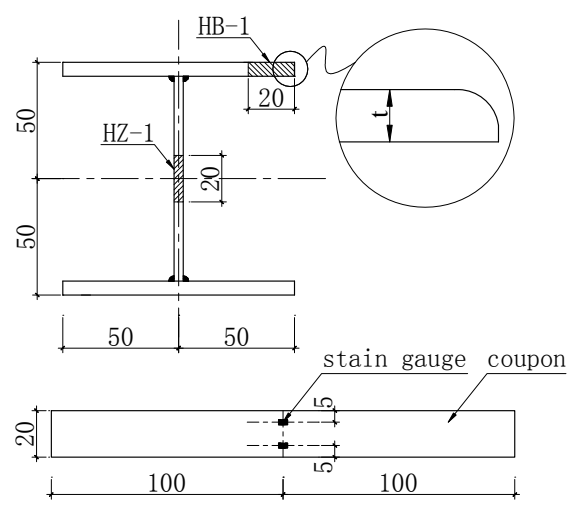

Figure 1. The Cutting Position and Dimensions of the Coupon

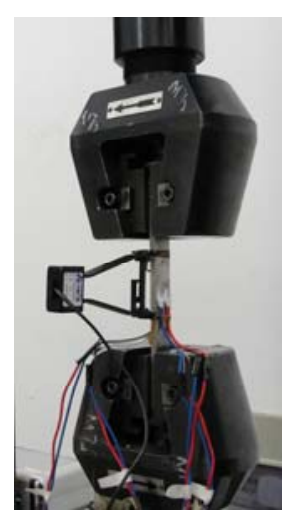

Figure 2. Material Test Setup

$$
\left\{\begin{array}{cl}
\varepsilon=\frac{\sigma}{E_{0}}+0.002\left(\frac{\sigma}{\sigma_{0.2}}\right)^{n} & \sigma \leq \sigma_{0.2} \\
\varepsilon=\frac{\sigma-\sigma_{0.2}}{E_{0.2}}+\left(0.008-\frac{\sigma_{1.0}-\sigma_{0.2}}{E_{0.2}}\right)\left(\frac{\sigma-\sigma_{0.2}}{\sigma_{1.0}-\sigma_{0.2}}\right)^{n_{0.2 .1 .0}^{\prime}}+\varepsilon_{t 0.2} & \sigma_{0.2} \leq \sigma \leq \sigma_{2.0}
\end{array}\right.
$$

Table 2. Material Properties from Tensile Coupon Tests

\begin{tabular}{cccccccccc}
\hline \multirow{2}{*}{ Coupons } & $E_{0}$ & $\sigma_{0.01}$ & $\sigma_{0.2}$ & $\sigma_{1.0}$ & $\sigma_{\mathrm{u} .}$ & \multirow{2}{*}{$e_{\mathrm{t} 0.2}$} & \multirow{2}{*}{$e_{\mathrm{t} 1.0}$} & $n$ & \multirow{2}{*}{$n_{0.2,1.0}$} \\
\cline { 2 - 9 } & $\mathrm{MPa}$ & $\mathrm{MPa}$ & $\mathrm{MPa}$ & $\mathrm{MPa}$ & $\mathrm{MPa}$ & & & \\
\hline HB-1 & 189347 & 91.13 & 249.30 & 298.88 & 708.77 & 0.0032 & 0.0116 & 2.98 & 2.00 \\
\hline HB-2 & 181645 & 104.33 & 267.89 & 307.19 & 700.17 & 0.0037 & 0.0117 & 3.18 & 1.70 \\
\hline HB-3 & 184405 & 118.69 & 271.02 & 325.23 & 687.55 & 0.0035 & 0.0118 & 3.63 & 2.30 \\
\hline AVG.HB & 185132 & 104.72 & 262.74 & 310.43 & 698.83 & 0.0034 & 0.0117 & 3.26 & 2.00 \\
\hline HZ-1 & 192295 & 93.23 & 235.76 & 283.96 & 674.84 & 0.0030 & 0.0115 & 3.23 & 2.30 \\
\hline HZ-2 & 190535 & 107.32 & 242.51 & 283.86 & 671.49 & 0.0033 & 0.0115 & 3.67 & 1.80 \\
\hline HZ-3 & 184632 & 103.49 & 247.10 & 291.45 & 672.08 & 0.0033 & 0.0116 & 3.44 & 2.00 \\
\hline AVG.HZ & 189154 & 101.35 & 241.79 & 286.43 & 672.80 & 0.0032 & 0.0115 & 3.45 & 2.03 \\
\hline
\end{tabular}


From Table 2, it is concluded that due to the shear cutting process, the proof stress $\sigma_{0.2}$ and ultimate stress $\sigma_{\mathrm{u}}$ of the coupons cut from the shearing edge were $20 \mathrm{MPa}$ higher than those of the coupons cut from the center of the web. That means the shear cutting process really introduces some degree of cold work into the shearing edge.

\subsection{Stub Column Tests}

Stub column tests were conducted in a $600 \mathrm{kN}$ capacity SCHENCK testing machine. Prior to the tests, the ends of stub columns were milled flat to ensure they were fully contacted with the load plate of the test machine. Seven stain gauges, six settled on the flanges and one on the center of the web at mid height, respectively, were used to measure the average compression strain of the cross section. Four displacement transducers (LVDT) were used to measure the axial shorting of the column. The positions of the strain gauges and the test arrangement are shown in Figure 3.

The test strengths are listed in Table 5. Load-displacement curves are presented in Figure 4.

Both of these two short columns failed in material yielding. Although the local imperfections of the stub columns in these tests were large (Avg. $=1.05 \mathrm{~mm})$, local buckling of the plate did not appear before the column reaching its ultimate strength (about $450 \mathrm{kN}$ ). That means the cross section is stocky enough to be considered fully effective in the design of long columns.

Strain-stress curves were obtained from stub column tests. The average strain from seven strain gauges was used as the strain, and the stress was calculated using the force divided by cross section area. Material properties from stub column tests were shown in Table 3. Comparing data in Table 2 with the data in Table 3, the initial elastic modulus from stub column tests are lower than those from the tensile coupon tests due to the existence of residual stresses, and the proof strengths from stub column tests are close to those from tensile coupon tests.
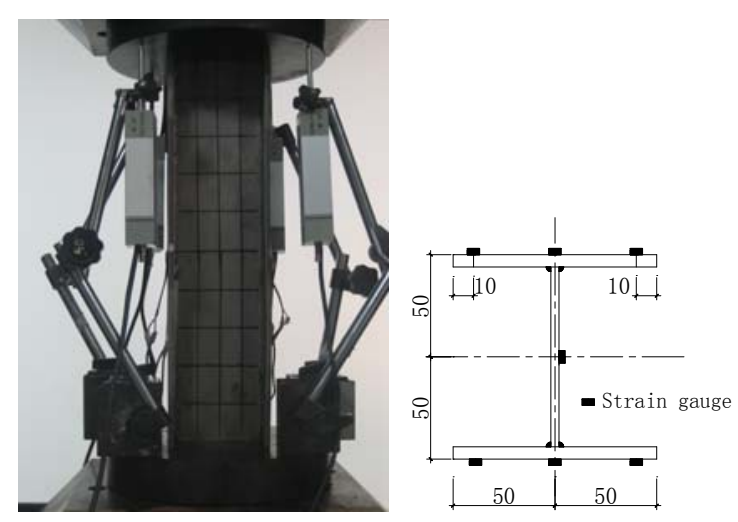

Figure 3. Stub column test setup and the positions of strain gauges

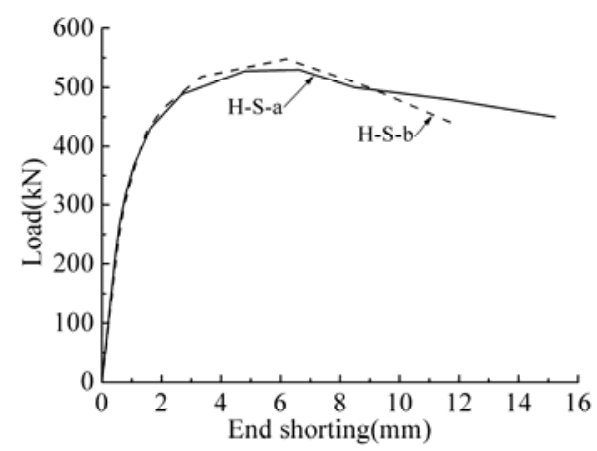

Figure 4. Load-End shorting curves of the stub column 
Table 3 Material properties from stub column tests

\begin{tabular}{ccccc}
\hline \multirow{2}{*}{ Specimens } & $E_{0}$ & $\sigma_{0.01}$ & $\sigma_{0.2}$ & \multirow{2}{*}{$n$} \\
\cline { 2 - 4 } & $\mathrm{MPa}$ & $\mathrm{MPa}$ & $\mathrm{MPa}$ & \\
\hline H-S-a & 174737 & 119.92 & 265.75 & 3.76 \\
\hline H-S-b & 179987 & 131.26 & 256.14 & 4.48 \\
\hline AVG. & 177362 & 125.59 & 260.95 & 4.12 \\
\hline
\end{tabular}

\section{$2.3 \quad$ Long Column Tests}

Long columns were tested in a $5000 \mathrm{kN}$ capacity hydraulic testing machine. One-way knife-edges were settled at both ends of the columns to make the columns pinned in one axis and fixed in the other one. Four columns were tested with pinned end condition in major axis, and three columns were tested with pinned end condition in minor axis.Test arrangement is shown in Figure 5. It should be noted that there was no rig settled at the mid height of the columns to restrain the lateral deformation.

Clamps were designed to prevent unwanted sliding between the column end and the load plate. Details of the clamps are given in Figure 6.

Tests were performed in a displacement-control model. A screw jack was settled at the bottom of the column. A LVTD was fixed under the bottom loading plate to help control the loading rate. Figure 7 shows the loading system in detail.

At each end of the column, four LVTDs, located at each corner of the end plate, were utilized to record the end plate rotations and the displacements. Another three LVTDs were assigned at the middle height of the column, two in the pinned direction and one in the fixed direction, respectively. At the top of the column, a load cell was used to record the applied load.

The test strengths are given in Table 5. Figure 8 and Figure 9 show the load-lateral displacement curves and the load-end shorting curves, respectively.

All the columns failed in the flexural buckling, and no local buckling was detected before the column reached its ultimate strength.

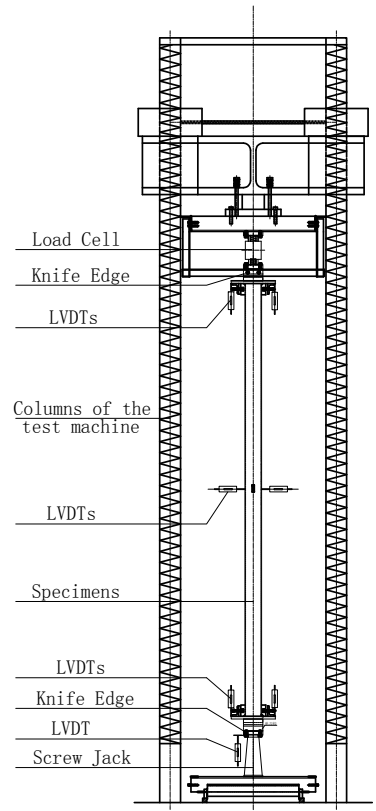

Figure 5. Long Column Test Setup 


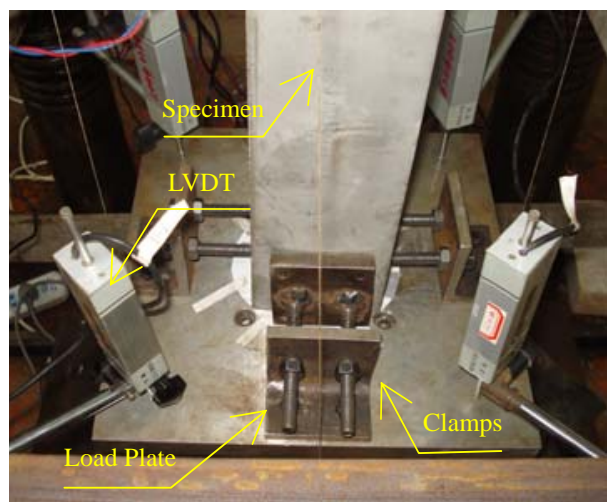

Figure 6. Clamps at the End of the Column

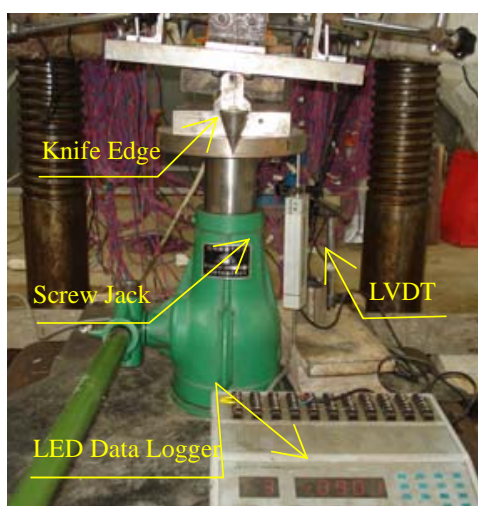

Figure 7. Details of the Loading System

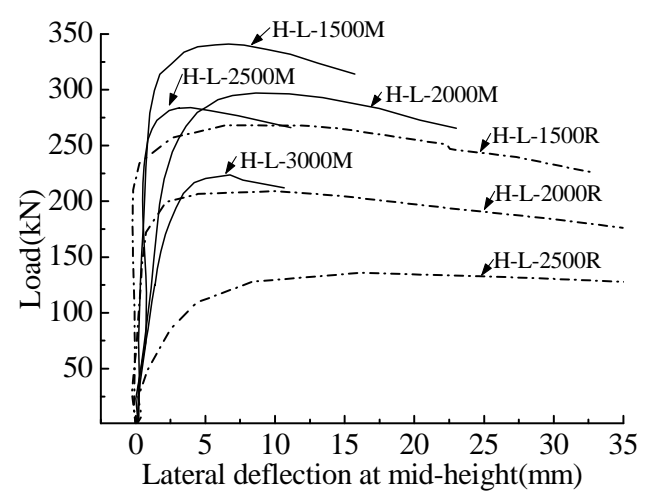

Figure 8. Load-lateral Deflection Curves of the Test Columns

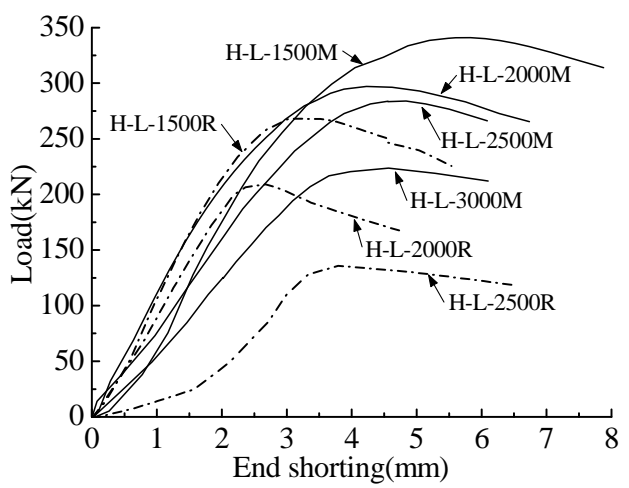

Figure 9. Load-end Shorting Curves of the Test Columns 


\section{FINITE ELEMENT ANALYSIS}

ANSYS [9] was employed to develop the finite element model. Nonlinear material properties, geometric imperfections, and residual stresses were introduced into the finite element model. The effects of the fabrication, the material enhancement at the shearing edge and the residual stresses due to welding, on the strength of stainless steel welded I-column were discussed.

\subsection{Material Model}

Three options for the material properties used in the finite element analysis: the material properties from the stub column tests, the material properties from the tensile coupon tests without enhancement in the flange edge, and the material properties from the tensile coupon tests with enhancement in the flange edge. For the material properties obtained from the stub column test, there was no parameter for the second part of Eq. 1. So, Eq. 2 (Quach et al. [10]) was used to calculate $\sigma_{1.0}$ and $n_{0.2,1.0}$. For the material properties from the tensile coupon tests without enhancement, the material properties from the coupon cut from the web were used for the whole cross section in the finite element model. For the material properties from the tensile coupon tests with enhancement, the material properties from the coupon cut from the flange edge were used for the edge region of the flange (20 $\mathrm{mm}$ wide from the edge), and the material properties from the coupons cut from the web were used for the rest region. Strain-stress curves used in finite element model are shown in Figure 10.

For the plastic loading, von Mises yield rule, associated flow rule, and isotropic hardening rule were utilized.

$$
\left\{\begin{array}{l}
\frac{\sigma_{1.0}}{\sigma_{0.2}}=0.662 \frac{1}{n}+1.085 \\
n_{0.2,1.0}=6.399\left(\frac{E_{0.2}}{E_{0}}\right)\left(\frac{\sigma_{1.0}}{\sigma_{0.2}}\right)+1.145
\end{array}\right.
$$

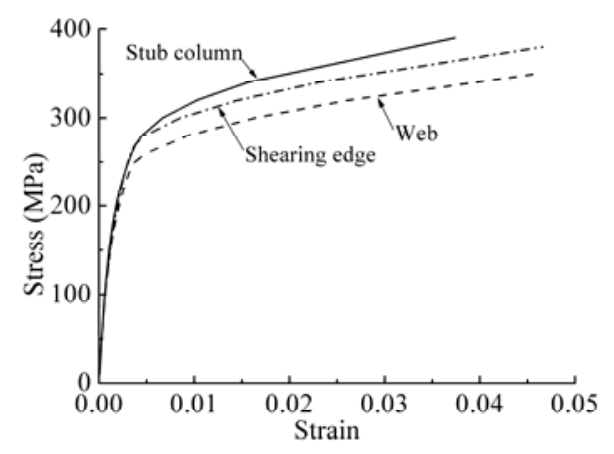

Figure 10. Strain-stress Curves used in Finite Element Model

\subsection{Element}

Shell 181, a 4-node structural shell element in ANSYS element library [9], was used. Shell 181 is suitable for analyzing thin to moderately thick shell structures. It is a 4-noded element with six degrees of freedom at each node with translations in the $\mathrm{X}, \mathrm{Y}$, and $\mathrm{Z}$ directions and rotations about the X, Y, and Z-axes. Shell 181 is well-suited for linear, large rotation and large strain nonlinear applications. 


\subsection{Boundary Conditions}

The boundary conditions for the stub column model and the long column model are shown in Figure 11. For the stub column model, constrain equations were used to make the displacement of the nodes at the loading end uniform in $\mathrm{Z}$ direction. At the loading end, all the degrees of freedom were fixed except the translational degree of freedom in $\mathrm{Z}$ direction. At the support end, all the degrees of freedom were fixed. The force was evenly applied on the nodes at the loading end. For the long column model, constraint equations were used to ensure that all the nodes at each end of the column act together as a rigid plane. A master node at each end represents the rigid plane. Typically, any node in the rigid plane can be used as the master node. Here, we used the node in the centroid of the cross section as the master node. Other nodes at this end were termed as slave nodes. The boundary conditions were applied on the master node. For the master node at the loading end, translational degrees of freedom in $\mathrm{X}$ and $\mathrm{Y}$ direction were fixed, and rotational degrees of freedom in $\mathrm{Y}$ and $\mathrm{Z}$ direction were fixed. For the master node at the support end, the boundary conditions were almost the same as those at the loading end, except that the translational degree of freedom in $\mathrm{Z}$ direction was also fixed. The force was applied on the master node at the loading end.

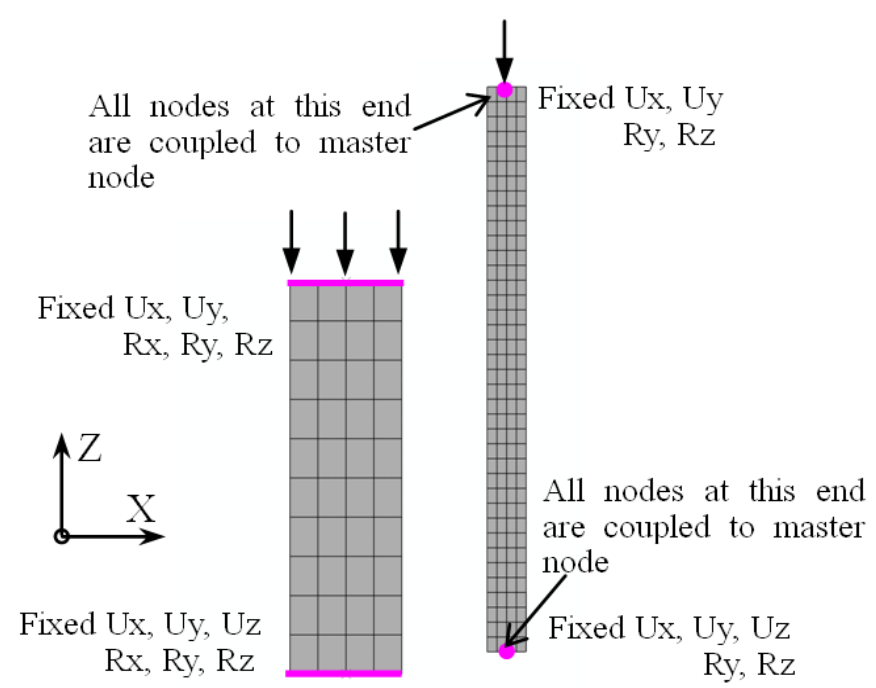

Figure 11. Boundary conditions for the stub columns and the long columns

\subsection{Geometric Imperfections and Residual Stresses}

Eigenbuckling modes were used as the shapes of the imperfections. Measured imperfection magnitudes were used as the magnitudes of imperfection. For the stub columns, only local imperfection was taken into account. For the long columns, both local imperfection and overall imperfection were introduced into the finite element model.

The residual stresses mode proposed by Wang et al. [11] were used in this paper. Wang et al. [11] measured the residual stresses in the stainless steel welded I-section of Grade 316. Figure 12 shows the residual stresses distribution mode and the residual stresses distribution introduced into finite element model. It should be noted that for the finite element model that uses the material properties from the stub column tests, residual stresses were not introduced into that model. 

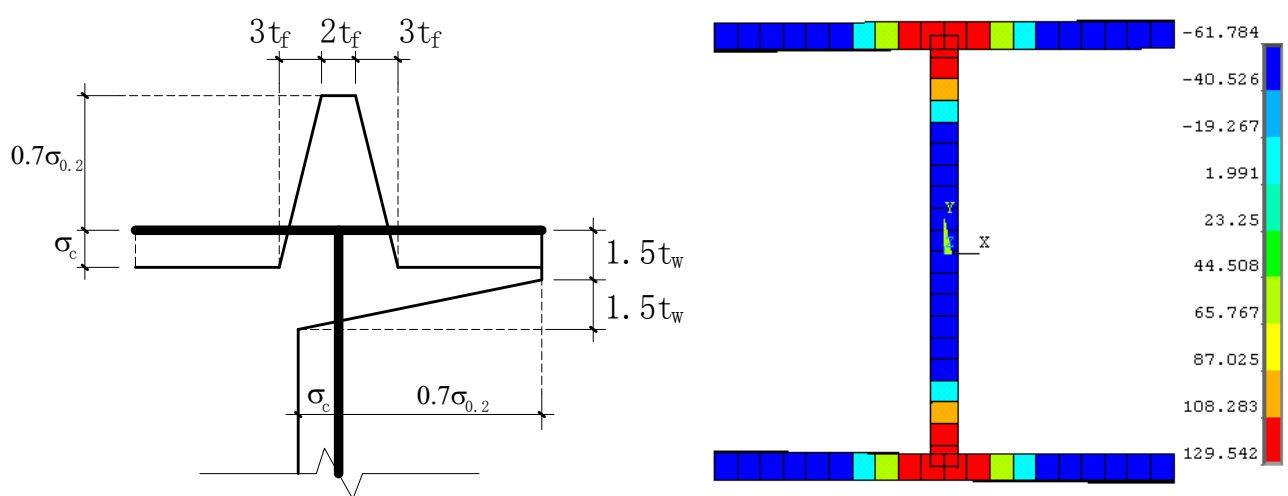

Figure 12. Residual stresses distribution mode proposed by Wang et al. [11]

\subsection{Analysis Cases}

For each column, finite element model was run five times with different material properties options and residual stresses options. Analysis cases are shown in Table 4.

Table 4. Analysis Cases for Each Column

\begin{tabular}{|c|c|c|c|c|c|}
\hline \multirow[b]{2}{*}{ Cases } & \multicolumn{3}{|c|}{ Material property options } & \multicolumn{2}{|c|}{ Residual stress options } \\
\hline & Stub columns & $\begin{array}{c}\text { Coupon tests } \\
\text { With enhancement }\end{array}$ & $\begin{array}{l}\text { Coupon tests } \\
\text { Without enhancement }\end{array}$ & With & Without \\
\hline$F_{\mathrm{w}}$ & & & $\sqrt{ }$ & & $\sqrt{ }$ \\
\hline$F_{\mathrm{c}}$ & & $\sqrt{ }$ & & & $\sqrt{ }$ \\
\hline$F_{\mathrm{r}}$ & & & $\sqrt{ }$ & $\sqrt{ }$ & \\
\hline$F_{\mathrm{r}+\mathrm{c}}$ & & $\sqrt{ }$ & & $\sqrt{ }$ & \\
\hline$F_{\mathrm{s}}$ & $\sqrt{ }$ & & & & \\
\hline
\end{tabular}

\subsection{Finite Element Analysis Results}

The finite element analysis results are listed in Table 5.

Table 5. Comparisons of the Test Results and the Finite Element Analysis Results

\begin{tabular}{|c|c|c|c|c|c|c|c|}
\hline Test Type & Specimens & $\frac{\text { Ultimate Load }}{F(\mathrm{kN})}$ & $F_{w} / F_{t}$ & $F_{c} / F_{t}$ & $F_{r} / F_{t}$ & $F_{r+c} / F_{t}$ & $F_{s} / F_{t}$ \\
\hline \multirow{2}{*}{ stub columns } & H-S-a & 530 & \multirow{2}{*}{0.846} & \multirow{2}{*}{0.870} & \multirow{2}{*}{0.845} & \multirow{2}{*}{0.868} & \\
\hline & H-S-b & 548 & & & & & \\
\hline \multirow{4}{*}{ major axis } & H-L-1500M & 341 & 1.086 & 1.111 & 1.084 & 1.109 & 1.160 \\
\hline & H-L-2000M & 297 & 1.034 & 1.055 & 1.039 & 1.064 & 1.099 \\
\hline & H-L-2500M & 284 & 0.941 & 0.967 & 0.948 & 0.959 & 1.000 \\
\hline & H-L-3000M & 224 & 1.045 & 1.063 & 1.061 & 1.079 & 1.128 \\
\hline \multirow{3}{*}{ minor axis } & H-L-1500R & 268 & 0.964 & 0.994 & 0.905 & 0.937 & 1.026 \\
\hline & H-L-2000R & 209 & 0.980 & 1.004 & 0.897 & 0.925 & 1.048 \\
\hline & H-L-2500R & 136 & 0.875 & 0.896 & 0.817 & 0.842 & 0.929 \\
\hline & Avg. & & 0.989 & 1.013 & 0.964 & 0.988 & 1.056 \\
\hline & S.Dev & & 0.071 & 0.071 & 0.099 & 0.098 & 0.080 \\
\hline
\end{tabular}


From Table 5, it is concluded that:

(1). All the five analysis cases can predict the column strength well. The average ratios of the finite element analysis results over the test results are around 1.0, with the maximum deviations less than 0.1 . However, it seems the finite element model does not work well for the stub columns. Ashraf et al.[12], and Bredenkamp and Van den Berg [4] also mentioned this phenomenon. That may be attributed to the welding. First, the area of the cross section increases due to the welding filler. Second, the heat, released in the welding process, changes the microstructure of the region alongside the welding, which may improve the material strength in the heat-affected zone.

(2). Compared the results of the analysis cases with shearing edge enhancement $\left(F_{\mathrm{c}}\right)$ and the model without that $\left(F_{\mathrm{w}}\right)$, we can conclude that the shearing edge enhancement can increase the column strength by $2 \% \sim 3 \%$.

(3). Compared the results of the analysis cases with residual stresses $\left(F_{\mathrm{r}}\right)$ and the model without that $\left(F_{\mathrm{w}}\right)$, it can be concluded that the effect of residual stresses on the column strength is obviously different for columns buckled in major axis and for columns buckled in minor axis. For columns buckled in major axis, residual stresses almost have no effect on the column strengths. While for columns buckled in minor axis, residual stresses can decrease the column strengths by $6 \% \sim 7 \%$. That is mainly due to the residual stresses distribution where the maximum compressive stress happens at the far end of the minor axis.

\section{COMPARISON OF TEST STRENGTHS WITH DESIGN STRENGTHS}

\subsection{Test Database}

Bredenkamp and Van den Berg [4] reported 13 long column tests on welded I $140 \times 70 \times 4.0 \times 3.5$ and I $180 \times 90 \times 6.0 \times 4.5$, and the material is 3CR12. Burgan et al. [5] reported 15 long column tests on welded I $160 \times 80 \times 6 \times 10$ and I $160 \times 160 \times 10 \times 6$, and the material is austenitic 1.4031 (S304) and duplex 1.4462 (S31803).

In Reference 4, all the tested sections are very slender. So the effective area should be calculated before the predictions of the column strength. In order to avoid the error from the determination of the effective area, this set of test data is not considered here.

Combined with the column tests in this paper, a total of 22 test data are obtained.

\subsection{Current Design Codes}

American design code (SEI/ASCE 8-02) [6] and European design code (Eurocode3: Part 1.4) [7] are considered here.

Perry formula is adopted in European design code to calculate the flexural buckling strength of stainless steel column. The reduction factor $\chi$ is defined as follows:

$$
\begin{aligned}
& \chi=\frac{1}{\phi+\sqrt{\phi^{2}-\lambda^{2}}} \leq 1 \\
& \phi=0.5\left[1+\eta+\lambda^{2}\right]
\end{aligned}
$$


where $\eta$ is imperfection parameter $=\alpha\left(\lambda-\lambda_{0}\right)$. For welded I-columns buckled in major axis, $\alpha$ and $\lambda_{0}$ are equal to 0.49 and 0.20 , respectively. For welded I-columns buckled in minor axis, $\alpha$ and $\lambda_{0}$ are equal to 0.76 and 0.20 , respectively.

In American design code, the tangent modulus theory is adopted. The flexural buckling stress, $F_{\mathrm{n}}$, is defined by Eq. 5.

$F_{\mathrm{n}}=\frac{\pi^{2} E_{\mathrm{t}}}{(K L / r)^{2}} \leq F_{\mathrm{y}}$

where $F_{\mathrm{n}}$ is the flexural buckling stress; $E_{\mathrm{t}}$ is the tangent modulus in compression corresponding to buckling stress; $K$ is the effective length factor; $L$ is the unbraced length of members; $r$ is the radius of gyration of full, unreduced cross section. Iterations are necessary in solving buckling stress.

\subsection{Comparisons}

Figure 13 shows the test strengths and the column curves from the design codes. It should be noted here that in the calculations of the column curves using the design codes, material properties from tensile coupon tests cut from the web center were used $\left(E_{0}=189154 \mathrm{MPa}, \sigma_{0.2}=241.79 \mathrm{MPa}\right.$, $n=3.45$ ). In addition, the partial factors (such as $\gamma_{\mathrm{m}}$ in the European design code) were set to 1.0.

In Figure 13, 'EN-major' and 'EN-minor' mean the column curves in the European design code for the welded I-column buckled in major axis and the column buckled in minor axis, respectively; 'ASCE' means the column curve in the American design code.

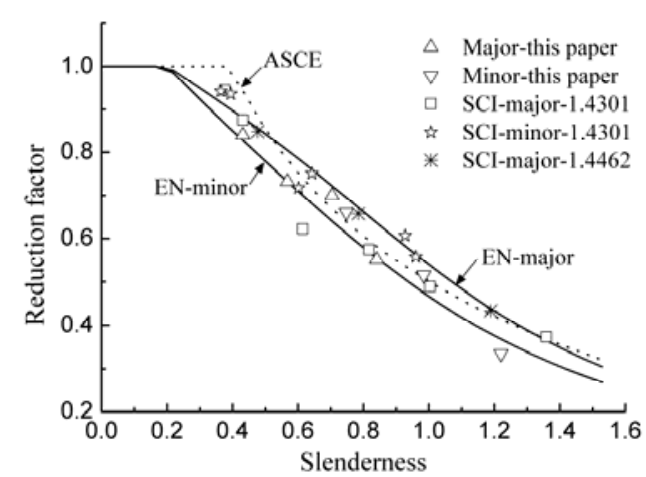

Figure 13. Comparisons between the Test Strengths and the Predictions of Design Codes

From Figure 13, those conclusions could be dawn:

(1) Most of the test data locate between the column curve for columns buckled in major axis and the column curve for the columns buckled in minor axis in the European design code.

(2) There is no obvious difference in the reduction factor for columns buckled in major axis and columns buckled in minor axis.

(3) American design code predicts the column strength well for columns with comparatively large slenderness. For columns with small slenderness, the predictions are unconservative. 
(4) Conservatively, the column curves in European design code for columns buckled in minor axis can be used as the design curve for welded I-column buckled in major axis and column buckled in minor axis.

\section{CONCLUSIONS}

(1) A series of tests on stainless steel welded I-columns were carried out. Two stub columns and seven long columns were tested. The stub columns failed in material yielding, and the long columns failed in flexural buckling.

(2) The effect of the fabrication process on the column buckling strengths were investigated using the finite element method. The shear cutting in cutting the plate into strips, can increase the material strength along the cutting edge, and this type of material enhancement can improve the column strength by $2 \% \sim 3 \%$. The residual stresses caused in welding process can decrease strength of welded I-column buckled in minor axis by $6 \%$ 7\%, while it has no effect on the strength of column buckled in major axis.

(3) The column curve in European design code for columns buckled in minor axis can be used as the design curve for welded I-columns buckled in major axis and columns buckled in minor axis.

\section{ACKNOWLEDGMENTS}

The research work described in this paper is supported by the Priority Academic Program Development of Jiangsu Higher Education Institutions and by the National Science Foundation of China through the projects No. 51178098, No. 51378105 and 51578134. The financial support is highly appreciated.

\section{REFERENCE}

[1] Kuwamura, H., "Local Buckling of Thin-walled Stainless Steel Members”, Steel Structures, 2003, Vol. 3, pp. 191-201.

[2] Saliba, N. and Gardner, L., "Cross-section Stability of Lean Duplex Stainless Steel Welded I-sections”, Journal of Constructional Steel Research, 2013, Vol. 80, No. 1, pp. 1-14.

[3] Yuan, H.X., Wang, Y.Q., Shi, Y.J. and Gardner, L., "Stub Column Tests on Stainless Steel Built-up Sections", Proceedings of the Fourth International Experts Seminar of Stainless Steel in Structures. Ascot, UK, 2012, pp. 1-14.

[4] Bredenkamp, P.J. and Van den Berg, G.J., "The Strength of Stainless Steel Built-up I-section Columns”, Journal of Constructional Steel Research, 1995, Vol. 34, No. 2-3, pp. 131-144.

[5] Burgan, B.A., Baddoo, N.R. and Gilsenan, K.A., "Structural Design of Stainless Steel Members-comparison between Eurocode 3, Part 1.4 and Test Results”, Journal of Constructional Steel Research, 2000, Vol. 54, No. 1, pp. 51-73.

[6] ASCE., "Specification for the Design of Cold-formed Stainless Steel Structural Members", American Society of Civil Engineers, SEI/ASCE-8-02, Reston, Virginia, 2002.

[7] EC3., "Eurocode 3: Design of Steel Structures - Part 1.4: General Rules - Supplementary Rules for Stainless Steels”, European Committee for Standardization, ENV 1993-1-4, CEN, Brussels, 2006. 
[8] Gardner, L. and Nethercot, D.A., "Experiments on Stainless Steel Hollow Sections - Part 1: Material and Cross-sectional Behavior”, Journal of Constructional Steel Research, 2004, Vol. 60, No. 9, pp. 1291-1318.

[9] ANSYS. Release, 10.0 Documentation, ANSYS Inc, Canonsburg, PA, 2005.

[10] Quach, W.M., Teng, J.G. and Chung, K.F., “Three-stage Full-range Stress-strain Model for Stainless Steels”, Journal of Structural Engineering, 2008, Vol. 134, No. 9, pp. 1518-1527.

[11] Wang, Y.Q., Guan, J. and Yong, Z., et al., "Experimental Study on the Residual Stress of Austenitic Stainless Steel 316 at I-section”, Industrial Building, 2012, Vol. 42, No. 5, pp. 45-50 (in Chinese).

[12] Ashraf, M., Gardner, L. and Nethercot, D.A. "Finite Element Modeling of Structural Stainless Steel Cross-sections", Thin-Walled Structures, 2006, Vol. 44, No. 10, pp. 1048-1062. 


\title{
EXPERIMENTAL STUDY ON FRACTURE TOUGHNESS OF HIGH-STRENGTH STRUCTURAL STEEL AND ITS BUTT WELD
}

\author{
Yuanqing Wang ${ }^{1}$, Xiyue Liu ${ }^{1,2, *}$, Yun $\operatorname{Lin}^{3}$, Yongjiu Shi ${ }^{1}$ and Hui Zhou ${ }^{4}$ \\ ${ }^{I}$ Key Laboratory of Civil Engineering Safety and Durability of China Education Ministry, \\ Department of Civil Engineering, Tsinghua University, Beijing 100084, China \\ ${ }^{2}$ College of Basic Education for Commanding Officers, NUDT, Changsha, 410072, China \\ ${ }^{3}$ School of Management, Fuzhou College of Foreign Studies and Trade, Fuzhou 350202, Fujian, China \\ ${ }^{4}$ Key Laboratory of Urban Security and Disaster Engineering of Ministry of Education, \\ Beijing University of Technology, Beijing 100124, China \\ *(Corresponding Author: E-mail: Liuxy85722@163.com)
}

\begin{abstract}
As steel strength increases, the fracture toughness may be quite different from that of normal steel, and the corresponding welded joints can be the critical spots due to possible brittle fracture behavior. Moreover, the design load for high-strength steel structure is larger and the steel with higher stress is more sensitive to defect, which increases the potentials of brittle fracture. The service of steel structures in cold regions increases the crisis of brittle fracture. Therefore, a series of three-point bending tests were conducted at low temperature to investigate the fracture toughness of high-strength steel and its butt weld. Fracture micro-mechanisms were analyzed through Scanning Electron Microscopy of the fractured surfaces in specimens. The fracture toughness indices (critical CTOD values) of high-strength steel and its butt weld all decrease as temperature decreases. The heat affected zone (HAZ) is more critical to fracture than the base material, indicated by much lower critical CTOD values and higher transition temperature. The fracture toughness of high-strength steel is relatively lower than the conventional steels (i.e. $235 \mathrm{MPa}, 345 \mathrm{MPa}$ and $390 \mathrm{MPa}$ ). The results obtained in this paper provide reference for the fracture resistant design of high-strength steel structures in cold regions.
\end{abstract}

Keywords: fracture toughness; high-strength steel; butt weld; low temperature; brittle fracture

DOI: $10.18057 /$ IJASC.2015.11.4.3

\section{INTRODUCTION}

High-strength steel has been popular and applied in long-span structures and high-rise buildings for the advantage of light weight and high loading capacity [1-4]. However, the mechanical properties and toughness of the high-strength steel may be quite different from that of normal steel, due to the different rolling process, crystal phases and chemical components. As steel strength increases, the elongation decreases and the yield to ultimate strength ratio increases generally according to some related researches [5-14], which indicates the lower plastic deformation capacity when failure. Therefore, the use of high-strength steels is limited.

Further, the welding for high-strength steel is difficult, and welding defect is prone to occur in weld metal and heat affected zone (HAZ). Besides, the effect of the heat input during welding on the toughness of HAZ is significant [18-20]. Welded joints can be the critical spots for structural integrity due to possible brittle fracture behavior [21]. Besides, based on the fracture mechanics, the steel with higher stress is more sensitive to defect [22]. For high-strength steel structure, the design load is obvious larger than that for conventional steel structure, which increases the potentials of brittle fracture. 
Additionally, a considerable number of steel structures were reported to be brittle fracture damaged in cold regions, and temperatures of the majority land area in China are quite low in winter [23-27]. For the study on brittle fracture of steel structure, despite the traditional impact toughness index can reflect the fracture resistant ability of materials to a certain extent, but it hardly gave an accurate evaluation for the structural security, while the fracture toughness index can evaluate it quantitatively.

Therefore, the extension and safe usage of high-strength steel welded structures especially requires investigations on the fracture toughness of the welded joints of high-strength steels at low temperature, as well as the ambient temperature.

\section{OVERVIEW OF THREE POINT BENDING TESTS}

A series of three-point bending (TPB) tests for the butt welds of high-strength steel with yield point of $460 \mathrm{MPa}$ and $960 \mathrm{MPa}$ were carried out at ambient temperature and low temperature in the present study. Five temperature points, i.e. $+20,0,-20,-40,-60{ }^{\circ} \mathrm{C}$, were selected for the series of tests, and three replicated specimens were performed for each temperature point. The crack tip opening displacement (CTOD) as a fracture toughness parameter was investigated by TPB tests at five different temperatures, and the transition procedure from ductile to brittle for the butt welds of high-strength steel are studied, so as to provide technical basis for the brittle fracture prevention design of high-strength steel structure. Besides, microstructure and fracture mechanisms were investigated by Scanning Electron Microscopy (SEM) of fracture surfaces in specimens.

\subsection{Specimen Materials}

High-strength steel plates of $14 \mathrm{~mm}$ thickness in the experiments were produced by the controlled-rolling technology, the chemical compositions of the $460 \mathrm{MPa}$ and $960 \mathrm{MPa}$ steel plates are given in Table 1.

Table 1. Chemical Compositions of High-strength Steel Plates wt $\%$

\begin{tabular}{|c|c|c|c|c|c|c|c|c|c|}
\hline \multicolumn{5}{|c|}{$460 \mathrm{MPa}$} & \multicolumn{5}{|c|}{$960 \mathrm{MPa}$} \\
\hline C & $\mathrm{S}$ & $\mathrm{P}$ & $\mathrm{Si}$ & $\mathrm{Mn}$ & C & $\mathrm{S}$ & $\mathrm{P}$ & $\mathrm{Si}$ & $\mathrm{Mn}$ \\
\hline 0.190 & 0.004 & 0.013 & 0.220 & 1.510 & 0.060 & 0.002 & 0.011 & 0.260 & 1.610 \\
\hline
\end{tabular}

The welding process for the $460 \mathrm{MPa}$ and $960 \mathrm{MPa}$ steel plates adopt full penetrated gas metal arc welding (GMAW) and submerged arc welding (SAW) respectively. The welding process has been qualified in accordance with JGJ81-2002 "Technical specification for welding of steel structure of building" [28]. The welding process parameters are listed in Table 2. The butt welds are of V-groove, the geometries of which are shown in Figure 1.

Table 2 Welding Process Parameters

\begin{tabular}{lllllllll}
\hline $\begin{array}{l}\text { Base } \\
\text { material }\end{array}$ & Method & Position & Wire & $\Phi / \mathrm{mm}$ & $\begin{array}{l}\text { Shielding } \\
\text { gas (Flux) }\end{array}$ & Voltage/V & Current/A & Velocity/cm/min \\
\hline $460 \mathrm{MPa}$ & GMAW & flat & JM-60 & 1.2 & $\begin{array}{l}\mathrm{CO}_{2} 20 \%+ \\
\mathrm{A}_{\mathrm{r}} 80 \%\end{array}$ & $28-35$ & $250-300$ & $30-45$ \\
$960 \mathrm{MPa}$ & SAW & flat & SLD-80 & 4 & SJ101 & $30-34$ & $530-570$ & $40-45$ \\
\hline
\end{tabular}




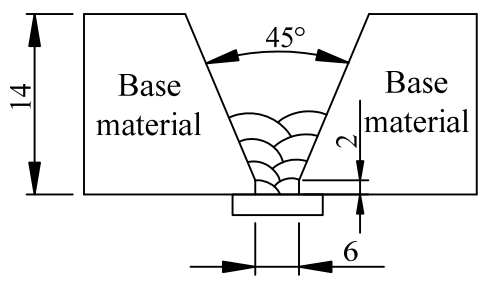

Figure 1. The V-shaped Groove Weld used in this Investigation

The samplings of specimen for weld metal and HAZ are shown in Figures 2(a) \& (b), respectively. For the specimens sampled from weld metal, the center of specimen coincide with the center of the weld gap as shown in Figure 2(a); for those sampled from the HAZ, the center of specimen is located away from the vertical fusion line at weld root with the distance of $5 \mathrm{~mm}$ as shown in Figure 20(b). The pre-crack direction is consistent with the rolling direction of plates.

The geometries and dimensions of the specimen as shown in Figure 2(c) were in accordance with the standard "Metallic materials-Unified method of test of determination for quasistatic fracture toughness" [29]. The specimen thickness B is $14 \mathrm{~mm}$, width $\mathrm{W}$ is $28 \mathrm{~mm}$, and distance between the bearing points $\mathrm{S}$ is $112 \mathrm{~mm}$. The single edge crack of the specimen was machined by $8 \mathrm{~mm}$ wire cutting and then headed by fatigue pre-crack of which the length is $3 \mathrm{~mm}$. The schematics of test specimen and test setup are shown in Figure 2(c).

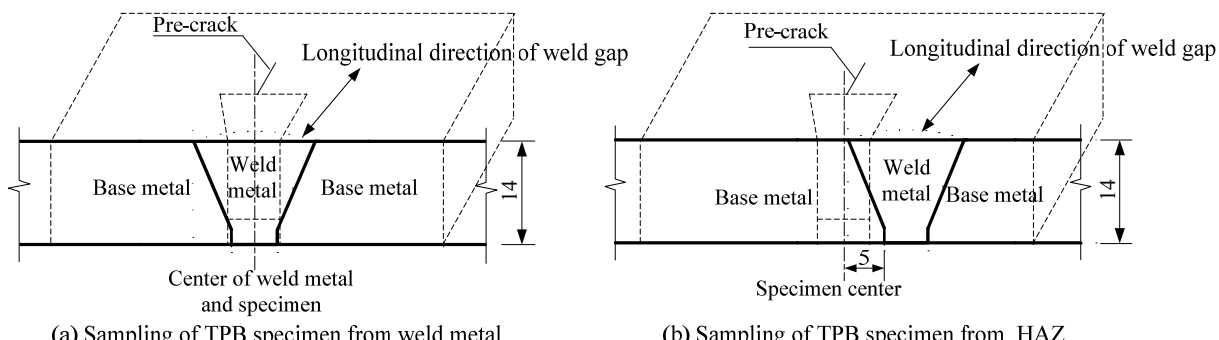

(a) Sampling of TPB specimen from weld metal

b) Sampling of TPB specimen from HAZ

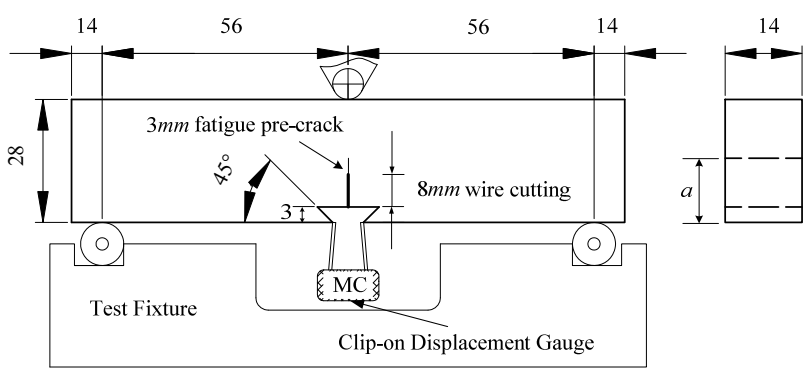

(c) Three-point bending specimen and test setup

Figure 2. Sampling and Geometry of Three-point Bending Specimen

\section{$2.2 \quad$ Experimental Equipment}

The three-point bending tests were implemented by the electronic universal testing machine (INSTRON) as shown in Figure 3(a). The specimens were refrigerated by mixed steam of air and liquid nitrogen in the sealed attemperator installed with INSTRON and the lowest temperature of $-70{ }^{\circ} \mathrm{C}$ can be achieved. Testing scene inside attemperator is shown in Figure 3(b). The fatigue test machine for pre-crack of TPB specimen is shown in Figure 3(c). 


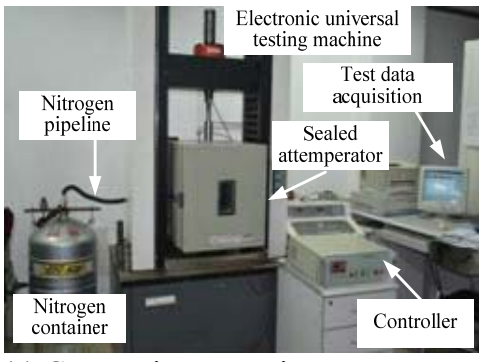

(a) Cryogenic test equipments

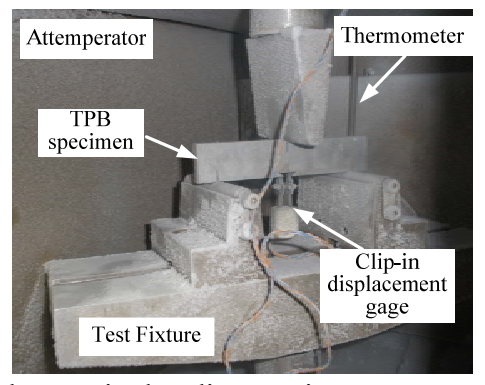

(b) Three-point bending test in attemperator Figure 3. Experimental Setup

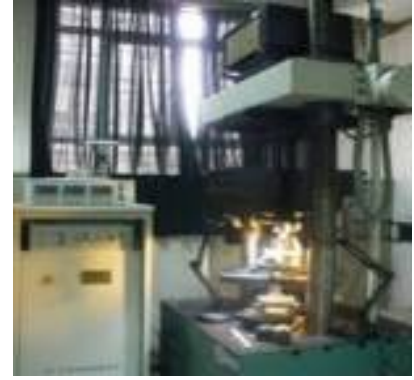

(c) Fatigue test machine (INSTRON)

\subsection{Experimental Protocol}

(1) Load punching should be guaranteed to be located at the center of specimen.

(2) Tests were performed from $+20{ }^{\circ} \mathrm{C}$ to $-60{ }^{\circ} \mathrm{C}$, and for each temperature points, the specimens were cooled at the same time, so as to improve test efficiency.

(3) The lasting time of cooling for specimens should not be less than 15 minutes and the deviation of test temperature to setting temperature should be within the range of $\pm 2{ }^{\circ} \mathrm{C}$ during the test.

(4) Loading rate maintain constant and the velocity of the loading beam was controlled to be about $1 \mathrm{~mm} / \mathrm{min}$ during experimental process.

(5) Prior to the failure of specimens, the relationship of displacement and load was recorded by computer.

\section{TEST RESULTS AND DISCUSSIONS}

In the present study, $\delta_{\mathrm{m}}$ (the CTOD value which is corresponded with the maximum load $P_{\mathrm{m}}$ ) was taken as the critical value of CTOD, for this value can be applied in all varieties of fracture situations and is convenient for analysis, as well as it can be determined accurately. The load $P$ and displacement $V$ were recorded by force sensor and clip-on displacement gauge, respectively. The $P$ values represent the load in the mid-span of specimen; $V$ values represent the crack mouth opening displacement. According to the standard GB/T 21143-2007 [29], the critical values of CTOD can be determined by Eq. (1) as follows:

$$
\delta=\frac{K_{I}{ }^{2}\left(1-\mu^{2}\right)}{2 \sigma_{y} E}+\frac{r_{p}\left(W-a_{0}\right) V_{p}}{r_{p}\left(W-a_{0}\right)+a_{0}+Z},
$$

Where $K_{I}=Y P /\left[B W^{1 / 2}\right]$, the value of $Y$ can be obtained by table look-up based on the value of $\left(a_{0} / W\right)$ according to the test standard [15], $B$ is the thickness of specimen, $W$ is the width of specimen; $r_{p}$ is the plastic rotational factor, for TPB test specimen, $r_{p}=0.44$; the plastic component of crack mouth opening displacement $V_{p}$ is obtained by the curve of $P-V$; the initial crack length $a_{0}$ was measured on the fracture surface; the Poisson's ratio $\mu$ is taken to be 0.3 , the elastic modulus $E$ and the yield point $\sigma_{\mathrm{y}}$ were obtained by the previous tensile tests; $Z$ is the thickness of the knife-edge on which the displacement gauge clipped.

The test results of three replicated specimens for the two high-strength steels and the butt welds obtained at the varied temperatures are listed in Table 3 and Table 4, respectively. 
Table 3. The critical CTOD Values $\delta_{\mathrm{m}}(\mathrm{mm})$ of $460 \mathrm{MPa}$ Steel and its Butt Weld

\begin{tabular}{|c|c|c|c|c|c|c|}
\hline \multirow{2}{*}{$T /{ }^{\circ} \mathrm{C}$} & \multicolumn{2}{|c|}{ Base material } & \multicolumn{2}{|l|}{ Weld metal } & \multicolumn{2}{|l|}{ HAZ } \\
\hline & Test results & Average & Test results & Average & Test results & Average \\
\hline & 0.32406 & & 0.56320 & & 0.10746 & \\
\hline \multirow[t]{3}{*}{20} & 0.41195 & 0.3835 & 0.41370 & 0.5824 & 0.30255 & 0.2296 \\
\hline & 0.41458 & & 0.77032 & & 0.27878 & \\
\hline & 0.42019 & & 0.62539 & & 0.34708 & \\
\hline \multirow[t]{3}{*}{0} & 0.33587 & 0.3893 & 0.34522 & 0.5408 & 0.32018 & 0.3125 \\
\hline & 0.41188 & & 0.65190 & & 0.27022 & \\
\hline & 0.46500 & & 0.48160 & & 0.29333 & \\
\hline \multirow[t]{3}{*}{-20} & 0.36394 & 0.3929 & 0.35757 & 0.3662 & 0.31121 & 0.2841 \\
\hline & 0.34989 & & 0.25929 & & 0.24766 & \\
\hline & 0.27008 & & 0.47094 & & 0.26235 & \\
\hline \multirow[t]{3}{*}{-40} & 0.49135 & 0.3177 & 0.67253 & 0.4774 & 0.15917 & 0.1942 \\
\hline & 0.19170 & & 0.28874 & & 0.16117 & \\
\hline & 0.04461 & & 0.07191 & & 0.15507 & \\
\hline \multirow[t]{2}{*}{-60} & 0.1543 & 0.1296 & 0.14151 & 0.0925 & 0.04222 & 0.0835 \\
\hline & 0.18997 & & 0.06405 & & 0.05311 & \\
\hline
\end{tabular}

Table 4. The Critical CTOD Values $\delta_{\mathrm{m}}(\mathrm{mm})$ of $960 \mathrm{MPa}$ Steel and its Butt Weld

\begin{tabular}{|c|c|c|c|c|c|c|}
\hline \multirow{2}{*}{$T /{ }^{\circ} \mathrm{C}$} & \multicolumn{2}{|c|}{ Base material } & \multicolumn{2}{|l|}{ Weld metal } & \multicolumn{2}{|l|}{ HAZ } \\
\hline & Test results & Average & Test results & Average & Test results & Average \\
\hline & 0.16652 & & 0.19019 & & 0.11803 & \\
\hline \multirow[t]{3}{*}{20} & 0.27909 & 0.2016 & 0.18366 & 0.2034 & 0.11458 & 0.1877 \\
\hline & 0.15911 & & 0.23628 & & 0.33039 & \\
\hline & 0.27212 & & 0.03827 & & 0.10164 & \\
\hline \multirow[t]{3}{*}{0} & 0.08881 & 0.1673 & 0.36872 & 0.2477 & 0.10985 & 0.1320 \\
\hline & 0.14099 & & 0.33623 & & 0.33453 & \\
\hline & 0.1238 & & 0.32006 & & 0.00997 & \\
\hline \multirow[t]{3}{*}{-20} & 0.27781 & 0.1556 & 0.19872 & 0.1896 & 0.11661 & 0.0562 \\
\hline & 0.06508 & & 0.04991 & & 0.04198 & \\
\hline & 0.05651 & & 0.1663 & & 0.02698 & \\
\hline \multirow[t]{3}{*}{-40} & 0.03891 & 0.0497 & 0.0581 & 0.0970 & 0.05245 & 0.0452 \\
\hline & 0.05381 & & 0.06673 & & 0.056 & \\
\hline & 0.04726 & & 0.08849 & & 0.0081 & \\
\hline \multirow[t]{2}{*}{-60} & 0.04138 & 0.0389 & 0.05181 & 0.0608 & 0.05576 & 0.0293 \\
\hline & 0.02793 & & 0.04201 & & 0.02417 & \\
\hline
\end{tabular}

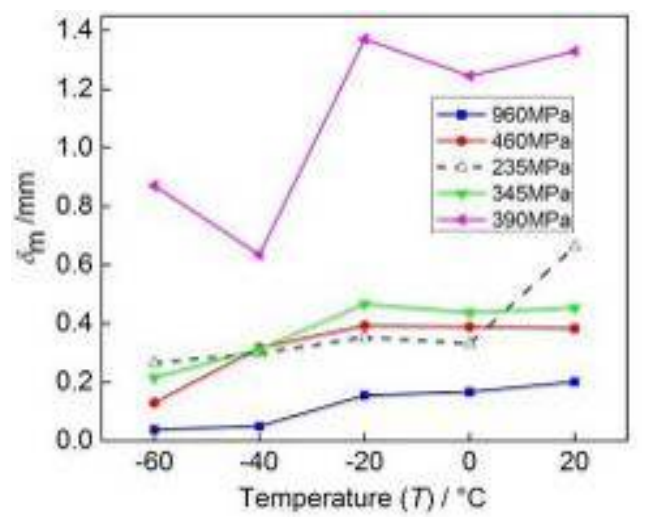

Figure 4. $\delta_{\mathrm{m}}$ Versus Temperature Curves for High-strength Steel and Other Three Structural Steels 
The tested $\delta_{\mathrm{m}}$ average values of high-strength steels $(460 \mathrm{MPa}$ and $960 \mathrm{MPa})$ with $14 \mathrm{~mm}$ plate thickness are compared with that of $235 \mathrm{MPa}, 345 \mathrm{MPa}$ and $390 \mathrm{MPa}$ steels with $12 \mathrm{~mm}$ thickness [26] as shown in Figure 4. The variation trends of all the five structural steels are decreasing as temperature decreases, the fracture toughness for $390 \mathrm{MPa}$ steel is the largest one, and that for the $235 \mathrm{MPa}, 345 \mathrm{MPa}$ and $460 \mathrm{MPa}$ steels are similar, the value for the $960 \mathrm{MPa}$ steel is the smallest among the five structural steels. That indicates the fracture toughness of low-alloyed steel is relative higher than ordinary carbon steel, however, when the strength of steel increases to a certain value, the fracture toughness reduces.

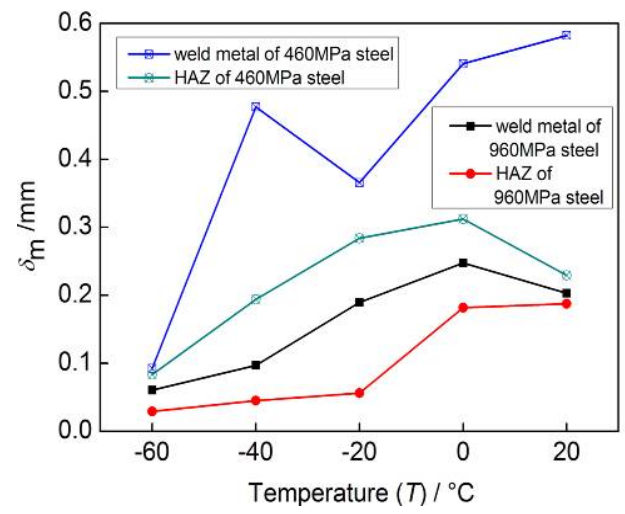

Figure 5. $\delta_{\mathrm{m}}$ Versus Temperature Curves for Butt Welds of 460Mpa and 960Mpa Steels

The average values of $\delta_{\mathrm{m}}$ versus temperature curves for the butt weld of $460 \mathrm{MPa}$ and $960 \mathrm{MPa}$ steel are shown in Figure 5. The variation trends of the $\delta_{\mathrm{m}}$ average values for weld metal and HAZ all decrease as temperature decreases, except the value of weld metal for $460 \mathrm{MPa}$ steel obtained at $-40{ }^{\circ} \mathrm{C}$, which may result from the discrete results of weld metal as shown in Table 3. As a whole, the average results of weld metal are higher than that of HAZ for both $460 \mathrm{MPa}$ and $960 \mathrm{MPa}$ steel, indicating that the fracture toughness is relative higher in weld metal.

The reduction amplitudes of $\mathrm{HAZ}$ for $460 \mathrm{MPa}$ and $960 \mathrm{MPa}$ steel in the range of $0^{\circ} \mathrm{C}$ to $-60{ }^{\circ} \mathrm{C}$ are $73.3 \%$ and $70.1 \%$, respectively, showing the significant influence of low temperature on the fracture toughness of welded high-strength steel, and indicating that the material transit from ductile to brittle in that temperature range. In addition, $\delta_{\mathrm{m}}$ average values of the weld for $960 \mathrm{MPa}$ steel are smaller than that for $460 \mathrm{MPa}$ steel as shown in Figure 5, indicating that when the steel strength increases to a certain value, the fracture toughness reduces, which agrees with the conclusions reached before.

The transition temperature of ductile-brittle is applied as a critical criterion for fracture resistant design in engineering. The typical curve of toughness versus temperature is S-shaped, which consists of three parts, i.e. the lower shelf, the transition region and the upper shelf. The lower shelf corresponds to the "brittle" mechanisms of fracture. As the temperature increases, a combination fracture mechanism of brittle and ductile is achieved in the transition region. If the temperature increases even further, the fracture mechanism transits to completely ductile fracture mechanism corresponding to the upper shelf. However, it is almost impossible to obtain such a typical curve by tests, for the dispersion of experimental data is always great. Large quantities of experimental researches have shown that the Boltzmann function can well describe the correlation of toughness and temperature [30], and the physical meanings of each parameter are definite. So in this paper, the average $\delta_{\mathrm{m}}$ values obtained by tests were regressed by Boltzmann function as Eq. (2), Where $\delta_{1}$, $\delta_{2}, T_{\mathrm{t}}$ and $T_{\mathrm{r}}$ are curve-fitting parameters; $T$ represents the temperature variable; $\delta$ is the critical CTOD value at temperature $T ; \delta_{1}$ and $\delta_{2}$ are the fracture toughness of the lower and upper shelf, respectively; $T_{\mathrm{t}}$ is the transition temperature of ductile to brittle; $T_{\mathrm{r}}$ is the temperature range of transition region. 


$$
\delta(T)=\frac{\delta_{1}-\delta_{2}}{1+\exp \left[\left(T-T_{\mathrm{t}}\right) / T_{\mathrm{r}}\right]}+\delta_{2}
$$

The temperature transition curves of fracture toughness for $460 \mathrm{MPa}$ and $960 \mathrm{MPa}$ steels are shown in Figure 6, as well as the corresponding welds. Curve-fitting parameters in Eq. (2) by regress of the test data are listed in Table 5.
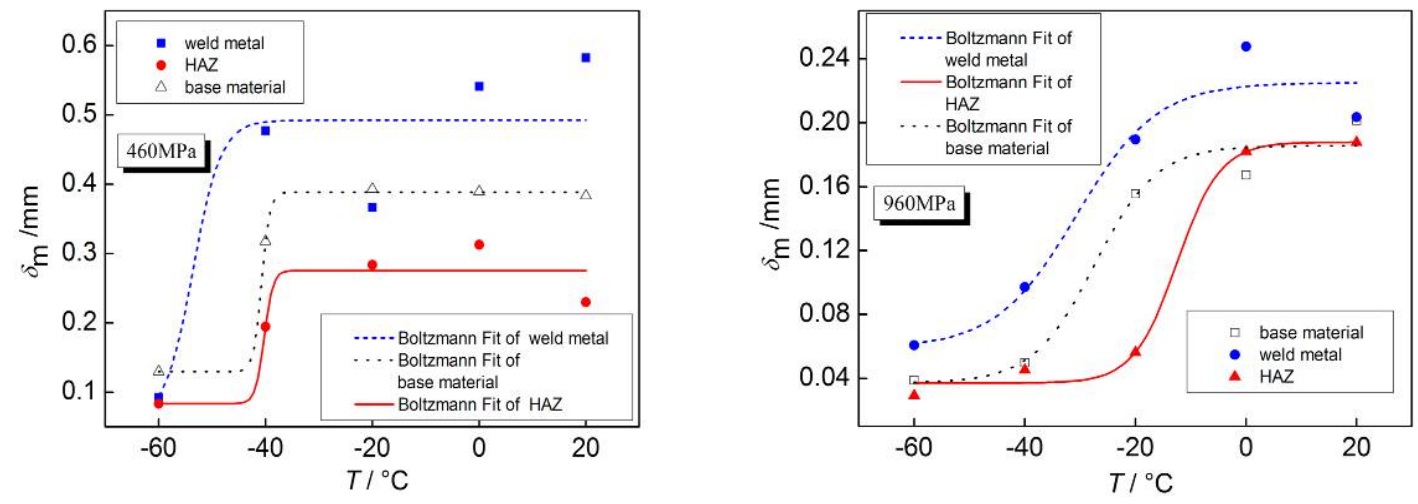

Figure 6. Temperature Transition Curves of

Fracture Toughness for 460Mpa and 960Mpa Steels

Table 5. Fitting Parameters of Boltzmann Function for $\delta_{\mathrm{m}}$ Falues

\begin{tabular}{|c|c|c|c|c|c|c|}
\hline Steel & Specimen & $\delta_{1} / \mathrm{mm}$ & $\delta_{2} / \mathrm{mm}$ & $T_{\mathrm{t}} /{ }^{\circ} \mathrm{C}$ & $T_{\mathrm{r}} /{ }^{\circ} \mathrm{C}$ & $R^{2}$ \\
\hline \multirow{3}{*}{$960 \mathrm{MPa}$} & Weld metal & 0.06 & 0.23 & -29.76 & 6.95 & 0.82 \\
\hline & HAZ & 0.03 & 0.18 & -12.45 & 3.92 & 0.98 \\
\hline & $\begin{array}{l}\text { Base } \\
\text { material }\end{array}$ & 0.04 & 0.19 & -27.33 & 5.6 & 0.90 \\
\hline \multirow{3}{*}{$460 \mathrm{MPa}$} & Weld metal & 0.06 & 0.50 & -53.58 & 2.62 & 0.77 \\
\hline & HAZ & 0.08 & 0.27 & -40.25 & 0.81 & 0.66 \\
\hline & $\begin{array}{l}\text { Base } \\
\text { material }\end{array}$ & 0.13 & 0.39 & -40.72 & 0.74 & 0.99 \\
\hline
\end{tabular}

Indicated by Table 5, the upper shelf value and the transition range of weld metal for both $460 \mathrm{MPa}$ and $960 \mathrm{MPa}$ steels are larger than that of base material and HAZ, moreover, the ductile-brittle transition temperatures are lower than base material and HAZ, showing that the fracture toughness of weld metal is relative high and the fracture property of weld metal itself is not a controlling factor.

On the other hand, the upper and lower shelf values of HAZ for the two high-strength steels are lower than base material, although the ductile-brittle transition temperature of $\mathrm{HAZ}$ for $460 \mathrm{MPa}$ steel $\left(-40.28^{\circ} \mathrm{C}\right)$ is close to that of base $\operatorname{metal}\left(-40.94^{\circ} \mathrm{C}\right)$, that may result from the limited quantity of test specimens, correlation coefficient of fitting results for HAZ by Boltzmann function is relative small. For $960 \mathrm{MPa}$ steel, the transition temperature of $\mathrm{HAZ}\left(-12.45^{\circ} \mathrm{C}\right)$ is larger than that of base material $\left(-27.33^{\circ} \mathrm{C}\right)$, indicating that the fracture toughness of $\mathrm{HAZ}$ deteriorate, and it is the weakest zone for the brittle resistant design of welded steel structure.

Compared with the fitting results of 460MPa steel, the upper shelf values of 960MPa steel and the corresponding welds are much lower, the ductile-brittle transition temperatures are higher than that of $460 \mathrm{MPa}$ steel, it demonstrates that as the steel strength increases to a certain extent, the fracture toughness decreases. Besides, the fracture toughness decreases more rapidly as the temperature decreases as shown in Figure 5, showing the more significant effect of temperature on the fracture toughness. 


\section{SEM OF TPB FRACTURED SURFACE}

The micro-morphology of TPB fracture surface was scanned by the electron microscope as shown in Figures 7, 8, 9, 10, 11 and 12, the scanning position was close to the fracture surface center, the scanning magnifications for $460 \mathrm{MPa}$ and $960 \mathrm{MPa}$ steels were $2000 \mathrm{x}$ and $1000 \mathrm{x}$ respectively.

As shown in Figure 7, the fracture surfaces for $460 \mathrm{MPa}$ steel at $20^{\circ} \mathrm{C}$ and $0{ }^{\circ} \mathrm{C}$ have lots of dimples and tearing ridges existed; as temperature decreases, the fracture surfaces are dominated by the brittle fracture characteristics with shiny cleavage planes. As for the fracture surfaces for weld metal and HAZ of $460 \mathrm{MPa}$ steel, there are considerable dimples and tearing ridges at $20^{\circ} \mathrm{C}$ as well, showing the feature of transgranular fracture, the dimples and tearing ridges gradually reduce until disappear and micro fractograph at $-60{ }^{\circ} \mathrm{C}$ exhibits typical intergranular brittle fracture feature with river patterns and cleavage stages. The microscopic characteristics changing with temperature are in accordance with the macro toughness index $\left(\delta_{\mathrm{m}}\right)$.
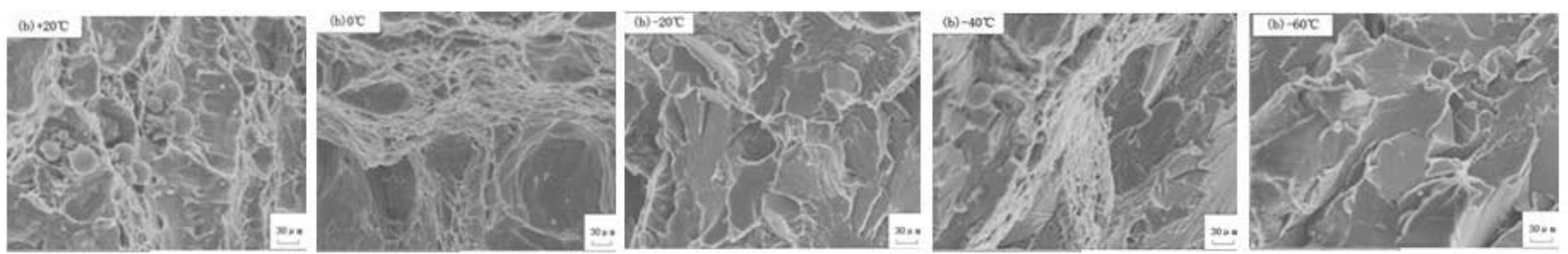

Figure 7. Micro-morphology of Fracture Surfaces for 460MPa Steel at Five Different Temperatures
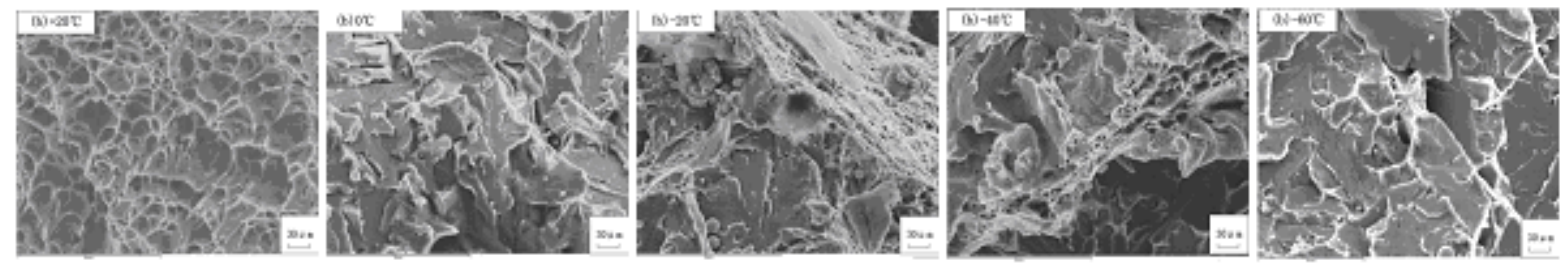

Figure 8. Micro-morphology of Fracture Surfaces for Weld Metal of 460Mpa Steel at Five Different Temperatures
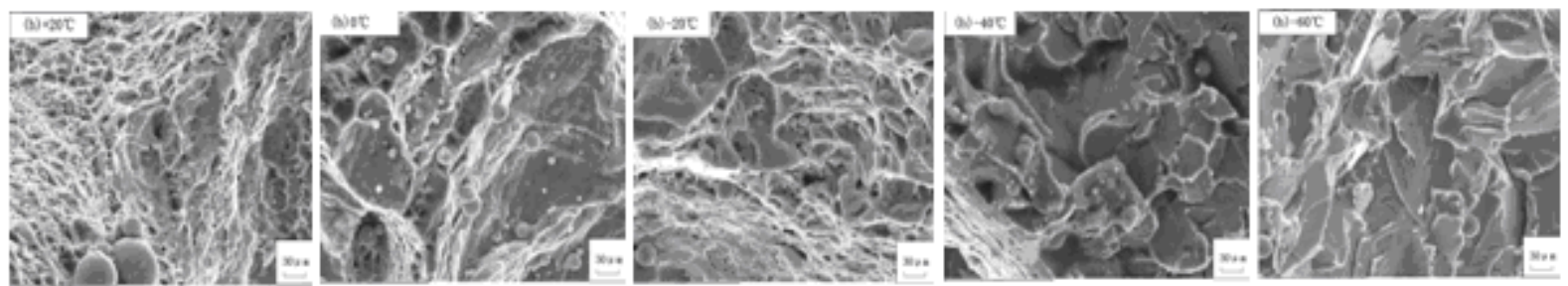

Figure 9. Micro-morphology of Fracture Surfaces for HAZ of 460Mpa Steel at Five Different Temperatures

As shown in Figures 10, 11 and 12, the micro-morphologies for 960MPa steel and its weld are different from that for $460 \mathrm{MPa}$ steel. The fracture surface for base material at $20{ }^{\circ} \mathrm{C}$ is quite uneven and the voids are relative large, while as the temperature decreases, the fracture surface becomes smooth and the voids change from large to small, from deep to shallow, the quasi-cleavage planes which exhibit some plastic deformation and the tearing ridges occur at $-20{ }^{\circ} \mathrm{C}$, showing the feature of quasi-cleavage fracture. When temperature decreases to $-40{ }^{\circ} \mathrm{C}$, the fractograph exhibits the cleavage step pattern. The transgranular fracture occurs at $-60{ }^{\circ} \mathrm{C}$ with tongue patterns in the fracture surface. 
As for the weld metal of $960 \mathrm{MPa}$ steel, there are dimples in the fractograph at $20{ }^{\circ} \mathrm{C}$ as shown in Figure 11, the micro fracture mechanism is void coalescence, as temperature decreases, the dimples become small and shallow until disappear. Dimples and cleavage steps both can be seen at $0{ }^{\circ} \mathrm{C}$, showing the mixed characteristic of ductile fracture and brittle fracture. Many tearing ridges occur at $-20{ }^{\circ} \mathrm{C}$, and the fractographs are dominated by the shinny cleavage planes which are shaped like crystal when temperature reduces to $-40{ }^{\circ} \mathrm{C}$ and $-60{ }^{\circ} \mathrm{C}$, showing the intergranular brittle fracture feature. Compared with the micro-characteristics of $960 \mathrm{MPa}$ steel and its weld metal, the fractograph of the HAZ has fewer and smaller dimples as shown in Figure 12, which indicates the worse toughness in HAZ. When temperature drops from $-20{ }^{\circ} \mathrm{C}$ and $-60{ }^{\circ} \mathrm{C}$, the cleavage cracks develop, the brittle fracture feature is more obvious for HAZ than base material and weld metal, which corresponds to the lowest $\delta_{\mathrm{m}}$ values and the highest transition temperature $\left(-12.45^{\circ} \mathrm{C}\right)$ for HAZ as listed in Table 4 and Table 5.
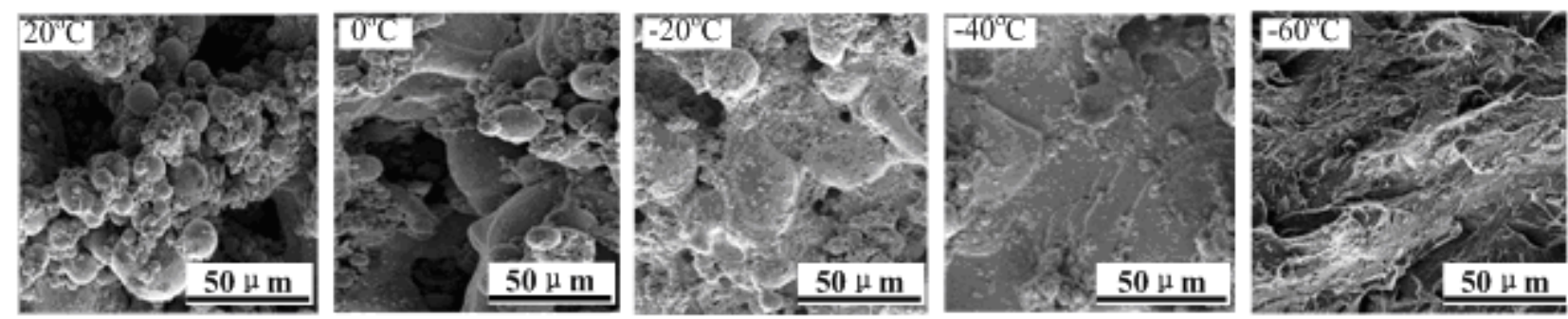

Figure 10. Micro-morphology of Fracture Surfaces for 960Mpa Steel at Five Different Temperatures
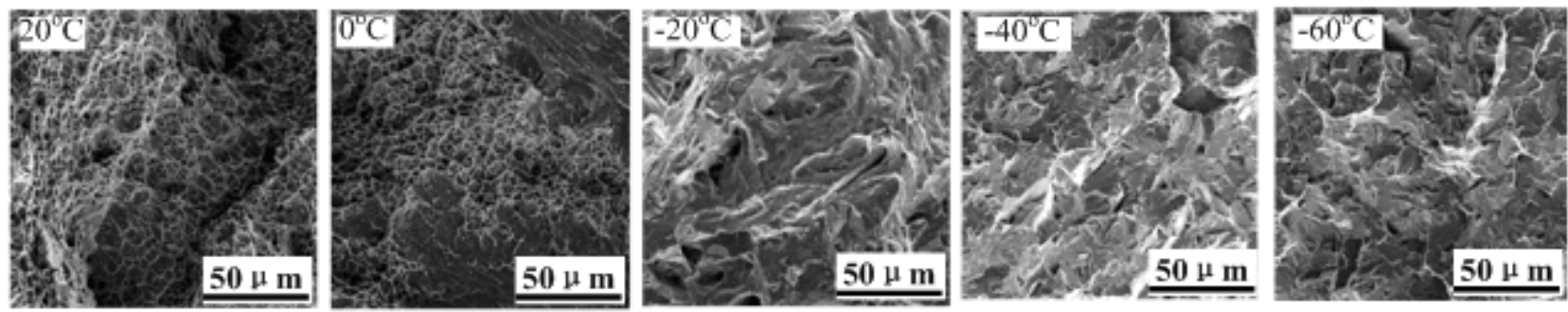

Figure 11. Micro-morphology of Fracture Surfaces for Weld Metal of 960Mpa Steel at Five Different Temperatures
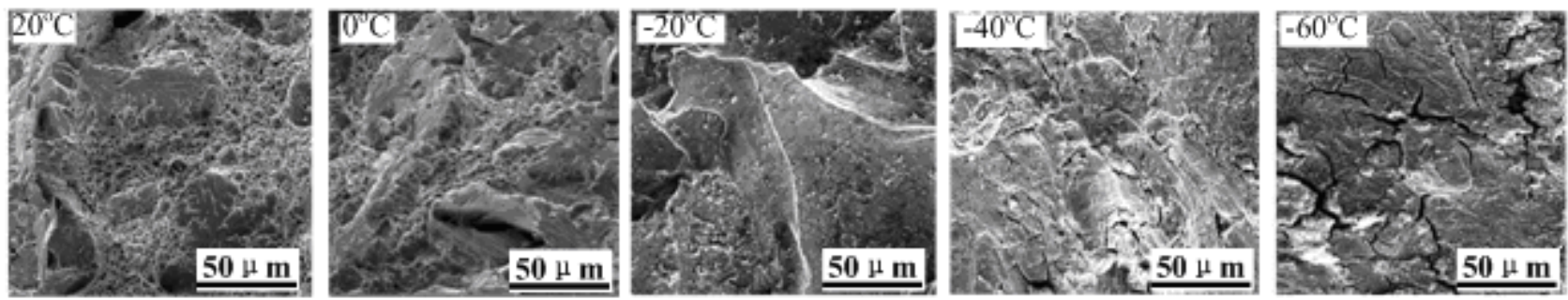

Figure 12. Micro-morphology of Fracture Surfaces for HAZ of 960Mpa Steel at Five Different Temperatures

\section{CONCLUSIONS}

(1) The variation trends of fracture toughness index (critical CTOD values $\delta_{\mathrm{m}}$ ) for high-strength steel and the corresponding butt weld are all reduced with temperature decreases. The decline amplitudes of $\delta_{\mathrm{m}}$ for the specimens are all larger than $64 \%$ as the temperature drops from $20^{\circ} \mathrm{C}$ to $-60^{\circ} \mathrm{C}$, showing the temperature sensitivity to fracture for the welded high-strength steel. 
(2) The fracture toughness of high-strength steels $(460 \mathrm{MPa}$ and $960 \mathrm{MPa})$ is lower than that of conventional steels, such as steels with yield point of $235 \mathrm{MPa}, 345 \mathrm{MPa}$ and $390 \mathrm{MPa}$. The fracture toughness for $390 \mathrm{MPa}$ steel is the largest, and that for $960 \mathrm{MPa}$ steel is the lowest, which indicates that the fracture toughness of low-alloyed steel is relative higher than ordinary carbon steels, however, when the strength of steel increases to a certain value, the fracture toughness reduces.

(3) Compared with the base material, the fracture toughness in weld metal is higher than that in base material as a whole, and the $\delta \mathrm{m}$ values in HAZ are the lowest, indicating the fracture toughness deteriorate in HAZ. Moreover, the ductile-brittle transition temperatures of HAZ are higher than that of weld metal and base material, the values are $-12.45^{\circ} \mathrm{C}$ and $-40.25^{\circ} \mathrm{C}$ for $960 \mathrm{MPa}$ and $460 \mathrm{MPa}$ steels respectively, which is in accordance with the deterioration of fracture toughness in HAZ. Accordingly, the toughness of HAZ should be the major consideration in the fracture resistant design of high-strength steel structures.

(4) The micro-morphologies of TPB specimens also show the large effects of temperature on the toughness of high-strength steels and the welds, and the fractographs all exhibit the brittle fracture mechanism at $-20^{\circ} \mathrm{C}$. Besides, the brittle fracture feature at low temperature is more obvious for HAZ, which is consistent with the lower macro toughness index $\delta_{\mathrm{m}}$. The toughness of high-strength steel gets worse in cold regions, and the toughness of HAZ is critical for brittle fracture prevention and should be the main concern in engineering.

\section{ACKNOWLEDGEMENTS}

This work was financially supported by the National Natural Science Foundation of China (Grant Nos. 51178244, 51378289 and 51408013).

\section{REFERENCES}

[1] Shi, G., Shi, Y.J. and Wang, Y.Q., "Engineering Application of Ultra-high Strength Steel Structure", Progress in Steel Building Structure, 2008, Vol. 10, No. 4, pp. 32-38.

[2] Liu, X.Y., Wang, Y.Q., Shi, Y.J. and Chen H., "Progress on Research for Brittle Facture of Steel Structure Constructed with High-strength Steel", Steel Structure, 2012, Vol. 9, No. S, pp. 135-145.

[3] Miki, C., Homma, K. and Tominaga, T., "High Strength and High Performance Steels and their Use in Bridge Structures", Journal of Constructional Steel Research, 2002, Vol. 58, pp.3-20.

[4] International Association for Bridge and Structural Engineering, "Use and Application of High Performance Steels for Steel Structures”, Zurich: IABSE, 2005, pp.118.

[5] Rogers, C.A. and Hancock, G.J., "Fracture Toughness of G550 Sheet Steels Subjected to Tension", Journal of Constructional Steel Research, 2001, Vol. 57, pp. 71-78.

[6] Valiente, A., Elices, M., Ruiz, J. and Alvarez, J.A., "Fracture Assessment of a High Strength Structural Steel on the Basis of Eurocode 3", Materials and Structures, 1999, Vol. 32, pp. 144-150.

[7] Toribio, J., "A Fracture Criterion for High-strength Steel Notched Bars", Engineering Fracture Mechanics, 1997, Vol. Vol. 4, No. 57, pp. 391-405.

[8] Chang, K. H. and Lee, C. H., "Residual Stresses and Fracture Mechanics Analysis of a Crack in Welds of High Strength Steels", Engineering Fracture Mechanics, 2007, Vol. 74, pp. 980-994. 
[9] Xu, S., Petri, N. and Tyson, W.R., "Evaluation of CTOA from Load vs. Load-line Displacement for C (T) Specimen", Engineering Fracture Mechanics, 2009, Vol. 76, pp. 2126-2134.

[10] Duan, L., "Mechanical Characteristics of High Performance Steel HPS 485W and Bending Behavior Study of Hybrid Girder", Chang'an University, Xi'an, 2010, pp.108.

[11] Jing, H.Y., Huo, L.X., Zhang, Y.F., Toyoda, M. and Fujita, A., "Effect of Yield Ratio on Fracture Toughness for High Strength Steel", Acta Metallurgica Sinica., 1996, Vol. 32, No. 3, pp. 265-273.

[12] Code of Practice for the Structural Use of Steel, Building Department, Hong Kong, 2005, pp. 13.

[13] EN 1993-1-10: 2005 (E), Eurocode 3-Design of Steel Structures Part 1-10: Material Toughness and Through-thickness Properties, European Standard, 2007, pp.10.

[14] EN 1993-1-12, Eurocode 3-Design of Steel Structures Part 1-12: Additional Rules for the Extension of EN 1993 up to Steel Grades S700, British Standard Institution, London, 2007, pp. 15 .

[15] ANSI/AISC 360-05, Specification for Structural Steel Buildings. American National Standard, 2005, pp.23.

[16] Weng, C.C. and White, R.N., "Cold-Bending of Thick High-Strength Steel Plates, Journal of Structural Engineering", ASCE, 1990, Vol. 116, No. 1, pp. 40-54.

[17] Kervick, R.J. and Springborn, P.K., "Cold-Bending and Forming Tube and Other Sections, Transactions", ASME, 1966, pp. 9-18.

[18] Chang, K.H. and Lee, C.H., "Residual Stresses and Fracture Mechanics Analysis of a Crack in Welds of High Strength Steels", Engineering Fracture Mechanics, 2007, Vol. 74, pp. 980-993.

[19] Shi, Y.W. and Hang, Z.X., "Evaluation of Fracture Toughness on 800MPa Grade HSLA Welds in Construction Machinery", Welding \& Joining, 2006, Vol. 35, No. 11, pp. 3-16.

[20] Zhou, Z.L., Xie, M., Lin, W.J. and Liu, Z.C., "Influence of Heat Input on the HAZ Fracture Toughness and Microstructure of WEL-TEN780A High Strength Steel”, Welding \& Joining, 1999, Vol. 10, pp. 8-15.

[21] Vojvodic Tuma, J., Sedmak, A., "Analysis of the Unstable Fracture Behaviour of a High Strength Low Alloy Steel Weldment", Engineering Fracture Mechanics, 2004, Vol. 71, pp. 1435.

[22] Barsom, J.M. and Rolfe, S.T., "Fracture and Fatigue Control in Structures: Applications of Fracture Mechanics", ASTM, West Conshohocken, PA., 1999, pp.3.

[23] Wu, Y.M., Wang, Y.Q. and Shi, Y.J., "Effects of Low Temperature on Properties of Structural Steel", Journal of University of Science and Technology Beijing, 2004, Vol. 11, No. , pp.442-448.

[24] Wang, Y.Q., Lin, Y., Zhang, Y.N. and Shi Y.J., "Experimental Study on Fracture Toughness of Q460C the High-strength Construction Steel at Low Temperature", Applied Mechanics and Materials, 2011, Vol. 71-78, pp.890-897.

[25] Wang, Y.Q., Liu, X.Y., Hu, Z.W. and Shi, Y.J., "Experimental Study on Mechanical Properties and Fracture Toughness of Structural Thick Plate and Its butt Weld Along Thickness and at Low Temperatures", Fatigue \& Fracture of Engineering Materials \& Structures, 2013, Vol. 36, No. 12, pp.1258-1273.

[26] Wu, Y.M., "Research for Mechanism of Brittle Fracture of Structural Steel and its Engineering Design Method", Tsinghua University, Beijing, 2004, pp.1.

[27] Hu, Z.W., "Research for Mechanical Properties of Brittle Fracture of Structural Steel Thick Plate and its Weld", Tsinghua University, Beijing, 2010, pp.2.

[28] JGJ 81-2002, "Technical Specification for Welding of Steel Structure of Building", Standards Press of China, Beijing, 2002, pp.10. 
[29] GB/T 21143-2007, "Metallic Materials-Unified Method of Test of Determination for quasistatic fracture toughness", Standards Press of China, Beijing, 2007, pp.13.

[30] Wang, Y.Q., Lin Y., Zhang Y.N. and Shi Y.J., "Experimental Study on Fracture Toughness of Butt Weld of Q460C the High-strength Construction Steel". Proceedings of Seventh International Conference on Advances in Steel Structures, Nan Jing, 2012, Vol. 1, pp. 668-675. 


\title{
STATIC EQUILIBRIUM FORM-FINDING ANALYSIS OF CABLE-STRUT SYSTEM BASED ON NONLINEAR DYNAMIC FINITE ELEMENT METHOD
}

\author{
Bin Luo ${ }^{1,2^{*}}$, Zhengxing Guo ${ }^{1,2}$, Xiangnan Chen ${ }^{1}$, Feng Gao ${ }^{3}$ and Kai Wang ${ }^{4}$ \\ ${ }^{1}$ Key Laboratory of C\& PC Structures of China Ministry of Education, \\ Southeast University, SiPaiLou 2, Nanjing, 210096, China \\ 2 Nantional Prestress Engineering Research Center, \\ Southeast University, SiPaiLou 2, Nanjing, 210096, China \\ 3 Shanghai Institute of Architectural Design \& Research(Co., Ltd) \\ No.258 Shi Men Er Road, Shanghai, 200041 ,China \\ 4 Architecture Design \&Research Institue of Southeast University, \\ SiPaiLou 2, Nanjing, 210096, China \\ *(Corresponding Author: E-mail: seurobin@seu.edu.cn
}

\begin{abstract}
Full tensile structures (such as cable domes, cable networks and cable trusses) are structures that only consist of cables and struts. There are three steps in its onsite construction: (1) assembly and connection, (2) towing and lifting and (3) tensioning and shaping. During construction process, the structure may suffer from large mechanism displacement and cable slack, so its initial shape was far from equilibrium. The form-finding analysis is a major difficulty in the construction process analysis. In this paper, we propose a new method for static equilibrium form-finding analysis of a cable-strut system based on a nonlinear dynamic finite element method and introduce virtual inertia and viscous damping force, as well as a series analysis techniques and a multi-step continuous solver. When the total system kinetic energy reaches its peak, the finite element model is updated, and the dynamic equilibria gradually converge to a static equilibrium state through iterative updating. To improve the analysis efficiency, stability and accuracy, key technical measures are proposed for time-step lengths, total energy peak value, model updating, convergence criteria and static equilibrium verification. In the case of the rigid cable dome in Wuxi New District Science and Technology Exchange Centre in China, we used this method to perform the mechanical analysis during the integral tow-lifting and tensioning process, and the project corresponded with our analysis. Meanwhile, we have to mention that during the construction process of integral tow-lifting, an inflection point exists in the adjustment phase, at which point the configuration stability is the worst and struts can fall sideways. Especially, for cable domes with a high rise-span ratio, the stability at the inflection point needs to be addressed.
\end{abstract}

Keywords: cable-strut system; static equilibrium state; form-finding; nonlinear dynamic finite elements; non-bracket tow-lifting construction technology

DOI: 10.18057/IJASC.2015.11.4.4

\section{INTRODUCTION}

A cable-strut system is a system that consists of cables and struts and can be a standalone structure, such as a cable dome, cable networks or a cable truss. It can also form structures with other steel substructures, such as a cable-stayed grid, a chord support dome or a beam string structure.

On-site construction of a cable-strut system requires three steps: (1) assembly and connection, (2) towing and lifting and (3) tensioning and shaping. Assembly and connection connects the cable and strut under zero-stress conditions based on topology; towing and lifting installs the assembled cable-strut system in the designated location using towing or lifting equipment; and tensioning and shaping establishes the pre-stress tensions and forms the structure by tensioning the cables or supporting the struts. Before the on-site construction, a numerical simulation analysis of the overall cable-strut system construction process that primarily focuses on the towing and lifting and tensioning and shaping is required to control the key construction processes and to verify the 
stability of the structure. Moreover, the simulation can provide the needed parameters which are the basis for construction and monitoring.

The construction process is dynamic, but in terms of the construction state at a given time point, the cable-strut system is in a static equilibrium state. Therefore, the cable-strut system construction process can be divided into several construction stages to perform the static equilibrium form-finding analysis.

There is a significant difference between the static equilibrium state during construction and the structure-forming state in the configuration of cable-strut system. The difference is especially significant during the early stages of the construction, including towing and installation and tensioning and shaping. The position of the cable-strut system gradually moves toward, closes in on and finally reaches its final state. Before tensioning, the cable-strut system is a mechanism system: it must establish the pre-stressed tension through tensioning and thus form the structure with structural rigidity. The shape-forming state required by the design is used as the initial configuration to set up the model. Form-finding analysis then uses this model to determine the cable-strut system static equilibrium state for the various construction stages. During the form-finding process, the cable-strut system indicates the mechanism displacement, while the elastic strain is small. In addition, because the flexible cable (i.e., steel wire bundles, steel strand, or steel rope) can only be pulled, not compressed or bent, part or all of the cable remains in the relaxed state during construction. Due to that a large displacement exists (including the mechanism displacement and cable relaxation), the linear static finite element used for the conventional structures cannot be used for this analysis.

Currently, the major cable-strut system static equilibrium form-finding analyses include the nonlinear static finite element method, the nonlinear force method, and the dynamic relaxation method.

(1) The nonlinear static finite element method is used to establish a finite element model and uses a nonlinear iteration method to determine the static equilibrium state. The explicit expression of the stiffness matrix of cables and an iteration solution was derived by Jayaraman [1]. To facilitate convergence, it assumes the path of motion or sets an initial displacement that approaches the equilibrium position; the rigidity of a relaxed catenary without pre-stressed tension and the rigidity of a mast without strain are not included in the total structure. The weight, however, is considered to be a concentrated load exerted on the connected node [2].

(2) The nonlinear force method is a nonlinear analysis method based on the force method and it can analyze various structure forms, including kinetically indeterminate systems and statically indeterminate systems. Moreover, the method can be used to solve problems about structures with mechanism displacement and perform force or state analysis of structures with coupled mechanism displacement and elastic displacement. The force method has more applications compared to the number of applications of the finite element displacement method, and in the equilibrium equation established by the force method the equilibrium matrix is an asymmetric full array matrix. The singular value decomposition of equilibrium matrix was used by Pellegrino and Calladine [3]. Based on the equilibrium matrix, we can perform kinematic analysis of planar deployable structures with angulated beams [4]. In contrast, the stiffness matrix established by the displacement method, is a symmetrical sparse matrix. Much more computing power is needed for the singular value decomposition of full array equilibrium matrix than for triangular decomposition of the stiffness matrix [5]. Based on the nonlinear force method, a new incremental algorithm to trace the non-linear equilibrium paths of pin-jointed structures was proposed. Geometrically, non-linear force method, which is derived from the force method, is applied instead of geometrically non-linear finite-element method. Singular value decomposition operation of the equilibrium 
matrix is introduced into the calculation of the responses of structures [6].

(3) The dynamic relaxation method can be used in the form-finding and load analysis of tension structures [7-12]. This method converts the static problem into a dynamic problem using a virtual mass and a viscous damping force. The structure is dispersed into virtual particles with virtual masses that are located at the spatial node position; under an unbalanced force, these dispersed virtual particles move along the unbalanced force direction macroscopically to reduce the overall unbalanced force in the structure. After a particular interval of time, if the overall kinetic energy of the structure is less than it was before, the kinetic energy is assumed to have reached its peak value between the two time points. All of the velocity components are then set to zero. Under the current unbalanced force, vibration restarts. This cycle repeats until the structure kinetic energy approaches zero, i.e., until it reaches the static equilibrium state. The dynamic relaxation method performs equilibrium iterations spatial point by spatial point and time point by time point; it does not require the formation of an overall stiffness matrix, and it does not experience error accumulation [13].

The current paper proposes a new analysis method to determine the static equilibrium state of a cable-strut system: the nonlinear dynamic finite element method.

\section{FORM-FINDING ANALYSIS USING THE NONLINEAR DYNAMIC FINITE ELEMENT METHOD}

The nonlinear dynamic finite element method (NDFEM) ${ }^{[14]}$ is used to determine the static equilibrium state of cable-strut system and is based on nonlinear dynamic finite elements. By introducing virtual inertia and a viscous damping force, we establish the equations of motion, which transform static problems that are difficult to solve into dynamic problems that are easy to solve. Moreover, through iterative updating of the configuration of the cable-strut system, the dynamic equilibrium state gradually converges to the static equilibrium state. A cable-strut system is in a static imbalanced state before the analysis, is in a dynamic balanced state during the analysis and reaches a static balanced state after convergence. In other words, the cable-strut system moves from an initial static imbalanced state to a stable static balanced state.

\subsection{Details of the NDFEM Form-Finding Analysis}

\subsubsection{Analytic logic}

The main content of the NDFEM form-finding analysis is the nonlinear dynamic equilibrium iteration and the configuration update iteration. The analysis includes the following steps: establishing an initial finite element model; conducting nonlinear dynamic finite element analysis; updating the finite element model when the total kinetic energy reaches its peak value; continuing dynamic analysis until the configuration converges; and conducting nonlinear static analysis on the converged finite element model to verify the static equilibrium state and extract the results.

\subsubsection{Specific Steps (Figure 1)}

(1) Preparation for analysis: Define the design and formation state of the cable-strut system, construction program and construction phases that need to be analyzed.

(2) Establish an initial finite element model: select a cable unit and strut unit that meet the accuracy requirement of the project; establish a finite element model according to the designed formation state or other assumed initial configuration; impose gravity and other loads (e.g., a hanging load), as well as boundary constraints, according to the required analysis for each construction phase; apply equivalent initial strain $\varepsilon_{p}$ or equivalent 
temperature difference $\Delta T_{p}$ to the cable-strut based on Eq. 1 and Eq. 2, and the known condition of the original cable length; and apply $\varepsilon_{p}$ or $\Delta T_{p}$ to the cable-strut, based on Eq. 3 and Eq. 4, and the known condition of the cable-strut internal forces (e.g., tractive force, tension).

$\varepsilon_{p}=S / S_{0}-1$

$\Delta T_{p}=-\varepsilon_{p} / \alpha=\left(1-S / S_{0}\right) / \alpha$

$\varepsilon_{p}=F /(E \times A)$

$\Delta T_{p}=-\varepsilon_{p} / \alpha=-F /(E \times A \times \alpha)$

where $\mathrm{S}$ is the element length of the model; $\mathrm{S}_{0}$ is the element original length; $\mathrm{E}, \mathrm{A}$ and $\alpha$ are the elastic modulus, cross-sectional area and coefficient of thermal expansion, respectively; and $\mathrm{F}$ is the cable-strut internal force.

(3) Set the analysis parameters and convergence criteria: The Rayleigh Damping Matrix (Eq. 6) can be used in a dynamic balance equation (Eq. 5) in which the self-resonant circular frequency and the damping ratio can be set virtually, as can the maximum number of time steps for single dynamic analysis $\left[\mathrm{N}_{\mathrm{ts}}\right]$ and the maximum number of dynamic iterations for a single time step $\left[\mathrm{N}_{\mathrm{ei}}\right]$. In addition, the initial time step size $\Delta \mathrm{T}_{\mathrm{s}(1)}$, the time step size adjustment coefficient $\mathrm{C}_{\mathrm{ts}}\left(\mathrm{C}_{\mathrm{ts}} \geqslant 1\right)$, the convergence displacement value of the dynamic equilibrium iteration $\left[\mathrm{U}_{\mathrm{e} i}\right]$, the convergence displacement value of the configuration update iteration $\left[\mathrm{U}_{\mathrm{ci}}\right]$ and the maximum frequency of the configuration iteration $\left[\mathrm{N}_{\mathrm{ci}}\right]$ can also be set virtually.

$[M]\{\ddot{U}\}+[C]\{\dot{U}\}+[K]\{U\}=\{F(t)\}$

$[C]=\alpha[M]+\beta[K]$

$\alpha=\frac{2 \omega_{i} \omega_{j}\left(\xi_{i} \omega_{j}-\xi_{j} \omega_{i}\right)}{\omega_{j}^{2}-\omega_{i}^{2}}$

$\beta=\frac{2\left(\xi_{j} \omega_{j}-\xi_{i} \omega_{i}\right)}{\omega_{j}^{2}-\omega_{i}^{2}}$

where $\{U\},\{\dot{U}\}$ and $\{\ddot{U}\}$ are the displacement vector, speed vector and acceleration vector, respectively; $\{F(t)\}$ is the load duration vector; [C] is the Rayleigh damping matrix; [M] is the mass matrix; $[\mathrm{K}]$ is the stiffness matrix; $\alpha$ and $\beta$ are Rayleigh damping coefficients; $\omega_{i}$ and $\omega_{j}$ are the self-resonant circular frequencies at step i and step $\mathrm{j}$, respectively; and $\xi_{i}$ and $\xi_{j}$ are the damping ratios that correspond to $\omega_{i}$ and $\omega_{j}$, respectively. If $\xi_{i}=\xi_{j}=\xi$, Eq. (7) and Eq. 8 can be simplified to Eq. 9 and Eq. 10: 


$$
\begin{aligned}
& \alpha=\frac{2 \omega_{i} \omega_{j} \xi}{\omega_{j}+\omega_{i}} \\
& \beta=\frac{2 \xi}{\omega_{j}+\omega_{i}}
\end{aligned}
$$

(4) Iteration analysis

(1) Adjust the $\mathrm{m}^{\text {th }}$ time step size of the dynamic analysis $\Delta \mathrm{T}_{\mathrm{s}(\mathrm{m})}$.

(2) Nonlinear dynamic finite element analysis: establish the nonlinear dynamic finite element equilibrium equation (Eq. 5). Solve the equation according to the time step $\Delta \mathrm{T}_{\mathrm{s}(\mathrm{m})}$. Track the displacement, speed, and total kinetic response of the cable-strut system. When the general movement direction of the cable-strut system is clear, the damping force can be ignored and an equation for undamped motion can be established to accelerate the movement of the static balance configuration and improve analysis efficiency, as shown in Eq. 11.

$[M]\{\ddot{U}\}+[K]\{U\}=\{F(t)\}$

(3) Determine the total kinetic energy peak value and the time point at which it occurs.

(4) Renew the finite element model, which includes refreshing the configuration of the cable-strut system and controlling the original length, or internal force, of the cable-strut.

(5) Determine whether the system has converged, or the refreshed frequency of the configuration iteration $\mathrm{N}_{\mathrm{ci}}$ has reached [ $\mathrm{N}_{\mathrm{ci}}$.

(1) If the maximum displacement at nodes of the renewed finite element model $U_{\text {ci }(m)}$ is smaller than $\left[\mathrm{U}_{\mathrm{ci}}\right]$, the configuration iteratively converges, and it enters step (6). (2) If $\mathrm{U}_{\mathrm{ci}(\mathrm{m})}>\left[\mathrm{U}_{\mathrm{ci}}\right]$ and $\mathrm{N}_{\mathrm{ci}}<\left[\mathrm{N}_{\mathrm{ci}}\right]$, the configuration enters the next iteration and goes back again to step (4). (3) If $\mathrm{U}_{\mathrm{ci}(\mathrm{m})}>\left[\mathrm{U}_{\mathrm{ci}}\right]$ but $\mathrm{N}_{\mathrm{ci}}=\left[\mathrm{N}_{\mathrm{ci}}\right]$, the analysis is finished.

(6) Verify the static equilibrium state.

\subsubsection{Key Measures}

(1) Time step and its adjustment

The time step $\Delta T_{s}$ is a key factor that determines the convergence speed in the NDFEM form-finding analysis. As $\Delta \mathrm{T}_{\mathrm{S}}$ decreases, the dynamic analysis converges more easily, but the total number of time steps $\Sigma \mathrm{N}_{\mathrm{ts}}$ needed to reach static equilibrium increases. Therefore, the analysis is inefficient. For a given dynamic analysis, a reasonable $\Delta T_{s}$ should ensure that under the premise of dynamic analytic convergence, the total kinetic energy reaches its peak within a small number of time steps $\mathrm{N}_{\mathrm{ts}}$. NDFEM form-finding analysis can be divided into three stages: early stage, intermediate stage, and late stage. (1)During the early stage, the cable-strut system moves dramatically. Smaller time steps can be set in the dynamic analysis for easier iteration convergence in the dynamic equilibrium. (2)During the intermediate stage, the main displacement direction of the cable-strut system is clear; it moves toward the static equilibrium configuration. At this point, larger time steps should be set to quickly approach the static equilibrium state in fewer time steps and fewer configuration updates. (3)During the late stage, the cable-strut system vibrates near the static equilibrium. At this stage, even larger time steps should be set to help the configuration converge as quickly as possible to the static equilibrium state. 


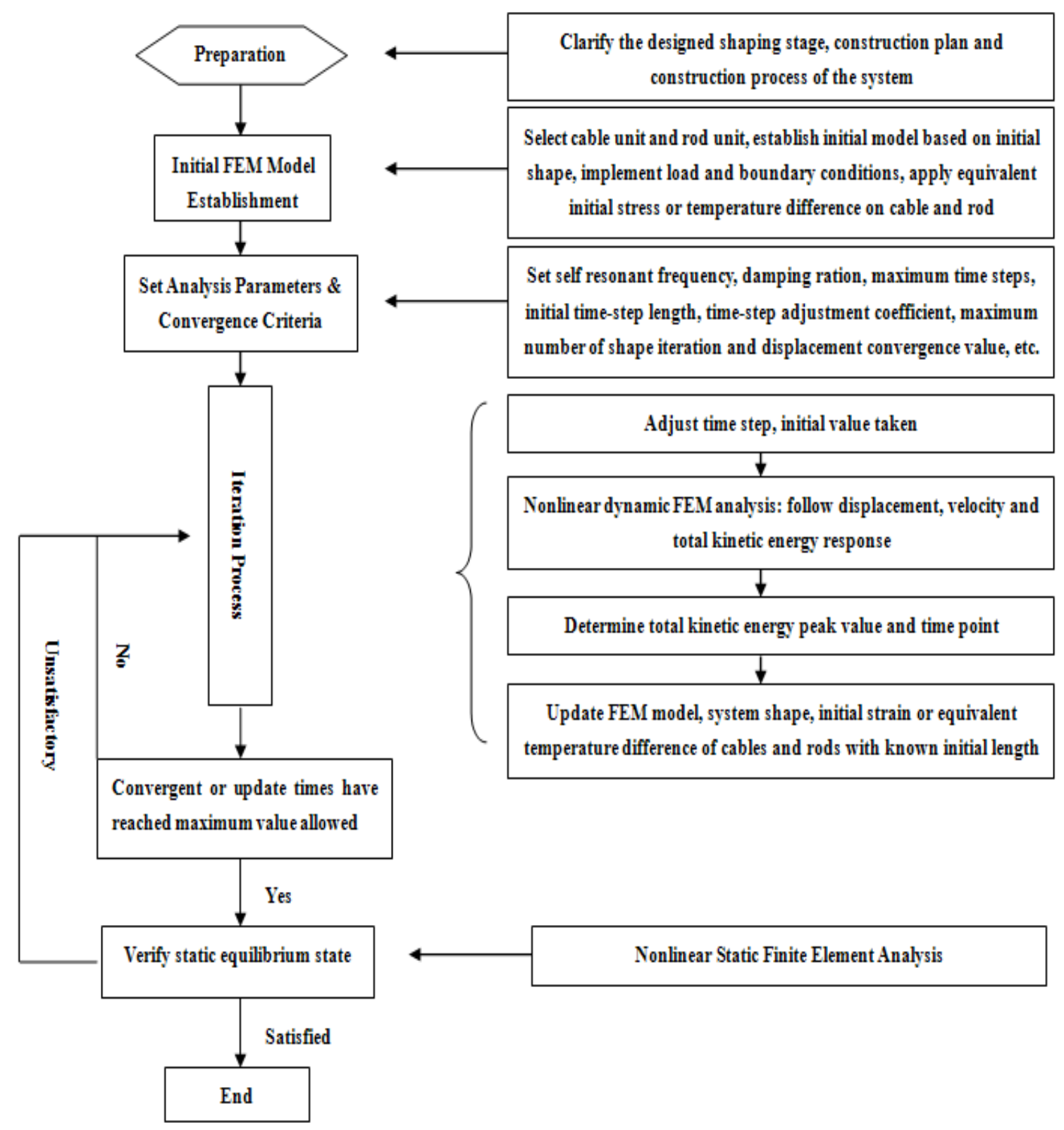

Figure 1. NDFEM form-finding Process

Because the time step size plays an important role in the dynamic equilibrium iteration and analytic efficiency, we propose using a time step adjustment coefficient $\mathrm{C}_{\mathrm{ts}}\left(\mathrm{C}_{\mathrm{ts}} \geqslant 1\right)$ to automatically adjust the time step sizes during each dynamic analysis. The adjustment strategy is as follows: (1) For the first configuration iteration, use the initial time step $\Delta \mathrm{T}_{\mathrm{s}(1)}$. (2) If at the time step for the $(\mathrm{m}-1)^{\text {th }}$ dynamic analysis $\mathrm{N}_{\mathrm{ts}(\mathrm{m}-1)}=\left[\mathrm{N}_{\mathrm{ts}}\right]$, the total kinetic energy has not decreased, the time step for the $\mathrm{m}^{\text {th }}$ dynamic analysis should be set as $\Delta \mathrm{T}_{\mathrm{s}(\mathrm{m})}=\Delta \mathrm{T}_{\mathrm{s}(\mathrm{m}-1)} \times \mathrm{C}_{\mathrm{ts}}$. (3) If the $(\mathrm{m}-1)^{\text {th }}$ dynamic analysis has not converged, the time step for the $\mathrm{m}^{\text {th }}$ dynamic analysis should be set as $\Delta \mathrm{T}_{\mathrm{s}(\mathrm{m})}=\Delta \mathrm{T}_{\mathrm{s}(\mathrm{m}-1)} / \mathrm{C}_{\mathrm{ts}}$. (2) Determining the total kinetic energy peak value $\mathrm{E}_{(\mathrm{p})}$ and the point at which it occurs $\mathrm{T}_{(\mathrm{p})}$.

The total structural kinetic energy $\mathrm{E}_{(\mathrm{k})}$ at the $\mathrm{k}^{\text {th }}$ time step in the kinetic analysis is shown in Eq. (12). The strategy to determine the peak value of the total kinetic energy and when it occurs is as follows: 
$E_{(k)}=\frac{1}{2}\{\dot{U}\}_{(k)}^{T}[M]\{\dot{U}\}_{(k)}$

where $\{\dot{U}\}_{(i)}$ is the velocity vector at the $\mathrm{k}^{\text {th }}$ time step.

(1) Assume $\mathrm{E}_{(0)}=0$. (2) At the $\mathrm{k}^{\text {th }}$ time step of dynamic equilibrium iteration convergence, if $\mathrm{k}<\left[\mathrm{N}_{\mathrm{ts}}\right]$ and $\mathrm{E}_{(\mathrm{k})}>\mathrm{E}_{(\mathrm{k}-1)}$, then the total kinetic energy has not reached its peak value; begin the $(\mathrm{k}+1)$ time step. If $\mathrm{k} \leq\left[\mathrm{N}_{\mathrm{ts}}\right]$ and $\mathrm{E}_{(\mathrm{k})}<\mathrm{E}_{(\mathrm{k}-1)}$, then parabolic curve fitting of the total kinetic energy at three consecutive time steps is performed to calculate the peak value of the total kinetic energy curve $\mathrm{E}_{(\mathrm{p})}$ and its time point $\mathrm{T}_{\mathrm{s}(\mathrm{p})}$ (Figure 2). If $\mathrm{k}=\left[\mathrm{N}_{\mathrm{ts}}\right]$ and $\mathrm{E}_{(\mathrm{k})} \geq \mathrm{E}_{(\mathrm{k}-1)}$, then $\mathrm{E}_{(\mathrm{p})}=\mathrm{E}_{(\mathrm{k})}$ and $\mathrm{T}_{\mathrm{s}(\mathrm{p})}=\mathrm{T}_{\mathrm{s}(\mathrm{k})}$. (3) When the dynamic equilibrium iteration does not converge at the $\mathrm{k}^{\text {th }}$ time step, if $\mathrm{k}=1$, then the configuration is not updated; after adjusting the time step, the next dynamic analysis begins. If $1<\mathrm{k}$ $\leq\left[\mathrm{N}_{\mathrm{ts}}\right]$, then $\mathrm{E}_{(\mathrm{p})}=\mathrm{E}_{(\mathrm{k}-1)}$ and $\mathrm{T}_{\mathrm{s}(\mathrm{p})}=\mathrm{T}_{\mathrm{s}(\mathrm{k}-1)}$.

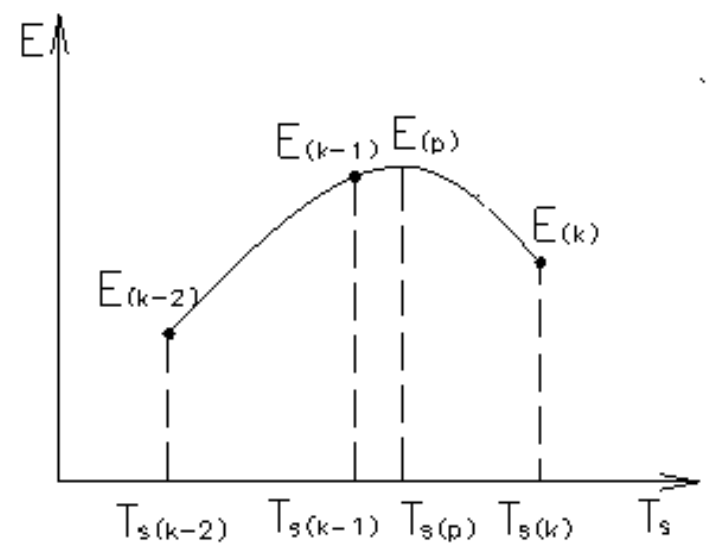

Figure 2. The peak value of total kinetic energy and when it occurs

(3) Updating the finite element model

After determining the total kinetic energy peak value and when it occurs, we updated the finite element model.

(1) A linear interpolation method is used to calculate the displacement at time point $T_{s(p)}$, which corresponds to the total kinetic energy $\mathrm{E}_{(\mathrm{p})}$, and to update the configuration of the cable-strut system.

(2) Update the equivalent initial strain or equivalent temperature difference of the cable and strut with the known original length based on the geometric length in the new model; there is no need to update the equivalent initial strain or equivalent temperature difference for the cable and strut with a known inner force.

(4) Iteration convergence criteria

NDFEM form-finding analysis has two levels of iterations: the first level is the dynamic equilibrium iteration, and the second level is the configuration update iteration.

In general nonlinear dynamic finite element analysis, the convergence criteria of the dynamic equilibrium iteration includes force and displacement. However, the NDFEM form-finding analysis requires multiple updates of the configuration. Based on the updated configuration and the constant original length or inner force, the equivalent initial strain or equivalent temperature difference of the cable and strut are re-determined. Therefore, to facilitate convergence without affecting the final analysis result, the dynamic equilibrium iteration only needs to set the displacement convergence criteria $\left[\mathrm{U}_{\mathrm{ei}}\right]$. 
A configuration update iteration only sets the displacement convergence criteria $\left[U_{c i}\right]$. When the maximum displacement of the updated finite element model node $U_{c i} \leq\left[U_{c i}\right]$ occurs, the configuration updated iteration has converged.

(5) Verify the static equilibrium state.

If the time step length $\Delta \mathrm{T}_{\mathrm{s}}$ or the maximum number of time steps $\left[\mathrm{N}_{\mathrm{ts}}\right]$ are too small, then the dynamic analysis displacement could be too small, i.e., although the convergence criteria of the updated iteration are satisfied, static equilibrium is not achieved. To avoid "false" balance, the static equilibrium state of the updated configuration that satisfies the convergence conditions must be examined. When nonlinear static finite element analysis is used, the solve should converge easily, and the small displacement should satisfy the required precision.

\subsection{Beneficial Effects}

NDFEM form-finding analysis converts the finite element analysis, which is difficult to equilibrate in the static state, into dynamic analysis, which can equilibrate easily. Moreover, through the iterative replacement of the configuration, the cable-strut system converges to static equilibrium, which solves the form-finding problem of the existence of huge displacement and mechanical displacement in the cable-strut system. The configuration of the structural design and formation state can be directly set as the initial configuration without making an assumption of movement trajectory for the cable-strut system or setting an initial displacement for convergence to the balanced position. In addition, it ensures stability and high efficiency.

(1) Due to the introduced virtual inertia force and damping force, nonlinear dynamic finite element analysis converges more easily than nonlinear static finite element analysis does. (2) For a solution obtained from a nonlinear dynamic equilibrium equation that is based on an entire finite element, the total kinetic energy is also accurate. (3) Curve fitting is conducted on the total kinetic energy from three consecutive time steps to determine the peak value of the total kinetic energy and when it occurs. A linear interpolation method is used to determine the displacement at this time point, and to refresh the configuration of the cable-strut system. (4) Time step size of the dynamic analysis is automatically adjusted during the analysis process, which decreases the number of time steps needed and greatly increases analytic efficiency. (5) After iterative convergence of the configuration, nonlinear static analysis is conducted based on the final refreshed finite element model of the cable-strut system to verify the results. (6) The form-finding problem can be solved when either the original length of the cable-strut is known, the inner force of the cable-strut is known, or the partial original length of cable-strut is known while the partial inner force of the cable-strut is known.

\section{AN ENGINEERING APPLICATION}

\subsection{Project Overview}

The roof of the Wuxi New District Science and Technology Exchange Centre is the first cable-dome project on the continent of China. The project involves a circular plane structure with a diameter of $24 \mathrm{~m}$, which is surrounded by a multi-storey reinforced concrete frame. The elevation of the external compressive ring is $16.550 \mathrm{~m}$, the elevation of the ground is $-5.000 \mathrm{~m}$, and the total elevation difference is $21.55 \mathrm{~m}$. We used a Geiger-type cable-strut system consisting three rings and ten frames (Figure 3). A rigid roof was used, and purlins were held on the top of the compressive struts above the inner tensile ring and outer compressive ring. Steel wire cables with a tensile strength of $1670 \mathrm{MPa}$ and with double PE coverings were used, while ridge cables were arranged 
continuously through the cable-clips on the top of compressive struts. Ring cables were also arranged continuously through the cable-clips under several compressive struts.

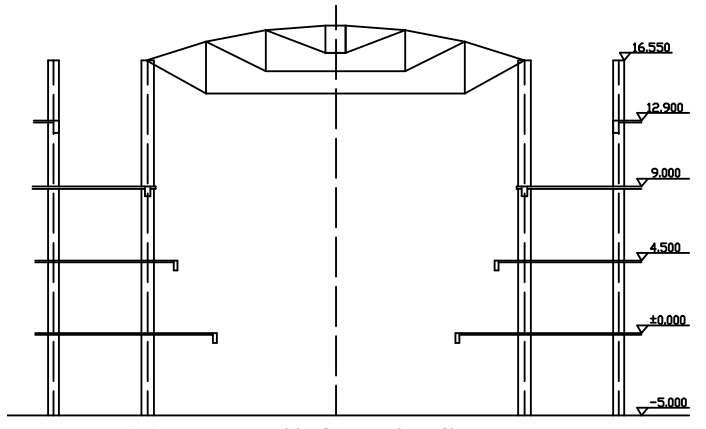

(a) Overall facade figure

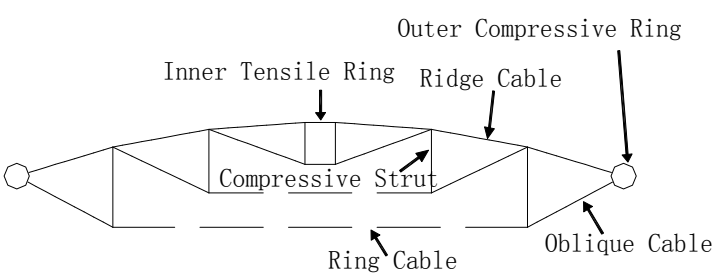

(b) Facade figure of the cable-dome

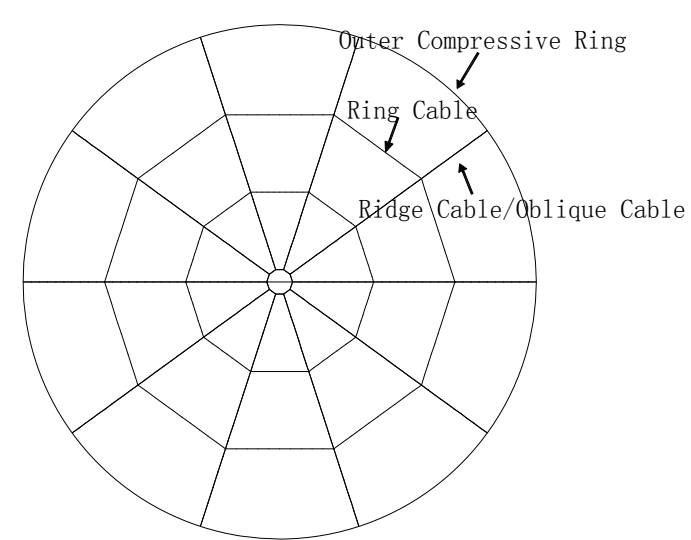

(c) Flat figure of the cable-dome

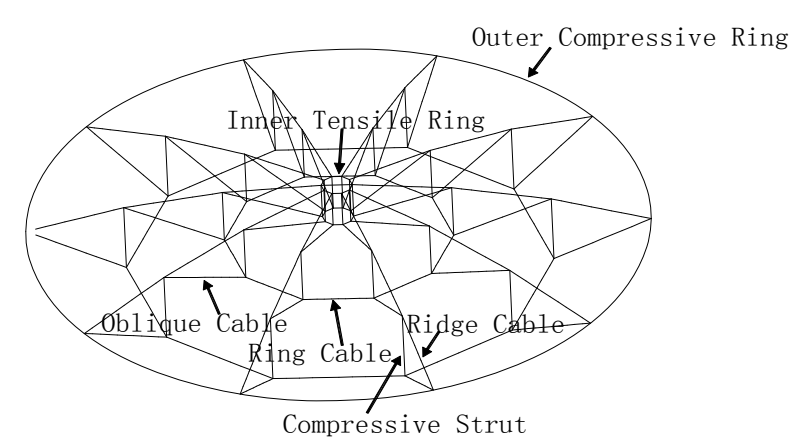

(d) Three-dimensional figure of the cable-dome

Figure 3. The Cable Dome Structure of

Wuxi Science and Technology Exchange Center in China

Based on the "tower-lifting of the cable-dome and the accumulation installation of the cable-struts method" [15], we set the oblique lifting-cable using the surrounding structures as the lifting-tower. We constructed the cable-dome using the method of non-bracket tow-lifting.

\subsection{Non-bracket Tow-lifting Construction Technology for Cable Domes}

The non-bracket tow-lifting cable-dome construction method includes assembling at a low altitude, tow-lifting at a moderate altitude and tensioning to form at a high altitude. The key concept is that the outer compressive ring is firstly installed in the design position. Then the inner tensile ring, the ridge cable nets and middle cable-struts are assembled near the ground. Cables and struts are assembled at a low altitude followed by subsequent lifting and towing. When the inner tensile ring is lifted, the outer ridge cables are towed by tool cables which are connected to the outer compressive ring, until the outer ridge cables are connected with the outer compressive ring. Finally, the outer oblique cables are simultaneously tensioned to form. The specific construction steps are listed below.

\subsubsection{Assemble at low altitude}

(1) Install the outer compressive ring in the design position

(2) In a no-stress condition, assemble the inner tensile ring, the ridge cable net, the central compressive struts, the oblique cables and the ring cables near the ground.

(3) Install lifting tool cables between the outer compressive ring and the inner tensile ring, which is 
supported by the outer compressive ring, and install the towing tool cables between the outer compressive ring and outermost ridge cables (Figure 4 (a)).

(4) Keep the ridge cable nets in a " $\omega$ " shape by lifting cables and towing cables alternately. Install the outer compressive struts, the ring cables and the oblique cables from the inside to the outside at a low altitude. Using the adjustment device in the head of the cable, lengthen the outermost oblique cables appropriately. Install the tensile tool cables between the outermost oblique cables and the ridge cables (Figure 4 (b))

When assembling the cable-struts, except the outermost oblique cables that need to be tensioned actively, the other tensile cables should be assembled at precisely the original length.

\subsubsection{Tow-lifting at a moderate altitude}

(1) The inner tensile ring and the outer ridge cables are lifted and towed alternatively. These cables are supported by the outer compressive ring. During each circular operation, traction should be maintained to ensure that the ridge cable nets maintain the " $\omega "$ shape, where as the compressive struts, ring cables and oblique cables all hang behind the ridge cables to guarantee the stability of the sagging cable-strut system (Figure 4 (c)).

(2) With the rise of the cable-strut system, the angle of the lifting cables should be close to level. Once this is achieved, connect the outermost ridge cables with the outer compressive ring using the towing cables (Figure $4(\mathrm{~d})$ ).

(3) Move the towing cables and lifting cables; now the ridge cable nets support the whole structure while the other cable-struts hang behind them.

\subsubsection{Tension to form at a high altitude}

(1) Tow the tension tool cables of the outermost oblique cables until the adjusted head of the cables is connected with the outer compressive ring (Figure 4 (e)).

(2) Move the tension tool cable and install the tension jack and tools.

(3) Tension the outermost oblique cables simultaneously until the structure is formed (Figure 4 (f)).

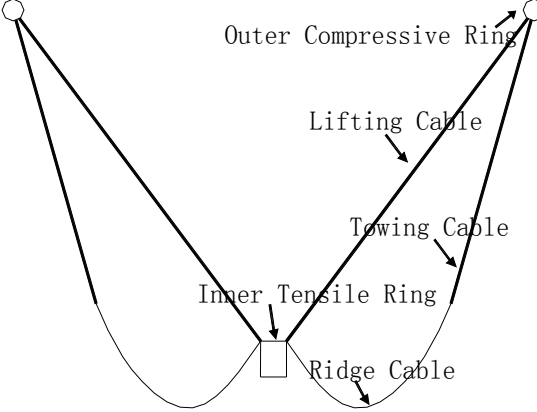

(a) Install the towing tool cables

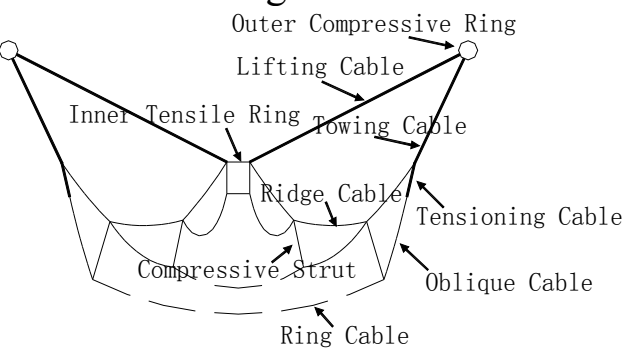

(c) Tow and lift alternatively

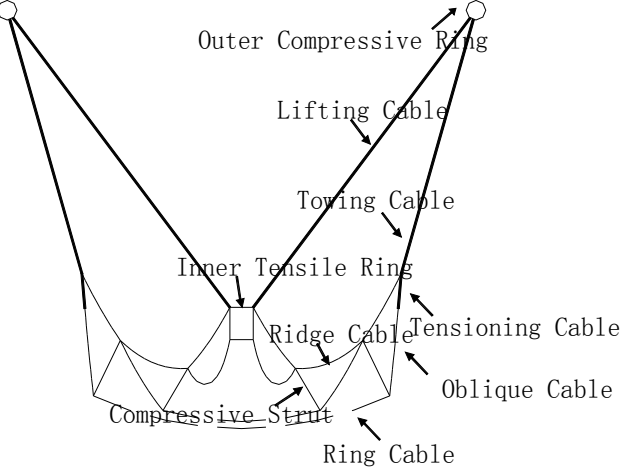

(b) Install the tensile tool cables

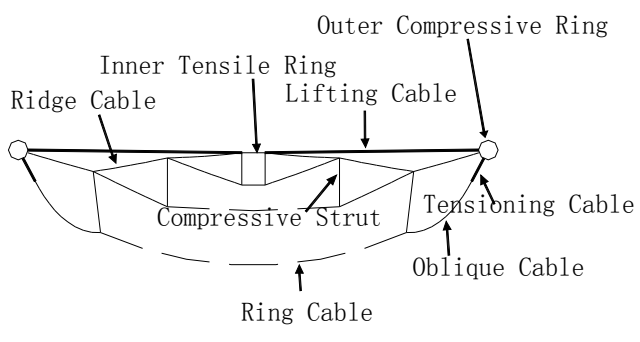

(d) Connect ridge cables with the compressive ring 


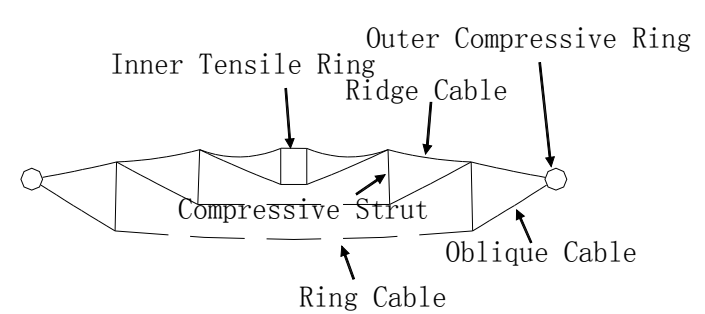

(e) Lengthen the outer oblique cables and connect them with the outer compressive ring

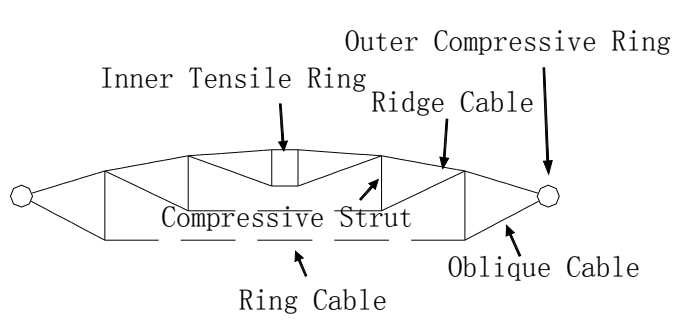

(f) Tension the outer oblique cables and form the structure

Figure 4. Non-bracket Tow-lifting Construction Process for the Cable Dome

The analysis cases are presented in Table 1.

Table 1. Analysis Cases during Lift-towing and Tension Process

\begin{tabular}{|c|c|c|c|c|c|}
\hline \multicolumn{2}{|c|}{ Cases } & $\begin{array}{c}\text { Original } \\
\text { length of } \\
\text { lifting } \\
\text { cables } / \mathrm{mm}\end{array}$ & $\begin{array}{c}\text { Original } \\
\text { length of } \\
\text { towing } \\
\text { cables } / \mathrm{mm}\end{array}$ & $\begin{array}{l}\text { Original } \\
\text { length of } \\
\text { tensioning } \\
\text { cables } / \mathrm{mm}\end{array}$ & $\begin{array}{c}\text { Length-put } \\
\text { of outer } \\
\text { oblique } \\
\text { cables/mm }\end{array}$ \\
\hline \multirow{8}{*}{ Tow-lifting } & 1 & 14000 & 17000 & 2000 & +200 \\
\hline & 2 & 11500 & 15000 & 2000 & +200 \\
\hline & 3 & 9000 & 13500 & 2000 & +200 \\
\hline & 4 & 6500 & 12800 & 2000 & +200 \\
\hline & 5 & 4500 & 12300 & 2000 & +200 \\
\hline & 6 & 2500 & 11800 & 2000 & +200 \\
\hline & 7 & 1000 & 11400 & 2000 & +200 \\
\hline & 8 & 0 & 11400 & 2000 & +200 \\
\hline \multirow{5}{*}{$\begin{array}{c}\text { Tow } \\
\text { tensioning } \\
\text { cables }\end{array}$} & 9 & -— & - - & 1600 & +200 \\
\hline & 10 & -— & -— & 1200 & +200 \\
\hline & 11 & -— & - - & 800 & +200 \\
\hline & 12 & -— & -— & 400 & +200 \\
\hline & 13 & - - & - & 0 & +200 \\
\hline \multirow{6}{*}{$\begin{array}{c}\text { Tension } \\
\text { outer } \\
\text { oblique } \\
\text { cables }\end{array}$} & 14 & - & - - & - & +160 \\
\hline & 15 & -— & -— & -— & +120 \\
\hline & 16 & - - & - - & -— & +80 \\
\hline & 17 & -— & -— & -— & +40 \\
\hline & 18 & - - & - & - - & +20 \\
\hline & 19 & -— & - - & -— & +0 \\
\hline
\end{tabular}

\subsection{Analysis of the Construction Process}

According to the symmetry of the structure, we used 10 sheets of lifting cables, towing cables and tensioning cables in the model, respectively. To reduce the total analysis time, we evaluate the cases from Case 19 to Case 1.After adding the tool cables and adjusting the original length, we set the former model of convergence as the initial model of the next case. For analysis of no damping motion Eq. (5), we set the parameters to: $\left[\mathrm{N}_{\mathrm{ei}}\right]=30,\left[\mathrm{~N}_{\mathrm{ts}}\right]=5, \Delta \mathrm{T}_{\mathrm{s}}(1)=0.1 \mathrm{~s}, \mathrm{C}_{\mathrm{ts}}=1.5,\left[\mathrm{U}_{\mathrm{ci}}\right]=1$ $\mathrm{mm},\left[\mathrm{U}_{\mathrm{ei}}\right]=0.005 \mathrm{~mm}$ and $\left[\mathrm{N}_{\mathrm{ci}}\right]=100$.

After analysis of the construction process, the static equilibrium configurations of the key cases are 
shown in Figure 5. The elevation curves of the key nodes compared by the outer compressive ring are shown in Figure 6. The lifting-cable force and the towing-cable force are shown in Figure 7. The outer ridge cable force and the outer oblique cable force are shown in Figure 8. From these figures, the following observations can be made:

(1) In the tow-lifting stages of Case 1-8, the cable-strut system is hanging, while the ridge cable network is in the " $\omega$ " shape. Other cable-struts are hanging under the ridge cable nets and the configuration is stable.

(2)The lifting force reaches a peak in Case 7. However, Case 8 maintains the original length of the lifting cable in Case 7 and the outer ridge cables are towed by the towing cables to the place where they will be fixed. Thus, the lifting force decreases, and the towing force peaks in Case 8 .

(3) For Case 1 to Case 16, the force in the outer oblique cables and outer ridge cables are comparatively small. In Case 17, the overall shape of the cable-dome initially appears, but by tensioning the outer oblique cables, the force in the outer oblique cables and ridge cables improves quickly until the structure is tensioned to form.

(4) Cases 9 to 16 are in various stages of configuration adjusting. The top of the outer ring and the middle ring compressive struts exceeded the outer compressive ring, so these stages changed from the hanging state to the stiffening state.

(5) The top of the inner tensile ring, the middle compressive struts and the outer compressive struts in Cases 11 and earlier were lower than the outer compressive ring, while in Cases 12 and later, they are higher than the outer compressive ring. Cases 11 and 12 are near the inflection point of the configuration adjustments.

In short, according to the changes to the configurations and the cable force, the configuration of the cable-strut system goes through three stages, including hanging, adjusting and stiffening, which corresponding to three construction stages: lift-towing, beginning tow-adjusting and late tow-adjusting. At the inflection point of the configuration adjustment, the top of the inner tensile ring, the middle compressive struts and the outer compressive struts exceed the plane of the outer compressive ring.

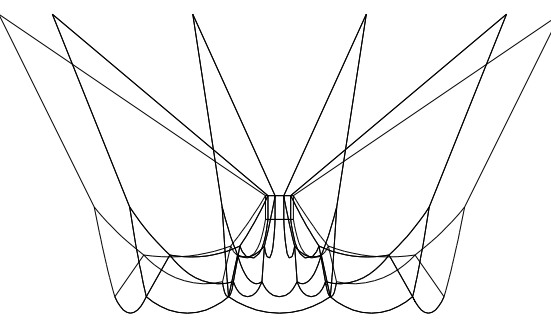

(a) Case 1

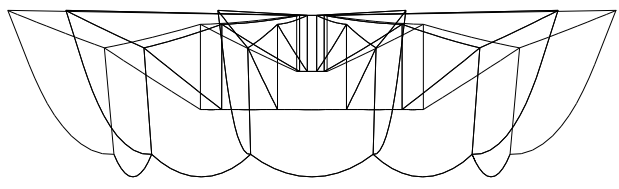

(c) Case 8

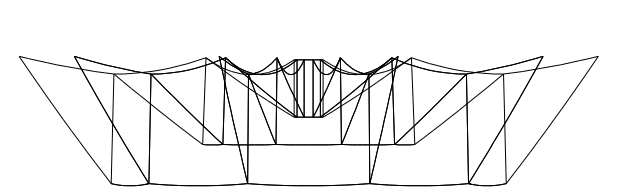

(e) Case 11 (b) Case 5

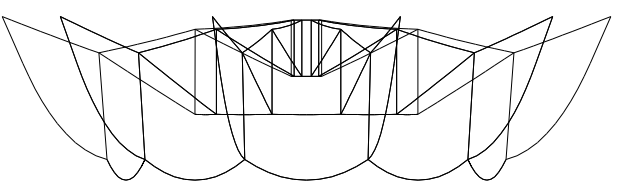

(d) Case 9

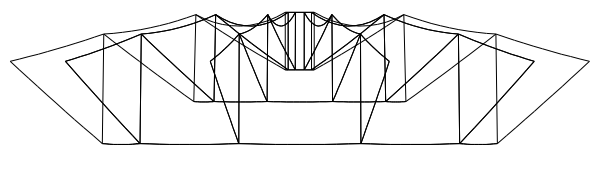

(f) Case 13 


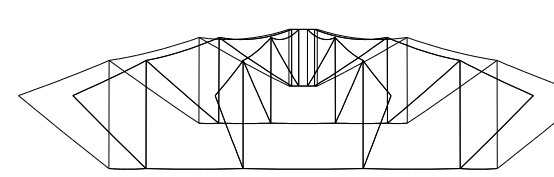

(g) Case 16

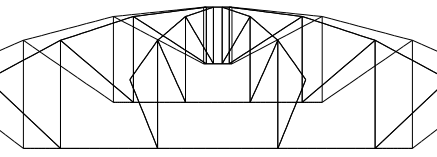

(h) Case 19

Figure 5. The Configurations of Key Cases in Static Equilibrium

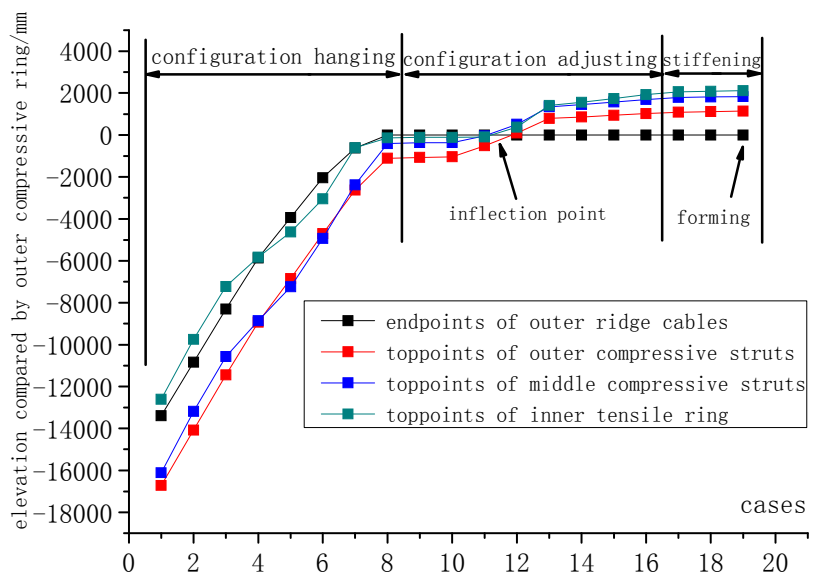

Figure 6. The Altitude Change Curve for Key Nodes during Construction

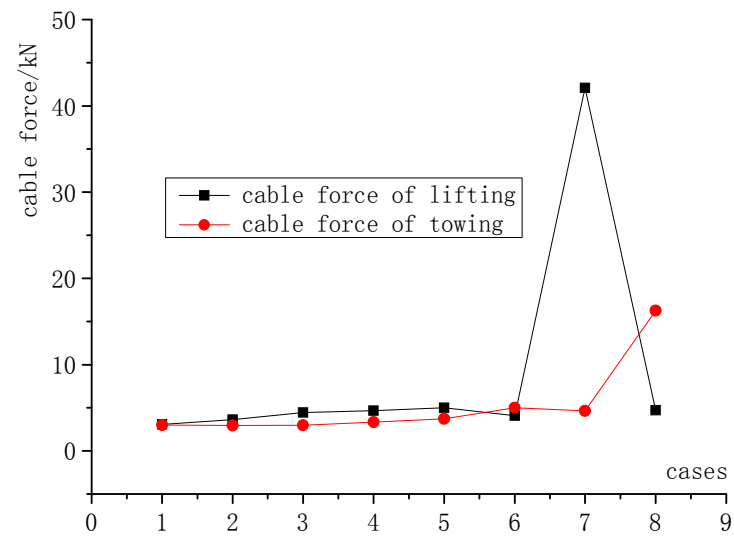

Figure 7. The Force Change Curve for Lifting and Towing during Construction

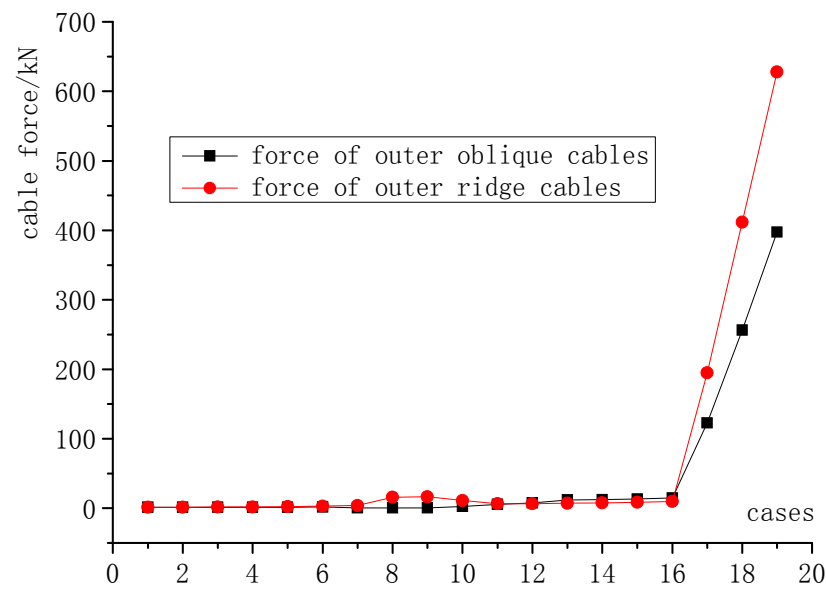

Figure 8. The Force Change Curve of the Outside Ridge Cable and the Oblique Cable during Construction 


\subsection{Stability Analysis}

The stage of configuration adjusting is relatively poor because of cable-strut configuration stability. Therefore, a stability analysis must be performed to prevent a large displacement of the compressive struts out of the plane and to avoid overturning instability. Because of the centre symmetry of the cable-dome, an initial displacement out of the plane should be introduced by making a small disturbing force. In particular, we imposed the small circular concentrated forces, with the same rotations, on the compressive struts nodes. This force application was based on the model of iterative convergence and the solved static equilibrium. If the force is too large, then displacement out of the plane, and even overturning of the compressive struts, can occur because the construction state is unstable. If the system is in static equilibrium after the displacement out of the plane, then it is basically stable. And after removing the disturbing force, if the struts can be restored to that state before the disturbance, then it is stable. In the analyses of the disturbing stability of Cases 9-16, the disturbing force was set to $1 \mathrm{kN}$, and the analysis results are shown in Table 2. The following observations can be made from Table 3:

(1) Except Cases 11 and 12, the lateral displacement of the compressive struts in the other analyses can be restored to stable conditions after removing the disturbing force. And Cases 11 and 12 are near the inflection points.

(2) According to Figures 9 and 10, in Cases 11 and 12, the outer compressive struts can be restored in the vertical plane after removing the disturbing force, while the middle compressive struts can be stable after the lateral displacement.

(3) For Cases 10 to 14, the displacement under disturbing force is comparatively large and it is hard to solve the problem under the disturbing force by the conventional non-linear static finite element method. However, the non-linear dynamic finite element method mentioned above was used to verify the stability.

(4) For cable-domes with a high-span ratio, the ridge cables are longer and at the inflection point of configuration adjustment, these ridge cables are slacker. Therefore, the stability of the configuration near the inflection point should be given more attention.

Table 2. Stability Analysis under Disturbing-force Application and Removal

\begin{tabular}{c|c|c|c|c}
\hline \multirow{2}{*}{ Cases } & $\begin{array}{c}\text { Non-linear } \\
\text { finite } \\
\text { element } \\
\text { method }\end{array}$ & $\begin{array}{c}\text { The maximum relative displacement } \\
\text { out of the plane of the top and end of } \\
\text { the compressive struts } / \mathrm{mm}\end{array}$ & \multirow{2}{*}{ Stability } \\
\cline { 3 - 4 } & $\begin{array}{c}\text { Under disturbing } \\
\text { force }\end{array}$ & $\begin{array}{c}\text { Removing } \\
\text { disturbing force }\end{array}$ & \\
\hline 9 & static & 525 & 0 & stable \\
\hline 10 & dynamic & 590 & 0 & stable \\
\hline 11 & dynamic & 990 & 766 & basically stable \\
\hline 12 & dynamic & 1249 & 1043 & basically stable \\
\hline 13 & dynamic & 1049 & 0 & stable \\
\hline 14 & dynamic & 928 & 0 & stable \\
\hline 15 & static & 761 & 0 & stable \\
\hline 16 & static & 485 & 0 & stable \\
\hline
\end{tabular}




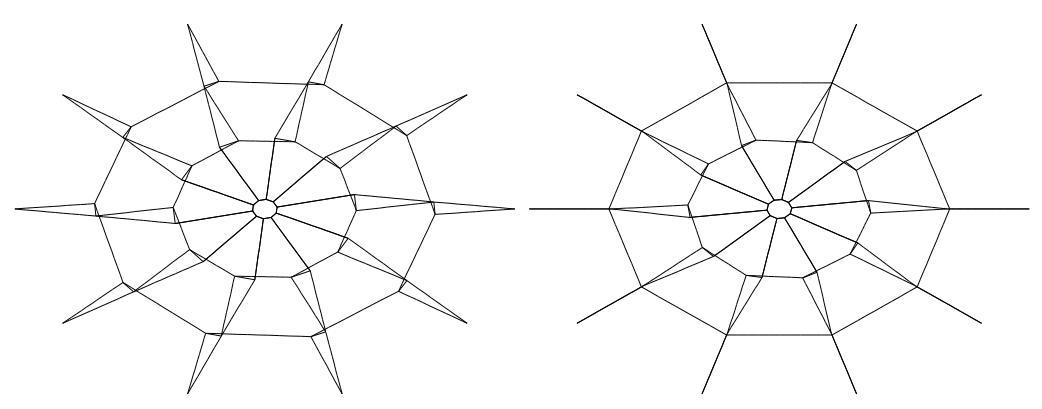

(a) under disturbing force

(b) removing disturbing force

Figure 9. The Configurations in the Static Equilibrium State for Case 11 under Ddisturbing-force Application and Removal

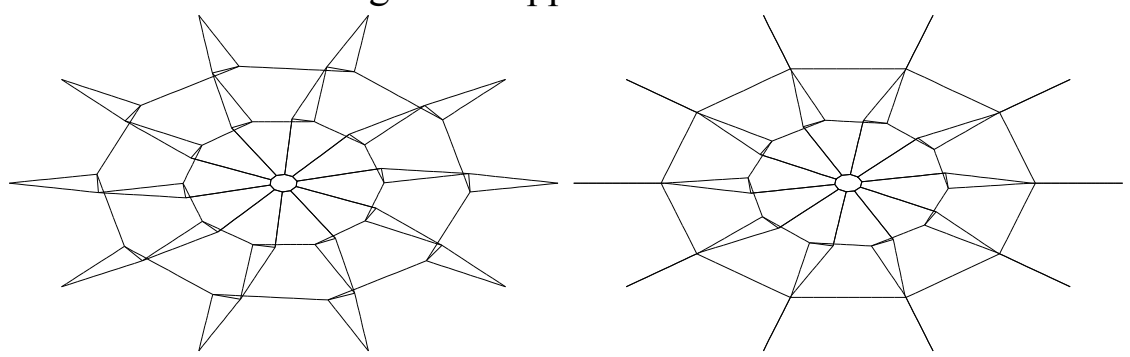

(a) under disturbing force

(b) removing disturbing force

Figure 10. The Configurations in the Static Equilibrium State for Case 12 under Disturbing-force Application and Removal

\subsection{Effects of Engineering Applications}

Regarding the requirements of configuration checking, as a general checking project, there are four provisions: (1) $80 \%$ of the outer compressive struts should meet the vertical deviation limit of $1 / 200$ (i.e. $16 \mathrm{~mm}$ ); (2) $80 \%$ of the middle compressive struts should meet the vertical deviation limit of $1 / 180$ (i.e. $14 \mathrm{~mm}$ ); (3) the maximum vertical deviation of the struts should be smaller than $1 / 150$; and (4) the allowed deviation of the central elevation was $1 / 500$ (i.e. $48 \mathrm{~mm}$ ).

On December 29, 2009, the cable-dome in Wuxi Science and Technology Exchange Center was tensioned to form. Only one outer strut exceeds the 1/200 limit and one middle strut exceeds 1/150, so provision (1) and provision (2) were met. The measured maximum vertical deviation of the outer compressive struts was $20 \mathrm{~mm}$ (i.e. 1 / 158), and the maximum vertical deviation of the middle compressive struts was $15 \mathrm{~mm}$ (i.e. 1/167), so provision (3) was met. The maximum value of the relative elevation of the top of the inner tensile ring and the outer compressive ring was $11 \mathrm{~mm}$ (i.e. $1 / 2180$ ), so provision (4) was met. In short, the quality of the tensioning to form was acceptable.

\section{CONCLUTION}

NDFEM form-finding analysis is based on the nonlinear dynamic finite element method and performs continuous time step dynamic analysis by introducing virtual inertia and a viscous damping force. When the total kinetic energy reaches its peak value, the finite element model is updated; through iteration, the dynamic equilibrium state of the cable-strut system gradually converges to the static equilibrium state. This method can solve form-finding problems when the original length of cables and struts are known, or the internal force of cables and struts are known, or the original length of part of cables and struts are known, while the internal force of part of cables and struts are known. 
(1) The logic and specific steps of the NDFEM form-finding analysis is proposed.

(2) To improve the analysis efficiency, stability and accuracy, key technical measures regarding the time step length, total kinetic energy peak value, model update, convergence criteria and static equilibrium testing are proposed.

(3) For a real domestic cable-dome project, we carried out an analysis of the tow-lifting and tensioning process. The configuration of the cable-strut system should go through three stages, including hanging, adjusting and stiffening, corresponding to the three construction stages of lift-towing, beginning tow-adjusting and late tow-adjusting; The " $\omega$ " shape is important and should be maintained to ensure that the low-stress hanging configuration of the cable-strut system is stable when tow-lifting the structure; The inflection point occurs in the adjusted stage of configuration, and the stability of the configuration at the inflection point is the worst. At this point, the compressive struts will be stable after certain lateral displacement out of the plane; for cable-domes with a high-span ratio, the stability of the configuration near the inflection point should be given more attention.

\section{ACKNOWLEDGEMENT}

This work was supported by The Twelfth Five Year National Science and Technology Support Program under Grant 2012BAJ03B06, a Project Funded by the Priority Academic Program Development of Jiangsu Higher Education Institutions (PAPD), the National Natural Science Foundation of China (Grant No.51308105) and the Fundamental Research Funds for the Southeast University (KYLX_0152,SJLX_0084).

\section{REFERENCES}

[1] Jayaraman, H.B., et al, "A curved element for the Analysis of Cable Structures", Computers \& Structures, 1981, Vol. 14, pp. 3-4, pp. 325-333.

[2] Shen, Z.Y. and Zhang, L.X., "Simulation of Erection Procedures of Cable Domes based on Nonlinear FEM", Chinese Journal of Computational Mechanics, 2002, Vol. 19, No. 4, pp. 414-419 (in Chinese).

[3] Pellegrino, S. and Calladine, C.R., "Matrix Analysis of Statically and Kinematically Indeterminate Frameworks", Int. J. Solids Struct., 1986, Vol. 22, pp. 409-428.

[4] Lu, J.Y., Li, N. and Luo, Y.Z., "Kinematic Analysis of Planar Deployable Structures with Angulated Beams based on Equilibrium Matrix", Advances in Structural Engineering, 2011, Vol. 14, No. 6, pp. 1005-1015.

[5] Luo, Y.Z. and Dong, S.L., "Nonlinear Force Method Analysis for Space Truss with Mobile Mechanisms", Chinese Journal of Solid Mechanics, 2002, Vol. 23, No. 3, pp. 288-294 (in Chinese).

[6] Lu, J.Y., Luo, Y.Z. and Li, N., "An Incremental Algorithm to Trace the Non-linear Equilibrium Paths of Pin-jointed Structures using the Singular Value Decomposition of the Equilibrium Matrix", Proc. IMechE Part G: J. Aerospace Engineering, 2009, Vol. 223, pp. 881-890.

[7] Barnes, M.R., "Form and Stress Engineering of Tension Structures", J. Structure Engineering Review, 1994, Vol. 6, No. 3-4, pp. 175-202.

[8] Lewis, W.J. and Lewis, T.S., "Application of Formian and Dynamic Relaxation to the Form Finding of Minimal Surfaces”, IASS Journal, 1996, Vol. 37, No. 3, pp. 165-186.

[9] Barnes, M.R., "Form Finding and Analysis of Tension Structures by Dynamic Relaxation", Int. J. Space Structures, 1999, Vol. 14, No. 2, pp. 89-104. 
[10] Lewis, W.J. and Jones, M.S., "Dynamic Relaxation Analysis of the Non-linear Static Response of Pretensioned Cable Roofs", Computers \& Structures, 1984, Vol. 18, No. 6, pp. 987-997.

[11] Oakley, D.R. and Knight, N.F, "Non-linear Structural Response using Adaptive Dynamic Relaxation on a Massively Parallel-processing System", Int. J. Num. Meth. Engrg., 1996, Vol. 39, pp. 235-259.

[12] Oakley, D.R. and Knight, N.F, “Adaptive Dynamic Relaxation Algorithm for Non-linear Hyperelastic Structures, Part I. Formulation”, Comput. Methods Appl. Mech. and Engrg., 1995, Vol. 126, pp. 67-89.

[13] $\mathrm{Wu}, \mathrm{X} . \mathrm{S}$. and Deng, H., "Form Finding of Slack Cable-bar Assembly by Dynamic Relaxation Method", Chinese Journal of Computational Mechanics, 2008, Vol. 25, No. 2, pp. 229-236 (in Chinese).

[14] Luo, B., "Nonlinear Dynamic FEM for Finding Static Equilibrium State of Cable-strut System”, China, ZL200910032743.6 [P]. 2009 (in Chinese).

[15] Guo, Z.X., Zong, Z.L., Luo, B. and Wang, Y.Q., "Cable Dome Construction Method of Tower Lifting and Cable-strut Accumulative Assemble" China, ZL200810234362.1 [P]. 2008 (in Chinese). 


\title{
RESEARCH ON THE MEMBRANE ACTION OF PROFILED STEEL SHEET-CONCRETE COMPOSITE FLOORS IN FIRE
}

\author{
Shenggang Fan ${ }^{1, *}$, Wenjun Sun ${ }^{1}$, Hongzhao Wei ${ }^{1}$ and Meijing Liu ${ }^{2}$ \\ ${ }^{1}$ Key Laboratory of Conrete and Prestressed Concrete Structure of Ministry of Education, School of civil \\ engineering, Southeast University, Nanjing, 210096, China \\ ${ }^{2}$ Department of civil engineering, Southeast University Chengxian College, Nanjing, 210088, China \\ *(Corresponding author: E-mail:101010393@seu.edu.cn)
}

\begin{abstract}
Based on the ISO-834 standard fire curve, fire tests on 2 full-scale profiled steel sheet-concrete composite floors were conducted. The behavior and crack developing process of a composite floor in fire was studied. The change laws of the temperature field distribution and the deflection were given. The failure mode and formation mechanism of the membrane action for the profiled steel sheet-concrete composite floors in fire were revealed. Using the finite element software ABAQUS, the numerical simulation and parametric analysis were performed to research the factors that influence on the membrane action of a composite floor in fire. The results show that the length-to-width ratio, the reinforcement strength and the reinforcement ratio are the main influential factors on the membrane action of a composite floor. The length-to-width ratio less than 2.0 is recommended to make full use of the membrane action of a composite floor. Improving the reinforcement strength and reinforcement ratio can contribute to the bearing capacity of the composite floor with the membrane action considered. Finally, the production condition and judging criteria of the membrane action in a composite floor under fire were also proposed.
\end{abstract}

Keywords: Composite floor; Membrane action; Fire; Temperature field; Bearing capacity

DOI: $10.18057 /$ IJASC.2015.11.4.5

\section{INTRODUCTION}

Though the design and analysis method of a building structure in room temperature is well-known, frequent fires have made the safety of building structures an unprecedented challenge. The essential behavior of a structure in fire is that the rise of temperature increase and heat transfer result in the decay of material performance. Parts of the members are damaged and cannot support the structure any more, and the balance of the structure system is broken, with internal force redistribution. As the fire spreads from the center, the damage range of structure extends continuously. As a result, the main structure may lose its bearing capacity or collapse in a wide range. Serious casualties, economic loss and bad social influence often result from the fire of a building structure. Consequently, the response and performance of a structure in fire have attracted great attention all over the world and have gradually become a research hotspot in the field of structure fire resistance.

Many studies show that the calculation theories and design methods of profiled steel sheet-concrete composite floors at room temperature are becoming perfect, whereas the calculation theory in fire is incomplete. Especially, the calculation theory and design method of composite floors, which the membrane action is considered, are not common. With the increment of temperature in fire, a large deflection leads to a membrane action in composite floors, and the ultimate bearing capacity of composite floor in fire as calculated by the plastic hinged lines theory is always relatively low. Thus, the membrane action of a composite floor could be considered in fire-resistant design, it will be of great significance for improving the fire resistance performance of the structure. 
There are some relevant studies on the fire resistance and the membrane action of profiled steel sheet-concrete composite floors. Chen et al. [1] performed a fire test on 5 pieces of different composite floors, and the behavior of composite floors with the change of temperature was studied. Li et al. [2] worked out the temperature field of composite floors in fire on the basis of heat transfer theory by developing a computer program and using the finite difference method. The relevant parametric analysis was conducted to derive the simplified calculation formula for the temperature field of a composite floor in fire. Lim et al. [3] performed a fire test on 6 slabs simply supported on 4 sides under a standard fire curve and investigated a variety of parameters that influence on the bearing capacity of slab in fire. A numerical simulation is conducted by the FE software SAFIR, and the result has been proven to be reliable by comparing the simulation results with test data. Bailey et al. [4] performed an ultimate strength test on 15 small-size slabs at room temperature. Based on the yield line theory and the principle of mechanical balance, the membrane action theory was verified and the simplified calculation formula of ultimate bearing capacity was also derived. Chen et al. [5] conducted a fire test on 3 simply supported and 4 continuous slabs subjected to the constant load. A simplified calculation method of the support reaction for a continuous slab during the rise of temperature period was proposed, and it proved to be reliable by comparing test data with the calculation results. Li et al. [6-9] performed the experimental research on 4 full-scale profiled steel sheet-concrete composite floors in fire. The membrane action of the slabs in the fire was verified. Using the numerical simulation analysis, the formula of ultimate bearing capacity and the design method of the composite floor, which the membrane action was considered, were proposed. Based on the result of Cardington fire test, Usmani et al. [10-12] used the energy method to derive the formula for ultimate bearing capacity of the composite floor by solving the equilibrium equation and the deformation compatibility equation, combining the existing research result.

Based on an ISO-834 standard fire curve, a fire test on 2 full-scale profiled steel sheet-concrete composite floors was conducted in this paper. The behavior and crack development process of the composite floors in fire were studied. The temperature field distribution in the composite floors was given. The failure mode and the mechanism of the membrane action of a composite floor in fire were revealed. Using the finite element software ABAQUS, a numerical simulation analysis and parametric analysis were conducted to research the temperature field and behavior of a composite floor in fire. The simulation results were proved to be reliable by comparing with the test data. The length-to-width ratio, thickness, concrete strength, reinforcement strength, reinforcement ratio of slab and thickness of concrete cover were investigated and analyzed to study the influence on membrane action of a composite floor in fire. The research results show that the length-to-width ratio, reinforcement strength and reinforcement ratio were the main influential factor. A larger length-to-width ratio, thickness, concrete strength of slab and thickness of concrete cover will not obviously help to develop the membrane action of composite floors. Finally, the production condition and judging criteria of composite floors in fire were also proposed.

\section{FORMATION MECHANISM OF MEMBRANE ACTION IN THE COMPOSITE FLOOR UNDER FIRE}

According to the existing results of full-scale fire test on the steel frame and fire cases in the practical engineering, the composite floors will not collapse overall when an external load is close to the ultimate bearing capacity in fire. With the increment of temperature in fire, the cracks in the composite floors were continuously developed and the stiffness of slab was gradually decayed. The larger deformation in the composite floor was generated, which causes the membrane action of a composite floor to appear. The membrane action of a composite floor in fire has been proven in the British Cardington fire test and the Taiwan Eastern Science Park fire case. 


\subsection{Conditions of Membrane Action in the Composite Floor}

According to the calculation theory of membrane action at room temperature proposed by Bailey et al. [13-14], the failure mode and membrane action of a composite floor are closely related to the constraint conditions of the slabs.

When the composite floor was subjected to vertical uniform loads and supported on frame beams, as shown in Figure 1(a), the failure mode of a composite floor depends on the ultimate bearing capacity of the supporting beams and slabs. There are two failure modes. Mode 1 suggests that if the ultimate bearing capacity of a composite floor is larger than the supporting beam, a plastic hinge will first appear in the middle of the supporting beam. With the increment of load, a yield line appears at the middle of the composite floor. The slab fails in a fold line mode. The membrane action will not be generated in this failure mode, as shown in Figure 1(b). Mode 2 suggests that if the ultimate bearing capacity of a composite floor is smaller than the supporting beam, the yield line will first appear inside the floor area. With the increment of load, the yield line will be continually increased. When the supporting beams around the slab have a large stiffness and strong constrain ability, the membrane action will be generated in the composite floor, as shown in Figure $1(\mathrm{c})$.

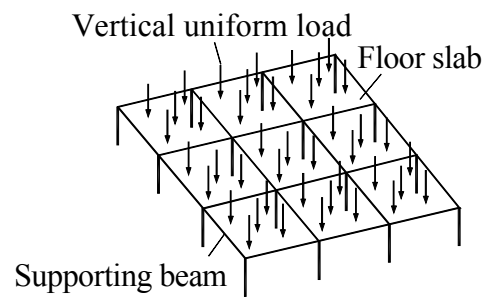

(a) Vertical Load on Floor Slab

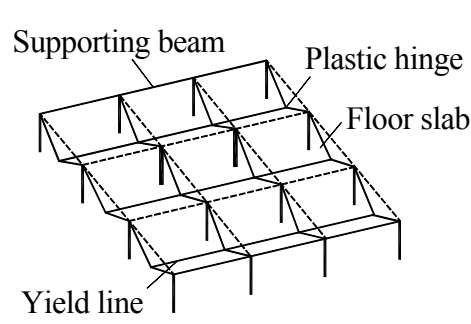

(b) Failure Mode 1

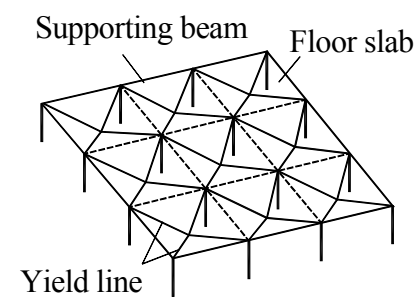

(c) Failure Mode 2

Figure 1. Failure Mode of Composite Floor

\subsection{Mechanism of Membrane Action in the Composite Floor under Fire}

The mechanism of the membrane action in the slab under fire is as follows [6, 8]. (1) At the initial stage of the fire, temperature has little influence on the mechanical property of concrete and steel. Compressive stress appears inside the slab because of the thermal expansion result from a high temperature, so the vertical bearing capacity can be improved. (2) As the temperature is increased, the stiffness of slab is decreased, and the material mechanical is property degraded. The concrete at the middle of the bottom slab is cracked, and part of yield line is generated, as shown in Figure 2(a). (3) With the increment of temperature, the yield line is gradually formed with the development of concrete cracks, as shown in Figure 2(b). The failure mechanism is not form until the yield line is appeared as shown in Figure 2(c). However, the floor is not collapse, so the vertical loads can still be subjected. (4) As the temperature gradually rises, the deflection of slab is continually increased, and the compression reinforcement at the top of the floor slab begins to transform to tensile reinforcement. The floor slab membrane action is gradually formed, with cracks appeared in the corner on the top surface of the slab, as shown in Figure 2(d). (5) With the increment of temperature, the membrane action is enhanced, and deflection at the middle of the slab is magnified. The cracks in the corner on the top surface of the slab is increased, and a yield line is appeared on the edge of slab (approximate ellipsoidal), as shown in Figure 2(e). (6) As the development of cracks, the yield line is more and more obvious. Most of the concrete in the ellipsoidal area is cracked, and the vertical loads are mainly subjected by the tensile reinforcement. The floor will be reached the ultimate state, as shown in Figure 2(f). 


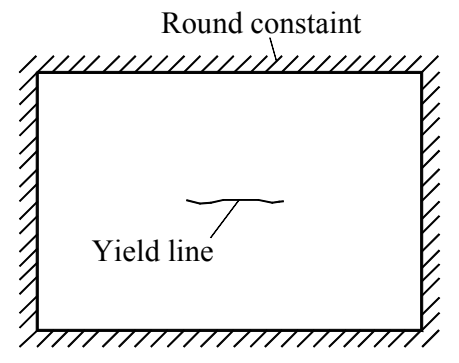

(a) Begin to Yield

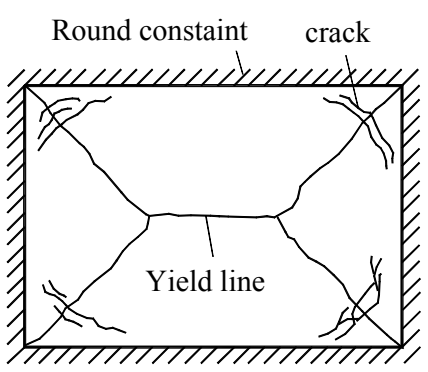

(d) Formation of Membrane Action

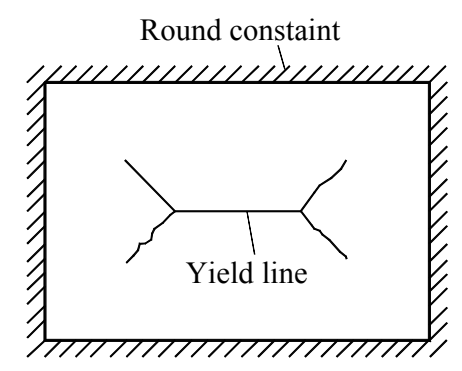

(b) Development of Yield Line

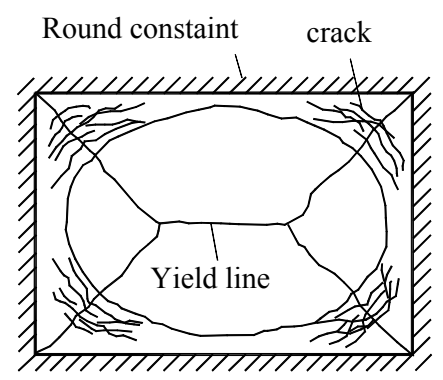

(e) Development

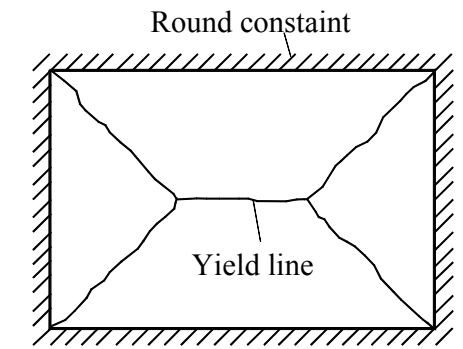

(c) Failure mechanism

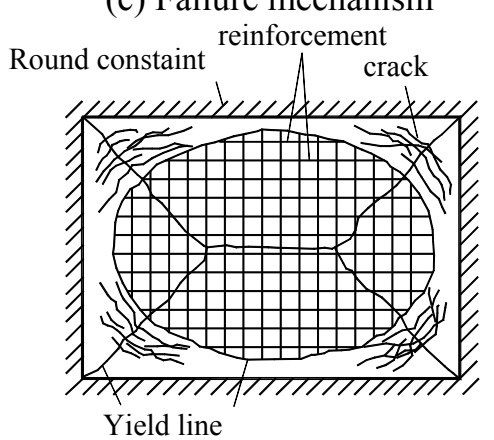

(f) Ultimate State

Figure 2. Membrane Action of a composite floor in Fire

\section{FIRE TEST OF A COMPOSITE FLOOR}

\subsection{Test Specimens}

Based on an ISO-834 standard fire curve, a fire test on 2 full-scale profiled steel sheet-concrete composite floors was conducted. The size of the composite floors was $3.0 \mathrm{~m} \times 1.86 \mathrm{~m}$ (length $\times$ width), and the thickness was $130 \mathrm{~mm}$. The YX51-253-760 profiled steel sheet was adopted, which was $1 \mathrm{~mm}$ thick, and the yield strength of steel was $235 \mathrm{~N} / \mathrm{mm}^{2}$. The concrete strength was 11.9 $\mathrm{N} / \mathrm{mm}^{2}$. Reinforcements were not laid at the bottom of the composite floor, and double two-way reinforcements were laid on the top of the slabs. The diameter of reinforcements was $8 \mathrm{~mm}$ and the distance was $150 \mathrm{~mm}$. The strength of reinforcements was $310 \mathrm{~N} / \mathrm{mm}^{2}$. The thickness of the concrete cover was $25 \mathrm{~mm}$. The load ratios (the ratio of the test load and ultimate load at room temperature) of the two composite floors were 0.6 and 0.75 in the test. A detailed size and grouping of the test specimens is shown in Table 1.

According to Bailey's theory [15], the premise of membrane action in fire is the strong constraint conditions of supporting beams around the slabs. After analyzing a variety of supporting beam solutions (such as a steel beam and a concrete beam), the reinforced concrete beam with larger stiffness was arranged around the composite floor. Therefore, the displacement in the horizontal direction of the slab can be constrained under a fire. Based on ABAQUS, the section size was determined by the repeated calculation of the supporting beams. The section sizes of supporting beams were $400 \mathrm{~mm} \times 350 \mathrm{~mm}$ on the short span and $500 \mathrm{~mm} \times 350 \mathrm{~mm}$ on the long span. The detailed sizes of test specimens and the surrounding supporting beams are shown in Figure 3. 
Table 1. Details Sizes and grouping of Test Specimens

\begin{tabular}{|l|l|l|l|l|l|l|}
\hline $\begin{array}{l}\text { Specim } \\
\text { en }\end{array}$ & $\begin{array}{l}\text { Size(length } \times \\
\text { width) } \\
/ \mathrm{m}\end{array}$ & $\begin{array}{l}\text { Thickness } \\
/ \mathrm{mm}\end{array}$ & $\begin{array}{l}\text { Concrete thickness } \\
\text { on the top of slab } \\
/ \mathrm{mm}\end{array}$ & $\begin{array}{l}\text { Reinforcement } \\
\text { distribution on } \\
\text { the top of slab }\end{array}$ & $\begin{array}{l}\text { Cover } \\
\text { thickness } \\
/ \mathrm{mm}\end{array}$ & Load ratio \\
\hline TB-1 & $3.0 \times 1.86$ & 130 & 79 & $\varphi 8 @ 150$ & 25 & 0.60 \\
\hline TB-2 & $3.0 \times 1.86$ & 130 & 79 & $\varphi 8 @ 150$ & 25 & 0.75 \\
\hline
\end{tabular}
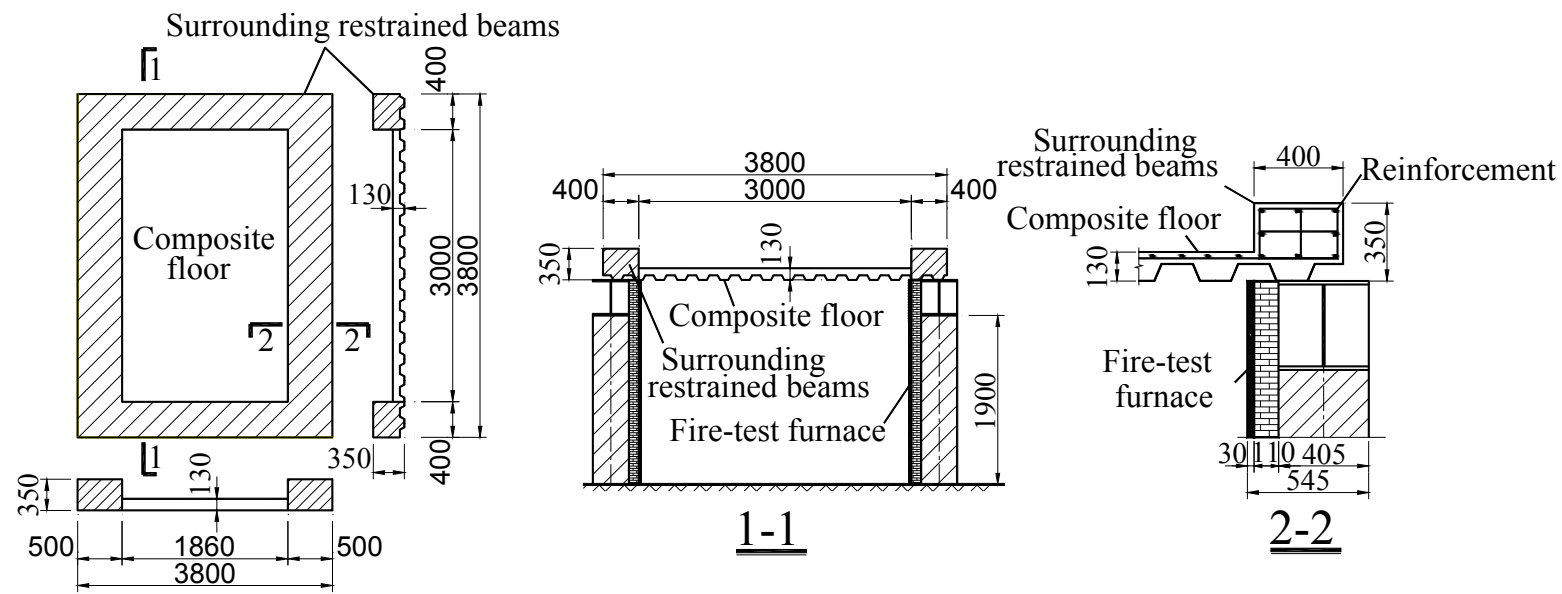

Figure 3. Detail Sizes of Test Specimen and Supporting Beams

To avoid local compression failure at the loading point by a concentrated load, steel plates of 200 $\mathrm{mm} \times 200 \mathrm{~mm} \times 10 \mathrm{~mm}$ were arranged at the loading point on the composite floor, as shown in Figure 4(a). Considering the rotation in the process of slab deformation, a semi-steel ball was in contact with the composite floor, which was placed at the loading end, as shown in Figure 4(b).

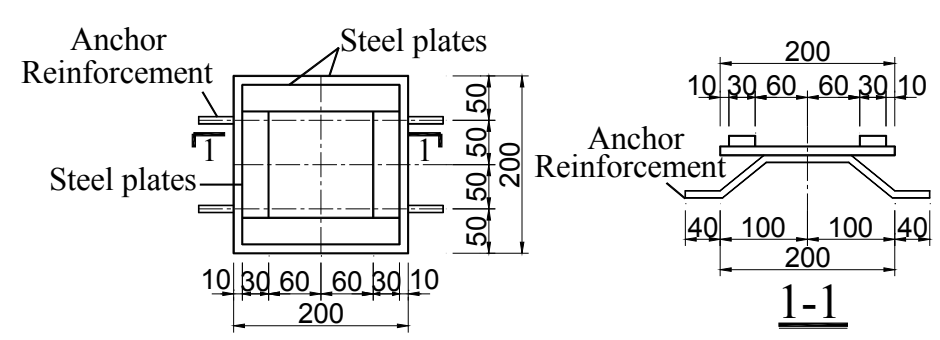

(a) Steel Plate
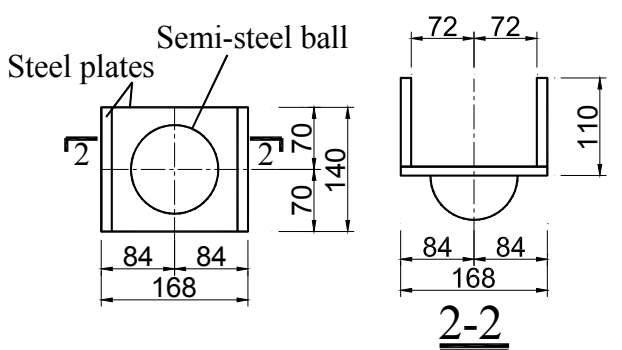

(b) Semi-steel Ball

Figures 4. Size of Steel Plate and Semi-steel Ball at Loading Point

The form work manufacture, reinforcement construction and concrete pouring of the composite floor were completed in the laboratory. The curing time of the concrete was 28 days. The manufacturing process of the test specimens is shown in Figure 5.

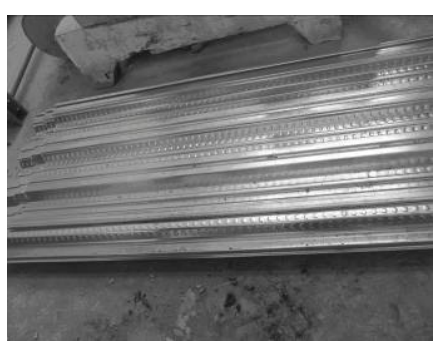

(a) Profile Steel Sheet

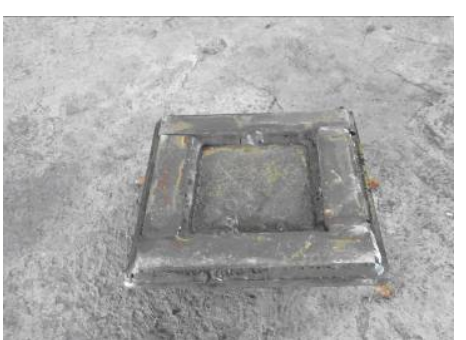

(b) Steel Plate

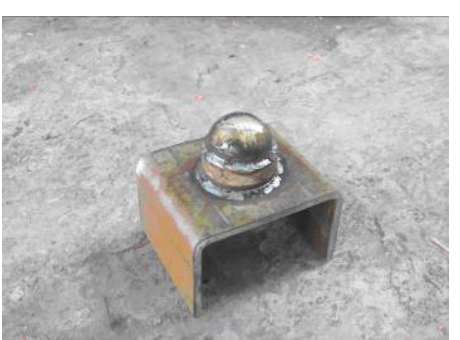

(c) Semi-steel Ball 


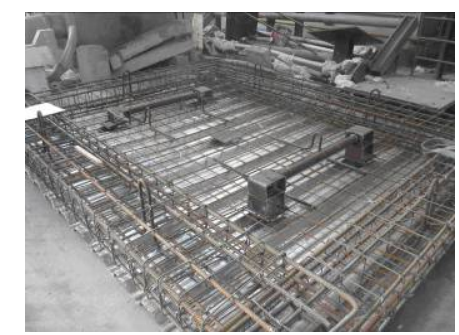

(d) Reinforcement Construction

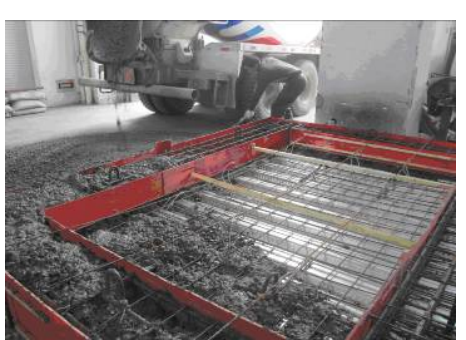

(e) Concrete Pouring

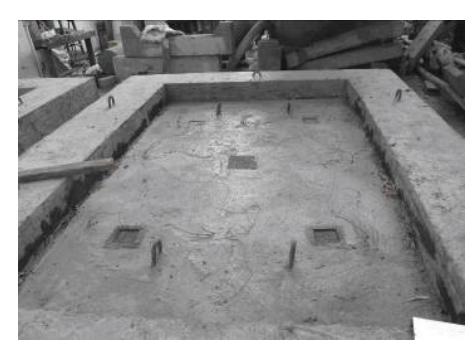

(f) Specimen

Figure 5. Manufacture Process of test Specimens

\subsection{Test Method}

The transient method was adopted in the fire test of composite floor in which a specific load was applied on the slab at room temperature, followed by the temperature rising. The failure phenomenon and membrane action of a composite floor in fire could be investigated. In a conventional fire test of the bearing capacity of slab, the test is completed when the deflection of the slab in fire is more than $\mathrm{L} / 20$ (L represents the short span of the slab). However, this criterion is not applicable for the fire test on the membrane action of a composite floor, due to the membrane action generated only in the condition of large deflection. The following two conditions were adopted as the end criterions of fire test on the membrane action: (1) fire-resistant time of a composite floor (about $90 \mathrm{~min}$ ) and (2) overall collapse of a composite floor.

According to the existing results of fire test, the value of load ratio was selected from 0.3 to 0.7 in a transient fire test of a composite floor. To study the membrane action of a composite floor in fire, a larger load ratio is needed. The load ratios of specimen TB-1 and TB-2 are selected respectively 0.6 and 0.75 . The ultimate load of the two composite floors is $64.47 \mathrm{~N} / \mathrm{mm}^{2}$, based on the calculation theory of bearing capacity at room temperature. The test loads of TB-1 and TB-2 are $38.68 \mathrm{~N} / \mathrm{mm}^{2}$ and $48.35 \mathrm{~N} / \mathrm{mm}^{2}$, respectively, in accordance with the load ratio.

The point loading method was adopted in the fire test of composite floor, where the vertical uniform load was equivalent to 5 concentrated loads. The slab was divided into 5 areas, as shown in Figure 6(a). Each loading point was located at the centroid of the corresponding bearing area. The concentrate load was applied by a distributive girder and a separate hydraulic jack between point 1 (point3) and points 2 (point4), and applied directly by a separate hydraulic jack at loading point 5 , as shown in Figure 6(b). The loading device is shown in Figure 6(c). To avoid the overturn of the distributive girder in the side direction, two steel bracings were set between point 1 (point3) and point2 (point4). In the process of test load, 3 jacks should be worked at the same time to ensure the synchronism of each loading point. The test load value of each loading point can be worked out, as shown in Table 2. A constant amplitude loading was adopted in the fire test, and the load value of each level is shown in Table 2.

The temperature of test furnace was increased according to the ISO834 curve, as shown in Formula (1). The duration time of fire is $90 \mathrm{~min}$.

$$
T(t)-T_{0}=345 \log _{10}(8 t+1)
$$

Where, $T(\mathrm{t})$ represents the air temperature of test furnace when time $t ; T_{0}\left({ }^{\circ} \mathrm{C}\right)$ refers to the room temperature, which is usually $20^{\circ} \mathrm{C}$; and $\mathrm{t}$ represents the time of the fire. 
Table 2. Test Load and Loading Levels of Specimens

\begin{tabular}{|c|c|c|c|c|c|c|c|c|}
\hline \multirow[b]{2}{*}{ Specimen } & \multirow{2}{*}{$\begin{array}{c}\text { Loading } \\
\text { point }\end{array}$} & \multicolumn{2}{|c|}{ Test load / kN } & \multicolumn{5}{|c|}{ Loading level / kN } \\
\hline & & $\begin{array}{c}\text { Loading } \\
\text { point }\end{array}$ & Jack & Level 1 & Level 2 & Level 3 & Level 4 & Level 5 \\
\hline \multirow{2}{*}{ TB-1 } & $1 \sim 4$ & 100 & 200 & 40 & 40 & 40 & 40 & 40 \\
\hline & 5 & 56.5 & 56.5 & 11.3 & 11.3 & 11.3 & 11.3 & 11.3 \\
\hline \multirow{2}{*}{ TB-2 } & $1 \sim 4$ & 100 & 200 & 40 & 40 & 40 & 40 & 40 \\
\hline & 5 & 56.5 & 56.5 & 11.3 & 11.3 & 11.3 & 11.3 & 11.3 \\
\hline
\end{tabular}

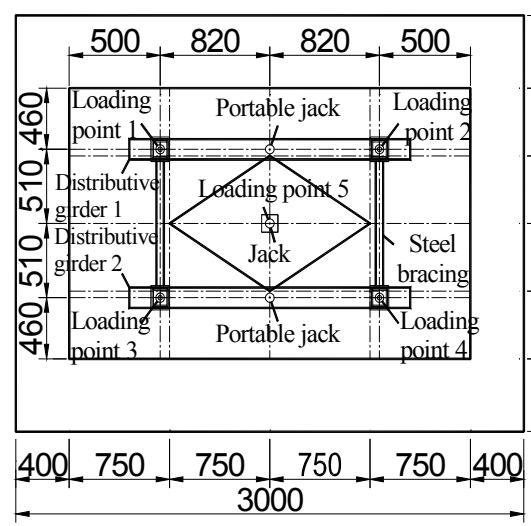

(a) Distribution of Loading Point

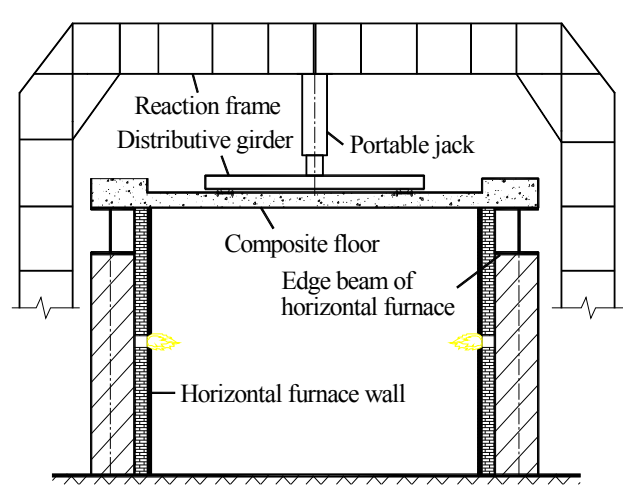

(b) Distributive Girders and Jacks

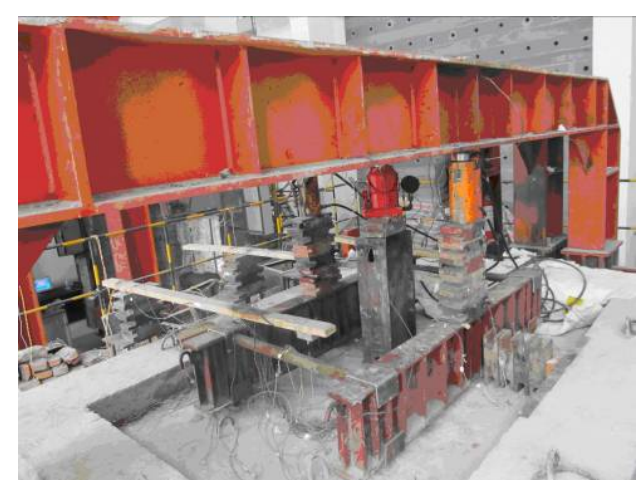

(c) Loading Device

Figure 6. Loading Point and Loading Device

\subsection{Test Device}

A horizontal fire furnace was adopted in the fire test of a composite floor, as shown in Figure 7(a). The size of the furnace chamber was $4 \mathrm{~m} \times 3 \mathrm{~m} \times 1.9 \mathrm{~m}$, and the highest temperature was $1150^{\circ} \mathrm{C}$. There were 4 measuring points of temperature in the furnace. The temperature and displacement could be recorded automatically once per minute by the data collection system of the fire furnace. There were four 50-ton reaction frames on the horizontal fire furnace that could move horizontally according to the demand. Two separate hydraulic jacks and an oil jack of $50 \mathrm{t}$ were used in the test, as shown in Figures 7(b) and (c). 


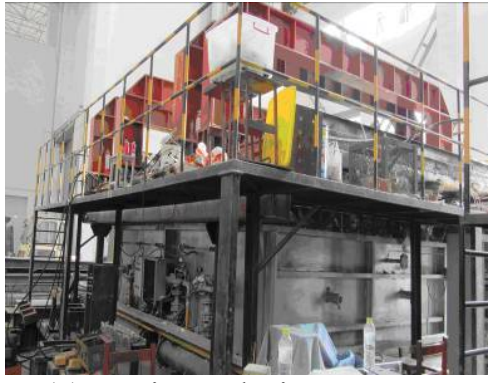

(a) Horizontal Fire Furnace

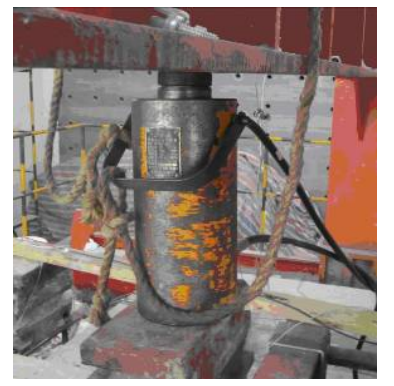

(b) Separate Hydraulic Jack

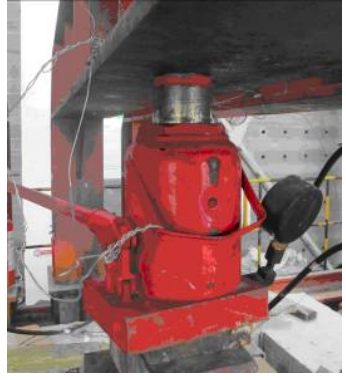

(c) Oil Jack

Figure 7. Test Device

A cable displacement meter was used to measure the deflection of the slab, as shown in Figure 8 (a). K-thermocouple $(0.5 \mathrm{~mm}$ in diameter) was used to measure the temperature of slab, as shown in Figure $8(\mathrm{~b})$. The measuring range of the thermocouple was $0 \sim 1300^{\circ} \mathrm{C}$. To ensure the accuracy of the data, the thermocouple was wrapped with a ceramic tube. During the first period of fire test (when the temperature is lower), the strain of reinforcement was recorded by a data acquisition instrument, as shown in Figure 8(c).

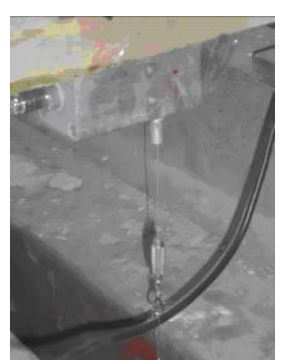

(a) Displacement meter

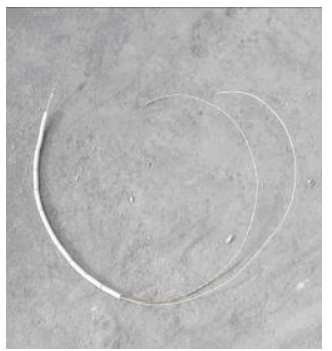

(b) Thermocouple

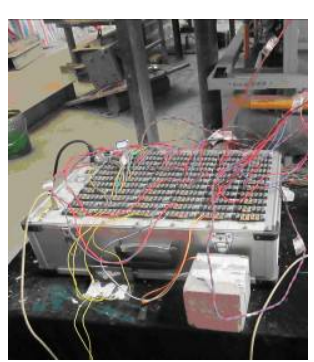

(c) Strain Acquisition Instrument

Figure 8. Data Acquisition Equipment

\subsection{Arrangement of Measuring Point}

The content of the measurement in the fire test mainly included the temperature and the deflection of slab. The thermocouples were arranged inside the slab before the concrete was poured. The measuring point distribution of temperature for reinforcement and slab are shown in Figures 9(a) and (b). The measuring point distribution of deflection is shown in Figure 9 (c).

\subsection{Test Process and Failure Phenomenon}

The two phases were included in the process of fire test, which were loading at room temperature and the rise of temperature. Because the specimen TB-1 was similar to TB-2, the failure process and failure phenomenon of TB-2 in fire are only introduced. 


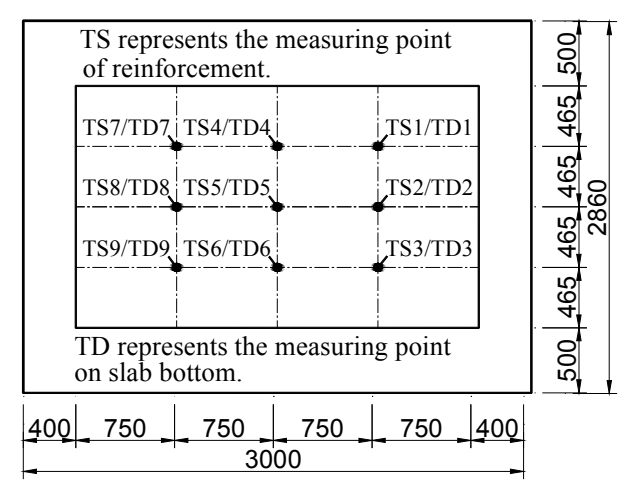

(a) Measuring Point of Temperature for Reinforcement and Bottom of Slab

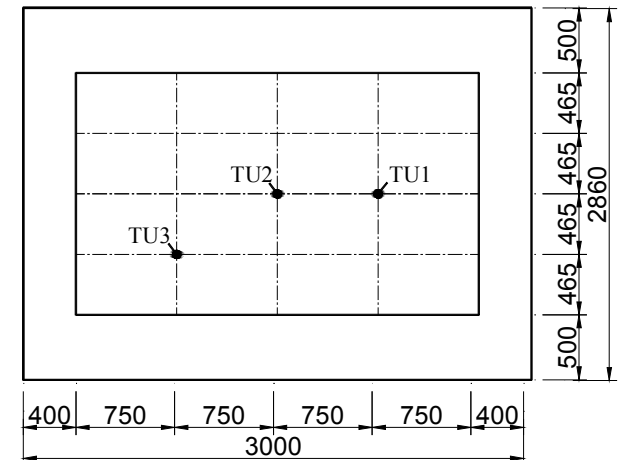

(b) Measuring Point of Temperature for Top of Slab

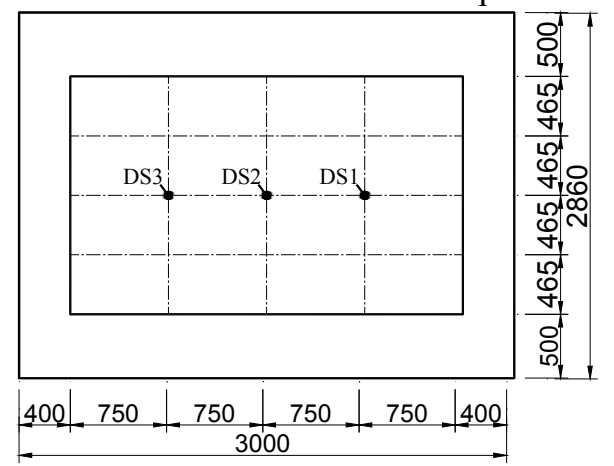

(c) Deflection Measuring Point

Figure 9. Measuring Point Distributions of Temperature and Deflection

For the loading process at room temperature, the deflection of specimen was increased with the load increment at the beginning stage. The first batch of concrete cracks at the corners was generated when applying the fourth level of the load, which was generally perpendicular to the slab diagonals, as shown in Figure 10(a). The maximum deflection of point DS2 was $19.5 \mathrm{~mm}$.

When the loading process at room temperature was completed, the specimen was in a constant load for a period of time before the temperature rise.

The process of fire test on specimen TB-2 was as follows: (1) The time of temperature rise to 20 min, the temperature of furnace chamber was $726.7^{\circ} \mathrm{C}$, and the temperatures for bottom and top of slab were $256.2^{\circ} \mathrm{C}$ and $30.5^{\circ} \mathrm{C}$, respectively. The deflection of point DS2 was $31.7 \mathrm{~mm}$. The width of first batch of concrete cracks was gradually increased, and the cracks were developed to the surrounding constraint concrete beams. (2) The time of temperature rise to $25 \mathrm{~min}$, the second batch of concrete cracks at the corners was generated, as shown in Figure 10(b). The temperature of furnace chamber was $739.9^{\circ} \mathrm{C}$, and the temperature for bottom and top of slab was $339.3^{\circ} \mathrm{C}$ and $35.3^{\circ} \mathrm{C}$, respectively. The deflection of point DS2 was $35.3 \mathrm{~mm}$. (3) The time of temperature rise to 43 min, a crack parallel to the long side of the slab was generated in the middle of long side, and a small amount of water vapor was appeared around the crack, as shown in Figure 10(c). The temperature of furnace chamber was $788.7^{\circ} \mathrm{C}$, and the temperatures for bottom and top of slab were $576.5^{\circ} \mathrm{C}$ and $56.6^{\circ} \mathrm{C}$, respectively. The deflection of point DS2 was $52.7 \mathrm{~mm}$. (4) The time of temperature rise to $78 \mathrm{~min}$, a group of cracks was ran through the slab, and the cracks in the corners became elliptical in shape. The temperature of furnace chamber was $893.7^{\circ} \mathrm{C}$, and the temperatures for bottom and top of slab were $790.7^{\circ} \mathrm{C}$ and $75.7^{\circ} \mathrm{C}$, respectively. The deflection of point DS2 was $96.2 \mathrm{~mm}$. (5) The time of temperature rise to $90 \mathrm{~min}$, the cracks were ran through in an elliptical shape on the top of slab, and the whole floor slab were elliptically went down. 
After the fire test was completed, the overall deformation of specimen TB-2 was shown in Figures 11(a). The cracks on the bottom of slab and on the top of slab were shown in Figures 11(b) and (c), respectively. The following conclusions could be drawn. (1) There were more cracks in the long direction than in the short direction. (2) The tiny cracks were formed around the loading point because of the concentrated load. (3) The cracks on the top surface of slab were elliptically distributed.

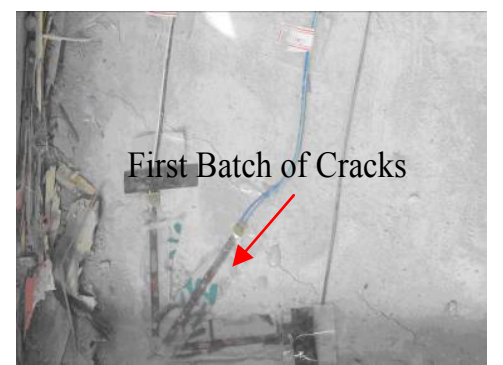

(a) First Batch of Crack

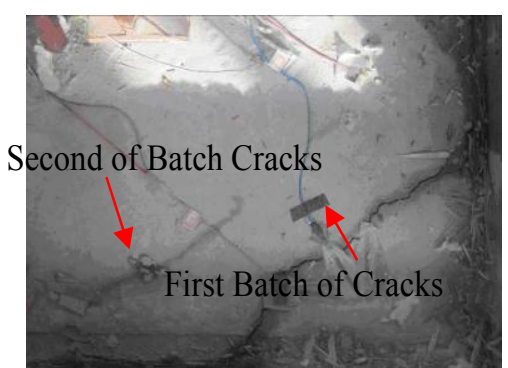

(b) Second Batch of Cracks

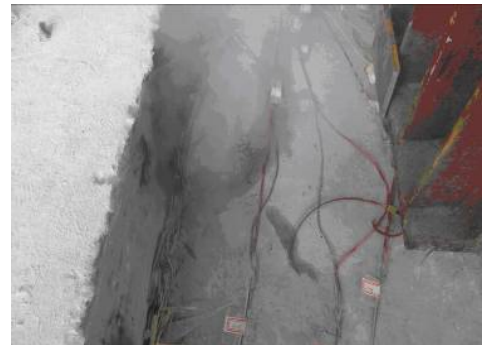

(c) Cracks in Long Direction

Figure 10. Development Processes of Cracks

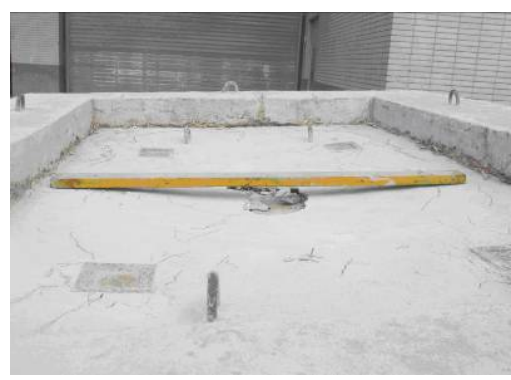

(a) Overall Deformation

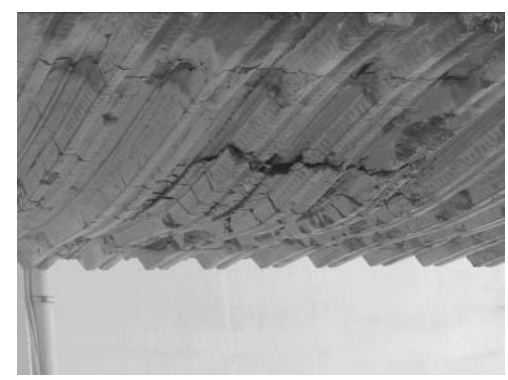

(b) Cracks on bottom of Slab

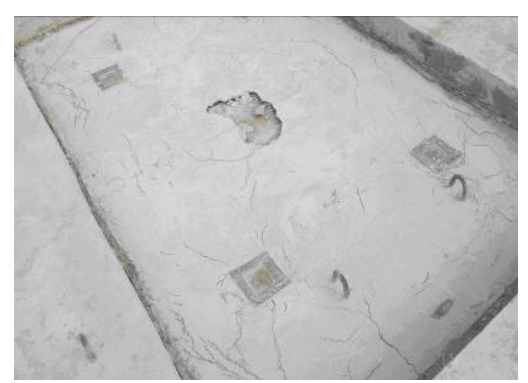

(c) Cracks on top of Slab

Figure 11. Failure Phenomenon

According to the failure phenomenon of fire test, when the deflection of slab in fire is very large, the compression reinforcement on the top of slab was gradually transformed into tensile reinforcement because of the restraint of the surrounding constraint concrete beams. The membrane action of composite floor was generated in the middle area (elliptical area). Conversely, a compression ring was formed outside the elliptical area, which was served as an anchor for reinforcement in the middle area. Thus, an elliptical crack was generated on the border of compression ring, due to the effect of tensile reinforcement.

\subsection{Test Result}

\subsubsection{Temperature of furnace}

The arrangement of the four temperature measuring points inside the fire furnace is shown in Figure 12(a). The temperature of furnace measured during the test process is shown in Figure 12(b) and (c). In the process of heating up, there was certain unevenness between the temperatures of each measuring point. The temperature at TP1 point was highest, and the temperature at TP4 point was lowest. 


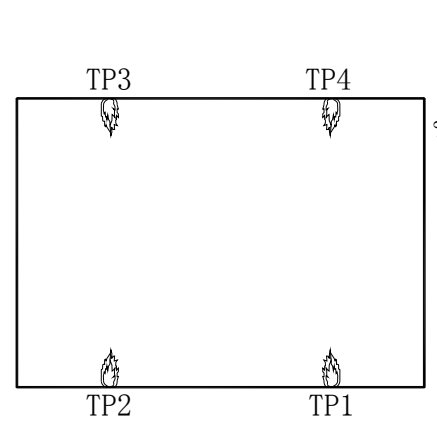

(a) Measuring points

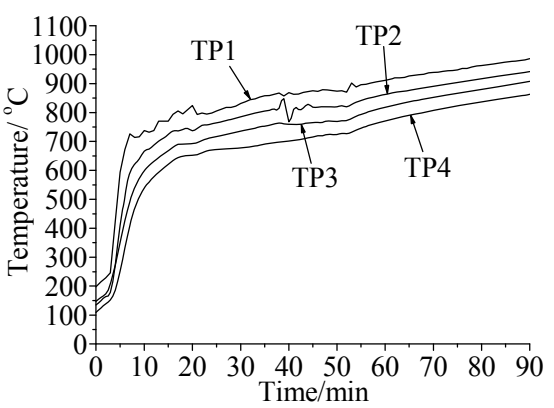

(b) Specimen TB-1

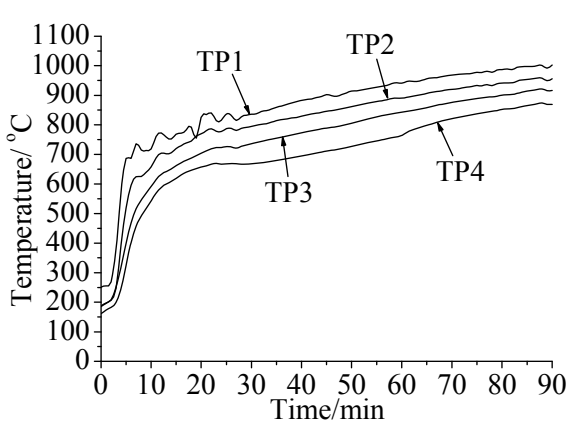

(c) Specimen TB-2

Figure 12. Furnace Temperatures in Fire

For the specimens TB- 1 and TB-2 in fire, the contrasts of temperature curve between the furnace temperature and ISO-834 standard curve are shown in Figures 13(a) and (b), respectively. The difference value of temperature between the furnace temperature and ISO-834 standard curve is shown in the Figure 13(c). The following conclusions can be drawn from Figure 13. (1) The furnace temperature was lower than the temperature of ISO-834 standard curve. The trend of furnace temperature curve was consistent with the ISO-834 standard curve. (2) In the process of fire test, the difference value of furnace temperature was constant in $50-100^{\circ} \mathrm{C}$. (3) In the initial stage of a fire, the heating rate of the furnace temperature was lower, and it was difficult to achieve the heating rate of ISO-834 curve. Thus, the maximum difference value of furnace temperature and temperature of IS 0834 curve was approximately $250^{\circ} \mathrm{C}$.

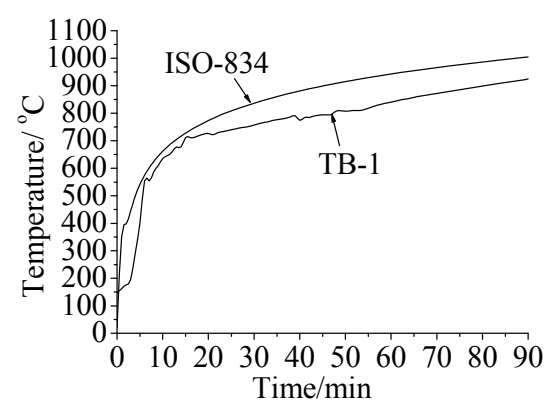

(a) Specimen TB-1

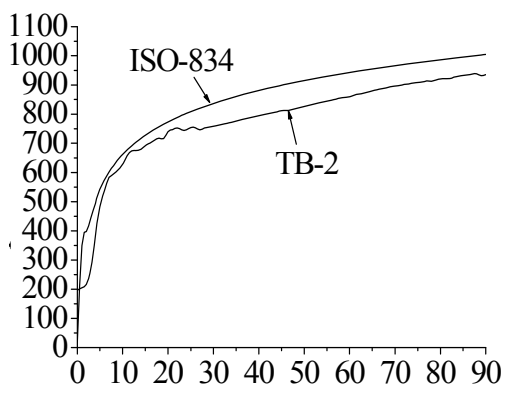

(b) Specimen TB-2

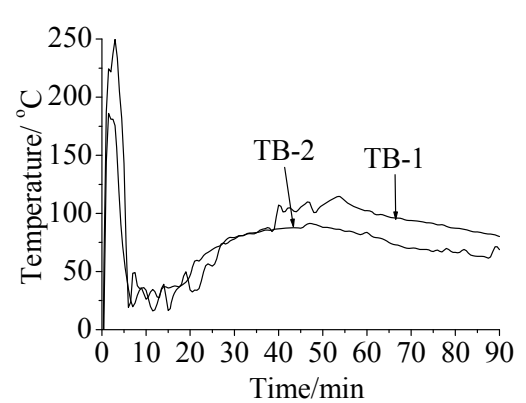

(c) Difference Value of Temperature

Figure 13. Comparisons between Furnace Temperature and Temperature of ISO-834 Curve

\subsubsection{Temperature on the bottom of slab}

The arrangement of temperature measuring point on the bottom of slab is shown in Figure 9(a). For the specimens TB-1 and TB-2, the comparisons of measuring point temperature with furnace temperature are shown in Figures 14(a) and (b), respectively. In the earlier stage (the time of temperature rise to $43 \mathrm{~min}$ ), the temperature on the bottom of slab was slowly increased, and was apparently lower than the furnace temperature. When the temperature was reached to $100^{\circ} \mathrm{C}$, it was constant for a period of time, because of the water vapor gathered around the thermocouple. In the later stage, the temperature on the bottom of slab was rapidly increased, and was gradually close to the furnace temperature.

\subsubsection{Temperature on the top of slab}

The arrangement of temperature measuring point on the top of slab is shown in Figure 9(b). For the specimens TB-1 and TB-2, the temperature curves of each measuring point are shown in Figures 15(a) and (b), respectively. The temperature on the top of slab was slowly increased, and was lower. 
The highest temperature in the middle area on the top of slab was approximately $90.6^{\circ} \mathrm{C}$, and the temperature in the corner area was approximately $64.8^{\circ} \mathrm{C}$.

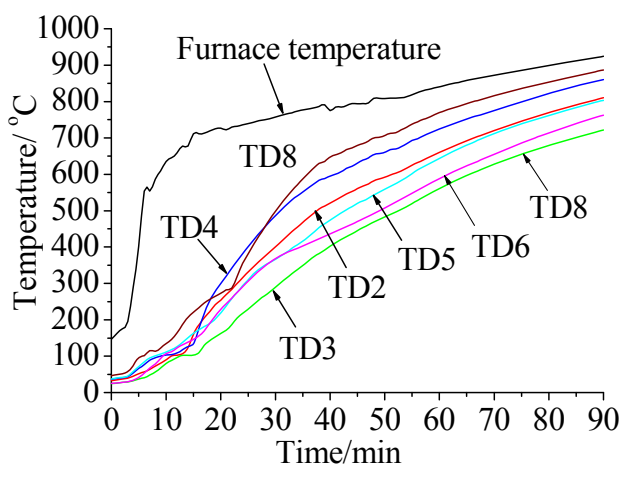

(a) Specimen TB-1

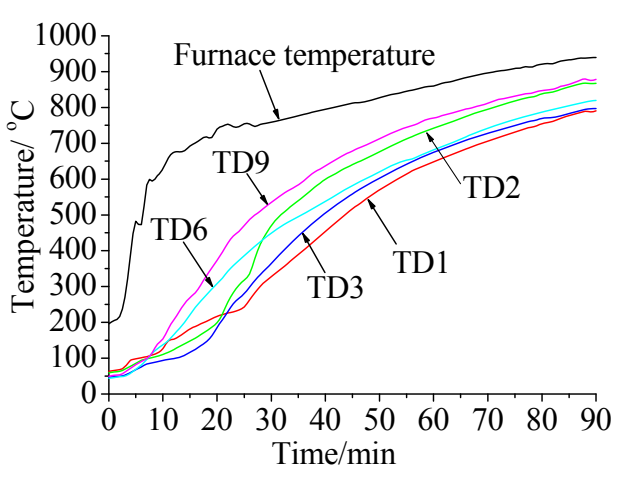

(b) Specimen TB-2

Figure 14. Comparisons between Temperature on the bottom of Slab and Furnace Temperature

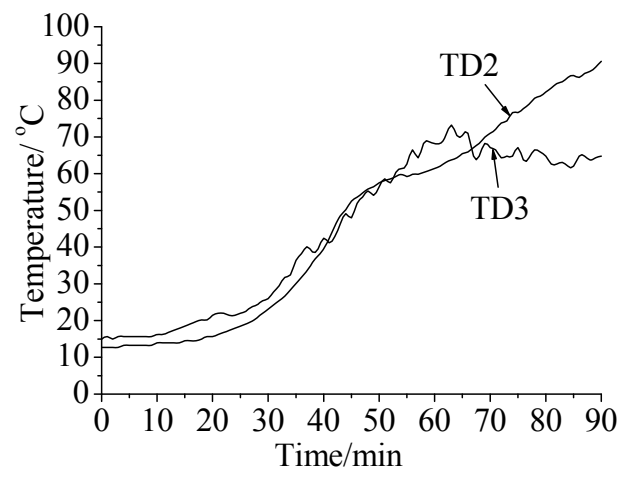

(a) Specimen TB-1

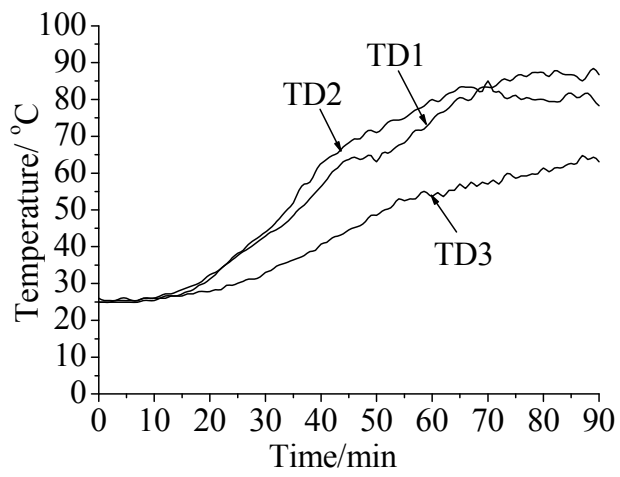

(b) Specimen TB-2

Figure 15. Temperature Curves on the Top of Slab

\subsubsection{Temperature of Reinforcement}

The arrangement of temperature measuring point for the reinforcement is shown in Figure 9(a). For the specimens TB-1 and TB-2, the temperature curves of reinforcements are shown in Figures 16(a) and (b), respectively. The temperature of reinforcement was gradually increased with the increment of fire time. However, the increased rate of temperature was slow, and the fluctuation was larger. The time of temperature rise to 30-40 min, a plateau was appeared in the temperature curve of reinforcement. The temperature of reinforcement was approximately $100^{\circ} \mathrm{C}$, and was constant for $30 \mathrm{~min}$, because a lot of water vapor was gathered around the reinforcement. In Figure 16, the temperature data of the part of measuring point (such as TS2, TS4 and TS7) were not collected, because of the thermocouples damaged.

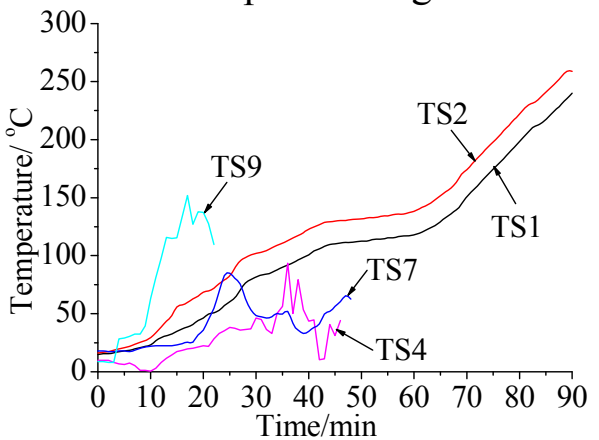

(a) Specimen TB-1

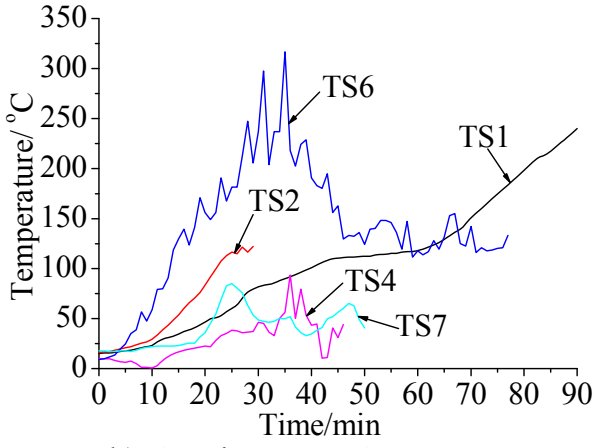

b) Specimen TB-2

Figure 16. Temperature of Reinforcement 


\subsubsection{Deflection of Slab}

The arrangement of deflection measuring point is shown in Figure 9 (c). During the loading period at room temperature, the load-deflection curves of each measuring point on the specimens TB-1 and TB-2 are shown in Figure 17(a). The mid-span deflections of specimens TB-1 and TB-2 were $13.9 \mathrm{~mm}$ and $19.5 \mathrm{~mm}$, respectively.

For the specimens TB-1 and TB-2 in fire, the deflection-time curves of each measuring point are shown in Figure 17(b). The deflection of slab was gradually increased with the increment of fire time. The deflection was slowly increased in the earlier stage, and was rapidly grown in the later stage. The time of temperature rise to $90 \mathrm{~min}$, the mid-span deflections of specimens TB-1 and TB-2 were $92.6 \mathrm{~mm}$ and $94.9 \mathrm{~mm}$, respectively. The two specimens were regarded as destroyed because all of the deflections were more than the limited value, which is $\mathrm{L} / 20$ ( $\mathrm{L}$ represents the short span of the slab).
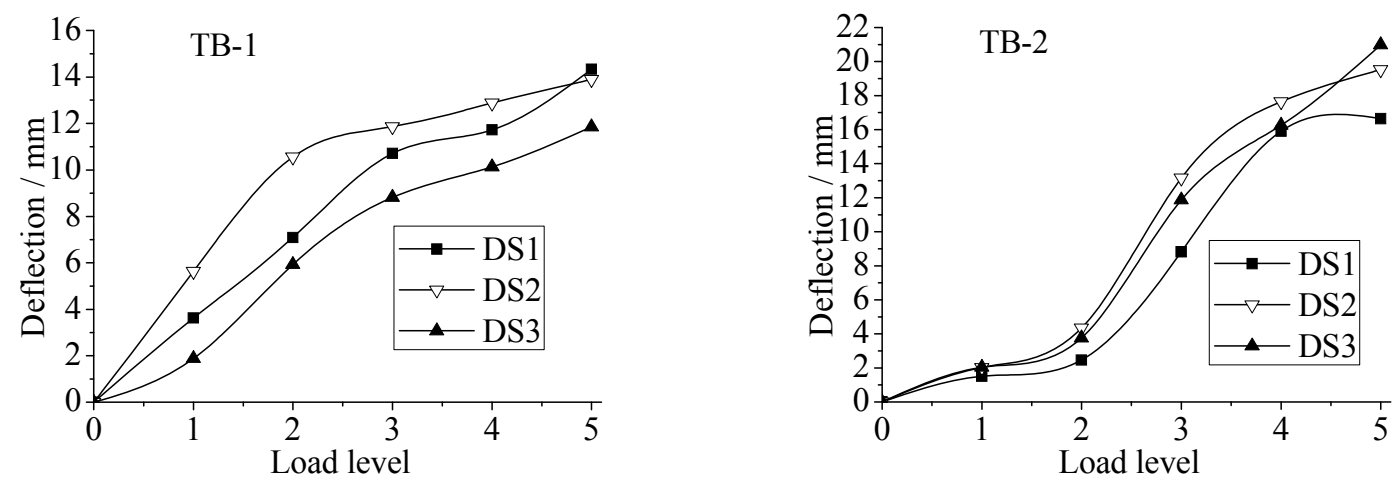

(a) Load-deflection Curves at Room Temperature
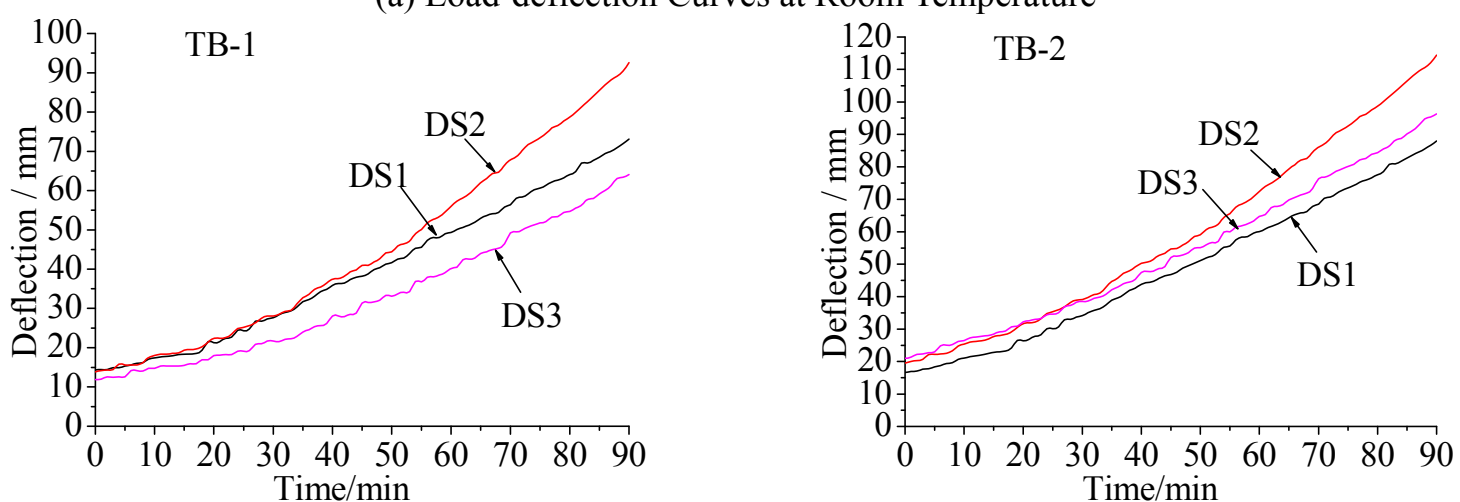

(b) Deflection-time Curves in fire

Figure 17. Deflection Curves of Slab

\section{NUMERICAL SIMULATION OF TEMPERATURE FIELD IN FIRE}

Based on the real curves of furnace temperature gained from the fire test, using the finite element software ABAQUS, a numerical simulation analysis of the 3-D transient temperature field was performed on the specimens TB-1 and TB-2 in the state of a single side under a fire. The internal temperature distribution of slab was studied. Compared with the test results, the accuracy of the finite element numerical simulation was verified. Furthermore, the relevant temperature data were provided to the later parametric analysis of a composite floor in fire. 


\subsection{Establishment of an Analytical Model}

When performing the numerical simulation analysis of a 3-D transient temperature field on a composite floor in fire, the following basic assumptions should be made. (1) The furnace temperature is uniformly distributed. (2) The temperature distribution is not influenced by the deformation and stress state of a composite floor. (3) The thermal contact resistance between concrete and steel is neglected, and heat can be freely transferred. (4) The cracking and bursting of concrete have no influence on the temperature field.

According to the symmetry of the structure and loads, an analysis model to calculate the temperature field was established in a one-quarter size model of the real test specimen size. Different mesh designs were adopted on the concrete and profiled steel sheet. Sweep meshing was used to divide the elements of concrete, and free meshing was used to divide the elements of profiled steel sheet. To improve the boundary condition compatibility of the element meshes, the profiled steel sheet had the same element size as the concrete. The element meshes of concrete and profiled steel sheet are shown in Figures 18 (a) and 18 (b), respectively. The element mesh of reinforcement is shown in Figure 18 (c). The concrete element was in a Hex-dominated shape, and the profiled steel sheet element was in a Quad-dominated shape.

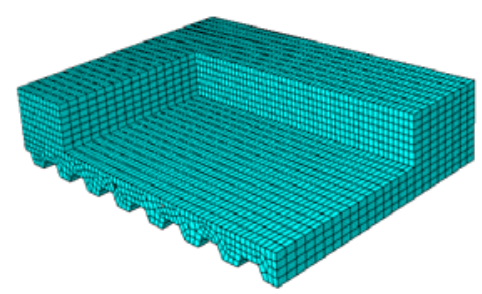

(a) Concrete

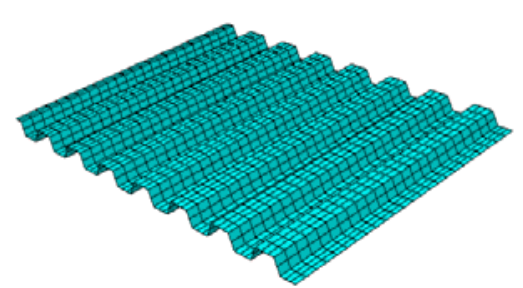

(b) Profiled Steel Sheet

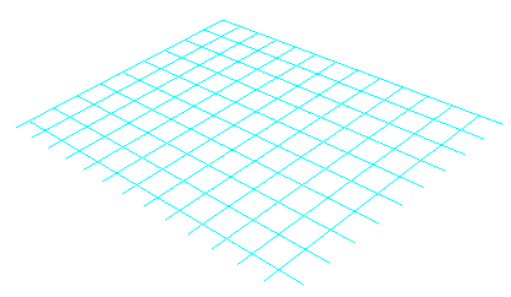

(c) Reinforcement

Figure 18. Element Meshes of Slab

In the analytical model, the hexahedral solid element DC3D8 was adopted as the element of concrete, which transfers heat linearly with 8 nodes. The degree of freedom of the element node was the temperature scalar. The DS4 shell element was adopted as the element of profiled steel sheet. The heat-transferring truss element DC1D2 was used as the element of reinforcement.

\subsection{Boundary Conditions and Relevant Parameters}

The initial temperature $T_{0}$ of slab in the analytical model was $20^{\circ} \mathrm{C}$. An adiabatic boundary was adopted in the central symmetrical boundary of slab, which made it easy to transfer heat between the different materials (concrete and steel). The degrees of freedom of the profiled steel sheet, concrete and reinforcement were bounded together.

The bottom slab of a composite floor was subjected to fire in the test. Heat was transferred between the bottom slab and furnace chamber through thermal convection and thermal radiation. According to the value of the parameters in the existing literature [10], the thermal convection coefficient $\alpha_{\mathrm{c}}$ on the bottom surface of slab was $15 \mathrm{~W} /\left(\mathrm{m} \cdot{ }^{\circ} \mathrm{C}\right)$, and the radiation coefficient $\varepsilon_{\mathrm{r}}$ was 0.5 . The thermal convection coefficient $\alpha_{\mathrm{c}}$ on the top surface of slab was $5 \mathrm{~W} /\left(\mathrm{m} \cdot{ }^{\circ} \mathrm{C}\right)$, and the Stephen Boltzmann coefficient $\sigma$ was $5.67 \times 10^{-8} \mathrm{~W} /\left(\mathrm{m}^{2} \cdot \mathrm{K}^{4}\right)$. 
According to the test phenomenon in fire, the evaporation of water had a significant influence on the distribution of the temperature field in the composite floor. Therefore, the moisture content of composite floor was considered in the analysis model of finite element. The detail specific heat of concrete $C_{\mathrm{c}}$ was prescribed in the Eurocode4 [16]. (1) When the moisture content of concrete $\mathrm{u}=0$, the specific heat $C_{c}$ can be calculated by Eq. 2. (2) When the moisture content $\mathrm{u}$ is $0.15 \%$, the specific heat $C_{\mathrm{c}}$ is $1470 \mathrm{~J} / \mathrm{kg} \cdot \mathrm{K}$ between $100^{\circ} \mathrm{C}$ to $115^{\circ} \mathrm{C}$, and conforms to a linear relationship between $115^{\circ} \mathrm{C}$ and $120^{\circ} \mathrm{C}$. The law in the other temperature is the same as that when $\mathrm{u}=0$. (3) When the moisture content $\mathrm{u}$ is $3.0 \%$, the specific heat $C_{\mathrm{c}}$ is $2020 \mathrm{~J} / \mathrm{kg} \cdot \mathrm{K}$ between $100^{\circ} \mathrm{C}$ and $115^{\circ} \mathrm{C}$, and conforms to a linear relationship between $115^{\circ} \mathrm{C}$ and $120^{\circ} \mathrm{C}$. The law in the other temperature is the same as that when $\mathrm{u}=0$. (4) When the moisture content is $1.5 \%-3.0 \%$, a linear interpolation is acceptable. The curves of specific heat with temperature for different moisture contents $u$ are shown in Figure 19.

$$
C_{\mathrm{c}}=900+80\left(\frac{T}{120}\right)-4\left(\frac{T}{120}\right)^{2}
$$

Where $C_{\mathrm{c}}$ represents the specific heat of concrete $(\mathrm{J} / \mathrm{kg} \cdot \mathrm{K})$ and $T$ refers to the temperature of the concrete $(\mathrm{K})$.

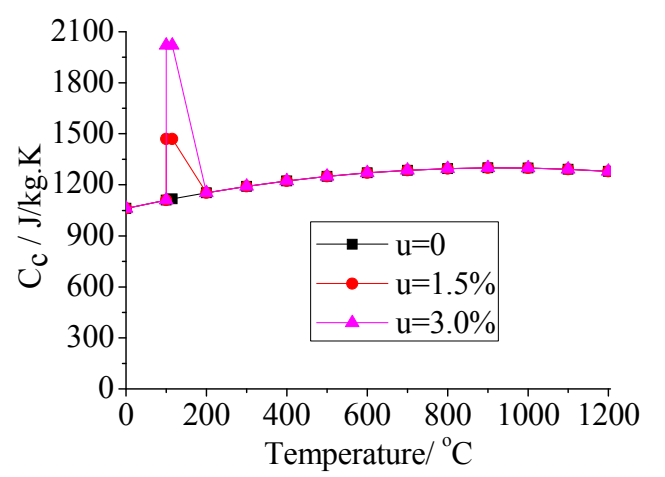

Figure 19. Curves of Specific Heat with Temperature

\subsection{Comparisons between the Numerical Simulation Results and the Test Results}

Through the numerical simulation analysis of temperature field, for specimen TB-1, the section temperature distribution of different moisture contents is shown in Figures 20 (a), (b) and (c). The following conclusions could be drawn from Figure 20. (1) The temperature was decreased step by step from the bottom to the top of slab. (2) The temperature at the crest of the profiled steel sheet was increased the fastest. The temperature on the two sides was higher than that in the middle at the crest of the profiled steel sheet, and the temperature in the middle was higher than that on the two sides at the trough of the profiled steel sheet. (3) The temperature on the top surface of slab was mainly distributed uniformly and was much lower than the temperature on the bottom surface of slab. Comparing the temperature profile of the different moisture contents of concrete, it could be concluded that the higher the moisture content is, the lower the section temperature is. Furthermore, the moisture content has a smaller influence on the temperature of the bottom slab than that of the top slab.

The comparisons of temperature between numerical simulation results and test results for the specimens TB-1 and TB-2 are shown in Figure 21 and Figure 22, respectively. The results for part of measuring points were provided in the figures. 


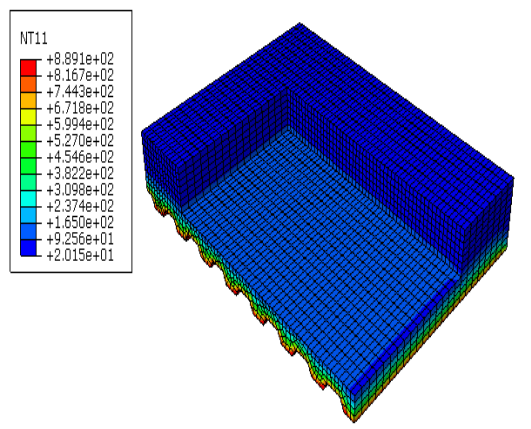

(a) $\mathrm{u}=0$

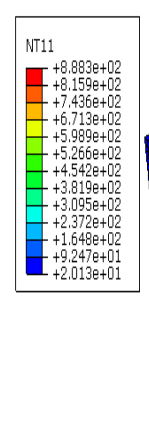

(b) $\mathrm{u}=0.15 \%$

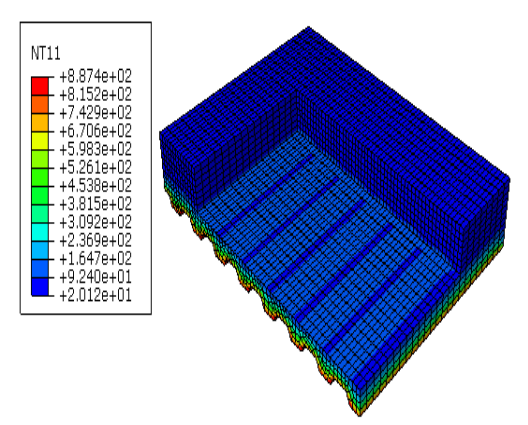

(c) $\mathrm{u}=3.0 \%$

Figure 20. Temperature Distribution of Different Moisture Content

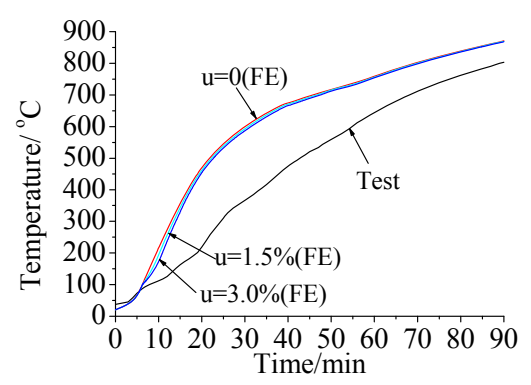

(a) Point TD5 on the bottom of Slab

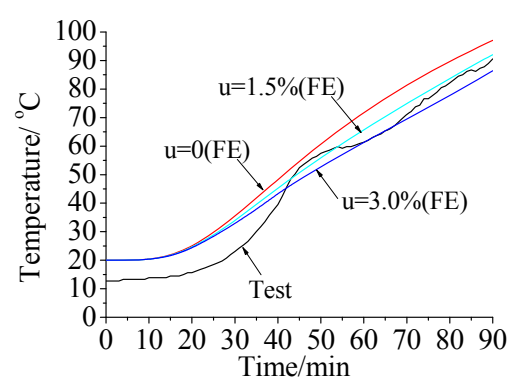

(b) Point TU2 on the top of Slab

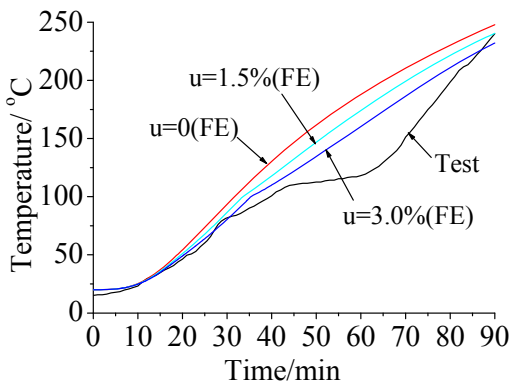

(c) Point TS1 of Reinforcement

Figure 21. Comparison of Temperature between the Numerical Simulation Results and Test Results for Specimen TB-1

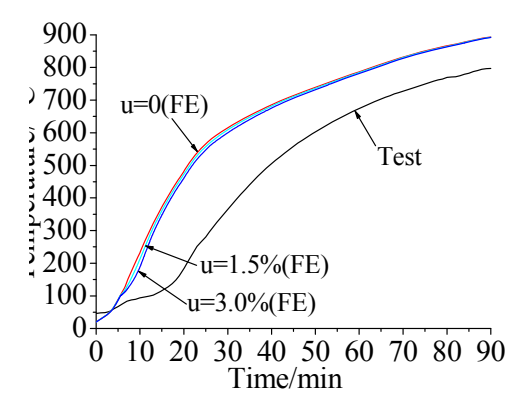

(a) Point TD3 on the bottom of Slab

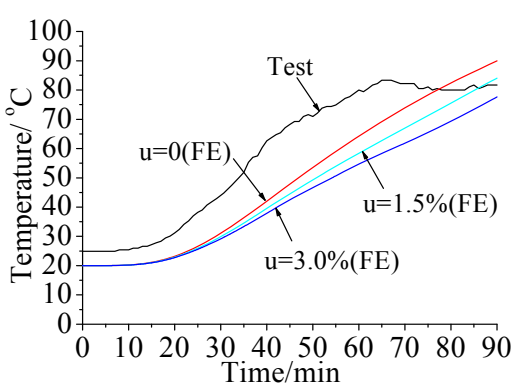

(b) Point TU2 on top of Slab

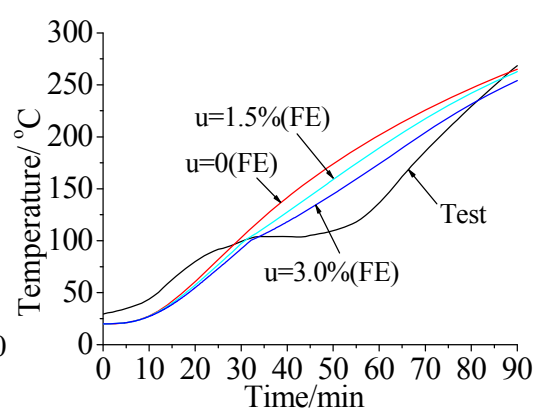

(c) Point TS3 of Reinforcement

Figure 22. Comparison of Temperature between the Numerical Simulation Results and Test Results for Specimen TB-2

As shown in Figure 21 and Figure 22, the moisture content of concrete has a different influence on the temperatures at the areas of slab in the fire. The influence on the high temperature area (the bottom slab) was not obvious, and the influence on the low temperature area (the top slab and reinforcement) was more obvious. The difference value between the numerical simulation results and the test result was large in the early period of fire test, and the difference value was gradually decreased with the increment of temperature. The main causes were analyzed. (1) The initial temperature in the numerical simulation model was $20^{\circ} \mathrm{C}$. However, the initial temperature of furnace in the fire test was set at a high value to simulate the ISO-834 standard curve. (2) In the process of fire test, a platform was appeared in the temperature curve of slab because of water evaporation in the concrete. Though the specific heat $C_{\mathrm{c}}$ between $100^{\circ} \mathrm{C}$ to $200^{\circ} \mathrm{C}$ was reduced in the finite element model and the final result was revised, the platform in the temperature curve was still hard to simulate accurately. (3) The discreteness of concrete material was larger, and is difficult to simulation. 
Based on the above analysis, for the temperature field of a composite floor in fire, the simulation result was generally in agreement with the test result. When the moisture content of concrete was $1.5 \%$, the simulation results were the most consistent with the test results. Thus, it is suggested that the moisture content of concrete be set to $1.5 \%$ in the analysis of temperature field for a composite floor in fire.

\section{PARAMETRIC ANALYSIS ON MEMBRANE ACTION OF A COMPOSITE FLOOR IN FIRE}

\subsection{Establishment of the Structural Analysis Model}

To simplify the structural analysis, the following assumptions should be made when establishing finite element model of a composite floor in fire. (1) The creep of concrete and steel at a high temperature was ignored. (2) The slip between the different materials (concrete and steel) was ignored. (3) The distribution of temperature field for a composite floor in fire is not influenced by the stress state.

The structural analysis model was established by the finite element software ABAQUS, with the sequentially coupled thermal-stress analysis method as the computation method. The computing element was divided by the same method as the numerical simulation model of temperature field. Because the membrane action of a composite floor in fire was mainly studied in the structure analysis, the ultimate deformation was larger when the floor was damaged, which may lead to distortion in the computing element. Therefore, a 3-D solid element in a reduced integration format with 8 nodes (C3D8R) was adopted as the element of concrete. The reinforcement was simulated by a 2-node truss element (T3D2), and the profiled steel sheet was simulated by a 4-node shell element (S4R) in a reduced integration format. According to the symmetry principle, the size of structural analysis model for a composite floor in fire was a quarter of the actual size. The mesh element of structural analysis model was shown in Figure 23 (a).

The boundary conditions and contact boundaries in the structural analysis model were set up in the following ways. (1) The symmetrical boundary perpendicular to the $\mathrm{X}$ axis were fixed on the constraint condition $\left(\mathrm{U}_{1}=\mathrm{U}_{\mathrm{R} 2}=\mathrm{U}_{\mathrm{R} 3}=0\right)$, which was the same as the boundary perpendicular to the $\mathrm{Y}$ axis $\left(\mathrm{U}_{2}=\mathrm{U}_{\mathrm{R} 2}=\mathrm{U}_{\mathrm{R} 3}=0\right)$. The slab was supposed to be simply supported. The boundary constraints in the $\mathrm{X}$ direction were $\mathrm{U}_{1}=\mathrm{U}_{3}=\mathrm{U}_{\mathrm{R} 2}=\mathrm{U}_{\mathrm{R} 3}=0$, and the boundary constraints in the $\mathrm{Y}$ direction were $\mathrm{U}_{2}=\mathrm{U}_{3}=\mathrm{U}_{\mathrm{R} 1}=\mathrm{U}_{\mathrm{R} 3}=0$, as shown in Figure 23 (b). (2) The degrees of freedom of the profiled steel sheet, concrete and reinforcement were bounded together. The degree of freedoms between the profiled steel sheet and concrete were tied by the constraint. The main surface was on the concrete, and the dependent surface was on the profiled steel sheet, as shown in Figure 23 (c). An embedded constraint was adopted as the constraint between the reinforcement and concrete.

\subsection{Verification of the Structural Analysis Model}

The analysis results of the finite element model were compared with the test results, and the deflection comparisons of specimen TB-1 and TB-2 are shown in Figures 24 (a) and (b), respectively. 


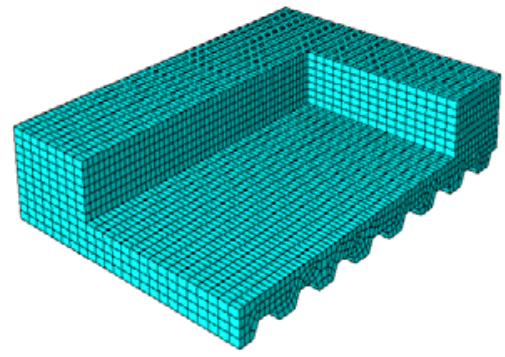

(a) Element Mesh

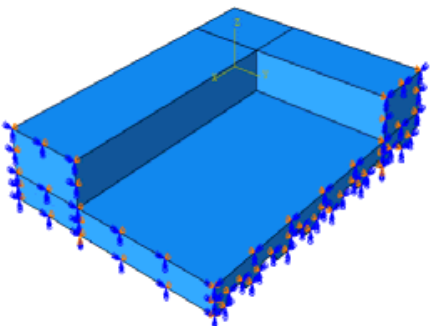

(b) Boundary Condition

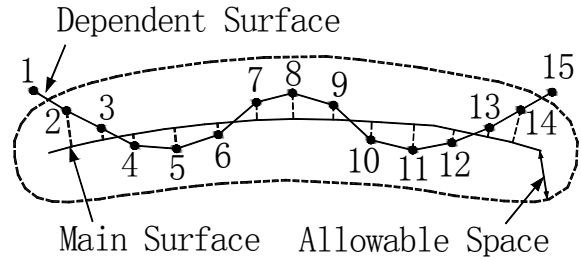

(c) Contact Boundary

Figure 23. Structural Analysis Model of a Composite Floor in Fire

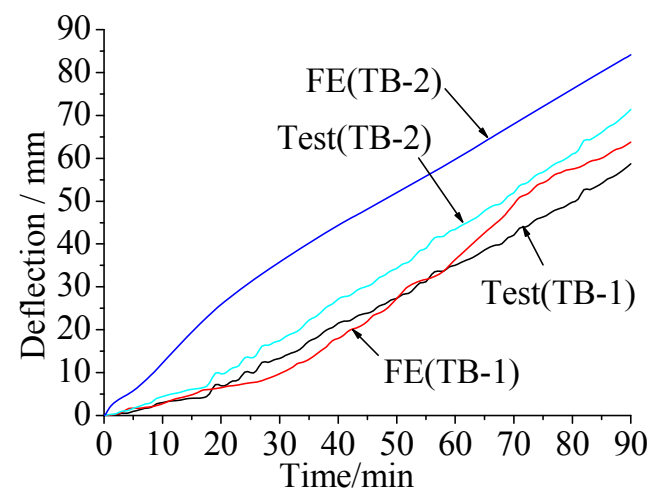

(a) Point DS1

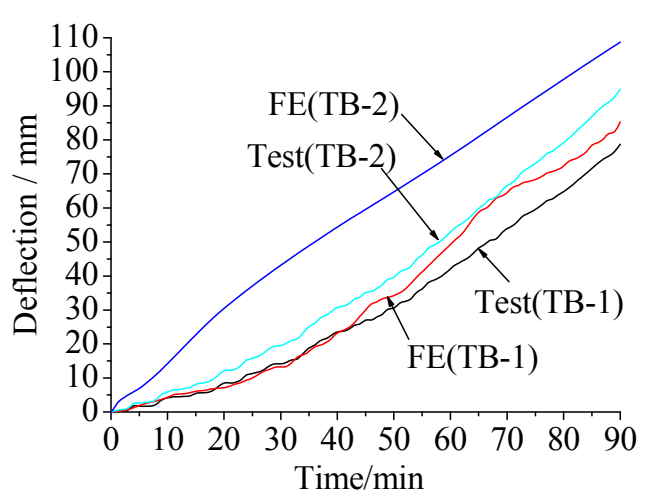

(b) Point DS2

Figure 24. Comparisons of Analysis Results and Test Results for the Deflection of Slab

According to Figures 24 (a) and (b), for specimen TB-1, the analysis results of the deflection were basically in consistent with the test results, though the analysis results were slightly larger than test results in the late period of fire. For specimen TB-2, the trends of deflection curve between the analysis results and the test results were the same, but there was a large difference of deflection values between the two in the early period of fire. With the increment of temperature, the difference was reduced gradually.

By the comparison of deflection between the analysis results and the test results, the structural analysis model of a composite floor adopted in this paper is feasible, and the analytical result is reliable.

\subsection{Parametric Analysis}

The ultimate bearing capacity of a composite floor with the membrane action considered is related to many factors, such as length-to-width ratio $L / B$ ( $L$ refers to the size of long side, $B$ refers to the size of short side), thickness of concrete cover $c$, concrete strength $f_{\mathrm{c}}$, yield strength of reinforcement $f_{\mathrm{y}}$, reinforcement ratio $\rho_{\mathrm{s}}$ and thickness of slab $h$. Based on the structural analysis model of a composite floor in fire, the parametric analysis was carried out to investigate the influence factors on the membrane action of slab in fire.

The basic parameters in the finite element model were set as follows. The length of slab $L$ was $3.0 \mathrm{~m}$ and the width $B$ was $3.0 \mathrm{~m}$. A profiled steel sheet of YX51-253-760 was adopted, with a thickness of $1 \mathrm{~mm}$, and the yield strength $f_{\mathrm{y}}$ was $235 \mathrm{~N} / \mathrm{mm}^{2}$. The diameter of reinforcement was $6 \mathrm{~mm}$, and the yield strength $f_{\mathrm{y}}$ was $310 \mathrm{~N} / \mathrm{mm}^{2}$. The reinforcement ratio $\rho_{\mathrm{s}}$ was adjusted by changing the interval distance of the reinforcements. The thickness of concrete cover $c$ was $25 \mathrm{~mm}$. The strength of concrete $f_{\mathrm{c}}$ was $20.1 \mathrm{~N} / \mathrm{mm}^{2}$. The thickness of slab $h$ was $130 \mathrm{~mm}$. The fire duration time of slab was $90 \mathrm{~min}$. 
The increasing coefficient $e$ of bearing capacity in fire can be calculated by Eq. 3, which the membrane action of a composite floor was considered.

$e=\frac{q_{\mathrm{T}}}{q_{0}}$

Where $q_{\mathrm{T}}$ represents the ultimate bearing capacity of a composite floor that the membrane action is not considered at $T^{\circ} \mathrm{C}$, and $q_{0}$ refers to the ultimate bearing capacity of a composite floor that the membrane action is considered at room temperature.

\subsubsection{Length-to-width $L / B$}

The influence of length-to-width ratio $L / B$ on the membrane action of a composite floor in fire was researched by changing the length and width of slab, if the other parameters were constant. The length-to-width ratio $L / B$ of slab was respectively selected as $1.0,1.5,2.0,2.5,3.0$ or 3.5 , and the corresponding finite element model of structural analysis was established. The ultimate bearing capacities of a composite floor at high temperature were calculated. At the same time, for contrastive analysis, the ultimate bearing capacities were worked out according to the method proposed by Zhang et al. [8]. The increasing coefficient curves of bearing capacity with the length-to-width ratio $L / B$, which were calculated by different methods, are shown in Figure 25 .

By the figure 25, we can see that (1) the results of finite element analysis have a similar trend with the computational results by Zhang. However, the finite element results are always lower than the results by Zhang. (2) The larger the length-to-width $L / B$ is, the smaller the increasing coefficient of bearing capacity $e$ is. For a composite floor with the lager length-to-width ratio in fire, the reinforcements along the short span were early yield, and the reinforcements along the long span were not fully used. Therefore, it is suggested that the length-to-width ratio of a composite floor should be smaller than 2.0 in the fire-resistant design if the membrane action of slab is considered.

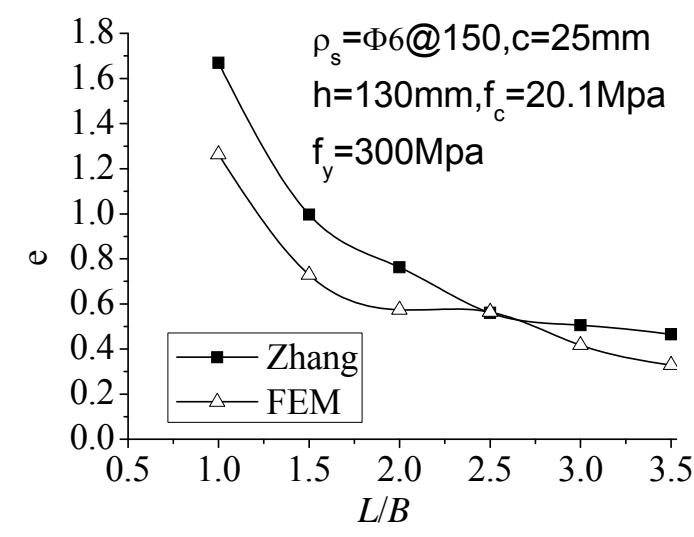

Figure 25. Increasing Coefficient of Bearing Capacity with Length-to-Width

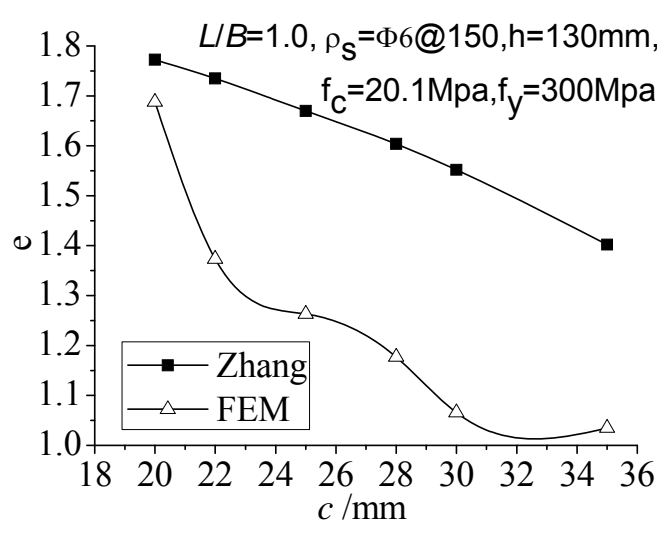

Figure 26. Increasing Coefficient of Bearing Capacity with Thickness of Concrete Cover

\subsubsection{Thickness of concrete cover $c$}

If the other parameters were constant, the thickness of concrete cover $c$ was respectively selected as $20,22,25,28,30$ or $35 \mathrm{~mm}$, and the corresponding finite element model of structural analysis was established. The ultimate bearing capacities of a composite floor at high temperature were determined. At the same time, for contrastive analysis, the ultimate bearing capacities were calculated according to the method proposed by Zhang et al. [8].The increasing coefficient curves 
of bearing capacity with the thickness of concrete cover $c$, which were calculated by different methods, are shown in Figure 26.

By the figure 26, we can see that (1) the results of finite element analysis are always lower than the results by Zhang. (2) The larger the thickness of concrete cover $c$ is, the smaller the increasing coefficient of bearing capacity $e$ is. The high thickness of concrete cover leads to an increment of temperature in the reinforcement, to the disadvantage of the generation of membrane action in fire. Thus, the concrete cover should not be thick in fire-resistant design.

\subsubsection{Strength of Concrete $f_{c}$}

If the other parameters were constant, the strength of concrete $f_{\mathrm{c}}$ was respectively selected as 13.4 , 16.7 or $20.1 \mathrm{~N} / \mathrm{mm}^{2}$, and the corresponding finite element model of structural analysis was established. The ultimate bearing capacities of a composite floor at high temperature were calculated. At the same time, for contrastive analysis, the ultimate bearing capacities were worked out according to the method proposed by Zhang et al. [8]. The increasing coefficient curves of bearing capacity with the strength of concrete $f_{c}$, which were calculated by different methods, are shown in Figure 27.

By the figure 27, we can see that the strength of concrete $f_{\mathrm{c}}$ has a small influence on the increasing coefficient of bearing capacity $e$. The strength of concrete does not greatly influence on the membrane action of a composite floor in fire, and the membrane force is mainly provided by the reinforcements.

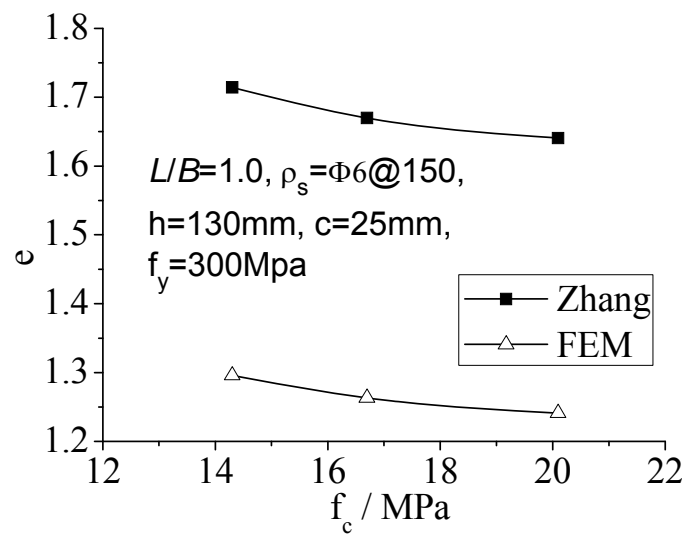

Figure 27. Increasing Coefficient of Bearing Capacity with Strength of Concrete

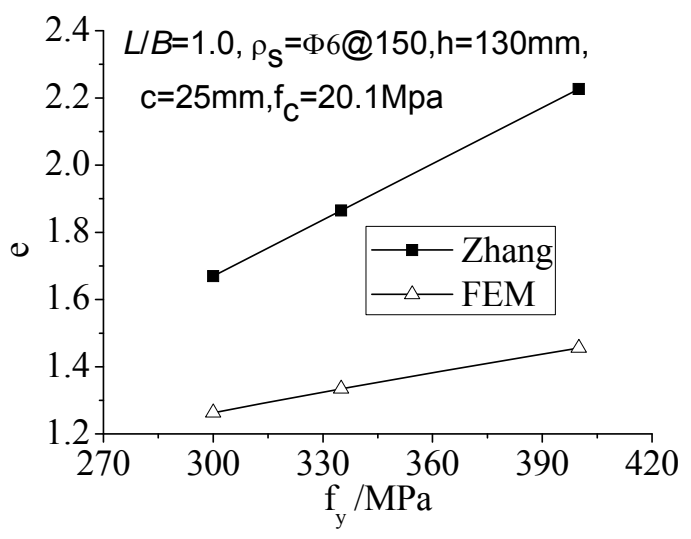

Figure 28. Increasing Coefficient of Bearing Capacity with Strength of Reinforcement

\subsubsection{Strength of Reinforcement $f_{y}$}

If the other parameters were constant, the strength of reinforcement $f_{\mathrm{y}}$ was respectively selected as 300,335 or $400 \mathrm{~N} / \mathrm{mm}^{2}$, and the corresponding finite element model of structural analysis was established. The ultimate bearing capacities of a composite floor at high temperature were calculated. At the same time, for contrastive analysis, the ultimate bearing capacities were worked out according to the method proposed by Zhang et al. [8].The increasing coefficient curves of bearing capacity with the strength of reinforcement $f_{\mathrm{y}}$, which were calculated by different methods, are shown in Figure 28.

By the figure 28, we can see that the stronger the strength of reinforcement is, the larger the increasing coefficient of bearing capacity $e$ is. The strength of reinforcement is the main influence factor on the membrane action a composite floor in fire. 


\subsubsection{Reinforcement ratio $\rho_{\mathrm{s}}$}

If the other parameters were constant, the reinforcement ratio $\rho_{\mathrm{s}}$ was adjusted only by changing the interval distance of reinforcement $d_{\mathrm{s}}$. The interval distances of reinforcement $d_{\mathrm{s}}$ were respectively selected as $100,130,150,180,200$ or $230 \mathrm{~mm}$, and the corresponding finite element model of structural analysis was established. The ultimate bearing capacities of a composite floor at high temperature were calculated. At the same time, for contrastive analysis, the ultimate bearing capacities were worked out according to the method proposed by Zhang et al. [8].The increasing coefficient curves of bearing capacity with the interval distance of reinforcement $d_{\mathbf{s}}$ ( the reinforcement ratio $\rho_{\mathrm{s}}$ ), which were calculated by different methods, are shown in Figure 29.

By the figure 29, we can see that the increasing coefficient of bearing capacity $e$ has a decreasing trend as the interval distance of reinforcement $d_{\mathrm{s}}$ increases. The reinforcement ratio is also the main influence factor on the membrane action a composite floor in fire.

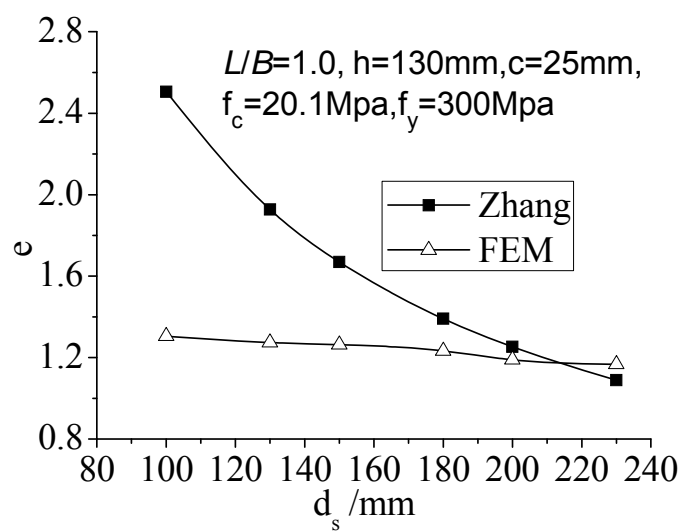

Figure 29. Increasing Coefficient of Bearing Capacity with Reinforcement Ratio

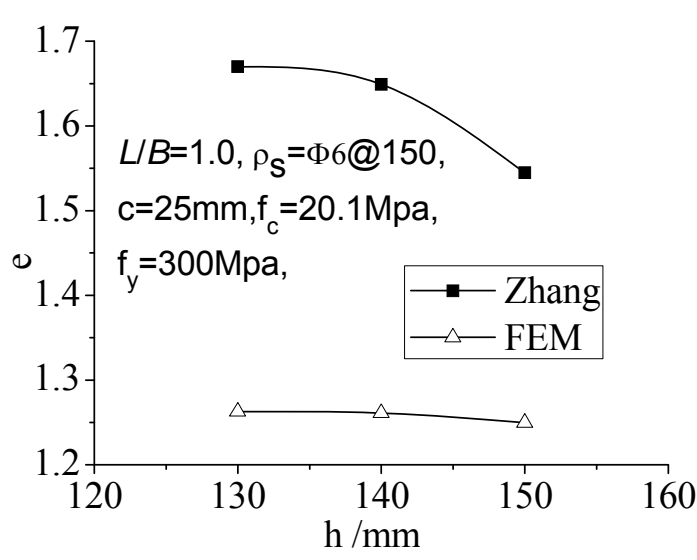

Figure 30. Increasing Coefficient of Bearing Capacity with Thickness of Slab

\subsubsection{Thickness of slab $\mathrm{h}$}

If the other parameters were constant, the thickness of slab $h$ was respectively selected as 130,140 or $150 \mathrm{~mm}$, and the corresponding finite element model of structural analysis was established. The ultimate bearing capacities of a composite floor at high temperature were determined. At the same time, for contrastive analysis, the ultimate bearing capacities were calculated according to the method proposed by Zhang et al. [8]. The increasing coefficient curves of bearing capacity with the thickness of slab $h$, which were calculated by different methods, are shown in Figure 30.

By the figure 30, we can see that the thickness of slab $h$ has a small influence on the increasing coefficient of bearing capacity $e$. The thickness of slab does not greatly influence on the membrane action of a composite floor in fire.

\section{CONCLUSIONS}

By the research and analysis mentioned above, the following conclusions can be drawn.

(1) The experimental phenomenon demonstrates that the composite floor remained integrated and is not burn-through, from the beginning to the end of the fire test, which could provide an important safeguard to avoid integral collapse. Slip between the steel sheet and concrete is also found in the 
fire test. It is suggested that shear connectors be installed between the two in the subsequent fire resistance research of a composite floor.

(2) According to the specimens tested in fire, the shape of cracks distribution on the top surface of the composite floor was an ellipse. Almost all of the reinforcements in the slab were in a state of tension. The central area of the composite floor was slide down in an ellipse shape with a large deformation, which the membrane action of a composite floor in fire was verified. The formation mechanism of membrane action for a composite floor in fire was revealed. Finally, the judgment criterion on the formation of membrane action in fire test was provided.

(3) A numerical simulation analysis for the temperature field of a composite floor in fire was performed through the finite element software ABAQUS. The simulation results were compared with the test results, and the feasibility and accuracy of analytical method was verified. Furthermore, the analytical results of temperature field demonstrated that the moisture content of concrete had little influence on the high-temperature area of slab, and larger influence on the low-temperature area of slab. It was suggested that the moisture content of concrete $u$ be $1.5 \%$ in the fire resistance analysis of a composite floor.

(4) A parametric analysis was performed to investigate the main influence factors on the membrane action of a composite floor in fire. The analytical result demonstrates that the length-to-width $L / B$ is the main influence factor on the membrane action of a composite floor in fire, and it is suggested that the length-to-width $L / B$ be less than 2.0 to make full use of the membrane action of a composite floor. The thickness of concrete cover $c$, the thickness of slab $h$ and the strength of concrete $f_{\mathrm{c}}$ had little influence on the membrane action. The strength of reinforcement $f_{\mathrm{y}}$ and the reinforcement ratio $\rho_{\mathrm{s}}$ are beneficial for improving the bearing capacity of a composite floor in fire.

\section{ACKNOWLEDGEMENTS}

The authors gratefully acknowledge the financial support of the National Natural Science Foundation of China (No. 51378105). The research was also supported by the Priority Academic Program Development of Jiangsu Higher Education Institutions and Jiangsu Provincial Forward-Looking Cooperation Foundation of Industry, Education and Research (No. BY2012200). These financial supports are gratefully acknowledged.

\section{REFERENCES}

[1] Chen, Y.O., Cheng, M.K. and Liu, J.K., "Experimental Research on Fire-resistance of Metal Deck Composite floor", Industrial Construction, 1999, Vol. 29, No. 12, pp. 23-27.

[2] Li, G.Q., Yin, Y.Z. and Jiang, S.C., "Analysis of the Temperature Distribution in Composite Slabs Subjected to Fires", Journal of Building Structure, 1998, Vol. 19, No. 5, pp. 47-50.

[3] Lim, L., Buchanan, A. and Moss, P., et al., "Numerical Modeling of Two-way Reinforced Concrete Slabs in Fire”, Engineering Structures, 2004, Vol. 26, No. 8, pp. 1081-1091.

[4] Bailey, C.G., White, D.S. and Moore, D.B., "The Tensile Membrane Action of Unrestrained Composite Slabs Simulated under Fire Conditions”, Engineering Structures, 2000, Vol. 22, pp. 1583-1595.

[5] Chen, L.G., Dong, J.L. and Dong, Y.L., "Analysis on the Deformation of the Reinforced Concrete Slabs under Fire", Journal of Qingdao Institute of Architecture and Engineering, 2005, Vol. 26, No. 3, pp. 1-4. 
[6] Li, G.Q., Zhou, H.S. and Guo, S.X., "Mechanism and Theoretical Model Membrane Action in Slabs of Steel Buildings Subjected to Fire", Journal of Building Structures, 2007, Vol. 28, No. 5, pp. 40-47.

[7] Zhang, N.S. and Li, G.Q., "An Innovative Analytical Method for the Membrane Action of Composite floors in Fire", China Civil Engineering Journal, 2009, Vol. 42, No. 3, pp. 29-35.

[8] Li, G.Q. and Zhang, N.S., "Experimental Study of Membrane Action of Composite floors under Fire", China Civil Engineering Journal, 2010, Vol. 43, No. 3, pp. 24-31.

[9] Li, G.Q., Guo, S.X. and Zhou, H.S., "Model Validation and Application of Membrane Action in Slabs of Steel Buildings Subjected to Fire", Journal of Building Structures, 2007, Vol. 28, No. 5, pp. 48-53.

[10] Lamont, S., Usmani, A.S. and Drysdale, D.D., "Heat Transfer Analysis of the Composite Slab in the Cardington Frame Fire Tests", Fire Safety Journal, 2001, Vol. 36, pp. 815-839.

[11] Gillie, M., Usmani, A.S. and Rotter, J.M., "A Structural Analysis of the Cardington British Steel Comer Test", Journal of Constructional Steel Research, 2002, Vol. 58, pp. 427-442.

[12] Usmani, A.S. and Cameron, N.J.K., "Limit Capacity of Laterally Restrained Reinforced Concrete Floor Slabs in Fire", Cement \& Concrete Composites, 2004, Vol. 26, pp. 127-140.

[13] Bailey, C.G. and Moore, D.B., "The Structural Behaviour of Steel Frames with Composite floors Subject to Fire: Part1: Theory", The Structural Engineer, 2000, Vol. 78, No. 11, pp. $19-27$.

[14] Bailey, C.G. and Moore, D.B., "The Structural Behaviour of Steel Frames with Composite floors Subject to Fire: Part2: Design”, The Structural Engineer, 2000, Vol. 78, No.11, pp. $28-33$.

[15] Bailey, C.G., "Efficient Arrangement of Reinforcement for Membrane Behaviour of Composite floors in Fire Conditions", Journal of Constructional Steel Research, 2003, Vol. 59, pp. 931-949.

[16] EC2, "Euro code 2: Design of Concrete Structures, Part 1-2: General Rules - Structural Fire Design", European Committee for Standardization, ENV 1993-1-2, CEN, Brussels, 1992. 


\title{
THE ART OF APPLICATION OF HIGH-STRENGTH STEEL STRUCTURES FOR BUILDINGS IN SEISMIC ZONES
}

\author{
Guo-Qiang $\mathrm{Li}^{1}$, Yan-Bo Wang ${ }^{2,}$ and Su-Wen Chen ${ }^{1}$ \\ I. State Key Laboratory for Disaster Reduction in Civil Engineering, Tongji University, China \\ 2. College of Civil Engineering, Tongji University, Shanghai, China \\ *(Corresponding Author: E-mail: ybwang@ tongji.edu.cn)
}

\begin{abstract}
Since recent advances of technology in material science and increasing demand for high strength materials, high-strength steel (HSS) has been applied to several landmark buildings and major projects. However, the application of high-strength steel in seismic structures is limited by the relative worse ductility, which usually decreases with the increase in yield strength. In this paper, key issues associated with the application of HSS in seismic structures are pointed out and discussed. The current state of the art of behavior of HSS and recent research on the seismic behavior of HSS carried out at Tongji University are presented. The effect of reheating and cooling during fabrication process on the mechanical properties of HSS is evaluated. Through the revisit and reconsideration on the basic level of seismic design philosophy, two new design methodologies for application of HSS structures for buildings in seismic zones are proposed. Finally, future works related to the application of high strength steels are recommended.
\end{abstract}

Keywords: High-strength steel, Seismic design, Application, Recent research

\section{INTRODUCTION}

Due to the architectural and structural advantages, high-strength steel (HSS, yield stress $\geq 460 \mathrm{MPa}$ ) has been increasingly used in high-rise buildings, large span buildings and bridges in the past two decades $[1,2]$. Compared with regular mild carbon steel members, the application of HSS members shows the following advantages:

- In lieu of conventional mild carbon steels, adoption of high-strength steels can reduce plate thickness and member size because of the increased allowable design stress.

- Consequently, the usable floor area of the structures could be increased and the self-weight of the structures could be reduced. Moreover, special architectural form leads to many difficulties in structural design. Thus, light weight and slim members are usually desirable.

- As a result of the reduction in plate thickness and member size, difficulties in welding thick plates and the amount of welding can be reduced.

- Owing to the lighter self-weight of structures, savings may be made in transportation and erection, and smaller foundations could be constructed.

- Mass-dependent dynamic forces, such as earthquake actions, can be reduced.

The price of high-strength steel is usually higher than the price of normal-strength steel. However, the increase in steel price is lower than the increase in steel strength. Thus, when providing with the same strength, the cost of high-strength steel is actually lower than the cost of normal-strength steel. The normalized prices of different steel grades of ref. [3] are reproduced here, as shown in Figure 1. If the strength can be fully utilized, it is economical to use high-strength steel in structures. With the recent development of steelmaking techniques and advances in welding techniques, HSS members can be produced at a reasonable cost with good quality in China. According to World Steel Association [4], there was an increase of $68 \%$ in steel production worldwide between 2000 
and 2010, with China experiencing an increase of 396\% for the same period, as shown in Figure 2. Similarly, global use of steel had increased $69 \%$ from 2000 to 2010, while the use of steel in China had increased over $400 \%$ for the same period. Because of the rapid industrialization and urbanization, China accounted for approximately $45 \%$ of the global steel production in 2010 [5], as shown in Figure 3. More than half of steel consumption was devoted to construction, which was the greatest steel market share in 2010.

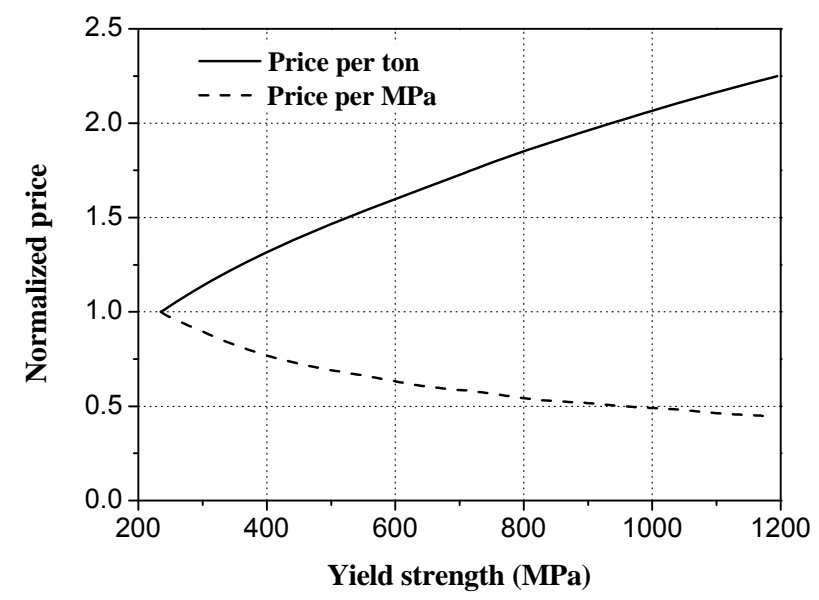

Figure 1. Comparison of Normalized Price among Different Steel Grades

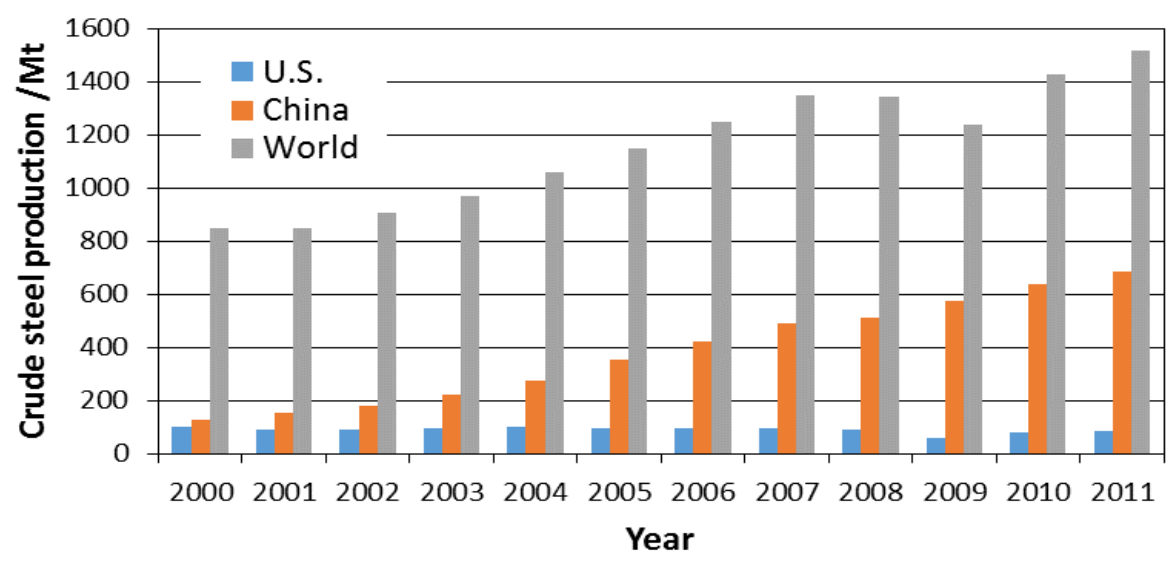

Figure 2. Annual Crude Steel Production

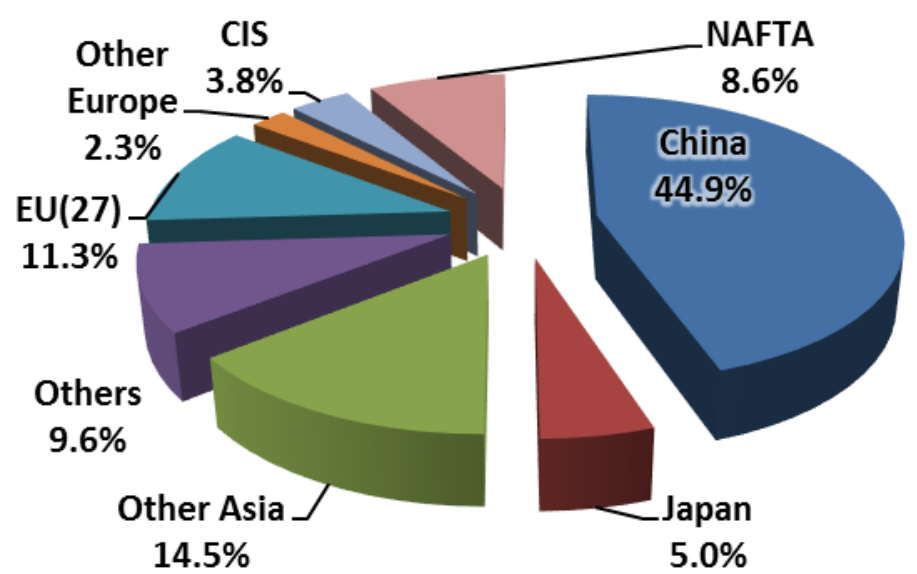

Figure 3. Global use of Steel in 2010 
However, the use of HSS is limited by current Chinese Code for Design of Steel Structures GB 50017-2003 [6] and Code for Seismic Design of Buildings GB 50011-2010 [7]. The former limits structural steel grade up to Q420 (with nominal yield strength of $420 \mathrm{MPa}$ ). The later requires a higher ductility of steels due to the expectation of inelastic behavior of structural elements and connections under rare earthquakes. With the increase in material strength, the yield to tensile strength ratio (Y/T ratio) and elongation ratio of HSS could hardly meet the requirements of GB 50011-2010 [7]. According to the annual report of China Steel Construction Society in 2010, the most used steel is Q345, which takes $62 \%$ of the total steel consumption, while Q460 HSS only takes $1 \%$ of the total consumption, as shown in Figure 4. Consequently, the necessity of requirements to investigate whether the members fabricated from HSS can be designed according to the existing codes or whether the codes need to be modified to include HSS is highlighted. Moreover, it is important to determine whether HSS could be used in seismic structures and how to use HSS in seismic structures.

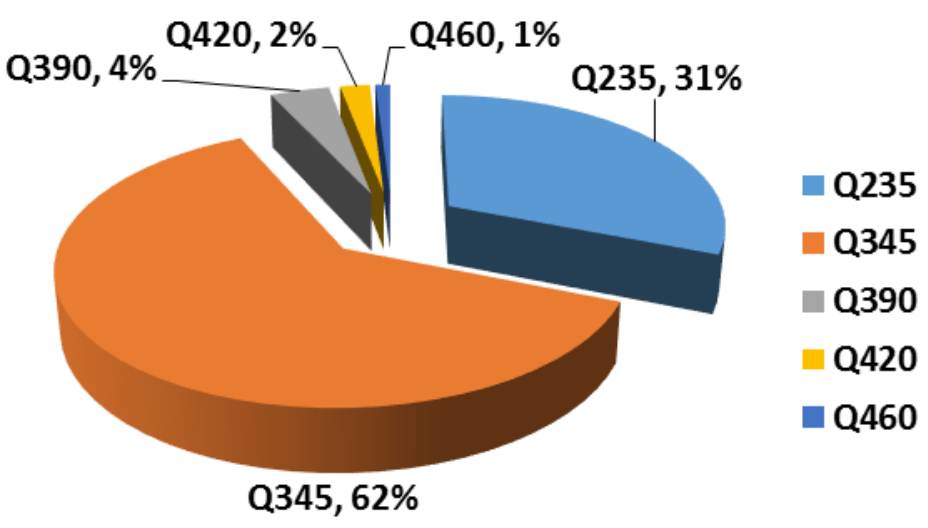

Figure 4. The Percentage of each Steel Grade Consumed in 2010 of Mainland China

In this paper, the key issues associated with the application of HSS in seismic structures are pointed out and discussed. The current state of the art of behavior of HSS and recent research on the seismic behavior of HSS carried out at Tongji University are presented. The effect of reheating and cooling during fabrication process on the mechanical properties of HSS is evaluated. Through the revisit and reconsideration on the basic level of seismic design philosophy, the design methodologies for application of HSS structures for buildings in seismic zones are proposed.

\section{LIMITS RELATED TO THE APPLICATION OF HSS IN SEISMIC RESISTANT STRUCTURES}

\subsection{Effect of Mechanical Properties on the Ductility of Structural Members}

It is expected that structures will undergo a certain degree of inelastic deformation under earthquake actions. Thus, structural members must process adequate ductility to dissipate earthquake energy. Previous researches [8-10] indicate $\mathrm{Y} / \mathrm{T}$ ratio and elongation ratio play fundamental rules in the influence on the ductility of structural members. It is obvious the elongation ratio of material has a direct influence on the deformation capacity of structural members. Meanwhile, Y/T ratio has an indirect influence on the ductility of structural members, as shown in Figure 5. Figure 5(a) shows a perforated or reduced tensile member, where $f_{y}$ is the yield strength, $f_{y}<f_{p} \leq f_{u}, f_{u}$ is the tensile strength, $N_{y}=A f_{y}, N_{p}=A_{n} f_{p}, A$ is the area of cross section, $A_{n}$ is the net area of reduced cross section. If the $\mathrm{Y} / \mathrm{T}$ ratio is high enough to result in 
$N_{y}>N_{P}$, the inelastic deformation will be localized in the reduced zone. Although the material itself has a good deformability, the ductility of the member will be significantly impaired by the localized deformation. Figure 5(b) shows a flexural member, where $M_{y}$ is the yield bending moment, $M_{p i}$ is the plastic bending moment. If the $\mathrm{Y} / \mathrm{T}$ ratio is close to 1 , the development of plastic zone in beam ends will be limited within a very short segment because the values of $M_{p 1}$ and $M_{p 2}$ are close. Consequently, the rotation capacity of the beam, which represents the ductility of flexural members, will be jeopardized.

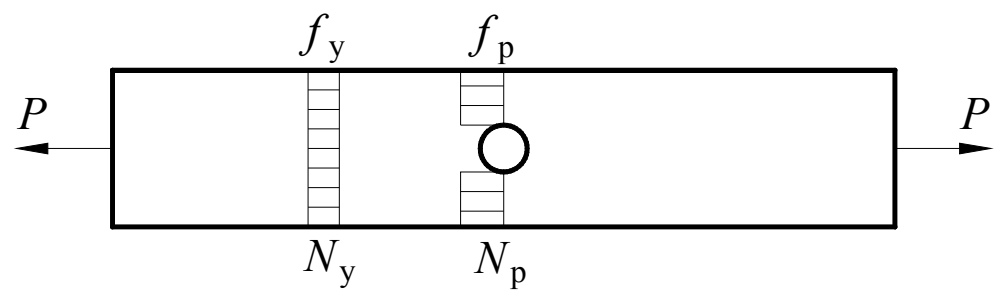

(a) Reduced members

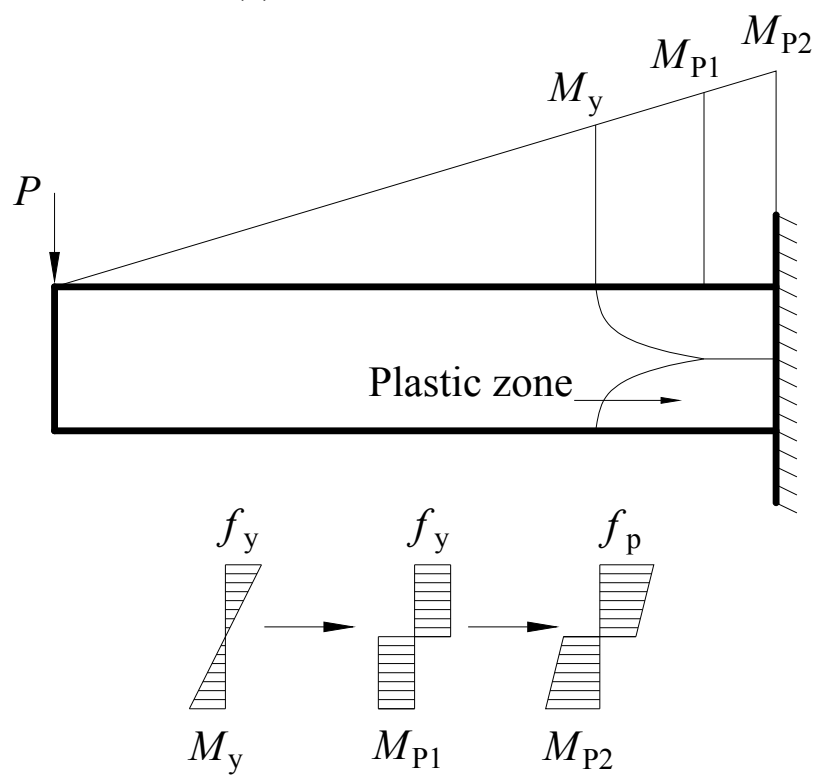

(b) Flexural members

Figure 5. The Effect of Yield Ratio on the Ductility of Members

\subsection{Limits of Current Design Codes}

The limits on Y/T ratio and elongation ratio have been specified in GB 50017-2003 [6] and GB 50011-2010 [7] to ensure the ductility and deformability of structural members, as summarized in Table 1. Compared to GB 50017-2003, seismic design code GB 50011-2010 has more strict limits on $\mathrm{Y} / \mathrm{T}$ ratio and elongation ratio. Requirements of material ductility specified in Eurocode3 [11] and Eurocode8 [12] utilize the parameters of tensile to yield strength ratio $\left(f_{\mathrm{u}} / f_{\mathrm{y}} \geq 1.10\right)$, elongation ratio (no less than 15\%) and ultimate strain (not less than 15 times of the yield strain). According to Chinese Code for Seismic Design of Buildings GB 50011-2010 [7], the ductility requirement of steel is higher than Eurocode 3 due to the consideration of inelastic behavior of structural members and connections under rare earthquakes. Based on the tensile coupon tests of various steel grade, Fukumoto [13] pointed out that the increase in strength will result in the increase in Y/T ratio and the decrease in elongation ratio, which indicates the HSS could hardly meet the ductility requirements for seismic design. For comparison with Table 1, the limits of material requirements 
specified in Steel Plates for Building Structure GB/T 19879-2005 [14] and High Strength Low Alloy Structural Steels GB/T 1591-2008 [15] are shown in Table 2 and Table 3, respectively. It can be seen that steel plates with nominal yield strength no less than $420 \mathrm{MPa}$ could not meet the ductility requirements of GB 50011-2010.

Table 1. Comparison of Requirements of Mechanical Properties GB 50011-2010 GB 50017-2003

1. Yield to tensile strength ratio $\leq$ 0.85

2. Ratio of elongation after failure $\geq 20 \%$

3. Well defined yielding plateau

1. Yield to tensile strength ratio $\leq 0.83$

2. Ratio of elongation after failure $\geq 15 \%$

3. $\varepsilon_{u} \geq 20 \varepsilon_{y}$

Table 2. Requirements of Mechanical Properties in GB/T 19879-2005

\begin{tabular}{ccccc}
\hline Steel grade & $\begin{array}{c}\text { Yield strength Tensile strength } \\
(\mathrm{MPa})\end{array}$ & $\begin{array}{c}\text { EPa }) \\
\text { Elongation Y/T ratio }\end{array}$ & & \\
\hline Q235GJ & $\geq 235$ & $400 \sim 510$ & $\geq 23 \%$ & $\leq 0.80$ \\
Q345GJ & $\geq 345$ & $490 \sim 610$ & $\geq 22 \%$ & $\leq 0.83$ \\
Q390GJ & $\geq 390$ & $490 \sim 650$ & $\geq 20 \%$ & $\leq 0.85$ \\
Q420GJ & $\geq 420$ & $520 \sim 680$ & $\geq 19 \%$ & $\leq 0.85$ \\
Q460GJ & $\geq 460$ & $550 \sim 720$ & $\geq 17 \%$ & $\leq 0.85$ \\
\hline
\end{tabular}

Table 3. Requirements of Mechanical Properties in GB/T 1591-2008

\begin{tabular}{ccccc}
\hline Steel grade $\begin{array}{c}\text { Yield strength Tensile strength } \\
(\mathrm{MPa})\end{array}$ & \multicolumn{3}{c}{ Elongation Y/T ratio } \\
\hline Q345 & $\geq 345$ & $470 \sim 630$ & $\geq 20 \%$ & $\leq 0.73$ \\
Q390 & $\geq 390$ & $490 \sim 650$ & $\geq 20 \%$ & $\leq 0.80$ \\
Q420 & $\geq 420$ & $520 \sim 680$ & $\geq 19 \%$ & $\leq 0.81$ \\
Q460 & $\geq 460$ & $550 \sim 720$ & $\geq 17 \%$ & $\leq 0.84$ \\
Q500 & $\geq 500$ & $610 \sim 770$ & $\geq 17 \%$ & $\leq 0.82$ \\
Q550 & $\geq 550$ & $670 \sim 830$ & $\geq 16 \%$ & $\leq 0.82$ \\
Q620 & $\geq 620$ & $710 \sim 880$ & $\geq 15 \%$ & $\leq 0.87$ \\
Q690 & $\geq 690$ & $770 \sim 940$ & $\geq 14 \%$ & $\leq 0.90$ \\
\hline
\end{tabular}

\subsection{Limits of Current Researches on HSS}

In aiming to extend current steel structure design codes to include HSS, recent researches have been performed on the behavior of HSS structural members under monotonic loading. The experimental and numerical investigations on HSS beams [16-19] have shown that yield strength and yield to ultimate strength ratio has significant influence on the rotation capacity of beam members. Compared with conventional steel, the rotation capacity of HSS beam with identical cross-sectional geometry was reduced by over $70 \%$. Although the current specifications are able to predict the flexural strength of HSS beams, the existing compactness criteria cannot guarantee the required rotation capacity for HSS members. Previous researches on ultimate bearing capacity, local and overall buckling behavior of HSS columns [20-24] have shown that the effects of initial geometric imperfection and residual stress on the buckling behavior of HSS columns are less detrimental than those on normal strength steel columns. The current steel structure design standards are slightly conservative for HSS. Minor modifications of existing design codes might be necessary to include the design of HSS structures in non-seismic regions. 
However, it is not economical to design structures as assuming them in elastic range under severe earthquake. Thus, it is recommended that structures shall be able to endure certain inelastic deformation to dissipate earthquake energy. The energy dissipation capacity of structure depends mainly on the energy dissipation capacity of structural members, which is not only a function of mechanical properties, but also affected by cross-sectional geometry and loading conditions. Currently, the application of HSS in seismic design is restricted by existing seismic design codes and constructional practice, which are established based on the study of conventional steel. Therefore, the seismic performance of HSS should be examined when it was related to the application of HSS in structural design for earthquake-resistance. Therefore, better understanding of inelastic cyclic behavior of HSS, as well as the seismic performance of HSS structural members, is important for determining the suitability of application of HSS for seismic resistant structure.

Currently, only limited investigations on the cyclic behavior and hysteretic model of HSS have been reported on the literatures. Dusicka et al. [25] investigated the inelastic cyclic behavior and low-cycle fatigue life of plate steels with the nominal yield strength up to $485 \mathrm{MPa}$. Ramberg-Osgood model was used to fit the experimental skeleton curves and the associated coefficients were obtained from data regression of the test result. Although the power function based on the Ramberg-Osgood model seems efficient to describe the nonlinear part of the cyclic skeleton curve, it is inconvenient to be implemented in numerical analysis in structural level due to the implicit expression of stress in the power function. To this end, an explicit expression of stress in terms of rational function with four fitting parameters was proposed by Shi et al. [26]. The model parameters were calibrated by Q460D steel (nominal yield strength of $460 \mathrm{MPa}$ ) based on the test results of 17 coupon specimens. However, in the previous researches, the verification of hysteretic model for HSS was limited to the material level. This is mainly attributed to the scarcity of test data of seismic behavior of HSS members, which highlights the necessary for an extensive study on cyclic response of HSS members. Moreover, further evaluation on the effect of mechanical properties on the cyclic behavior and energy dissipation capacity of HSS structural members is required.

\section{MECHANICAL PROPERTIES AFTER REHEATING AND COOLING DURING FABRICATION PROCESS}

According to Chinese code GB/T 1591-2008 [15] and European code EN 10025-6 [27], HSSs are currently delivered in the quenched and tempered condition and thermo-mechanically controlled processed (TMCP) condition. Both quenching and TMCP have a controlled-cooling process, which is usually an accelerated cooling process by water, oil, or forced-air, to get the preferred crystalline phases of the alloy and the finer grain size. The cooling speed is an important factor for the ductility and strength of steels. However, fabrication process such as flame cutting, welding, and flame straightening will introduce a reheating and cooling process on the local area of steel members. The maximum temperature of flame cutting and welding is over $1200^{\circ} \mathrm{C}$. The maximum temperature of flame straightening is about $650^{\circ} \mathrm{C}-900^{\circ} \mathrm{C}$ depending on heating time. Similar as tempering, the experience of such high temperatures may produce a serious reduction in the strength and hardness of the heat-affected zones.

In order to evaluate the effect of reheating and cooling on the mechanical properties of HSS, tensile tests of 8 coupons were carried out from a flame straightened Q690D box column, as shown in Figure 6. The box column specimen was fabricated from $16 \mathrm{~mm}$ Q690D steel plate with the cross-sectional width and height of $250 \mathrm{~mm}$. Full-thickness heating and air cooling was applied on the triangular areas of webs and rectangular area of top flange. Tensile coupons are machined from the bottom flange and the heating areas of top flange and webs. Eight tensile coupons were tested in 
accordance with the specifications of GB/T 228-2002 [28], and the values of the tests are summarized in Table 4 . In the Table $4, E$ is the Young's modulus, $f_{y}$ is the $0.2 \%$ proof stress, which is adopted as the yield strength of steel, $f_{u}$ is the ultimate tensile stress, and $\delta$ is the percentage of elongation after fracture. It can be seen from Table 4, the effect of reheating and cooling on the elongation ratio should not be ignored. Compared with the bottom flange, the elongation ratio of heat-affected zone in top flange is reduced by up to $12 \%$. Moreover, the yield strength and tensile strength of top flange are reduced by $21 \%$ and $11 \%$, respectively. The reduction of yield strength is about twice of the reduction of tensile strength. The reductions of the yield and tensile strengths of webs are $18 \%$ and $9 \%$. Therefore, this influence of reheating during fabrication process should be considered in the design of HSS structures. Otherwise, the "premature" local and overall buckling and unexpected location of plastic hinge might appear in HSS structure to impair its seismic performance.

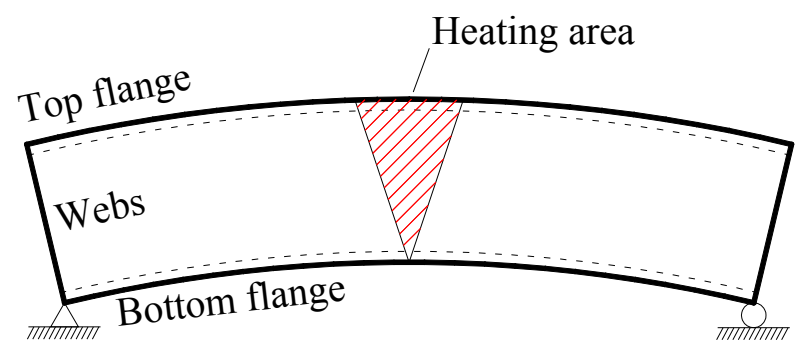

(a) Elevation view

Back web

Heating area

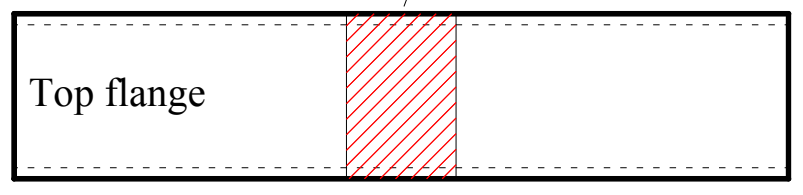

Front web

(b) Plane view

Figure 6. Flame Straightening of Box Column

Table 4. Mechanical Properties of Flame Straightened Q690D Steel

\begin{tabular}{ccccc}
\hline Specimens & $f_{y}(\mathrm{MPa})$ & $f_{w}(\mathrm{MPa})$ & $\boldsymbol{f}_{y} / \tilde{f}_{\mathrm{w}}$ & $\delta(\%)$ \\
\hline \multirow{2}{*}{ Top flange } & 593.8 & 696.3 & 0.85 & 18.0 \\
Mean value & 600.4 & 728.3 & 0.82 & 18.6 \\
\hline \multirow{2}{*}{ Front web } & 597.1 & 712.3 & 0.84 & 18.3 \\
& 601.7 & 706.7 & 0.85 & 19.4 \\
Back web & 587.5 & 748.3 & 0.84 & 18.9 \\
Mean value & 653.1 & 712.8 & 0.82 & 19.6 \\
\hline \multirow{2}{*}{ Bottom flange } & 760.2 & 762.1 & 0.93 & 19.5 \\
Mean value & 746.9 & 732.5 & 0.9 & 19.3 \\
\hline
\end{tabular}

\section{RECONSIDERATIONS ON THE BASIC LEVEL OF SEISMIC DESIGN PHILOSOPHY}

The current seismic design philosophy is based on the assumption that structural members and connections can undergo a certain plastic deformation without a loss in structural bearing capacity under expected rare earthquake actions. The correctness of this assumption is ensured by the 
specified material requirements in current seismic design code. Accordingly, as HSS could not meet the material requirements, HSS members are not permitted to use in seismic structures. However, the application of HSS in seismic structures could be reconsidered in the level of seismic resistant design philosophy when we give up this assumption. Consequently, two design methodologies for HSS seismic resistant structures are proposed herein.

\subsection{Determination of Design Earthquake Action}

In view of structural performance under earthquake, design earthquake action could be reduced in accordance with the ductility of structures, as shown in Figure7. Structures with good ductility could be designed under a reduced earthquake loading, so the inelastic behavior of structures is expected under actual earthquake action and the earthquake energy could be dissipated by plastic deformation of members and connections. Instead, brittle structures should be designed under more serious earthquake actions than ductile structures to reduce the requirement of structural ductility.

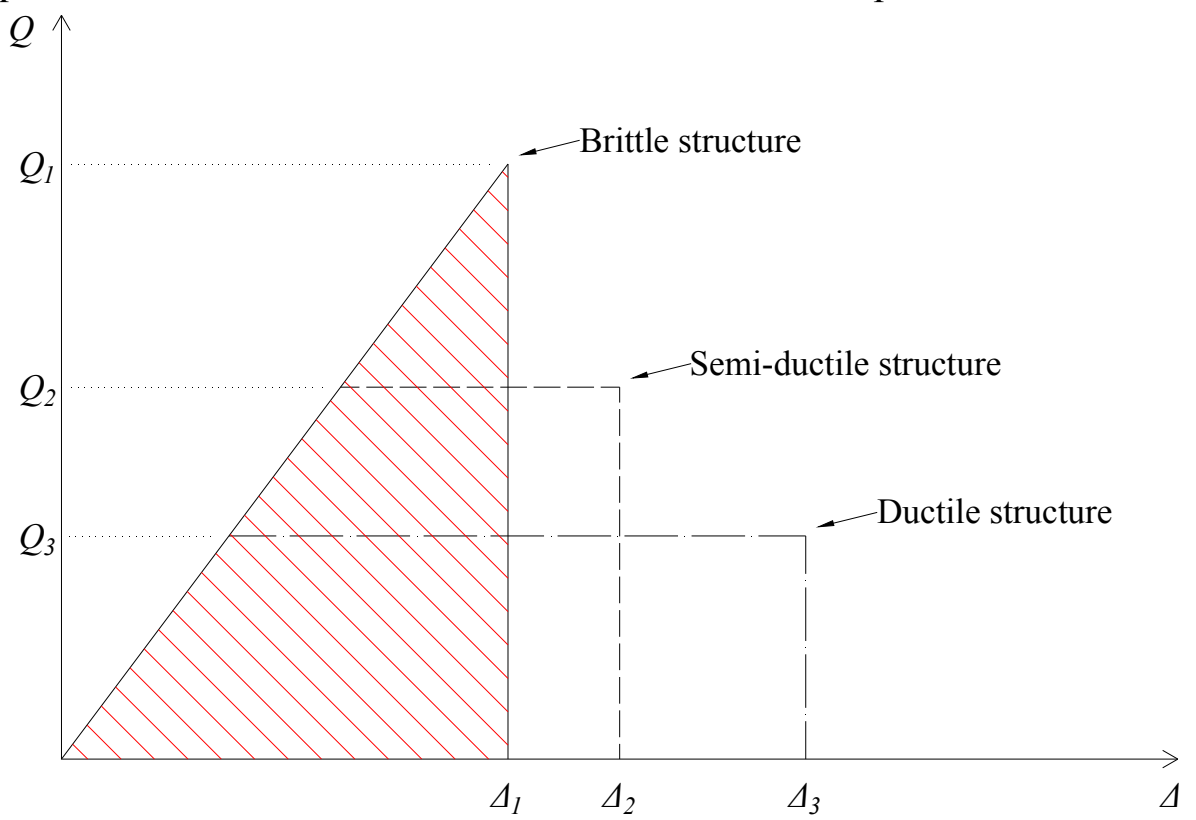

Figure7. The Effect of Ductility on the Requirement of Design Seismic Actions

\subsection{Selection of Structural Systems}

The design based on the assumption of preventing steel structures from inelastic status under expected rare earthquakes is usually uneconomical and unreasonable. Thus, seismic resistant buildings are mostly designed as dissipative structures which allow for the formation of plastic hinges in the expected locations, such as "strong column, weak beam" philosophy. However, the ductility of HSS members is not guaranteed to satisfy the demands of structural plastic behavior during earthquake actions. It is important to note that the ductility of structures, in addition to the ductility of materials and members, also depends on the selection of structural systems. If an appropriate structural system is selected for HSS structures, the plastic deformations can be isolated in the specified dissipative members to prevent the yield of HSS members.

One of such suggested structural systems is consisted of semi-rigid frames and special energy dissipation members, as shown in Figure 8. Semi-rigid frames can provide sufficient deformation under seismic force [29]. Special lateral force resistant members, such as buckling restrained braces (BRB) and buckling restrained steel plate shear wall (BRSW), are designed to possess sufficient plastic deformation capacity and energy dissipation capacity [30, 31]. Consequently, HSS members designed with sufficient over strength will not yield during earthquakes. 


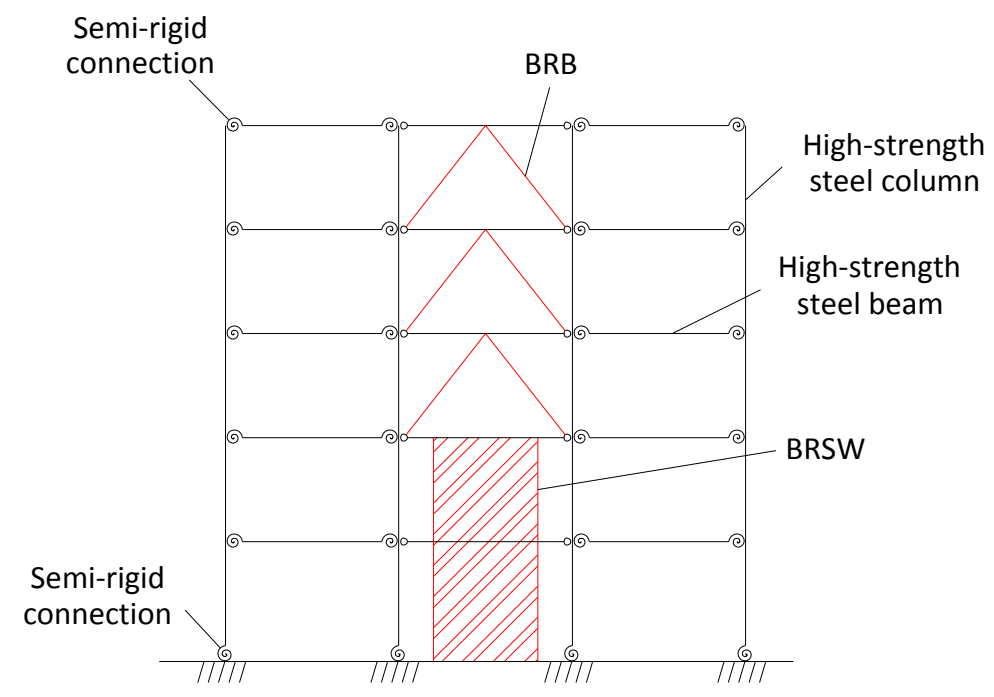

Figure 8. Structure System providing Elastic Design of High-strength Steel Member

The other suggested structural system by Dubina et al. [32] is called dual steel structures (DSS), as shown in Figure 9. DSS is constituted by several bays of HSS moment-resisting frames and at least one bay of eccentrically braced frame with removable links fabricated from normal strength steel or low yield strength steel. The plastic deformations of normal and low yield strength steel members are expected to occur under moderate or rare earthquake actions to reduce the ductility demand of HSS members. The energy dissipation members can behave as fuses of structures. The non-dissipative members are designed with HSS of enough overstrength to prevent inelastic deformation and critical damage. Therefore, HSS frames can sustain the robustness of the gravity load bearing system.

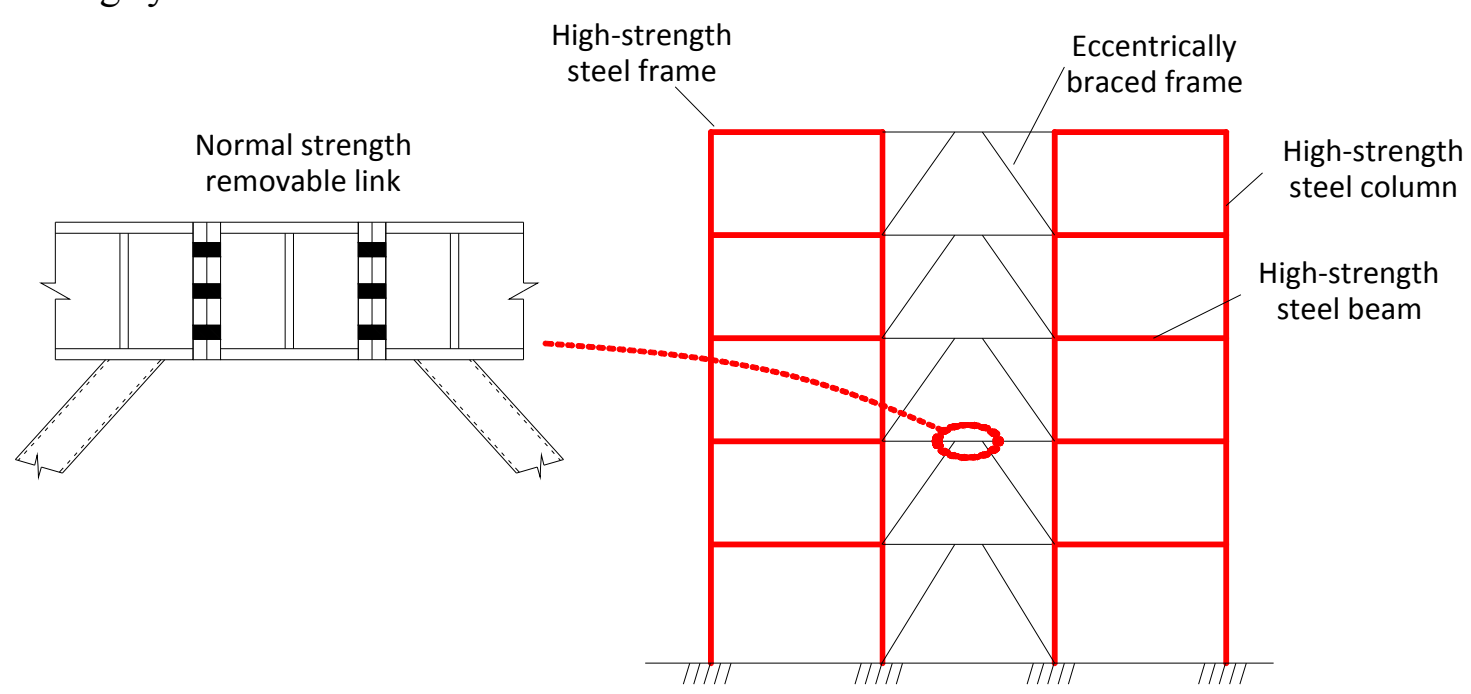

Figure 9. Dual Steel Structure System by Dubina et al. [32]

In those suggested structure systems for HSS structures, energy dissipation members and links are designed as only employed in seismic force-resisting systems instead of bearing gravity load. Therefore, those members and links could be easily replaced if damage occurred after strong earthquake. The interruption of the function and occupation of buildings can be significantly reduced compared with conventional structure systems. 


\subsection{Adjustment of Reliability Index}

Moreover, under probability-based design criteria, the targeted reliability index of members with insufficient ductility could be strengthened to enhance the safety of those members. Structural members are classified into ductile members and brittle members in Unified Standard for Reliability Design of Building Structures GB 50068-2001 [33]. Although HSS members could not meet the material requirements of ductile members as normal strength steel, it is uneconomical to be designed as brittle members since it has considerable ductility higher than that of brittle members. Therefore, a new class named semi-ductile member is suggested, as shown in Table 5 and Table 6. If HSS could not meet the material requirements of ductile member while can meet the material requirements of semi-ductile member, the targeted reliability index of semi-ductile failure should be adopted in the design of HSS members.

Table 5. Classification of Ductility for High-strength Steel Members

\begin{tabular}{cccc}
\hline $\begin{array}{c}\text { Material } \\
\text { properties }\end{array}$ & $\begin{array}{c}\text { Ductile } \\
\text { member }\end{array}$ & $\begin{array}{c}\text { Semi-ductile } \\
\text { member }\end{array}$ & $\begin{array}{c}\text { Brittle } \\
\text { member }\end{array}$ \\
\hline Elongation & $\geq 20 \%$ & $\geq 14 \%$ & $\leq 10 \%$ \\
Y/T & $\leq 0.85$ & $\leq 0.9$ & - \\
\hline
\end{tabular}

Table 6. Targeted Reliability Index of High-strength Steel Members for Ultimate Limit State

\begin{tabular}{cccc}
\hline \multirow{2}{*}{ Failure mode } & \multicolumn{3}{c}{ Important category } \\
\cline { 2 - 4 } & I & II & III \\
\hline Ductile failure & 3.7 & 3.2 & 2.7 \\
Semi-ductile failure & 4.2 & 3.7 & 3.2 \\
Brittle failure & 4.7 & 4.2 & 3.7 \\
\hline
\end{tabular}

\section{RECENT RESEARCH PROGRESS ON SEISMIC BEHAVIOR OF HSS IN TONGJI UNIVERSITY}

\subsection{Material Properties}

The mechanical properties of Q460C and Q690D steel were studied through monotonic-loading and cyclic-loading experiments [34]. The stress-strain relationships were obtained from 40 tensile coupon tests, as shown in Figure 10. It can be seen that the strain hardening of Q460C and Q690D steels is not as significant as normal strength steels. Moreover, for some Q460C coupons, there is even no well-defined yield plateau. The stress-strain hysteretic curves were obtained from the cyclic-loading experiments, as shown in Figure 11a. Based on the generalization of the typical hysteretic curve, each half cycle of hysteretic loops was divided into elastic part, transition part and hardening part. A trilinear kinematic hardening model was used to predict the cyclic response of HSS, with considering the observed Bauschinger effect and cyclic strain hardening, as shown in Figure 11b. In order to verify the accuracy of the proposed HSS hysteretic model, quasi-static cyclic loading tests of Q460C and Q690D steel beam-column specimens of an accompanied study were simulated and compared. 


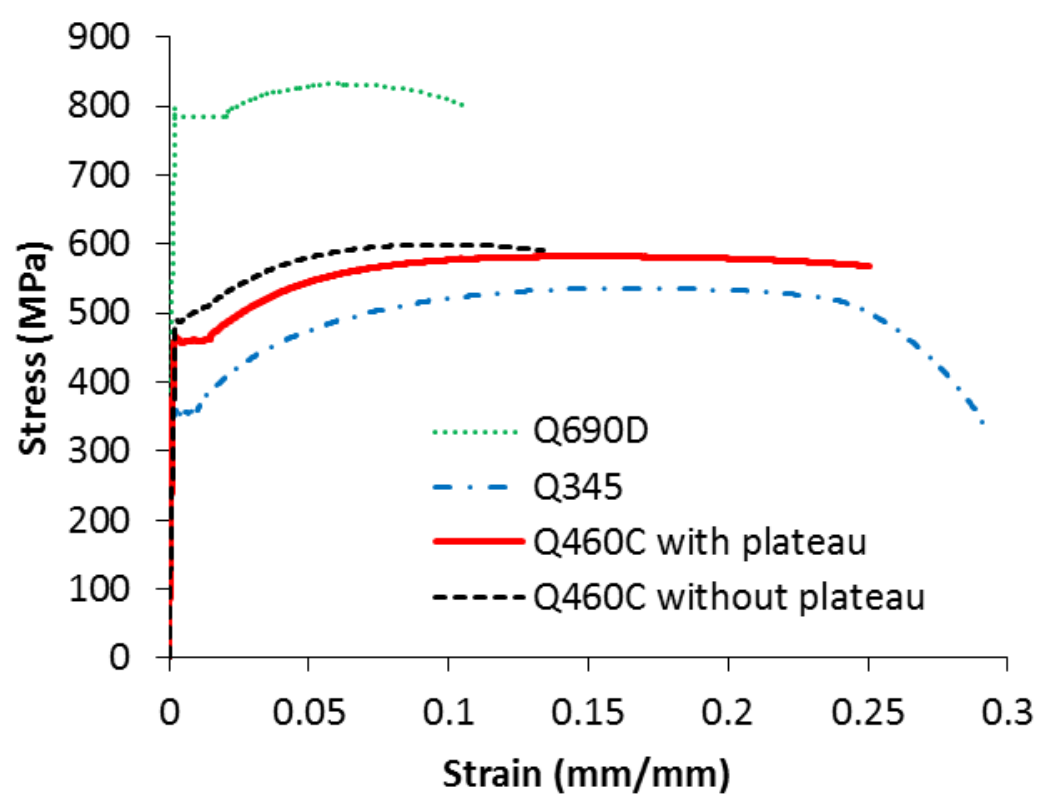

Figure 10. Typical Stress-strain Relationship of Q460C Steel

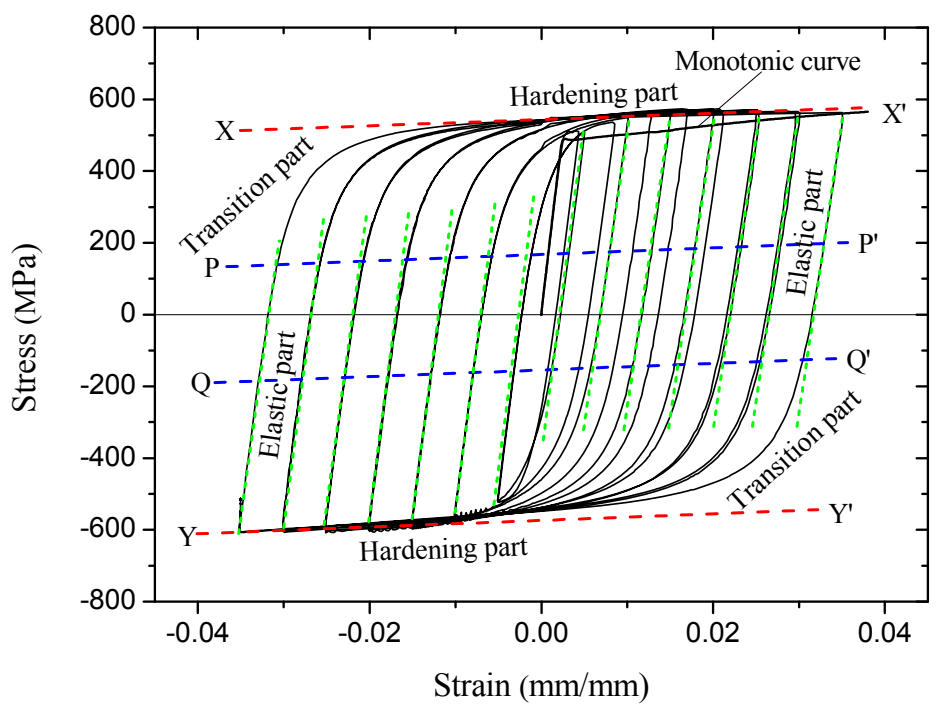

(a) Generalization of the typical hysteretic curve for Q460 steel 


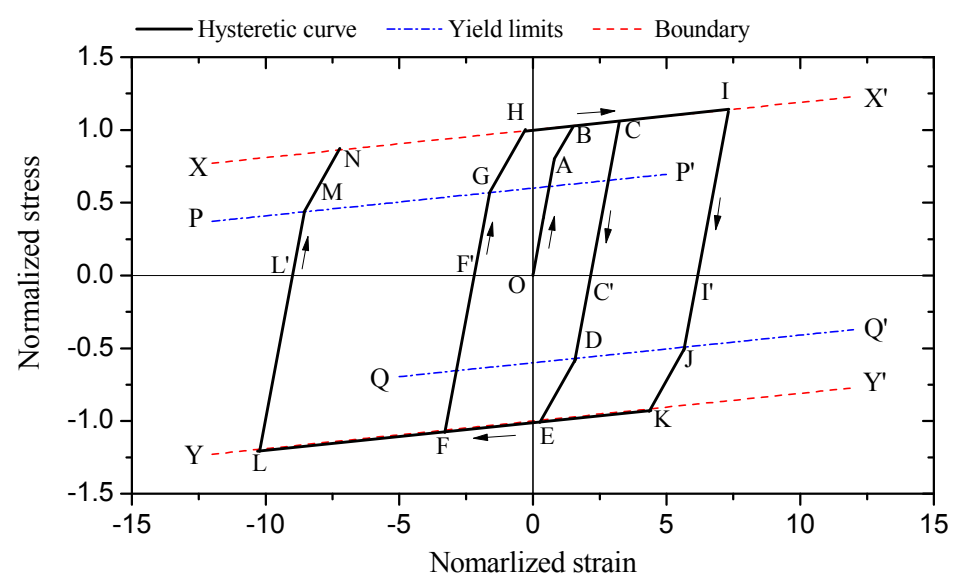

(b) Trilinear kinematic hardening model

Figure 11. Proposed Hysteretic Model for Q460 Steel

\subsection{Hysteretic Behavior}

A total of 12 welded H-section and box-section beam-column specimens with nominal yield strengths of $460 \mathrm{MPa}$ and $690 \mathrm{MPa}$ were tested to evaluate the seismic behavior of HSS members [35]. The fabricated specimens were tested under constant axial loading combined with quasi-static cyclic lateral loading. Ultimate strength, ductility and energy dissipation capacity were evaluated base on the observations of the obtained lateral load-displacement hysteretic curves. All the moment-rotation curves achieved plump hysteretic loops at large storey drift ratio up to $1 / 30$, indicating a good capacity of energy dissipation for the tested HSS H-section and box-section beam-column specimens even under severe earthquake. The effect of cross-sectional geometry on energy dissipation capacity of HSS beam-column members was investigated experimentally and numerically. Moment-curvature hysteretic curves were developed to minimize the influence of the potential slipping and inevitable elastic deformation of the fixed support at column end. Based on the analysis of moment-curvature curves, a trilinear hysteretic model was proposed for HSS welded $\mathrm{H}$-section and box-section columns, as shown in Figure 12. 


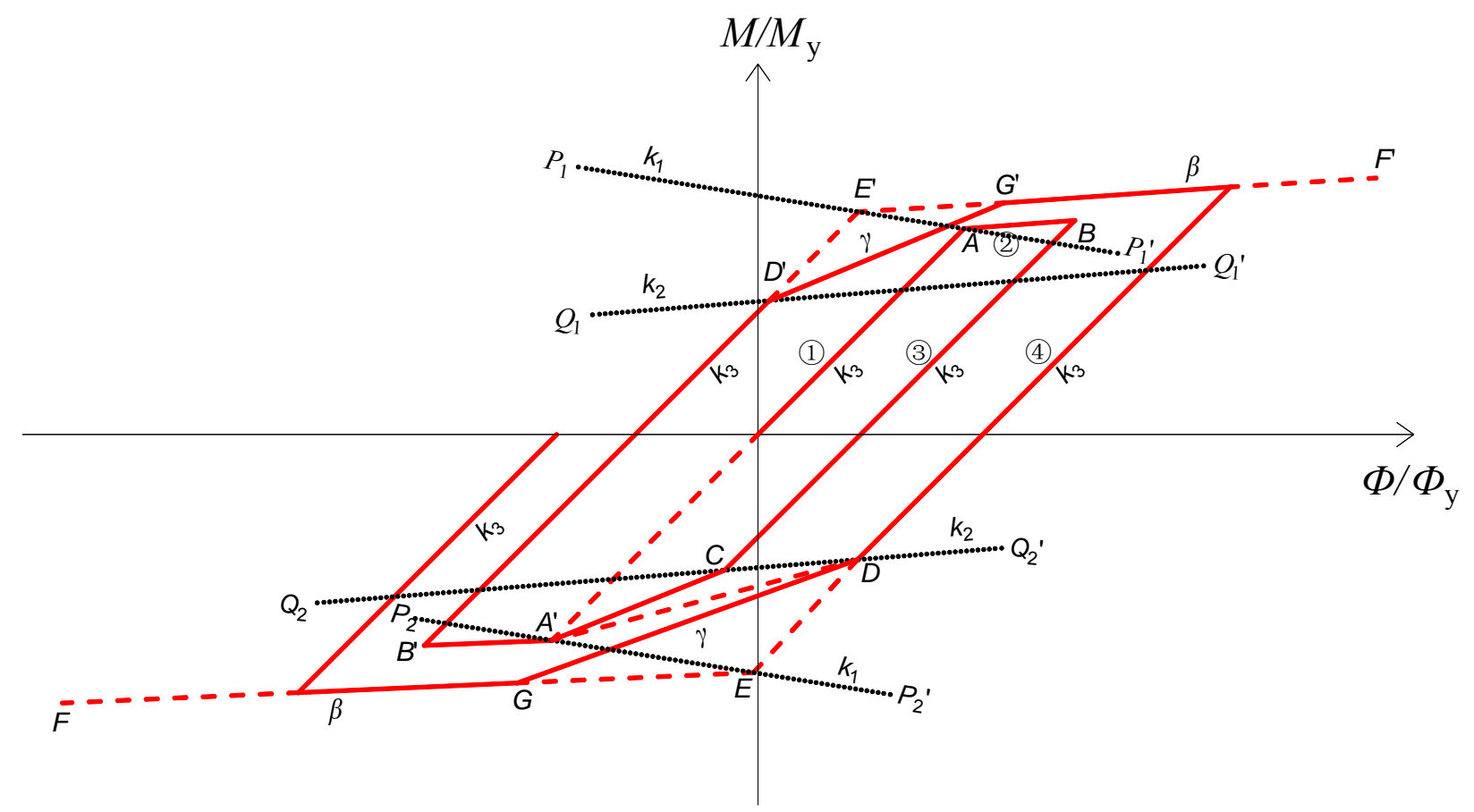

Figure 12. Proposed Moment-curvature Hysteretic Models

\section{CONCLUSION AND RECOMMENDED FUTURE WORK}

Key issues of using high strength steels in seismic structures are discussed. Two design methodologies for HSS seismic resistant structures are proposed. Recent research work on the seismic performance of high-strength steel conducted at Tongji University is introduced. The effect of reheating and cooling during fabrication process on the mechanical properties of HSS is evaluated. The significant reduction of the strength of HSS by reheating should be considered in seismic design. Although certain efforts have been achieved on HSS structures, future research work is necessary, as suggested below, to include HSS in the structural design specifications.

(1) Statistic research of material properties and determination of partial factors for resistance;

(2) Ultimate bearing capacity and deformability of fundamental HSS members;

(3) Hysteretic behavior and hysteretic model of HSS beam and beam-column;

(4) Connections of HSS members;

(5) Fatigue behavior of HSS members and connections;

(6) Structural system for HSS structures;

(7) Determination of targeted reliability index and partial factors for actions;

(8) Determination of design earthquake action and criteria for performance-based design.

\section{ACKNOWLEDGEMENTS}

This study was supported by the Ministry of Science and Technology of China (Grant No. 2012BAJ13B02) and China Postdoctoral Science Foundation (Grant No. 2014M561518), which are gratefully acknowledged. 


\section{REFERENCES}

[1] Rosier, G.A., Croll, J.E., "High Strength Quenched and Tempered Steels in Structures Seminar Papers of Association of Consulting Structural Engineers of New South Wales", Steel in Structures, Sydney, Australia, 1987.

[2] Pocock, G., "High Strength Steel use in Australia, Japan and the US", Structural Engineer, 2006, Vol. 84, pp. 27-30.

[3] Collin, P. and Johansson, B., "Bridges in High Strength Steel", Responding to Tomorrow's Challenges in Structural Engineering", IABSE Symposium, Zurich, Switzerland, ETH Honggerberg, 2006, pp. 434-5.

[4] World Steel Association, Annual Crude Steel Production Archive, http://www.worldsteel.org/statistics/statistics-archive/annual-steel-archive.html. 2012.

[5] World Coal Association. Coal Statistics - Coal Facts 2011, http://www.worldcoal.org/resources/coal-statistics/. 2011.

[6] GB 50017-2003, Code For Design of Steel Structures. Beijing: China Architecture \& Building Press, 2003 (in Chinese).

[7] GB 50011-2010. Code for seismic design of buildings Beijing: China Architecture \& Building Press, 2010 (in Chinese).

[8] Kato, B., "Deformation Capacity of Steel Structures", Journal of Constructional Steel Research, 1990, Vol. 17, pp. 33-94.

[9] Kato, B., "Role of Strain-hardening of Steel in Structural Performance", ISIJ International, 1990, Vol. 30, pp. 1003-9.

[10] Earls, CJ., "Influence of Material Effects on Structural Ductility of Compact I-Shaped Beams", Journal of Structural Engineering. 2000, Vol. 126, pp. 1268-78.

[11] CEN. Eurocode 3: Design of Steel Structures, Part 1-1: General Rules and Rules for Buildings, EN 1993-1-1. Brussels: European Committee for Standardization, 2005.

[12] CEN. Eurocode 8: Design of Structures for Earthquake Resistance, Part 1-1: General Rules, Seismic Actions and Rules for Buildings, EN 1998-1. Brussels: European Committee for Standardization, 2004.

[13] Fukumoto, Y., "New Constructional Steels and Structural Stability", Engineering Structures, 1996, Vol. 18, pp. 786-91.

[14] GB/T 19879-2005. Steel Plates for Building Structure, 2005.

[15] GB/T 1591-2008. High Strength Low Alloy Structural Steels, 2008.

[16] Earls, C.J., "Suitability of Current Design Practice in the Proportioning of High Performance Steel Girders and Beams", Proceedings of the 17th International Bridge Conference, Pittsburgh: Engineers' Society of Western Pennsylvania, 2000, pp. 91-8.

[17] Green, P.S., Sause, R. and Ricles, J.M., "Strength and Ductility of HPS Flexural Members", Journal of Constructional Steel Research, 2002, Vol. 58, pp. 907-41.

[18] Earls, C.J. and Shah, B.J., "High Performance Steel Bridge Girder Compactness", Journal of Constructional Steel Research, 2002, Vol. 58, pp. 859-80.

[19] Sause, R. and Fahnestock, L.A., "Strength and Ductility of HPS-100W I-Girders in Negative Flexure", Journal of Bridge Engineering, 2001, Vol. 6, pp. 316-23.

[20] Rasmussen, K.J.R. and Hancock, G.J., "Plate Slenderness Limits for High Strength Steel Sections", Journal of Constructional Steel Research, 1992, Vol. 23, pp. 73-96.

[21] Rasmussen, K.J.R. and Hancock, G.J., "Tests of High Strength Steel Columns", Journal of Constructional Steel Research, 1995, Vol. 34, pp. 27-52.

[22] Ban, H., Shi, G., Shi, Y. and Wang, Y., "Overall Buckling Behavior of $460 \mathrm{MPa}$ High Strength Steel Columns: Experimental Investigation and Design Method", Journal of Constructional Steel Research, 2012, Vol. 74, pp. 140-50. 
[23] Wang, Y-B., Li, G-Q., Chen, S-W. and Sun, F-F., "Experimental and Numerical Study on the Behavior of Axially Compressed High Strength Steel Columns with H-section", Engineering Structures, 2012, Vol. 43, pp. 149-59.

[24] Wang, Y-B., Li, G-Q., Chen, S-W. and Sun, F-F., "Experimental and Numerical Study on the Behavior of Axially Compressed High Strength Steel Box-columns", Engineering Structures, 2014, Vol. 58, pp. 79-91.

[25] Dusicka, P., Itani, A.M. and Buckle, I.G., "Cyclic Response of Plate Steels under Large Inelastic Strains", Journal of Constructional Steel Research, 2007, Vol. 63, pp. 156-64.

[26] Shi, G., Wang, M., Bai, Y., Wang, F., Shi, Y. and Wang, Y., "Experimental and Modeling Study of High-strength Structural Steel under Cyclic Loading", Engineering Structures, 2012, Vol. 37, pp. 1-13.

[27] CEN. Hot Rolled Products of Structural Steels, Part 6: Technical Delivery Conditions for Flat Products of High Yield Strength Structural Steels in the Quenched and Tempered Condition, EN 10025-6. Brussels: European Committee for Standardization, 2004.

[28] GB/T 228-2002 Metallic Materials: Tensile Testing at Ambient Temperature, Beijing: China Standard Press, 2002 (in Chinese).

[29] Shi, W.L., Li, G.Q., Ye, Z.M. and Xiao, R.Y., "Cyclic Loading Tests on Composite Joints with Flush End Plate Connections", International Journal of Steel Structures, 2007, Vol. 7, pp. 119-28.

[30] Lu, Y. and Li, G.Q., "Slim Buckling-restained Steel Plate Shear Wall and Simplified Model", Advanced Steel Construction, 2012, Vol. 8, pp. 282-94.

[31] Li, G.Q., Sun, F.F., Chen, S.W. and Guo, X.K., Application of Buckling-Restrained Braces in Steel Frameworks against Earthquakes, 2010.

[32] Dubina, D., Stratan, A. and Dinu, F., "Dual high-strength Steel Eccentrically Braced Frames with Removable Links", Earthquake Engineering and Structural Dynamics, 2008, Vol. 37, pp. 1703-20.

[33] GB 50068-2001. Unified Standard for Reliability Design of Building Structures, Beijing: China Architecture \& Building Press, 2001 (in Chinese).

[34] Wang Y-B, Li G-Q, Cui W, Chen S-W, Sun F-F. Experimental investigation and modeling of cyclic behavior of high strength steel. Journal of Constructional Steel Research. 2015; 104:37-48.

[35] Wang Y-B, Li G-Q, Cui W, Chen S-W. Seismic behavior of high strength steel welded beam-column members. Journal of Constructional Steel Research. 2014;102:245-255. 


\title{
FORM-FINDING ANALYSIS OF IRREGULAR TENSEGRITY STRUCTURES BY MATRIX ITERATION
}

\author{
JinYu Lu ${ }^{1,2, *}, \mathrm{Na} \mathrm{Li}^{3}$ and GanPing Shu ${ }^{1,2}$ \\ ${ }^{1}$ Key Lab of Concrete and Prestressed Concrete Structures of Ministry of Education, Nanjing 210096, China \\ ${ }^{2}$ School of Civil Engineering, Southeast University, Nanjing 210096, China \\ ${ }^{3}$ College of Electronic and Mechanical Engineering, Nanjing Forestry University, Nanjing 210037, China
}

\begin{abstract}
This paper proposed a novel form-finding method for irregular tensegrity structures base on matrix iteration. On the basis of two different forms of structural equilibrium equations, the estimated elemental self-stresses and nodal coordinates were constructed via the singular value decomposition of equilibrium matrix and eigenvalue decomposition of force density matrix, respectively. The configuration of tensegrity that satisfies the specified coordinates was determined through the iterative computation of self-stresses and nodal coordinates, and the constraint condition was introduced in the construction of the estimated nodal coordinates simultaneously. The detailed algorithm procedure was listed and the convergent criterion was also defined. In the end, several illustrated examples were given to prove the validity of the algorithm. Numerical examples and physical models showed that the proposed form-finding method was correct and efficient. The form-finding algorithm could be applied to find tensegrity structures that satisfied the given geometrical forms, and the creation of novel irregular tensegrity, as long as the topological relation and several known coordinate of nodes were given.
\end{abstract}

Keywords: Irregular tensegrity, Form-finding, Equilibrium matrix, Force density matrix, Numerical method

DOI: $10.18057 / \mathrm{IJASC} .2015 .11 .4 .7$

\section{INTRODUCTION}

Tensegrity, a kind of self-balancing system where the cables are in continuous tensional status and a few of struts are located among the cables, is light-weight but efficient, in that they could be stiffened by specified inner prestressing. Tensegrity structures have been already applied to several research fields [1,2], such as mechanical control, aerospace, biology, etc.. In addition, an alternative form of tensegrity, i.e. cable dome, has been widely used in the large span structures in contemporary architecture.

As a sort of form-sensitive structure, the superior mechanical property of tensegrity comes from its reasonable geometrical configuration. The topology, geometry and the prestressing both affect its stability and stiffness. Hence, form finding is the core of tensegrity researches [3]. The form-finding algorithms were divided into two categories by Tibert and Pellegrino [4], respectively static method and dynamic method, ranging from analytic method to force density method proposed by Schek and Linkwitz, and to dynamic relaxation method introduced earlier by Motro and Belkacem. These early form-finding algorithm gave more prominence to the research of reasonable topological relations. Accordingly, the form-finding results were mainly regular tensegrity structures, attaching little emphasis upon geometrical configuration. In recent decades, with the increasingly deeper researches, relevant scholars have made some improvements based on the classic algorithms and created several novel form-finding algorithms [5-9]. The irregular tensegrity and its geometrical configuration have achieved attention gradually. Meanwhile, the evolution theory began to be introduced to the form-finding optimization of tensegrity. The form-finding algorithms based on intelligence have some development, mainly including genetic algorithm [10-13], simulated annealing method [14], and Monte Carlos random search method [15]. 
On the basis of random thoughts, the intelligent algorithms could resolve the optimization problems covering the case of large solution space and the complex relations between objects and variables. More recently, novel form-finding algorithms were proposed to improve on the stability of the tensegrity structures [16]. However, the procedure needs so many search steps that it requires much more computation time. It should be noted that Estrada et al [7], Tran and Lee [8] introduced a form-finding algorithm based on the iterative computation of force density and coordinate. The algorithm merely needs to provide the connections of cables and struts, i.e. the topology, without the help of self-stress values and initial node coordinates, which has the advantage of faster convergence. Nonetheless, it is hard to control the nodal coordinates or the shape of form-finding results.

The paper offers a coordinate-based form-finding algorithm for irregular tensegrity. Firstly, it provides two different forms of equilibrium equations, namely, constructing self-stress with the singular value decomposition (SVD) of equilibrium matrix and nodal coordinates with eigenvalue decomposition of force density matrix. Moreover, the detailed form-finding algorithm flow is given, utilizing the nonlinear iterative computation of the self-stress and nodal coordinates, where the given coordinates are treated as constraint condition. Finally, two examples prove the effectiveness and stability of the form-finding algorithm. The topological connections of examples refer to the six-strut expanded octahedral tensegrity and six-strut truncated tetrahedral tensegrity. Furthermore, the forming method that six rigid struts hold up a flexible cable net is used in the construction process of physical model, and specific joints are designed for the implementation of model.

\section{EQUILIBRIUM EQUATION}

Without loss of generality, Figure 1 shows that node $i$ connects component $g$ and $h$ together. The internal forces are denoted as $t_{g}$ and $t_{h}$ respectively, while node $i$ is subjected to loads $p_{i x}, p_{i y}$ and $p_{i z}$. Based on the force balance relation, the equilibrium equation of node $i$ could be deduced as follows:
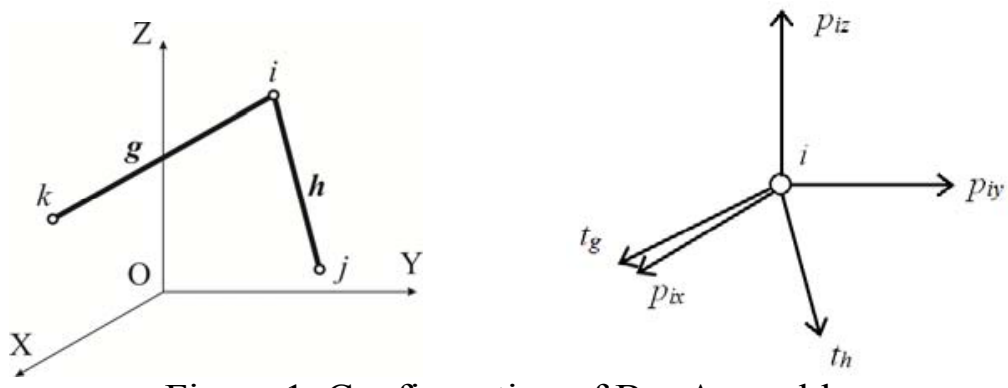

Figure 1. Configuration of Bar Assembles

$\left(x_{j}-x_{i}\right) \zeta_{h}+\left(x_{k}-x_{i}\right) \zeta_{g}=p_{i x}$

$\left(y_{j}-y_{i}\right) \zeta_{h}+\left(y_{k}-y_{i}\right) \zeta_{g}=p_{i y}$

$\left(z_{j}-z_{i}\right) \zeta_{h}+\left(z_{k}-z_{i}\right) \zeta_{g}=p_{i z}$

where $\zeta$ is force density and equals to $t / l$. Supposing that tensegrity contains $n$ nodes and $b$ elements, the global equilibrium equation can be assembled as matrix form [17]:

$\mathbf{A} \zeta=\mathbf{P}$ 
here, $\zeta=\left(\zeta_{1}, \zeta_{2}, \ldots, \zeta_{b}\right)^{\mathrm{T}}$ is the vector of force density, $\mathbf{P}=\left(\mathbf{P}_{x}, \mathbf{P}_{y}, \mathbf{P}_{z}\right)^{\mathrm{T}}$ represents the vector of nodal load and $\mathbf{P}_{x}=\left(p_{1 x}, p_{2 x}, \ldots, p_{n x}\right)^{\mathrm{T}}$ denotes the vector in $X$ degrees of freedom (DOF). The equilibrium matrix, i.e. $\mathbf{A}=\left(\mathbf{A}_{x}, \mathbf{A}_{y}, \mathbf{A}_{z}\right)^{\mathrm{T}}$, establishes the relation between nodal load and elemental internal force. Taking $X$ DOF as example, equilibrium matrix could be denoted as:

$$
\mathbf{A}_{x}=\boldsymbol{\Phi}^{\mathrm{T}} \operatorname{diag}(\boldsymbol{\Phi} \mathbf{x})
$$

in which, $\mathbf{x}=\left(x_{1}, x_{2}, \ldots, x_{n}\right)^{\mathrm{T}}$ denotes the vector of nodal coordinates, and the incidence matrix $\boldsymbol{\Phi}$ with the dimension of $b \times n$ is introduced to represent the topological connections of cables and struts. For example, the component $h$ shown in Figure 1 has initial node $i$ and terminal node $j$. In this case, $\boldsymbol{\Phi}_{h i}=1$ and $\boldsymbol{\Phi}_{h j}=-1$ should be satisfied for this element, and the other components follow the same analogy. Eq. 2 can be regarded as the equilibrium equation that takes elemental force density $\zeta$ as unknown variable. If we take nodal coordinates as unknown variable, the equation can be rewritten as:

$\mathbf{D X}=\mathbf{P}$

where $\mathbf{X}=(\mathbf{x}, \mathbf{y}, \mathbf{z})^{\mathrm{T}}$ indicates nodal coordinates vector, $\mathbf{D}$ is force density matrix, can be signified as:

$\mathbf{D}=\boldsymbol{\Phi}^{\mathrm{T}} \operatorname{diag}(\zeta) \boldsymbol{\Phi}$

Equality $\mathbf{P}=\mathbf{0}$ should be satisfied in the state of self-equilibrium for tensegrity. The following equations ought to be fulfilled:

$\mathbf{A} \zeta=\mathbf{0}$

$\mathbf{D X}=\mathbf{0}$

When the rank of equilibrium matrix is less than $b$, the structure might contain at least one self-stress mode, which is one of the necessary conditions to be a tensegrity structure.

\section{COORDINATE-BASED FORM-FINDING METHOD FOR IRREGULAR TENSEGRITY}

\subsection{Solution of Elemental Self-stress}

The singular value decomposition (SVD) is carried out for equilibrium matrix [18] A:

$\mathbf{A}=\mathbf{U S V}^{\mathbf{T}}$

Thus, orthogonal matrix $\mathbf{V}=\left(\mathbf{v}_{1}, \mathbf{v}_{2}, \ldots, \mathbf{v}_{b}\right)^{\mathrm{T}}$ is obtained. If there are $s$ modes of self-stress, it should meet the following relations [19]:

$\mathbf{A} \mathbf{V}_{s}=\mathbf{0}$

The self-stress $\zeta$ could be constructed by the vector of $\mathbf{V}_{s}=\left(\mathbf{v}_{b-s-1}, \mathbf{v}_{b-s}, \ldots, \mathbf{v}_{b}\right)^{\mathrm{T}}$. For single self-stress mode $(s=1)$, the form-finding process could use vector $\mathbf{v}_{b}$ to construct force density vector $\zeta$. Moreover, due to the principle that the struts withstand pressure and cables bear tension, if $\mathbf{v}_{b}$ does not satisfy tension-compression symbols, it is necessary to add orthogonal vectors to reconstruct the force density $\zeta[7]$. 


\subsection{Solution of Nodal Coordinate}

Nodal coordinates of tensegrity structures corresponds the nontrivial solution of Eq. 7. As force density matrix $\mathbf{D}$ is square, the eigenvalue decomposition is carried out:

$$
\mathbf{D}=\boldsymbol{\Psi} \Sigma \boldsymbol{\Psi}^{\mathrm{T}}
$$

where the orthogonal matrix $\boldsymbol{\Psi}=\left(\boldsymbol{\psi}_{1}, \boldsymbol{\psi}_{2}, \ldots, \boldsymbol{\psi}_{n}\right)^{\mathrm{T}}$. The nodal coordinates $\mathbf{X}$ could be constructed by vector $\boldsymbol{\psi}_{i}$. Supposing that the number of known nodes are $n_{0}$, the corresponding coordinate value is $\mathbf{X}_{0}$, and the remaining nodal value is $\mathbf{X}^{*}$. $n_{0}$ vectors are selected from $\boldsymbol{\Psi}$ to generate submatrix $\boldsymbol{\Psi}^{\prime}$. It can be blocked as $\boldsymbol{\Psi}^{\prime}=\left(\boldsymbol{\Psi}_{0}, \boldsymbol{\Psi}^{*}\right)^{\mathrm{T}}$. It gives

$$
\left(\begin{array}{ll}
\boldsymbol{\Psi}_{0} & \boldsymbol{\Psi}^{*}
\end{array}\right)^{\mathrm{T}} \boldsymbol{\alpha}=\left(\begin{array}{ll}
\mathbf{X}_{0} & \mathbf{X}^{*}
\end{array}\right)^{\mathrm{T}}
$$

$\boldsymbol{\alpha}$ in Eq. 11 is an undetermined combination coefficient. The required nodal coordinates could be solved:

$$
\mathbf{X}^{*}=\Psi^{*} \Psi_{0}^{-1} \mathbf{X}_{0}
$$

\subsection{Algorithm Procedure}

Eq. 6 and Eq. 7 establish the structural force balance relations, and the unknown variables are force density vector $\zeta$ and nodal coordinate vector $\mathbf{X}$. In addition, equilibrium matrix $\mathbf{A}$ and force density matrix $\mathbf{D}$ are assembled by $\mathbf{X}$ and $\zeta$. Thus, the nonlinear algorithm is applied to solve the problem iteratively. The detailed procedure of form-finding algorithm is presented as follows.

1) The topology and required coordinate $\mathbf{X}_{0}$ of tensegrity are given. Calculate incidence matrix $\boldsymbol{\Phi}$. Initialize each component of force density vector $\zeta_{0}$, where -1 for struts and +1 for cables.

2) Assemble force density matrix $\mathbf{D}$ according to Eq. 5 and conduct eigenvalue decomposition. Estimate the unknown nodal coordinate $\mathbf{X}^{*}$. Then modify the force density vector $\zeta$.

3) Assemble equilibrium matrix $\mathbf{A}$ according to Eq. 3 and conduct SVD. Thus, the new force density vector $\zeta$ is constructed.

4) Compute the redundant nodal force $\Delta \mathbf{P}=\mathbf{A} \zeta$ and the minimum nonzero singular value $\mathbf{S}_{r r}$ of equilibrium matrix $\mathbf{A}$. If the convergence target $\|\Delta \mathbf{P}\|_{2}<\xi_{p}$ and $\mathbf{S}_{r r}<\xi_{p}$ are both fulfilled, algorithm terminates. Otherwise, return to step 2 . Here $\xi_{P}$ is a small quantity, assuming $1 \mathrm{E}-10$. 


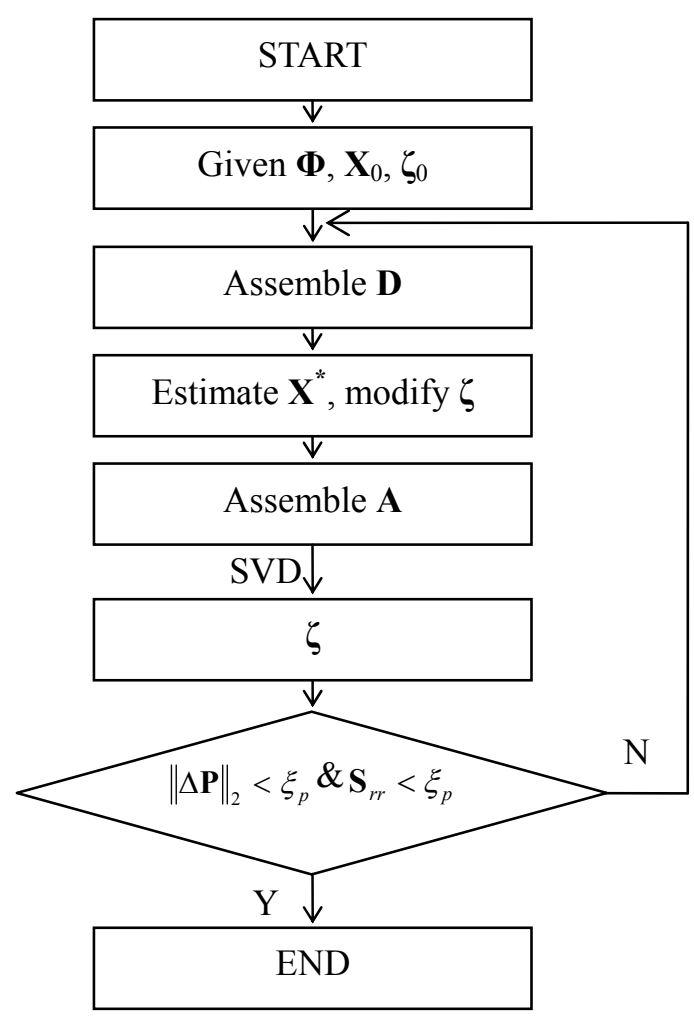

Figure 2. Algorithm Flow Chart

\section{NUMERICAL EXAMPLES}

\subsection{Form-finding of Tensegrity Structure Consists of 6 Struts and 24 Cables}

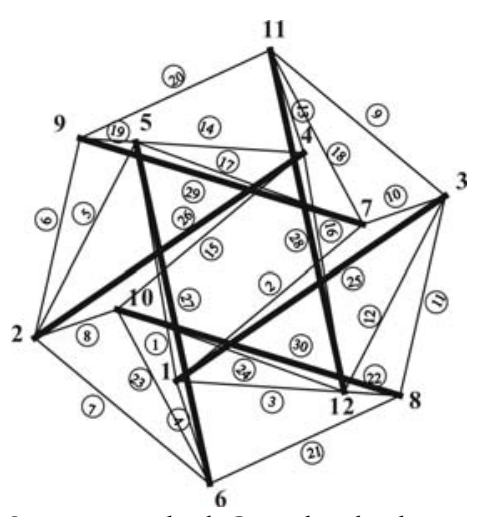

Figure 3. Expanded Octahedral Tensegrity

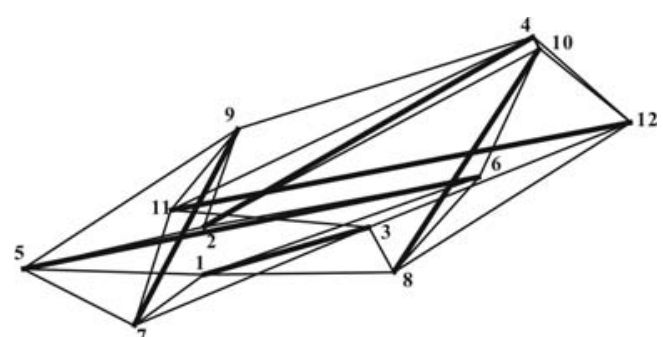

Figure 4. Computed Iirregular Tensegrity Structure

The topology of the computed structure refers to the classical expanded octahedral tensegrity shown in Figure 3. The structure has 30 elements and 12 nodes, and each node links 4 cables and 1 strut. Now the coordinates of some nodes are specified as $1(0,0,0), 2(0,100,0), 3(200,0,0)$, $4(400,300,0), 6(300,200,100)$. Supposing that $\xi_{\mathrm{p}}=1 \mathrm{E}-10$. According to the proposed algorithm, the form-finding result is presented in Figure 4. The procedure converges in 14 iterations. The computed structure contains one self-stress mode and one internal infinitesimal mechanism. It is proved to be geometrically stable since the force product is positive definite [20]. The coordinates of nodes are shown in Table 1, and Table 2 lists the internal force coefficients $t$ of cables and struts. The form-finding convergence process is illustrated in Figure 5. The physical model shown in Figure 6 are formed and stiffened by the turnbuckle installed in cable 13. Utilizing the level control of turnbuckle, the structure can achieve different stiffness. The specific joint construction is illustrated in Figure 7. 
Table 1. Nodal Coordinates of Computed Tensegrity

\begin{tabular}{ccccccccccccc}
\hline Node & 1 & 2 & 3 & 4 & 5 & 6 & 7 & 8 & 9 & 10 & 11 & 12 \\
\hline X-Value & 0.0 & 0.0 & 200.0 & 400.0 & -180. & 300.0 & -67.5 & 205.0 & 63.6 & 388.3 & -6.5 & 472.4 \\
Y-Value & 0.0 & 100.0 & 0.0 & 300.0 & -61.5 & 200.0 & -146. & 8.5 & 183.5 & 362.5 & -3.6 & 277.0 \\
Z-Value & 0.0 & 0.0 & 0.0 & 0.0 & $\begin{array}{c}-113 . \\
0\end{array}$ & 100.0 & -51.0 & 73.1 & -63.0 & 56.0 & -98.3 & 133.4 \\
\hline
\end{tabular}

Table 2. Internal Force Coefficient for Cables and Struts

\begin{tabular}{ccccccccccc}
\hline Element & 1 & 2 & 3 & 4 & 5 & 6 & 7 & 8 & 9 & 10 \\
\hline $\begin{array}{c}\text { Internal } \\
\text { force }\end{array}$ & 1.953 & 1.867 & 1.510 & 3.930 & 1.743 & 1.256 & 3.383 & 3.060 & 1.748 & 1.646 \\
Element & 11 & 12 & 13 & 14 & 15 & 16 & 17 & 18 & 19 & 20 \\
\hline $\begin{array}{c}\text { Internal } \\
\text { force }\end{array}$ & 0.677 & 1.084 & 4.006 & 2.245 & 0.880 & 0.657 & 1.322 & 1.611 & 3.640 & 2.019 \\
Element & 21 & 22 & 23 & 24 & 25 & 26 & 27 & 28 & 29 & 30 \\
\hline $\begin{array}{c}\text { Internal } \\
\text { force }\end{array}$ & 2.171 & 4.296 & 1.912 & 1.356 & -2.23 & -5.64 & -7.67 & -6.05 & -4.89 & -5.40 \\
& & & & & 7 & 8 & 2 & 7 & 5 & 8 \\
\hline
\end{tabular}

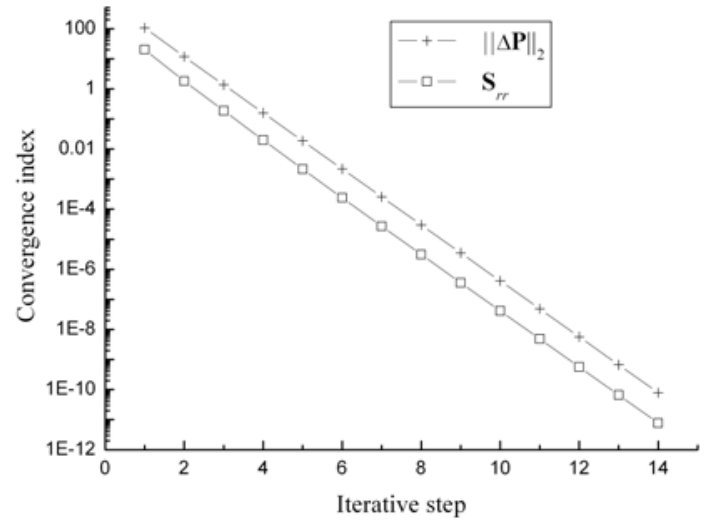

Figure 5. Iterative Procedure of Form-finding

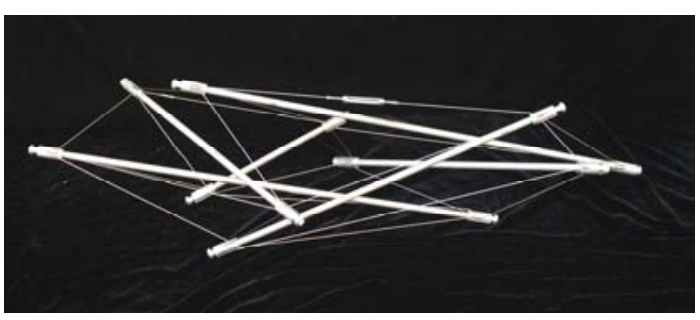

Figure 6. Physical Model of Computed Tensegrity

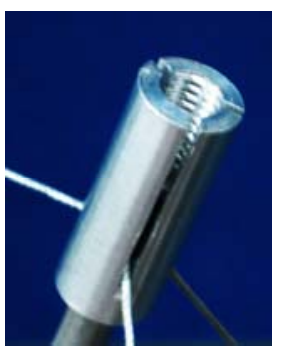

Figure 7. Joint Construction
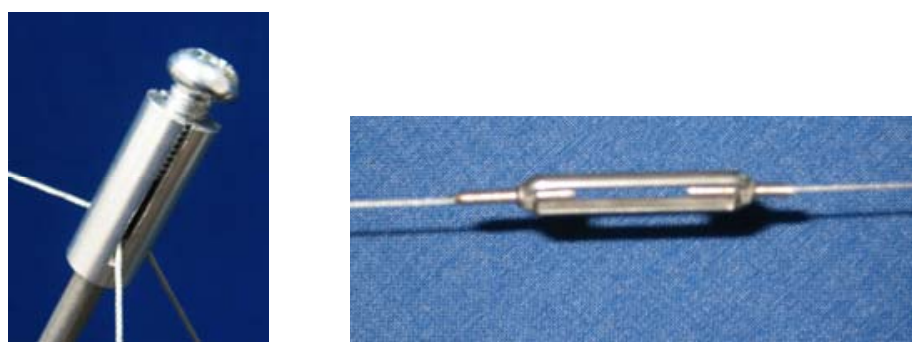

Figure 8. Turnbuckle

If the coordinates of some nodes are specified as $1(0,0,0), 3(5,0,-1), 6(0,3,0), 9(2,2,5), 12(6,2,1)$, the tensegrity configuration could be found after 14 iterations. Figure 9 and Figure 10 show the computed structural configuration and iterative procedure, respectively. And the corresponding nodal coordinates and the internal force coefficients of elements are listed in Table 1 and Table 2. 

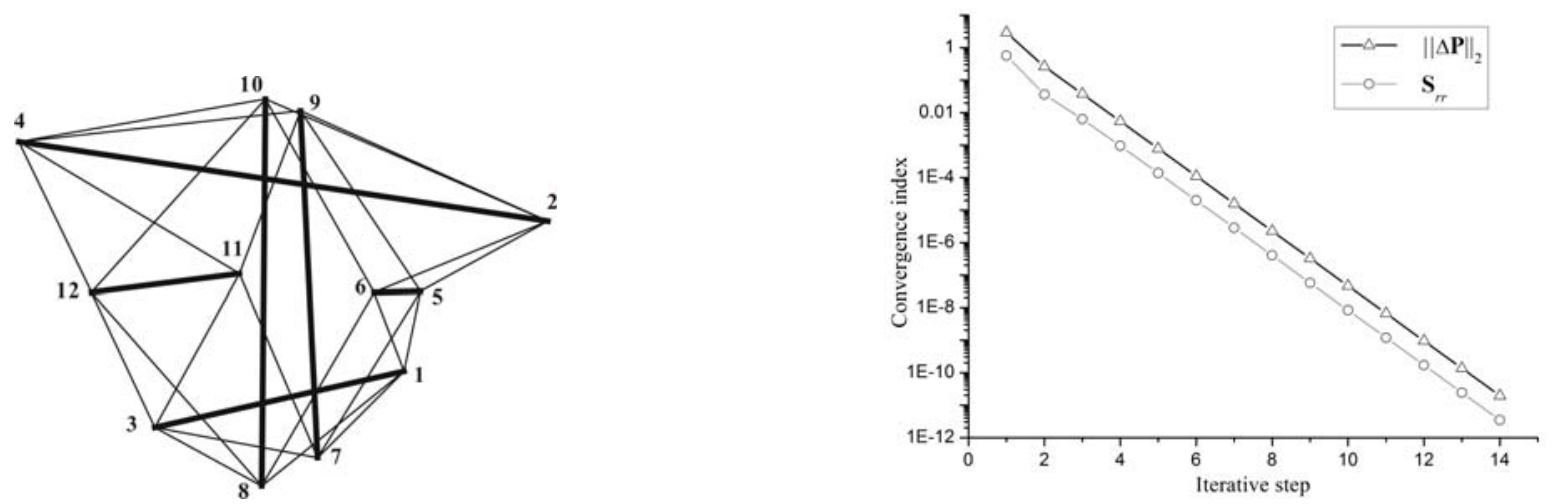

Figure 9. Computed Irregular Tensegrity Structure Figure 10. Iterative Procedure of Form-finding

Table 3. Nodal Coordinates of Computed Tensegrity

\begin{tabular}{|c|c|c|c|c|c|c|c|c|c|c|c|c|}
\hline Node & 1 & 2 & 3 & 4 & 5 & 6 & 7 & 8 & 9 & 10 & 11 & 12 \\
\hline X-Value & 0.000 & $\begin{array}{c}-3.84 \\
5\end{array}$ & 5.000 & 8.643 & $\begin{array}{c}-0.33 \\
2\end{array}$ & 0.000 & 2.199 & 2.532 & 2.000 & 2.753 & 4.071 & 6.000 \\
\hline Y-Value & 0.000 & 4.672 & 0.000 & $\begin{array}{c}-1.92 \\
0\end{array}$ & 0.464 & 3.000 & $\begin{array}{c}-2.32 \\
1\end{array}$ & 0.840 & 2.000 & 1.903 & $\begin{array}{c}-2.38 \\
9\end{array}$ & 2.000 \\
\hline Z-Value & 0.000 & 0.393 & $\begin{array}{c}-1.00 \\
0\end{array}$ & 7.106 & 1.562 & 0.000 & $\begin{array}{c}-0.46 \\
4\end{array}$ & $\begin{array}{c}-3.04 \\
8\end{array}$ & 5.000 & 5.385 & 4.007 & 1.000 \\
\hline
\end{tabular}

Table 4. Internal Force Coefficient for Cables and Struts

\begin{tabular}{ccccccccccc}
\hline Element & 1 & 2 & 3 & 4 & 5 & 6 & 7 & 8 & 9 & 10 \\
\hline $\begin{array}{c}\text { Internal } \\
\text { force }\end{array}$ & 1.868 & 3.621 & 2.634 & 1.534 & 4.184 & $\begin{array}{c}10.16 \\
5\end{array}$ & $\begin{array}{c}5.058 \\
9.726\end{array}$ & 1.896 & 1.703 \\
Element & 11 & 12 & 13 & 14 & 15 & 16 & 17 & 18 & 19 & 20 \\
\hline $\begin{array}{c}\text { Internal } \\
\text { force }\end{array}$ & 3.522 & 1.482 & 5.821 & 9.509 & 9.498 & 4.886 & 1.903 & 5.364 & 2.707 & 3.021 \\
Element & 21 & 22 & 23 & 24 & 25 & 26 & 27 & 28 & 29 & 30 \\
\hline $\begin{array}{c}\text { Internal } \\
\text { force }\end{array}$ & 4.219 & 2.558 & 4.344 & 2.239 & $\begin{array}{c}-3.81 \\
2\end{array}$ & $\begin{array}{c}-27.6 \\
83\end{array}$ & $\begin{array}{c}-2.74 \\
0\end{array}$ & $\begin{array}{c}-5.22 \\
3\end{array}$ & $\begin{array}{c}-7.80 \\
8\end{array}$ & $\begin{array}{c}-8.98 \\
0\end{array}$ \\
\hline
\end{tabular}

\subsection{Form-finding of Tensegrity Structure Consists of 6 Struts and 18 Cables}

Figure 11 shows a regular expanded octahedral tensegrity which has 6 struts and 18 cables. Each node links 1 strut and 3 cables. Nodes 1, 2, 4, 5, 7 and 8, which do not lie in the same plane, generate a space hexagon. Now it is required that the six nodes should constitute a regular hexagon of side length $200 \mathrm{~mm}$, and node 10 is located at the position of $600 \mathrm{~mm}$ above the centroid of hexagon. Figure 12 presents the calculated self-equilibrium and stable configuration whose force product is positive definite. The convergence process is shown in Figure 13. Both of the redundant nodal force and minimum nonzero singular value are lower than 1E-10 after about 190 iterative computations. The physical model is illustrated in Figure 14. 


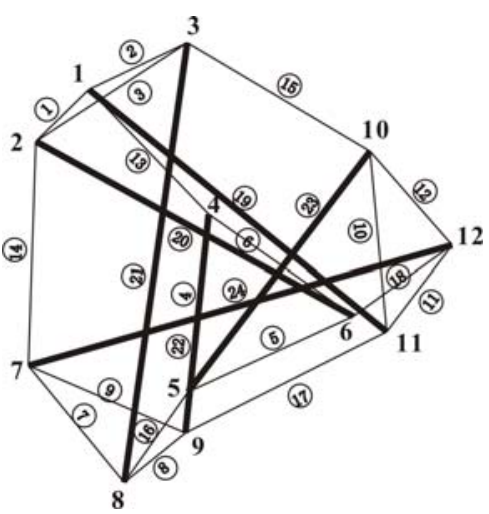

Figure 11. Expanded Octahedral Tensegrity

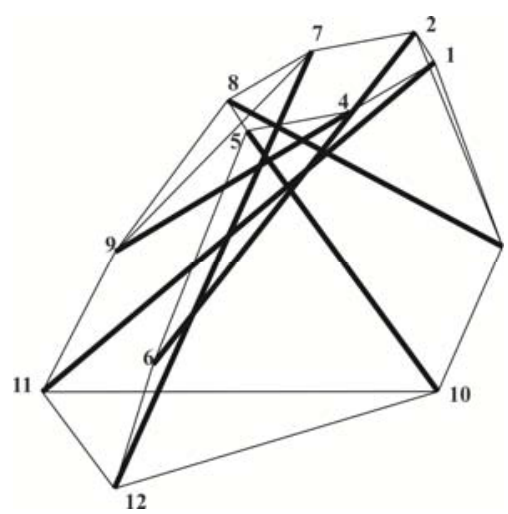

Figure 12. Computed Irregular Tensegrity Structure

Table 5. Nodal Coordinates of Computed Tensegrity

\begin{tabular}{ccccccccccccc}
\hline Node & 1 & 2 & 3 & 4 & 5 & 6 & 7 & 8 & 9 & 10 & 11 & 12 \\
\hline X-Value & 200.0 & 100.0 & 183.0 & 100.0 & -100. & -251. & -100. & -200. & -511. & 0.0 & -714. & -357. \\
& & & & & 8 & 0 & 0 & 8 & 0 & 6 & 8 \\
Y-Value & 0.0 & 173.2 & 52.2 & -173. & -173. & -514. & 173.2 & 0.0 & 109.6 & 0.0 & -10.0 & -601. \\
& & & 2 & 8 & & & & \\
Z-Value & 0.0 & 0.0 & 375.4 & 0.0 & 0.0 & 273.2 & 0.0 & 0.0 & 276.0 & 600.0 & 465.0 & 454.6 \\
\hline
\end{tabular}

Table 6. Internal Force Coefficient for Cables and Struts

\begin{tabular}{ccccccccccccc}
\hline Element & 1 & 2 & 3 & 4 & 5 & 6 & 7 & 8 & 9 & 10 & 11 & 12 \\
\hline $\begin{array}{c}\text { Internal } \\
\text { force }\end{array}$ & 1.350 & 0.746 & 0.572 & 1.352 & 1.422 & 1.163 & 1.309 & 1.018 & 1.487 & 0.454 & 0.590 & 0.463 \\
Element & 13 & 14 & 15 & 16 & 17 & 18 & 19 & 20 & 21 & 22 & 23 & 24 \\
\hline $\begin{array}{c}\text { Internal } \\
\text { force }\end{array}$ & 1.487 & 1.478 & 0.866 & 1.491 & 1.191 & 1.093 & $\begin{array}{c}-1.62 \\
-1.59\end{array}$ & $-\begin{array}{c}-0.87 \\
7\end{array}$ & $\begin{array}{c}-1.56 \\
-0.88\end{array}$ & -1.58 \\
\hline
\end{tabular}

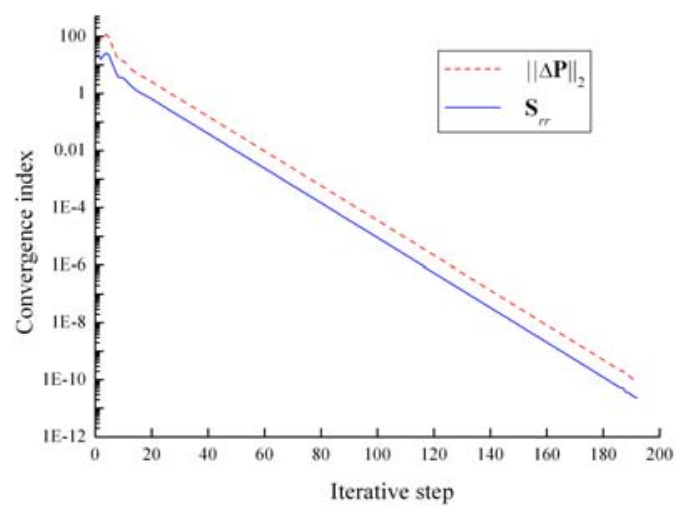

Figure 13. Iterative Procedure of Form-finding

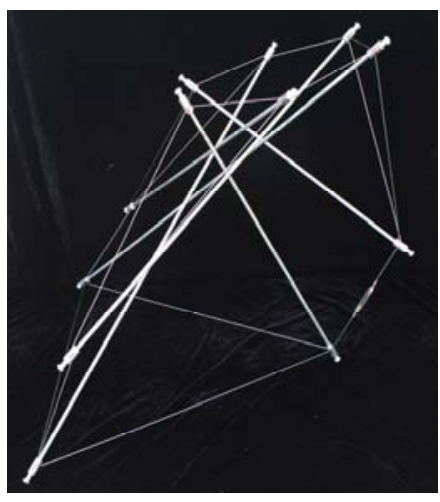

Figure 14. Physical Model of Computed Tensegrity 


\section{CONCLUSION}

This paper proposes a coordinate-based approach for the form-finding of irregular tensegrity. The algorithm resolves form-finding problems of cable-strut structures' self-equilibrium state with partly-known nodal coordinates. Based on the SVD of equilibrium matrix and eigenvalue decomposition of force density matrix, the self-stress and coordinates are constructed. And then the specified nodal coordinates are introduced as constraint conditions in the computation of coordinate values. Though a few of nonlinear iterations, the required structural configuration is determined eventually. The form-finding algorithm merely needs to provide cable-strut topological connections and some known nodal coordinates. As a result, it could be applied to find some novel irregular tensegrity structures and some tensile structures that satisfy specific geometrical shape in the foreseeable future.

\section{ACKNOWLEDGEMENT}

The research was supported by the National Natural Science Foundation of China (Grant no. 51008065, 51208263 and 51308105), the Fundamental Research Funds for the Central Universities and the Excellent Young Teachers Program of Southeast University (No. 2242014R30005), the Open Project of Jiangsu Key Laboratory of Engineering Mechanics, Southeast University, A Project Funded by the Priority Academic Program Development of Jiangsu Higher Education Institutions. The authors also thanked Ms. Xilei Zhao, Mr. Xinghua Li, Yudi Sun and Cheng Chen for their great help in making physical models.

\section{REFERENCES}

[1] Motro, R., "Tensegrity Structural Systems for the Future”, UK. Herms Science Publishing Limited, Kogan Page Limited, 2003.

[2] Skelton, R.E., Oliveira, M.C., "Tensegrity Systems", Springer Dordrecht Heidelberg London New York, 2009.

[3] Juan, S.H., Tur, J.M.M., "Tensegrity frameworks: static analysis review", Mechanism and Machine Theory, 2008, Vol. 43, No. 7, pp.859-881.

[4] Tibert, G. and Pellegrino, S., "Review of Form-finding Methods for Tensegrity Structures", International Journal of Space Structures, 2003, Vol. 18, No. 4, pp. 209-223.

[5] Zhang, L., Maurin, B. and Motro, R., "Form-finding of Nonregular Tensegrity Systems", Journal of Structural Engineering, ASCE, 2006, Vol. 132, No. 9, pp. 1435-1440.

[6] Zhang, J.Y., Ohsaki, M. and Kanno, Y., "A Direct Approach to the Design of Geometry and Forces of Tensegrity Systems”, International Journal of Solids and Structures, 2006, Vol. 43, pp. 2260-2278.

[7] Estrada, G.G., Bungartz, H.J. and Mohrdieck, C., "Numerical form Finding of Tensegrity Structure", International Journal of Solids and Structures, 2006, Vol. 43, pp. 6855-6868.

[8] Tran, H.C. and Lee, J., "Advanced form Finding of Tensegrity", Computers and Structures, 2009, Vol. 88, pp.236-247.

[9] Zhang, L.Y., Li, Y., Cao, Y.P. and Feng, X.Q., "Stiffness matrix based form-finding method of tensegrity structures", Engineering Structures, 2014, Vol. 58, pp.36-48.

[10] Paul, C., Lipson, H. and Cuevas, F.V., "Evolutionary Form-forming of Tensegrity Structures", Proceedings of the 2005 Genetic and Evolutionary Computation, Washington, USA, 2005, pp. 3-10.

[11] Rieffel, J., Cuevas, F.V. and Lipson, H., "Automated Discovery and Optimization of Large Irregular Tensegrity Structures”, Computers and Structures, 2009, Vol. 87, pp. 368-379. 
[12] Xu, X. and Luo, Y., "Form-finding of nonregular tensegrities using a genetic algorithm", Mechanics Research Communications, 2010, Vol. 37, pp. 85-91.

[13] Koohestani, K., "Form-finding of tensegrity structures via genetic algorithm", International Journal of Solids and Structures, 2012, Vol. 49, No. 5, pp. 739-747.

[14] $\mathrm{Xu}, \mathrm{X}$. and Luo, Y., "Force Finding of Tensegrity System using Simulated Annealing Algorithm", Journal of Structural Engineering, ASCE, 2010, Vol. 136, No. 8, pp. 1027-1031.

[15] Li, Y., Feng, X.Q., Cao, Y.P. and Gao, H., “A Monte Carlo Form-finding Method for Large Scale Regular and Irregular Tensegrity Structures", International Journal of Solids and Structures, 2010, Vol. 47, pp. 1888-1898.

[16] Koohestani, K., "A computational framework for the form-finding and design of tensegrity structures", Mechanics Research Communications, 2013, Vol. 54, pp.41-49.

[17] Lu, J.Y., Luo, Y.Z. and Li, N., "An Incremental Algorithm to Trace the Non-linear Equilibrium Paths of Pin-jointed Structures using the Singular Value Decomposition of the Equilibrium Matrix", Proc. IMechE Part G: J. Aerospace Engineering, 2009, Vol. 223, pp. 881-890.

[18] Lu, J.Y., Li, N. and Luo, Y.Z., "Kinematic Analysis of Planar Deployable Structures with Angulated Beams based on Equilibrium Matrix", Advances in Structural Engineering, 2011, Vol. 14, No. 6, pp. 1005-1015.

[19] Pellegrino, S. and Calliadine, C.R., "Matrix Analysis of Statically and Kinematically Indeterminate Frameworks", International Journal of Solids and Structures, 1986, Vol. 22, No. 4, pp. 409-428.

[20] Pellegrino, S., "Analysis of Pre-stressed Mechanisms", International Journal of Solids and Structures, 1990, Vol. 26, No. 12, pp. 1329-1350. 